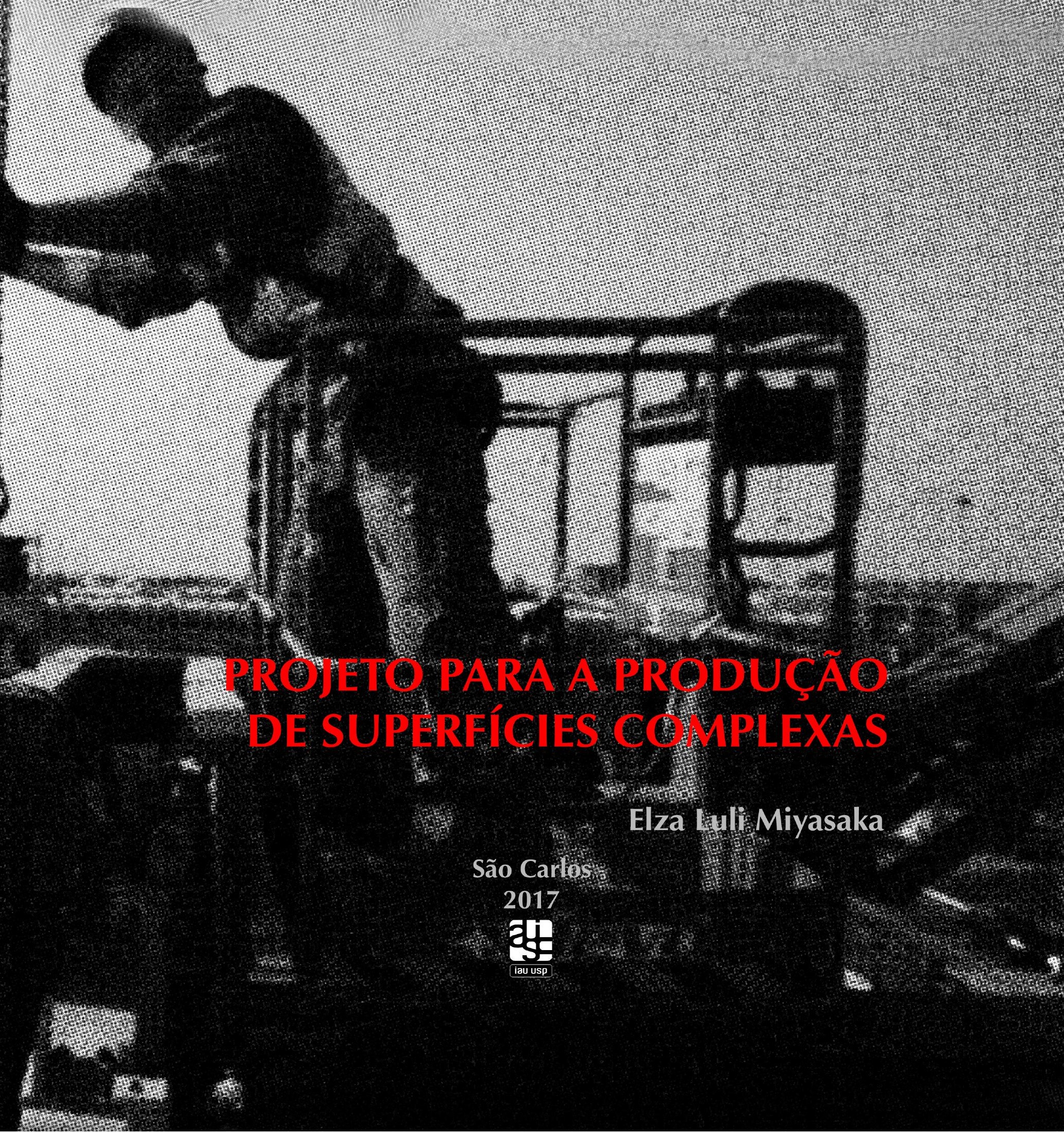


In Memorian a Tony Miyasaka 

Universidade de São Paulo

Instituto de Arquitetura e Urbanismo

Programa de Pós-Graduação em Arquitetura e Urbanismo

Área de Concentração Arquitetura, Urbanismo e Tecnologia

ArquiTec - Arquitetura, Tecnologia e Habitação

\section{Projeto para a Produção de Superfícies Complexas}

Elza Luli Miyasaka

Márcio Minto Fabricio

São Carlos

2017 

Universidade de São Paulo

Instituto de Arquitetura e Urbanismo

Programa de Pós-Graduação em Arquitetura e Urbanismo

Área de Concentração Arquitetura, Urbanismo e Tecnologia

ArquiTec - Arquitetura, Tecnologia e Habitação

\title{
Projeto para a Produção de Superfícies Complexas
}

Elza Luli Miyasaka

Tese de Doutorado apresentada ao Programa de Pós- Graduação em Arquitetura e Urbanismo do Instituto de Arquitetura e Urbanismo da Universidade de São Paulo, como parte dos requisitos necessários à obtenção título de Doutor em Arquitetura e Urbanismo, área de concentração Arquitetura, Urbanismo e Tecnologia.

Orientador:

Prof. Assoc. Márcio Minto Fabricio

\author{
"Versão Corrigida" \\ São Carlos \\ 2017
}




\section{AUTORIZO A REPRODUÇÃO TOTAL OU PARCIAL DESTE TRABALHO, POR QUALQUER MEIO CONVENCIONAL OU ELETRÔNICO, PARA FINS \\ DE ESTUDO E PESQUISA, DESDE QUE CITADA A FONTE.}

\section{Ficha Catalográfica}

ITHP

Mipratin. Elen Inti

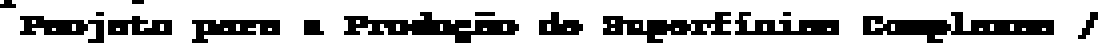

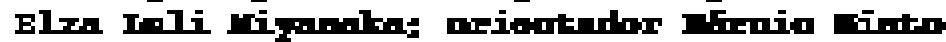

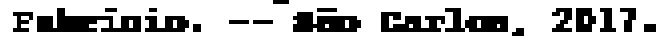
475

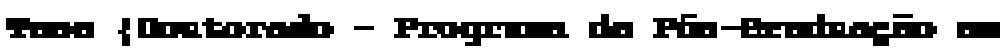

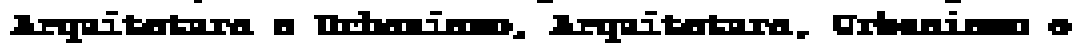

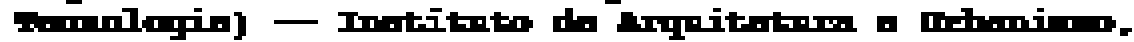

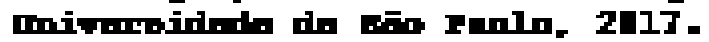

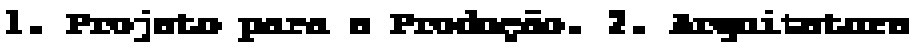

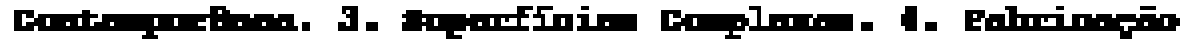

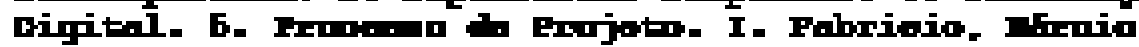
mint. neimt. II. mitnln. 


\section{FOLHA DE JULGAMENTO}

\section{Candidato(a): Elza Luli Miyasaka}

Título da tese: "Projeto para a Produção de Superfícies Complexas"

Data da defesa: 16/10/2017

Orientador: Prof. Dr. Marcio Minto Fabricio

\section{Comissão Julgadora:}

Resultado:
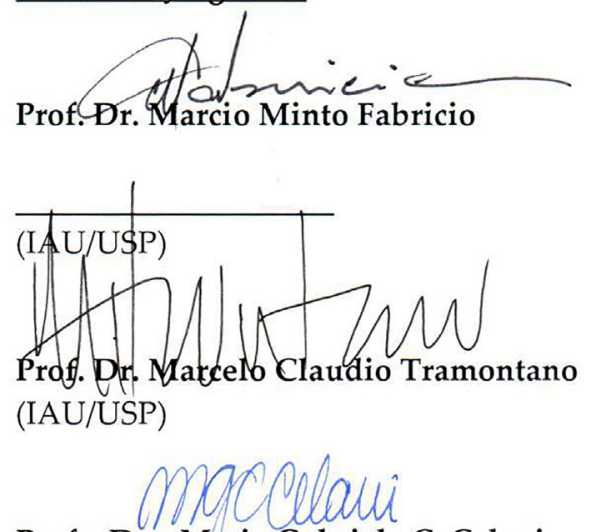

Profa. Dra. Maria Gabriela C. Celani (UNICAMP)

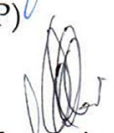

Prof. Dr. Mareo Antonio de Almeida (FFCLRP/USP)

Profa. Dra. Undęrléa Miotto Bruscato

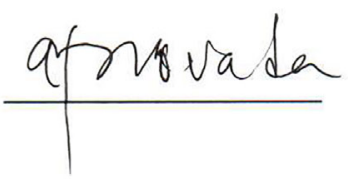
(UFRGS)
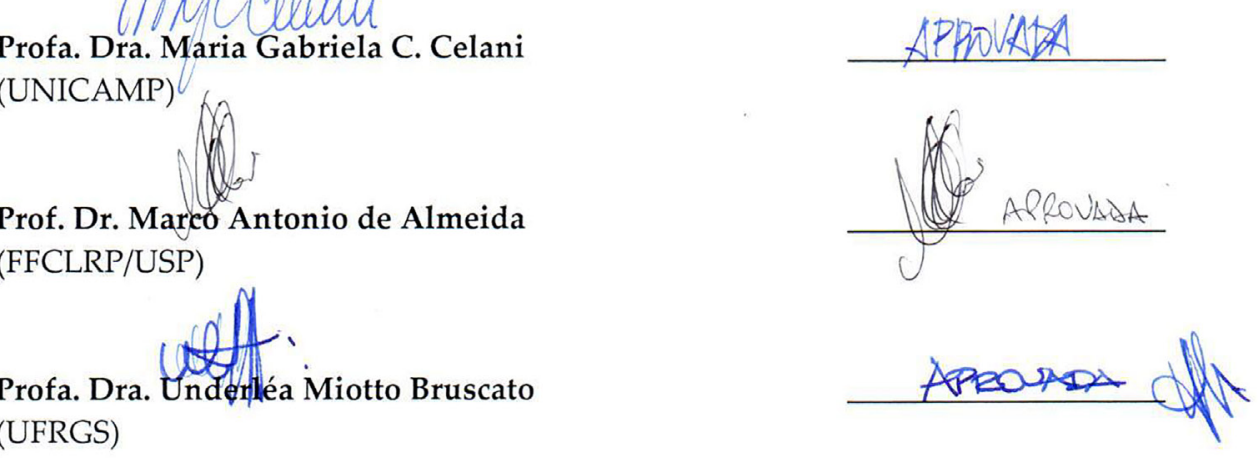

Coordenadora e Presidente da Comissão de Pós-Graduação do Programa de PósGraduação em Arquitetura e Urbanismo: Profa. Dra. Cibele Saliba Rizek. 

Dedico esse trabalho a todas as mulheres que fazem a diferença em minha vida:

Marialva Manfrin, minha esposa; Tereza Miyasaka, minha mãe; Cristina Akemi Miyasaka, minha irmã; Tokico Murakawa Moriya, minha tia; Fernanda Silva Miyasaka, minha irmã; Erika Moretini, Leila Heck, Tânia Registro e Sumi Kawasaki minhas grandes amigas. 


\section{Agradecimentos}

À Coordenação de Aperfeiçoamento de Pessoal de Nível Superior - CAPES pela oportunidade de ter realizado a pesquisa no Brasil e pela Bolsa do Programa de Doutorado Sanduíche no Exterior (PDSE) processo no. 99999.003519/2015-05 que possibilitou a estadia da estudante vivenciando as atividades do laboratório e aprofundando na temática durante um ano do processo de pesquisa.

Um agradecimento especial ao Prof. Assoc. Márcio Minto Fabricio, meu orientador, que esteve sempre do meu lado no processo de pesquisa contribuindo no meu crescimento pessoal e me mostrando novas possibilidades para o mundo, pela consistência e por ter me dado novos ângulos de visão para o trabalho.

À Profa. Assoc. Ingrid Paoletti minha parceira de pesquisa, que entrou em minha vida e permanecerá como uma grande irmã, de competência e sabedoria, que me mostra como realizar um percurso acadêmico de sucesso.

Ao Prof. Dr. Roberto Naboni, pesquisador e fundador do Actlab - Laboratório da Universidade Politécnica de Milão, competente pela gerência de pesquisadores e pela coordenação do laboratório, investindo em pesquisas de ponta na área de projetos inovativos e 
com empreendimentos de pesquisa avançada.

À Profa. Maya Zheilazkova uma grande amiga que me acolheu no laboratório de Milão e com toda delicadeza soube me direcionar dentro das discussões contemporâneas relativas à arquitetura. E também aos meus colegas do laboratório, companheiros de trabalho e de conversas.

Aos técnicos Eng. Giuseppe Chiarandá, Arq. Omer Mert Cek, Eng. Roberto Ferrari, Eng. Gary Tortona, Arq. Francesco Catalano e Arq. Bernado Jacobsen, que nos dispensaram momentos preciosos dos horários de seus trabalhos.

Ao Prof. Assoc. Miguel Antônio Buzzar, que sempre me apoiou nas inquietações de pesquisa e ao mesmo tempo me posicionou em situações políticas da arquitetura e urbanismo brasileiras.

À Profa. Dra. Anja Pratshke que com tanta sabedoria soube me ensinar como fazer e escrever, dentro do processo de me tornar uma pesquisadora. E também ao Prof. Dr. Marcelo Tramontano que me mostrou como fazer e ao mesmo tempo ter a vida leve e vivida. 
Ao Prof. David Sperling que é tão sensível e capaz para me mostrar os outros lados possíveis da utilização das tecnologias avançadas em territórios como o Brasil.

À Profa. Assoc. Gabriela Celani que me introduziu aos diferentes equipamentos de produção para a fabricação digital e, que abriu outros caminhos para conhecer novos campos, me ditando possibilidades e potencialidades para o trabalho.

Ao Prof. Dr. Marco Antônio de Almeida, que desde o mestrado tem me colocado em contato com literaturas que fazem com que eu possa compreender melhor o contexto social da informação e sua evolução dentro de uma perspectiva histórica e crítica.

Ao Prof. Dr. Jarryer De Martino meu grande amigo, que esteve ao meu lado nos milhões de momentos da pesquisa em que as angústias estavam à tona, me deu atenção, me acalentou com carinho e delicadeza.

À Profa. Dra. Cynthia Nojimoto que tenho um carinho especial, que me acolheu em todos os instantes de inquietações e com sabedoria soube me orientar e fazer olhar com maior clareza os caminhos pelos quais eu deveria atentar e refletir.

À Profa. Dra. Mariele Luckantuchi que esteve comigo na produção de artigos e que mostrou outras formas de ver o mundo, pessoa muito singela, que sabe como conduzir uma pesquisa e como organizar e disciplinar o processo.

À Profa. Dra. Michele Caixeta companheira de artigos e do grupo de pesquisa, que dividiu comigo inquietações e descobertas, mulher forte, sensível e sábia, me ensina a investigar e aprender com isso. 
Ao Prof. Dr. José Roberto Geraldine Jr. que me deu a oportunidade de trabalhar na Escola e que a médio prazo me possibilitou a experiência de desenvolver a pesquisa no exterior.

Ao Prof. Dr. José Carlos Faim Bezzon, que tenho como exemplo de profissional ético e de sucesso. Ao Prof. Henrique Vischnewiski, companheiro de trabalho, que tem a leveza e conhecimentos admiráveis, e a Profa. Flávia Olaia, que acreditou no meu trabalho e me mostra a cada dia como ser uma pessoa melhor.

Ao Grupo de Pesquisa ArquiTec, que me acolheu em todos os momentos e que possibilitou as discussões e aconselhamentos sobre meu objeto de pesquisa.

À revisão realizada com carinho e competência de Viviane Alves, à equipe de pós graduação, Marcelinho, Geraldo, Flávia e Mara da secretaria de Pós Graduação - CPG, que estiveram sempre muito solícitos e amistosos para os assuntos relacionados aos requisitos da pós-graduação, e finalmente a grande amiga Marta Tessarin, pela competência e amizade.

Muito Obrigada. 


\section{Resumo}

MIYASAKA, Elza Luli (2017) Projeto para a Produção de Superfícies Complexas. 1998. 415p. Tese (Doutorado em Arquitetura, Urbanismo e Tecnologia) - Instituto de Arquitetura e Urbanismo, Universidade de São Paulo, São Carlos, 2017.

O cenário de metrópoles como Londres, Nova lorque, Dubai, Shangai, Seul e outras exibe alguns tipos de edifícios com formas orgânicas e fluidas, que fazem parte de uma proposta que utiliza ferramentas informacionais e programação para a sua criação e materialização. Este trabalho investiga como viabilizar as superfícies consideradas complexas, desses edifícios, através do tema Projeto para a Produção, etapa que aprofunda o processo do fazer, posterior à criação. A complexidade é caracterizada pela utilização de um alto nível tecnológico para a elaboração dos sistemas, do componente em sua morfologia e, em relação ao módulo, material e geometria (PAOLETTI, 2006).

Para o entendimento do problema, o texto contextualiza o momento contemporâneo e a participação dos instrumentos digitais no cotidiano, fazendo uma retrospectiva dos modos de produção e da automação da indústria, e faz um paralelo com a construção civil. Trata desde a 1a. Revolução Industrial até a 4a. Revolução Industrial, de acordo com Schwab (2016) 
Para discutir o Projeto para a Produção, verifica-se o estado da arte, posteriormente confrontando duas vertentes conceituais da atuação do papel do arquiteto no processo: uma que defende que os profissionais têm atuado mais próximos à fabricação digital, com arquivos enviados diretamente para a fábrica - File to Factory (Arquivo-Fábrica) -, e outra que entende que o processo é distribuído em etapas e equipes específicas e depende de habilidades e conhecimentos particulares para a produção do objeto.

Este trabalho apresenta dois casos desenvolvidos na Itália: o primeiro projetado pelos arquitetos do escritório Norman Foster \& Associates, o Pavilhão da União dos Emirados Árabes para a exposição internacional de Milão, que foi confeccionado com painéis de argamassa armada estampados com a textura das dunas do deserto, e o segundo, a torre corporativa do escritório Zaha Hadid Architects, do complexo CityLife Milano, que possui a superfície de vedação com painéis de vidro em formato de paralelogramas, que evidenciam a torção da torre em seu eixo vertical.

Finalmente, o trabalho propõe um modelo de Projeto para a Produção de superfícies complexas a partir do aprofundamento dos estudos de caso, considerando que a proposta faz parte de uma etapa do projeto que é efetuada por equipes de profissionais habilitados para a elaboração dos detalhamentos, busca de soluções, pesquisa aprofundada a respeito dos materiais a serem utilizados e dos requisitos necessários para a realização dos trabalhos no local de implantação.

Palavras Chave: Projeto para a Produção, Arquitetura Contemporânea, Superfícies Complexas, Fabricação Digital, Processo de Projeto. 


\section{Abstract}

MIYASAKA, Elza Luli (2017) Projeto para a Produção de Superfícies Complexas. 1998. 415p. Tese (Doutorado em Arquitetura, Urbanismo e Tecnologia) - Instituto de Arquitetura e Urbanismo, Universidade de São Paulo, São Carlos, 2017.

The scenery of big cities such as London, New York, Dubai, Shanghai and Seoul exhibits some types of buildings with organic and fluid shapes that are part of a proposal that uses information tools and programming for their creation and feasibility. This work investigates how feasible surfaces considered complex through the theme Design for Production, a stage that deepens the process of making, after creation. The complexity is characterized as the use of a high technological level for the elaboration of the systems, of the component in its morphology and, in relation to the module, material and geometry (PAOLETTI, 2006).

For the understanding of the problem, the text contextualizes the contemporary moment and the participation of the digital instruments in the daily life, making a retrospective of the ways of production and the automation of the industry and parallels with the civil construction. It deals from the 1st. Industrial Revolution until the 4th. Industrial Revolution, according to Schwab (2016). 
In order to discuss the Design for Production, the state of the art is verified, later confronting two conceptual aspects of the role of the architect in the process, one that argues that the professionals have directly acted in the digital manufacture with files sent directly to the factory - File to Factory - and another that understands that the process is distributed in stages and specific teams and depends on particular skills and knowledge to the production of the object.

It presents two cases developed in Italy: the first one designed by Norman Foster \& Associates, the United Arab Emirates Pavilion for the Milan International Exbition, which was made with panels of Glass Fiber Reinforced Concret stamped with the texture of the desert dunes and the second one a corporate tower designed by Zaha Hadid Architects' office for the CityLife Milano, which has a parallelogram glass panel sealing surface that demonstrates the twisting of the tower on its vertical axis.

Finally, the work proposes a model of a Design for Production of complex surfaces from the deepening of the case studies, considering that the proposal is part of a project stage carried out by teams of professionals qualified to perform the details, search for solutions, in-depth research regarding the materials to be used and the requirements necessary to carry out the works at the place of implantation.

Keywords: Design for Production, Contemporary Architecture, Complex Shapes, Digital Fabrication, Design Process. 


\section{Lista de Figuras}

Figura 1: Estrutura metálica em desmonte do Pavilhão da União dos Emirados Árabes. Foto: autor. Data: 2016.

Figura 2: Grande Peixe de Barcelona, projeto de Frank Gehry. Um dos primeiros objetos desenvolvidodos a partir de análises computacionais. Foto: autor. Data: 2016 44

Figura 3: Maquete do Museu de Arte do Rio (MAR). Fotos: Andres Otero, Leonardo Finotti. Fonte: Imagens cedidas por Bernardes + Jacobsen Arquitetura. .64

Figura 4: Modelagem gráfica da cobertura que foi impressa em papel para recorte das formas. Nos pontos centrais, estão localizados os pilares para saída de águas pluviais. Execução da estrutura de ferro, concretagem da laje. Fonte: Imagens cedidas por Bernardes + Jacobsen Arquitetura.

Figura 5: Renderização da cobertura idealizada a partir de ondas do mar. Fonte: Imagens cedidas por Bernardes + Jacobsen Arquitetura. .66

Figura 6: Montagem das formas sobre a plataforma para posterior concretagem. Fonte: Imagens cedidas por Bernardes + Jacobsen Arquitetura.

Figura 7: Formas de blocos de isopor moldados por carnavalescos a partir de planta impressa em papel. Fonte: Imagens cedidas por Bernardes + Jacobsen Arquitetura.

Figura 8: Execução da estrutura de ferro para concretagem da laje. Fonte: Imagens cedidas por Bernardes + Jacobsen Arquitetura.

Figura 9: Trabalhador fixando elemento em placa de maderia. Fonte: autor. Data: 2016.

Figura 10: Imagem ilustrativa editada das revoluções de acordo com o grau de automação no modo de produção. Fonte: Roser (2015). 
Figura 11: Hungerford Fish Market evidencia as peças de pilar, vigas, travamentos em ferro fundido montadas e encaixadas. Fonte: www.studyblue.com/notes/note/n/1-fair-review/deck/6480891. Data de Acesso: 06 jun 2017.

Figura 12: Linha de montagem Toyota House, trabalhadores em montagem das unidades habitacionais. Disponível em: www.contemporist.com/2008/07/05/did-you-know-toyota-builds-houses. Data de acesso: 02 nov 2016.

Figura 13: Conexões: 1. Tradicional, 2. e 3. Impressas em 3D. Disponível em: 3dprint. com/64376/cutting-edge-3d-printing/. Data de Acesso: 10 abr 2017. 128

Figura 14: Conexão confeccionada em impressora 3D. Foto: David Galjaard. Disponível em: www.architectmagazine.com. Data de acesso: 10 abr 2017

Figura 15: Grelha base para fabricação dos painéis de argamassa armada. Fonte: Imagens cedidas por Gary Tortona - Canbuild. Data: 2015.

Figura 16: Edifício residencial Highpoint do arquiteto Berthold Lubetkin e Tecton ao norte de Londres. Fonte: www.kristerbladh.co.uk/blog/?p=1153. Data de Acesso: 06 jun 2017

Figura 17: Complex Doubly Curved Exhibition Plataform, elemento de 40m de extensão. Viabilizado pelo escritório Design to Production. Fonte: www.generativeart.com/on/cic/papers2005/36.ScheurerSchindlerBraach_final.htm. Data de Acesso: 08 jun 2017.

Figura 18: Tree-Structure Canopy, estrutura em aço, para o Marriott Tower(2011) Foto: Eibe Sönnecken. Disponível em: asteriosagkathidis.wordpress.com/2011/04/10/ tree-structure-canopy/. Data de Acesso: 07 jun 2017

Figura 19: La Nuvola, Foto: autor. Data: 2016 185

Figura 20: Renderização do Pavilhão da União dos Emirados Árabes. Fonte: Foster \& Partners. Data 2014.

Figura 21: La Nuvola. Fonte: http://www.fuksas.com/it/Progetti/Nuovo-Centro-Congressi-Roma-EUR-e-Hotel-Rome. Data de Acesso: 3 ago 2017.

Figura 22: Fundazione Feltrinelli - Milano. Fonte: www.dezeen.com/2010/03/15/porta-volta-fondazione-feltrinelli-by-herzog-de-meuron-2/. Data de Acesso: 25 ago 2015. 193

Figura 23: Aeroporto Internacional Fuimicino - Roma. Fonte: Rimond. Data: 2016........194 
Figura 24: CityLife - Milano. Foto: autor. Data 2016.

Figura 25: Conexão entre laje suporte e subestrutura do painel da torre CityLife. Foto: autor. Data: 2016. 209

Figura 26: Renderização do pavilhão da União Emirados Árabes. Fonte: Foster \& Partners. Data: 2014 211

Figura27:PlantadaExpo-Milano_2015.Fonte:TEGTemaworkingGroup.Data:2015......217

Figura 28: Entrada Principal do pavilhão. Foto: Nigel Young + Foster \& Partners, Data: 2016. 219

Figura 29: Imagem das dunas do deserto referência conceitual para o projeto da União dos Emirados Árabes. Fonte: Foster \& Partners. Data: 2016. 221

Figura 30: Entrada do pavilhão com painéis altos e curvos que dão a impressão de estar no meio do deserto. Foto: Nigel Young + Foster \& Partners. Data: 2016...219

Figura 31: Projeto de Compatibilização dos diversos sistemas realizado na plataforma BIM. Fonte: Rimond. Data: 2015. .236

Figura 32: Imagem ilustrativa do equívoco entre estrutura principal e porta do edifício. Fonte: Rimond. Data: 2015 237

Figura 33: Exemplo de incompatibilidade de área de entrada e estrutura do edifício. Fonte: Rimond. Data: 2015 237

Figura 34: Desenho esquemático do pavilhão. Fonte: Foster \& Partners. Data 2014.....241

Figura 35: Vista Leste do Pavilhão da União dos Emirados Árabes. Fonte: Rimond. Data: 2015. .242

Figura 36: Vista Norte - Entrada principal para visitação do Pavilhão da União dos Emirados Árabes. Fonte: Rimond. Data: 2015.

Figura 37: Vista Sul do Pavilhão da União dos Emirados Árabes. Fonte: Rimond. Data: 2015. .244

Figura 38: Corte Pavilhão em rampa do Pavilhão da União dos Emirados Árabes. Fonte: Rimond. Data: 2015. 247

Figura 39: Planta nível 3,7 - Área de Visitação. Fonte: Rimond. Data: 2015. .248

Figura 40: Planta nível 0,0 - Área Executiva e Administrativa. Fonte: Rimond. Data: 
Figura 41: Planta nível 7,4 - Área Executiva e Manutenção. Fonte: Rimond. Data: 2015 ....249

Figura 42: Estrutura Pavilhão - vista da desmontagem. Foto: autor. Data: $2016 .$.

Figura 43: Estrutura principal em grelha, setor de entrada. Foto: Filippo Poli. Data 2014/15.

Figura 44: Máquina de corte a laser, esteira de colocação das chapas metálicas Foto: autor. Data: 2016.

Figura 45: Máquina de corte a laser, saída dos elementos seccionados. Foto: autor. Data: 2016. .256

Figura 46: Comando da máquina de corte a laser. Foto: autor. Data: 2016. .256

Figura 47: Peça metálica em fase de montagem em fábrica. Foto: Davide Radogna. Data: 2016 257

Figura 48: Planilhas para montagem da estrutura. Foto: Davide Radogna. Data: 2016....258

Figura 49: Estratégia para elaboração dos painéis de Argamassa Armada - GRC. Fonte: Foster \& Partners. Data: 2014 260

Figura 50: Painéis planos externos com textura das dunas. Foto: autor. Data: 2016.......260

Figura 51: Adequação das curvas dos painéis, de acordo com a escala humana. Fonte: Rimond. Data: 2016. .262

Figura 52: Desenho Painel em Argamassa Armada + Subestrutura + Estrutura. Fonte: Foster \& Partners. Data: 2014 .264

Figura 53: Vista de Painel em Argamassa Armada+ Subestrutura + Estrutura. Fonte: Foster \& Partners. Data: 2014 264

Figura 54: Detalhe de apoios entre painel, subestrutura e estrutura principal. Fonte: autor. Data: 2016. .265

Figura 55: Relação entre estrutura, subestrutura e painel de argamassa armada. Foto: Rimond. Data: 2015. 266

Figura 56: Detalhe de painel por trás. Foto: autor. Data: 2016 .267

Figura 57: Maquete do painel curvo. Fonte: Foster \& Partners. Data: 2014 .268 
Figura 58: Parte da forma para produção do painel. Fonte: Foster \& Partners. Data: 2014. .268

Figura 59: Mockup e Montagem do painel de Argamassa Armada curvo. Foto: Filippo

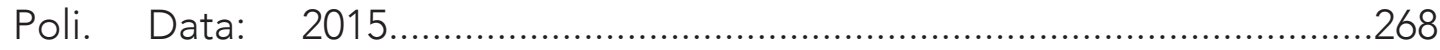

Figura 60: Base para a fabricação dos painéis planos de Argamassa Armada. Fonte: Fábrica Canbuild_Coreia. Foto: Gary Tortora, Data: 2014/15. .271

Figura 61: Painel de Argamassa Armada para fechamento de canto. Foto: autor. Data: 2016. .272

Figura 62: Painel de Argamassa Armada recortado para acabamento de canto. Foto: autor. Data: 2016.

.272

Figura 63: Painel de Argamassa Armada com simulação de linha de emenda. Foto: autor. Data: 2016.

Figura 64: Painel de Argamassa Armada pequeno e com recorte. Foto: autor. Data: 2016 .273

Figura 65: Painel de Argamassa Armada com curvatura para o setor do Canyon. Foto: Rimond. Data: 2015. .273

Figura 66: Grelha de madeira, base estrutural da forma do painel com projeção. Foto: Garry Tortona - Canbuild. Data: 2015. .274

Figura 67: Revestimento da base para molde dos painéis curvos do setor do Canyon. Foto: Garry Tortona - Canbuild. Data: 2015. 274

Figura 68: Confecção dos painéis curvos, com encaixe entre eles. Foto: Garry Tortona - Canbuild. Data: 2015. .275

Figura 69: Painel Curvo com subestrutura acoplada. Foto: Garry Tortona Canbuild. Data: 2015. 275

Figura 70: Acabamento final com lavagem de ácido. Foto: Garry Tortona Canbuild. Data: 2015. .275

Figura 71: Planta Chave de Localização do Painel. Fonte: Foster \& Partners. Data: 2014. 278

Figura 72: Mapa de Localização do Painel. Fonte: Foster \& Partners. Data: 2014. ........278

Figura 73: Identificação do Painel. Foto: autor. Data: 2016. 278 
Figura 74: Organização do canteiro na etapa de colocação dos painéis de argamassa armada. Fonte: Rimond. Data: 2015.

Figura 75: Torre Hadid e Pódio. Fonte: http://www.zaha-hadid.com/architecture/citylife-milano/. Data de Acesso: 21 jul 2017

Figura 76: Local do empreendimento, antiga área de realização de feiras. Fonte: http:// www.city-life.it/en/project\#\&gid=1\&pid=1. Data de Acesso: 21 jul 2017 ......286

Figura 77: Vista aérea do empreendimento. Fonte: http://www.zaha-hadid.com/architecture/citylife-milano/. Data de Acesso: 21 jul 2017.

Figura 78: Projeto urbano. Área do empreendimento. Fonte: http://www.city-life.it/en/ project. Data de acesso: 21 jul 2017. .288

Figura 79: Localização da torre e do complexo residencial desenvolvidos pelo escritório Zaha Hadid Architects. Fonte: http://www.city-life.it/en/project. Data acesso: 21 jul 2017 289

Figura 80: Vista aérea das residências de Zaha Hadid Architects. Foto: Autor. Data: 2016. 291

Figura 81: Três Torres do empreendimento empresarial. Fonte: http://www.city-life.it. Data de acesso: 04 jan 2017 .292

Figura 82: Maquete ilustrativa do edifício misto. Fonte: http://www.zaha-hadid.com/architecture/citylife-milano/\#. Data acesso: 21 jul 2017. .302

Figura 83: Planta Pódio. Fonte: http://www.zaha-hadid.com/architecture/citylife-milano. Data de acesso: 27 jun 2017. 303

Figura 84: Planta Torre. Fonte: www.zaha-hadid.com/architecture/citylife-milano. Data de acesso: 27 jun 2017 306

Figura 85: Hall do setor dos elevadores. Foto: autor. Data: 2016. .304

Figura 86: Corte da torre com pódio. Fonte: http://www.zahahadid.com/architecture/ citylife-milano. Data de acesso: 27 jun 2017. .306

Figura 87: Corte da torre. Fonte: http://www.zaha-hadid.com/architecture/citylife-milano. Data de acesso: 27 jun 2017 307

Figura 88: Estrutura da Torre. Fonte: http://www.zaha-hadid.com/architecture/citylife-milano. Data de acesso: 27 jun 2017 309 
Figura 89: Núcleo central de concreto. Foto: autor. Data: 2016.

Figura 90: Largura da área de escritórios e circulação, coluna inclinada em $6^{\circ}$ piso. Foto: Autor, Data: 2016. 309

Figura 91: Corte em nível com expansão da laje para fixação da pele externa. Fonte: Arup Milão, Arq. Francesco Catalano. Data: 2016.

Figura 92: Torre + pódio em construção. Foto: autor. Data: 2016 ....................................312

Figura 93: Seção da pele de vidro externa e interna. Fonte: Arup Milão, Arq. Francesco Catalano Data: 2016.

Figura 94: Croqui explicativo dos ângulos da pele externa. Fonte: Arup Milão, Arq. Francesco Catalano Data: 2016.

Figura 95: Detalhe da conexão entre a laje e fixação da esquadria interna e externa. Fonte: Arup Milão, Arq. Francesco Catalano. Data: 2016.

Figura 96: Planta esquemática da rotação do edifício. Fonte: Arup, Arq. Francesco Catalano, Data: 2015. 318

Figura 97: Geometria da torre. Fonte: www.designboom.com/architecture/zaha-hadid-office-tower-citylife-milano/. Data de acesso: 17 jan 2017. 319

Figura 98: Superfície interna padrão e superfície externa rotacionada. Foto: autor. Data: 2016. 320

Figura 99: Vista frontal e corte da célula. Fonte: Arup Milão, Arq. Francesco Catalano, Data: 2016. 321

Figura 100: Perspectiva do empreendimento vista pelo lado da fenda. Foto: autor. Data: 2016. 322

Figura 101: Diferentes tipos de painéis. Fonte: Arup. Data: 2016 .....................................326

Figura 102: Vidro em esforço para curva. Foto: autor. Data: 2016 ....................................329

Figura 103: Diagrama de torção do vidro a frio e grau de esforço maior na base da torre. Fonte: Arup Milão, Arq. Francesco Catalano, Data; 2015. 331

Figura 104: Indicação de corte do vidro em relação a placa mestra. Fonte: Arup Milão, Arq. Francesco Catalano. Data: 2015. 331

Figura 105: Vista interna das peles de vedação. Inclinação positiva - 6. andar. Foto: autor 
Data: 2016

Figura 106: Vista interna das peles de vedação. Inclinação negativa - $6^{\circ}$ andar. Foto: autor. Data: 2016

Figura 107: Imagem ilustrativa dos diferentes tipos de painéis que compõem o podium. Fonte: Arup. Data: 2016 .335

Figura 108: Estrutura de referência (Benchmark), para estudo do comportamento do sistema. Foto: autor. Data: 2016

Figura 109: Gindaste instalado para realização dos trabalhos da Torre CityLife - Milão. Foto: autor. Data: 2016.

Figura 110: Esqueleto estrutural da Torre CityLife. Foto: autor. Data: 2016. .377

Figura 111: Comunicação visual no edifício da Torre City Life. Foto: Autor. Data: 2016....389

Figura 112: Peça em madeira com sulcos para curva em duas direções. Foto: autor. Data: 2016 409 


\section{Lista de Diagramas}

Diagrama 1: Esquema do processo de projeto com a definição do tema de estudo. Fonte: Autor...

Diagrama 2: Impacto das tecnologias da Indústria 4.0 na cadeia de valor da construção civil. Fonte: (OESTERREICH; TEUTEBERG, 2016). 121

Diagrama 3: Fluxo de informações para a manufatura. Fonte: (KATSUNDO, 1994)........143

Diagrama 4: Projeto e Processo de Projeto para a Produção, esquema adaptado de (WILLIAMS et al., 2011, p. 228) ...................................................................166

Diagrama 5: Delineamento da Pesquisa. Fonte: autora..................................................205

Diagrama 6: Organograma da organização do trabalho no projeto da União dos Emirados Árabes. Fonte: Rimond. Data: 2015......................................................224

Diagrama 7: Fluxo de aprovação de projetos. Fonte: autor, baseado nos documentos pesquisados, Data: 2016.........................................................................229

Diagrama 8: Distribuição dos trabalhos inseridos no sistema BIM. Fonte: Rimond. Data: 2015.

Diagrama 9: Organograma de Desenvolvimento de projeto. Fonte: autor, segundo entrevista de Roberto Ferrari - Ramboll . Data 2016 ................................................298

Diagrama 10: Projeto para a Produção de Superfícies Complexas. Fonte: Autor.............370 


\section{Lista de Tabelas}

Tabela 1: Comparativo das iniciativas contemporâneas comentadas anteriormente. Fonte: autor.

Tabela 2: Processos de transformação de metais utilizados na indústria contemporânea. Fonte: Caneparo (2014).

Tabela 3: Processos de transformação de madeira utilizados na indústria contemporânea. Fonte: Caneparo (2014). 125

Tabela 4: Etapas do processo de Projeto para a Produção de Superfícies Complexas.....177

Tabela 5: Quadro comparativo entre as correntes conceituais de processo de produção do objeto

Tabela 6: Relação de autores que trabalharam o conceito de Projeto para a Produção....411 
Lista de Siglas

BMBF - Federal Ministry of Education and Research

2D - duas dimesnões

3D - três dimensões

BIM - Building Information Modelling - Modelagem da Informação da Construção ou Modelo da Informação da Construção

CAD - Computer Aided Design - Desenho Assistido por Computador

CAM - Computer Aided Manufacturing - Manufatura Assistida por Computador

CAP - Computer Aided Planning - Planejamento Assistido por Computador

CATIA - Computer Aided Three-Dimensional Interactive Application - Aplicação Interativa Tridimensional Assistida por Computador -

CIM - Computer Integrated Manufacturing - Manufatura Integrada por Computador

CNC - Computer Numeric Control - Comando Numérico Computadorizado

CPS - Cyber-Physical System - Sistema Ciber-Físico

EPS - Expanded Polystyrene - Poliestireno expandido 
GPS - Global Positioning System - Sistema de Posicionamento Global

GRC - Glassfiber Reinforced Concrete - Argamassa Armada com Fibra de Vidro 14.0 - Industry 4.0 - Indústria 4.0

loT - Internet of Things - Internet das Coisas

MEP - Mechanical, Electrical and Plumbing - Mecânica, Elétrica e Hidráulica

MODICON - Modular Digital Controler - Controlador Modular Digital

NESTING - processo de organização para o corte

NURBS - Non Uniform Rational Basis Splines - malha manipulável para modelagem

PIB - Produto Interno Bruto

RAC - Robótica e Automação em Construção

STP - Sistema Toyota de Produção

TIC - Tecnologias de Informação e Comunicação 


\section{Sumário}

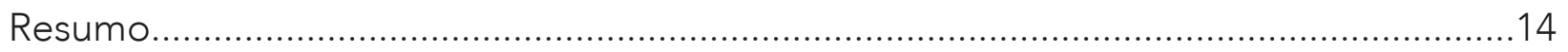

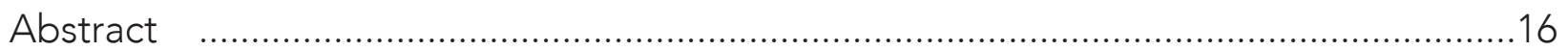

APRESENTAÇÃO

INTRODUÇÃO

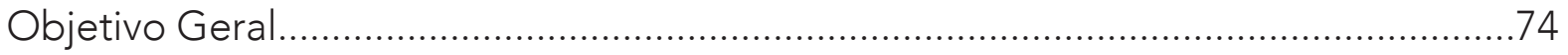

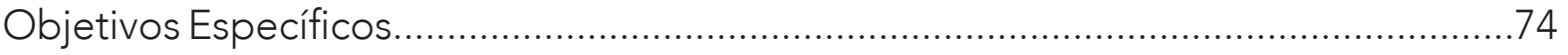

C_1

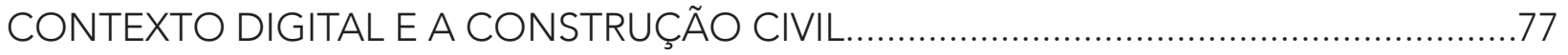

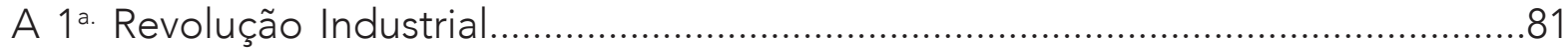

A industrialização da Construção Civil na 1a. Revolução Industrial .............................85

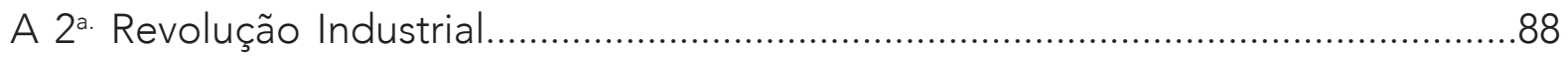

A industrialização da Construção Civil na 2a. Revolução Industrial ..............................92

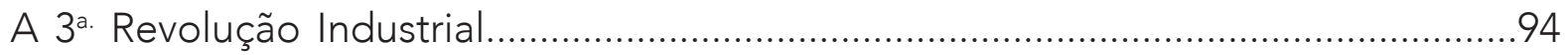

A industrialização da Construção Civil na 3a. Revolução Industrial..............................97

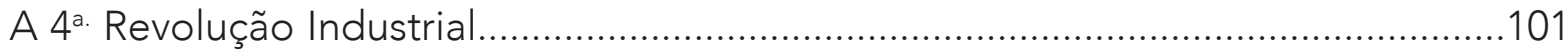

A industrialização da Construção Civil na 4ª. Revolução Industrial ...........................114 
C_2

PROJETO PARA A PRODUÇÃO File to Factory ou Design for Production?..................131

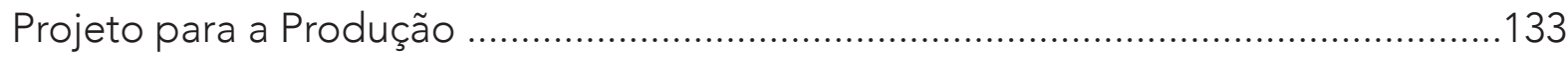

Processo Arquivo-Fábrica (File to Factory)........................................................148

Projeto para a Produção (Design for Production).................................................158

C_3

MÉTODO 185

C_4

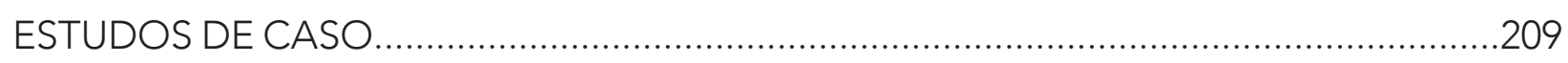

PAVILHÃO DA UNIÃO DOS EMIRADOS ÁRABES (UEA) EXPO MILÃO 2015...........211

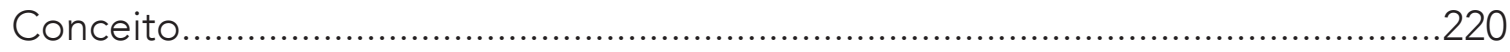

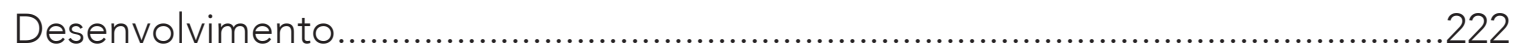

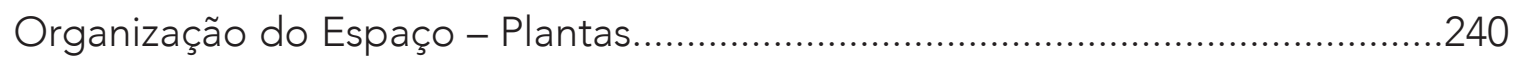

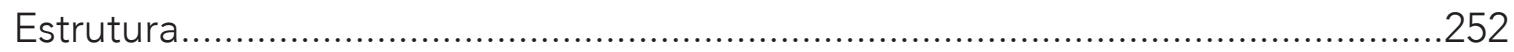

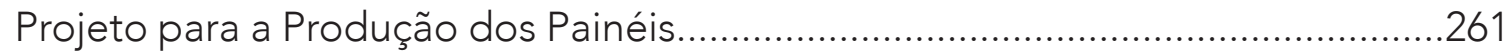

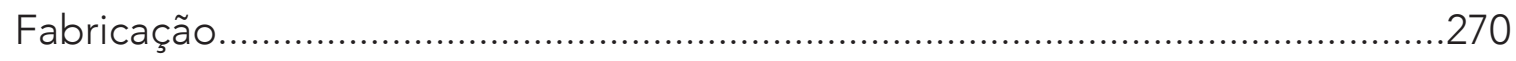

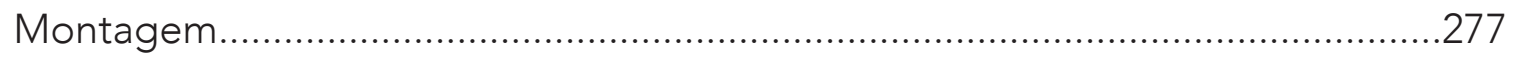

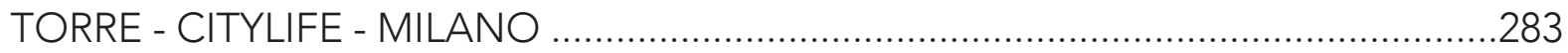

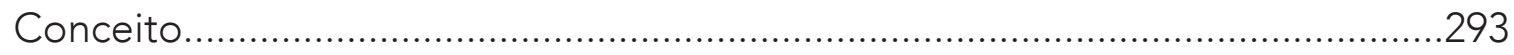

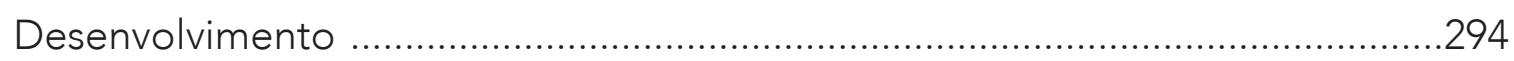

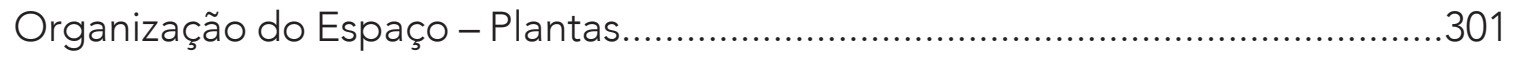

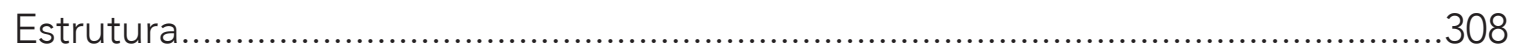




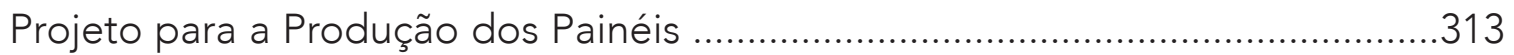

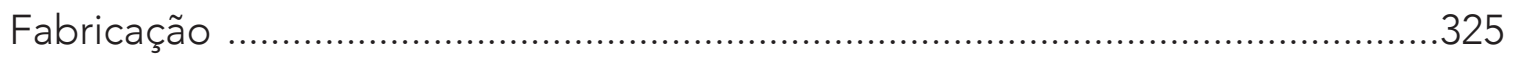

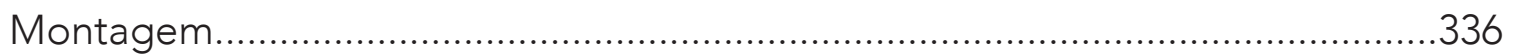

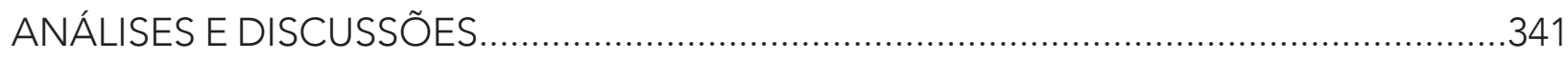

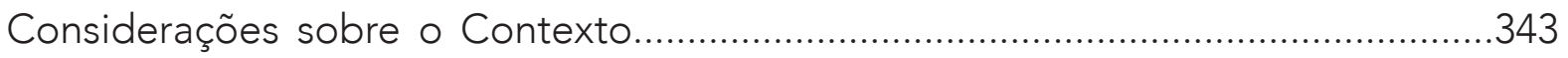

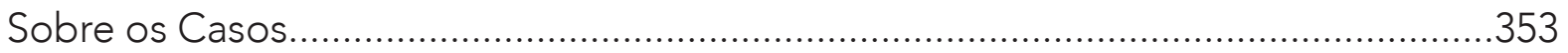

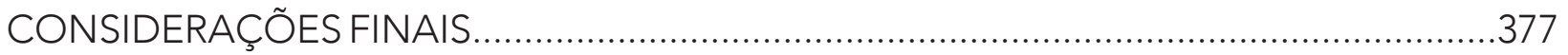

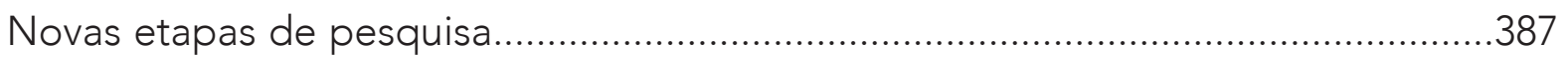

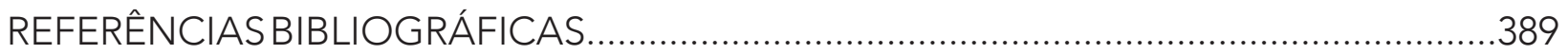

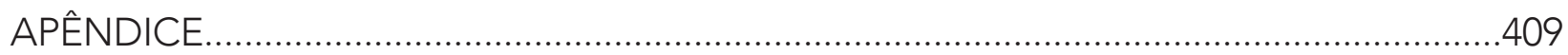

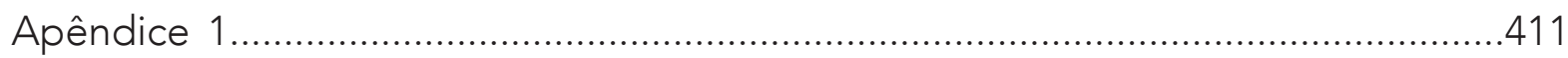




\section{APRESENTAÇÃO}

O desenvolvimento de uma pesquisa científica, bem como a sua construção escrita, é um longo processo, iniciado por um plano em que o pesquisador coloca suas inquietações frente a uma situação e também demonstra suas inseguranças perante o cenário que ele acredita ser a realidade. No caminho, passa pelas várias disciplinas, na tentativa de discutir e buscar com os mestres as respostas para solucionar os problemas e para deixar mais clara a teia de temáticas e conexões que o envolvem.

A coleta dos dados é uma experiência tanto em profundidade, que vai em busca das respostas às perguntas colocadas, entrando pelos universos da realidade, da literatura e das reflexões, quanto em extensão, que olha para os caminhos que se abrem diante das imensas áreas e inúmeras possibilidades. Nesse processo, muitas vezes o curso não depende unicamente do pesquisador, mas das portas que 
Ihe são abertas. E a redação final é a verdadeira reconstrução das intenções; é o esforço de realizar as ligações entre os temas e compreender efetivamente a realidade que 0 atormenta.

Esse caminho, em grande parte, da jornada é um processo solitário, em que muitos personagens contribuem com palavras que estamos prontos para ouvir e, em outros momentos, são necessárias novas tentativas para chegarmos à maturidade de apreender. Esses são os sábios que iluminam o caminho e que mostram algumas pedras, nos dão água e força para continuarmos a trilhar e buscar. Dentre eles, estão nossos orientadores, colegas, conhecidos e também desconhecidos, que passam e simplesmente sussurram alguma palavra que, naquela situação, acaba fazendo a conexão para alguma indagação.

Mesmo que envolvido por um grupo de pesquisa, o processo é individual; as reflexões são resultado de amarrações pessoais e certamente partem de um olhar focado para os objetos que são possíveis de serem trabalhados e estão de acordo com a capacidade para esse espectro de visão. Fazer uma monografia sempre é um olhar pessoal, que mostra um campo visível, e certamente nunca conse- 
guirá abordar todos os aspectos da realidade, mas apenas aqueles sensíveis aos olhos do pesquisador solitário.

A investigação que será descrita nas próximas páginas surgiu ainda na fase do mestrado, quando, no grupo de pesquisa nomads.usp, investigavam-se novas formas de projetar, com tecnologias inovativas e fabricação digital. A indagação era: como seria construir esses projetos com formas orgânicas na realidade. $O$ processo de projeto e produção de um molde parecia possível de ser dissecado, mas a pergunta se repetia:

- Como são projetadas e construídas as superfícies complexas de edifícios contemporâneos?

Responder a essa pergunta envolvia pelo menos dois grandes assuntos: o primeiro estava relacionado com 0 desenvolvimento do projeto para a fabricação da superfície; etapa de dividir em partes para a fabricação dos componentes, pensar nas conexões, no melhor polígono para cada componente, no material proposto, nas propriedades mecânicas, na elaboração de famílias ou componentes singulares, no conforto e na segurança da pele e nos equipamentos para sua manutenção e limpeza e, 
posteriormente, na montagem em canteiro de obras, com todas as variáveis incorporadas do local e da diversidade. Essa etapa é habitualmente chamada, na literatura, de Projeto para a Produção e será abordada posteriormente, mas, em poucas palavras, significa planejar a produção e a montagem da superfície.

O segundo assunto a ser abordado são as superfícies complexas, que são cada vez mais comuns em edifícios contemporâneos nos grandes centros econômicos. Essas características de superfícies complexas surgiram com o desenvolvimento das tecnologias da informação, principalmente associadas aos equipamentos digitalizados na década de 1960, e atualmente, com o avanço das máquinas, as possibilidades de projetação e produção são incrementadas a cada dia.

A temática superfícies complexas é compreendida como um produto de um contexto de desenvolvimento das tecnologias de informação e comunicação. E, como não poderia deixar de ser, a construção civil e a arquitetura fazem parte dessa realidade social. Por esse motivo, o trabalho se preocupa em contextualizar a sociedade digitalizada, focando principalmente o processo de produção e suas 36 
tendências contemporâneas.

Essas inquietações em relação à viabilização de superfícies complexas no edifício foram incorporadas à experiência da autora de ter trabalhado em canteiro de obras, na construção de Bases de Apoio Comunitário em sistema industrializado fechado do arquiteto João Filgueiras Lima - Lelé, o que incentivou a busca da compreensão dos sistemas industriais contemporâneos, no sentido de entender o processo de Projeto para a Produção e a construção do edifício.

A partir dessas apreensões, esse trabalho tem a intenção de responder às indagações e também colocar as novas questões que surgiram a partir desse trajeto, já que a atividade de pesquisa é uma constante e não se encerra, criando novos ciclos repletos de outras questões. Diante disso, pretende-se apresentar alguns pontos e, assim, realizar o salto para a requalificação de novos conhecimentos.

O trabalho foi estruturado em:

A Introdução faz uma contextualização da arquitetura contemporânea, define o objeto superfícies complexas, aborda o Projeto para a Produção, descreve os motivos pelos 
quais se consideram importantes o estudo e a investigação e coloca o objetivo e suas proposições.

O Capítulo 1 faz uma contextualização dos modos de produção industrial e seus níveis de automatização, os rebatimentos na Construção Civil até chegar aos dias atuais.

O Capítulo 2 trata do tema Projeto para a Produção na Arquitetura e discute duas vertentes para a produção digital: uma que entende o processo como File to Factory (Arquivo-Fábrica), em que os arquitetos encaminham os arquivos diretamente para a produção, e outra que entende como Projeto para a Produção, que considera que existe um processo com etapas e desenvolvimentos específicos de Projeto para a Produção.

O Capítulo 3 descreve o Método da pesquisa, especifica como foram escolhidos os estudos de caso, quais foram as estratégias para a busca dos dados e coloca o delineamento da pesquisa.

O Capítulo 4 apresenta e discute os dois casos analisados e, finalmente, apresenta as características, soluções e organização para a construção dos edifícios. Demonstra o Projeto para a Produção das superfícies complexas elabo- 
radas nos edifícios.

O Capítulo Análises e Discussões discute os dados e propõe algumas reflexões a respeito do problema, apontando para a resposta às questões e aos pressupostos colocados. Elabora um modelo do Projeto para a Produção de superfícies complexas.

E, nas Considerações Finais, verifica-se a contribuição do conteúdo em relação à literatura apresentada e analisa o trabalho como um todo. 
Figura 1: Estrutura metálica em desmonte do Pavilhão da União dos Emirados Árabes. Foto: autor. Data: 2016. 

A introdução faz uma abordagem sobre os caminhos teóricos contemporâneos descritos por Sykes (2013) localiza o campo da pesquisa e faz um apanhado sobre a transformação da manufatura com a participação crescente dos equipamentos digitais e sua influência sobre a construção civil. A pesquisa trabalha essencialmente com superfícies complexas de edifícios contemporâneos que utilizam fabricação digital para a sua execução, através da etapa de Projeto para a Produção. Apresenta e especifica o objeto da pesquisa, expõe os objetivos, bem como os pressupostos, do trabalho.

O uso de máquinas para o processamento de dados teve um grande avanço, principalmente após a Segunda Guerra Mundial, resultado de um tratamento de informações com operações binárias, graças às descobertas eletrônicas para o desenvolvimento da computação e os cálculos eletrônicos para uso militar em lançamento de mísseis.

Os avanços tecnológicos nas áreas da informação, principalmente a partir da década de 1990, possibilitaram modificações nas maneiras de projetar, fabricar e representar na construção civil e no desenvolvimento da arquitetura (SYKES, 2013). O trabalho de Frank O. Gehry no Pavilhão 


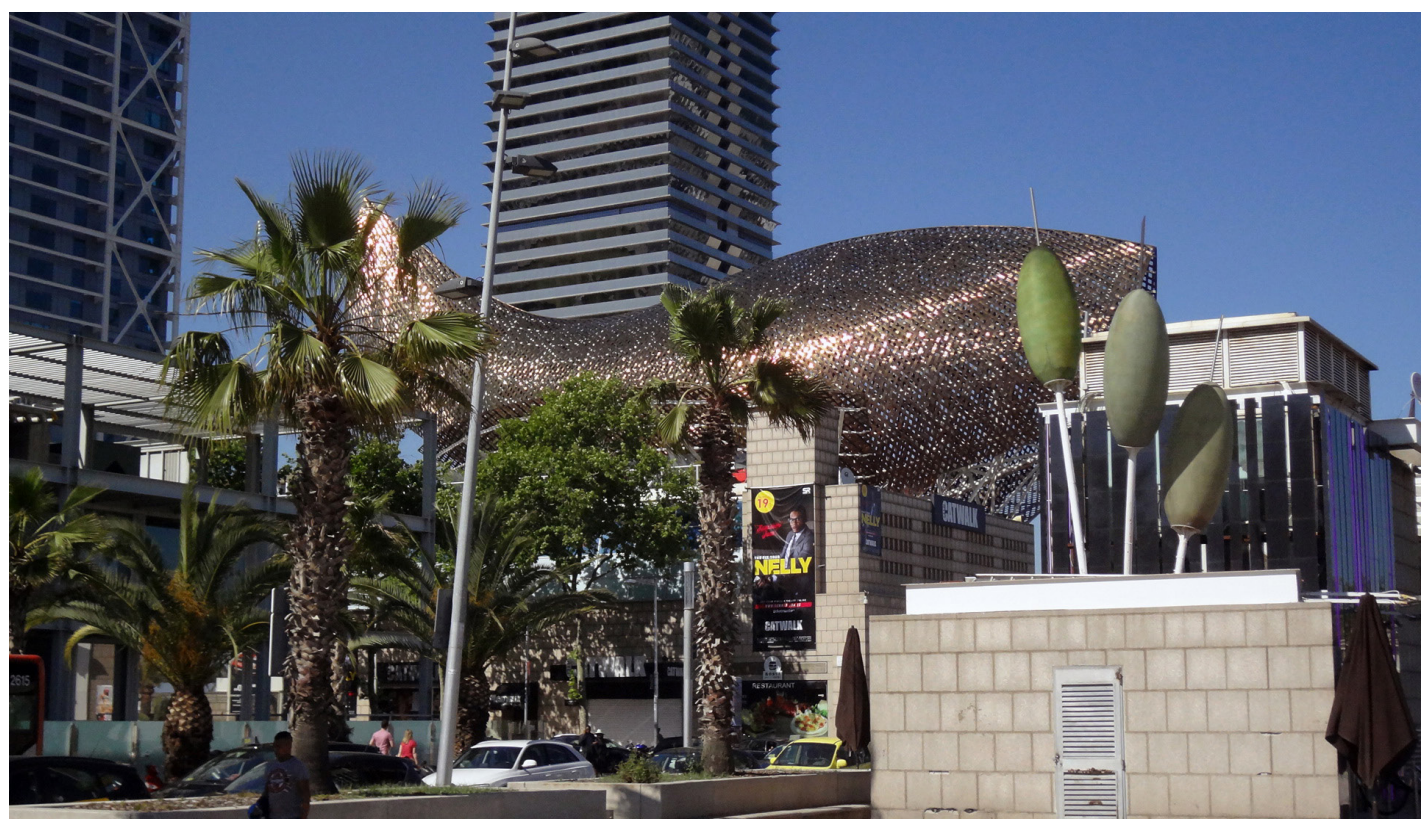

do Grande Peixe de Barcelona (1992) (Figura 2) utilizou diversos programas para a sua viabilização. O processo envolveu uma maquete física, que correspondia à superfície do modelo digital gerada para estudos de análise estrutural e confecção do objeto. A produção e a montagem foram direcionadas pelo modelo digital, que organizava todos os componentes e suas etapas de construção (NABONI; PAOLETTI, 2015).

De acordo com Sykes (2013), as três temáticas tratadas

Figura 2: Grande Peixe de Barcelona, projeto de Frank Gehry. Um dos primeiros objetos desenvolvidodos a partir de análises computacionais. Foto: autor. Data: 2016. 
por teóricos e críticos da arquitetura a partir da década de 1990 são as questões que envolvem: 1. o meio ambiente e suas estratégias para prevenir os danos ambientais, 2. a realidade e o cotidiano e 3. a digitalização na arquitetura.

Nas vastas vertentes de pesquisa voltadas para o meio ambiente, existem arquitetos envolvidos com o desenvolvimento de materiais reciclados, o uso da captação e o armazenamento de energia local, renovável e eficiente, e o setor que utiliza componentes vivos como meio para diminuir a demanda energética, tal como a utilização das extensas coberturas vegetais, além do uso de técnicas tradicionais que aproveitam materiais locais como a terra, a palha e a pedra para a construção de edifícios.

O outro tema tratado são os conceitos de contemporaneidade e cotidiano. Esses se concentram na produção da arquitetura para a realidade, de forma mais prática e menos teórica, para o homem comum e seu dia a dia, a partir da experiência humana, contrária aos projetos de caráter monumental, como é o caso dos edifícios de Gehry. Essa corrente está focada no contexto da população com interesse no local, no lugar onde o edifício existe (SYKES, 2013). 
Se fizermos uma reflexão a respeito do desenvolvimento das tecnologias utilizadas nos países emergentes, provavelmente várias discussões da literatura brasileira sobre a temática fabricação digital estarão inseridas nessa vertente da realidade, sendo necessária uma abordagem desde questões de encaminhamentos políticos, de empregabilidade, de nível de formação dos técnicos até muitos outros pontos fundamentais para a perfeita compreensão da situação. Em outras palavras, tratar dos avanços na tecnologia para a construção de superfícies complexas no Brasil não pode ser analisado de forma independente; há de se problematizar de forma mais aprofundada, singular para o contexto do país, o que não é a intenção nesse momento, pois esse é um tema que será abordado nas próximas etapas da pesquisa.

Para este trabalho, é importante colocar que o Brasil é um país que vive situações peculiares de países latino-americanos e emergentes. Consequentemente, o processo de industrialização da construção civil é também efeito das iniciativas de governo implementadas e resultantes das intenções políticas e econômicas.

De acordo com Cano (2012) os países passam por um pro46 
cesso de desindustrialização histórica e ele justifica esse conteúdo pelo amadurecimento da indústria dos países desenvolvidos que aconteceu nas décadas de 1960-70, com a exportação de bens manufaturados e a utilização de tecnologia avançada. Após esse período, o que se verifica nos anos posteriores é uma desaceleração dos crescimentos da indústria diante da expansão dos serviços, associada ao processo de globalização e neoliberalismo dos anos 1970, com a crescente participação da China e outros países asiáticos no mercado mundial.

O mesmo autor cita que, entre os setores industriais, a manufatura ou indústria da transformação é a que abarca e possibilita o desenvolvimento tecnológico e dos outros setores da economia, participa com 40\% do valor acrescido, é o principal vetor das políticas de desenvolvimento e o que está mais influenciado pelo mercado internacional. Embora os avanços tecnológicos estejam presentes e em franco desenvolvimento nos países com alto investimento industrial na construção civil, nos países emergentes, como é o caso do Brasil, a realidade parece um pouco diferente, com a coexistência de diferentes patamares de desenvolvimento tecnológico nas obras de construção. 
O processo de desindustrialização de diversos países emergentes aconteceu com o crescimento das indústrias cada vez em menor escala, o que resultou na diminuição da participação dos produtos no mercado mundial, diminuição dos investimentos, da produtividade, da competitividade interna e externa e da consequente estagnação do setor. Nos países emergentes, a industrialização atual está situada em um palco onde as condutas políticas são inexistentes nas últimas décadas, as ações governamentais optam pela escolha por altas taxas de juros e câmbio valorizado, grande dependência de commodities de exportação, baixo investimento no setor secundário e mercado interno cada vez mais aberto para produtos estrangeiros de alto valor agregado (CANO, 2012).

Esta e outras tantas políticas públicas fazem com que o país tenha algumas características, tais como largas diferenças sociais discriminatórias, níveis de educação que estão longe dos preconizados, políticas com caráter privilegiado de poucos, privatização de instituições com finalidades público-coletivas, carências de atendimentos em necessidades básicas, tais como habitação, saúde e cultura, não inserção no mercado de trabalho pelas baixas 
qualificações e oportunidades de emprego, além de tantas outras questões que envolvem a carência de vontades políticas para a obtenção de resultados que sejam focados na apropriação da cidadania.

Sendo assim, a construção civil está inserida nesse contexto e faz parte do setor industrial, uma vez que participa da transformação da matéria prima em um objeto e faz parte do mercado de consumo, com a incorporação de investimentos internacionais, respondendo aos anseios dos consumidores. Abiko et al. (2005) descrevem que a construção civil é composta pelo segmento das edificações e de construção pesada e tem importante participação no $\mathrm{PIB}$, além de atuar diretamente na indústria de produção de materiais e de bens de capital para a construção.

O investimento no setor dos países emergentes tem uma importância política e social que interfere em vários ramos da sociedade, na rápida geração de emprego para profissionais com mão de obra pouco qualificada, na renda, no aumento da competitividade na economia, movimenta a indústria associada direta e indiretamente ao ramo, diminui as diferenças regionais, induz o crescimento econômico, atrai capital estrangeiro, gera divisas e interfere 
diretamente no desenvolvimento do país (TEIXEIRA; CARVALHO, 2005). Assim, o tema tratado sobre a realidade e o cotidiano de Sykes (2013), deve ser associado à realidade brasileira, à condição de uma população com carências de acessibilidade em vários aspectos voltados às necessidades mínimas.

A terceira temática, com suas diversas vertentes, citada por Sykes (2013), preocupa-se com a participação da digitalização e as possibilidades para o desenvolvimento, a produção e a montagem do edifício que utilizam como ferramentas os programas computacionais, interferindo nas diferentes etapas do processo da edificação. Esse é o ramo pelo qual esse trabalho se debruça, tentando contextualizar, analisar e criticar alguns segmentos que envolvem os procedimentos, focando especialmente na etapa de Projeto para a Produção.

Nessa linha, provavelmente estão as arquiteturas consideradas monumentais e de autoria, dentro de um contexto da sociedade do espetáculo, como bem contextualiza Pedro Fiori Arantes:

Esse é um fenômeno recorrente nos projetos contemporâneos, nos quais os edifícios se apresentam como totalidades em si, desgarrando-se da 
cidade, de qualquer contexto ou território. Eles cumprem funções para além do lugar e do local, são edifícios e infraestruturas transnacionais de circulação do capital. Essa arquitetura torna-se, por isso, autorreferente, tal como as finanças. Daí a irrelevância do contexto - não há mais que se preocupar em formar a cidade, um mundo coeso, eventualmente homogêneo. Assim, pode-se chegar a um verdadeiro "espaço delirante", sem restrições de estrutura, de materiais, recursos e mesmo de qualquer uso [...] (ARANTES, 2008, p. 189).

O trabalho não fecha os olhos para essa situação e visão, mas considera que essa temática seria objeto para outra pesquisa tanto ou mais densa do que a que se apresenta nesse momento; considera, portanto, que o assunto possa ser abordado em uma próxima ocasião.

As tecnologias digitais possibilitam representações detaIhadas e fabricação precisa para qualquer tipo de estrutura ou forma complexa. Nesse sentido, Kolarevic \& Klinger (2010) descrevem que novos protocolos são necessários para a elaboração e produção dos edifícios, sendo que a informação e sua veiculação são a essência do trabalho. Os ramos que utilizam conceitos baseados em estruturas biológicas e ecológicas têm sido as linhas indutoras dos métodos desenvolvidos com a intenção de otimizar os custos e processos na arquitetura, na engenharia, nas pes- 
quisas e na estética.

Froese (2010) separou as Tecnologias de Informação e Comunicação (TIC) utilizadas na construção civil em 3 eras distintas: a primeira, iniciada há mais de 40 anos e ainda presente, está centrada no desenvolvimento de ferramentas para assistir tarefas específicas como CAD (Computer Aided Design), análises estruturais e estimativas. A segunda, iniciada em meados dos anos 1990, foca nos sistemas de comunicação como e-mail, web, sistemas de gestão de documentação e outros e a terceira refere-se à tentativa de interação entre esses vários instrumentos em um sistema global no sentido de realizar a compatibilização e a modelagem.

Nos anos 1970, foram introduzidos os primeiros programas de computadores na utilização de projetos de arquitetura; estes representavam a primeira geração de plataformas que auxiliavam no desenho eletrônico de projetos. No artigo, Achten (2007) descreve seis pontos importantes modificados com os usos da digitalização:

- Uso de energia de forma inteligente, equipes dinâmicas de projeto e gestão de informação; 
- Novos componentes;

- Prototipagem rápida, com a vasta gama de equipamentos para modelagem e análise do objeto, muito mais rápidos que as técnicas manuais;

- Uso das mídias de forma versátil, com nuvens e equipamentos capazes de realizar simulações e testes;

- Utilização da internet, facilitando a comunicação e a troca de informações em tempo real,

- Uso dos sistemas BIM, para a visão geral do edifício, com modelos mestres.

A digitalização dos processos na área de desenvolvimentos e da construção civil possibilitou a gestão mais qualificada dos vários projetos como estruturas, hidráulica, elétrica, ar-condicionado etc., que preveem e buscam soluções para os problemas antecipadamente; possuem maior facilidade para trabalhar com diferentes parceiros, independentemente de sua localização territorial; são capazes de monitorar a eficiência energética do edifício ainda nas fases de projeto, além produzirem modelos e simulações eficientes para estudos e análises dos obje- 
tos. Os processos se tornaram mais ágeis e específicos, influenciando os protocolos e, consequentemente, a atuação dos profissionais envolvidos.

Na pesquisa realizada de 1998 a 2012 por Lu et al. (2014) foram analisadas as aplicações das Tecnologias de Informação e Comunicação no setor da construção civil e verificou-se que as utilizações das tecnologias tiveram um rápido aumento no século 21. Dentre as tecnologias mais citadas, estão a busca de informação via WEB, as tecnologias sem fio (WIRELESS), a Realidade Aumentada, os Sistemas Eletrônicos de Gestão de Dados e os programas $B I M$, sendo que os principais assuntos tratados são em relação a: eficiência da informação organizacional, tomada de decisões, colaboração, desempenho e comportamentos organizacionais. $\bigcirc$ uso estava voltado principalmente para a comunicação entre contratantes e empresas, sendo que a utilização nas áreas de desenvolvimento de projeto e gestão tem crescido rapidamente nos últimos anos.

Mitchell; McCullough (1996), com a primeira publicação do livro Digital Design Media no início de 1990, constituíram um guia sobre a atuação, os objetos utilizáveis para a arquitetura e o desenvolvimento de projetos a partir de 54 
um quadro teórico que disseca a lógica dos diversos instrumentos, ferramentas e de como são os programas disponíveis. Com linguagem simples, Mitchell e McCullough descrevem a máquina como um processador de informações de acordo com as intenções do usuário. No conteúdo do livro, apresenta-se uma compreensão aprofundada dos diversos elementos utilizados para a construção do projeto e utilização de novas tecnologias e de como estas devem alterar o modo de fazer arquitetura.

Nesse processo de fazer, os autores descrevem as várias possibilidades de atuação do arquiteto: como designer, na produção do modelo, na programação para produção do modelo, em engenharia reversa, na utilização de protótipos a partir de impressoras 3D, na utilização de dispositivos móveis para a reprodução de pequenas partes e suas interconexões e, desse modo, atua diretamente em máquinas controladas numericamente em modelos descritivos. Como vantagens desse processo, Mitchell e McCullogh comentam que, a médio prazo, há uma tendência de diminuir os custos, uma redefinição nas relações entre arquiteto e produção, eliminação de processos intermediários na produção de formas curvas complexas, 
aumentando a possibilidade de sua produção; os processos tendem a ser mais previsíveis do que os processos tradicionais; os projetistas trabalham com informações mais detalhadas sobre as possibilidades de manufatura; há um encurtamento do ciclo de produção e as possibilidades de experimentação em protótipos é muito mais facilitada. Sendo assim, os autores, já nos anos 1990, esclareciam vários aspectos da utilização dos computadores no processo de criação e produção do edifício, apontando as modificações que ocorrem nos protocolos de trabalho e que se alterarão no decorrer dos tempos.

Charles Jenks (1997), no livro The Architecture of the Jumping Universe (A arquitetura no Salto do Universo), comenta que as principais ideias dos novos projetos estão relacionadas à retroalimentação, à auto-organização e à participação dos computadores na representação da arquitetura. Com o uso das ferramentas, é possível conceber curvas, estruturas dinâmicas e grelhas deformadas, além de utilizá-las como instrumento de produção de padrões não lineares, com formas de ondas.

Nesse livro, Jenks anuncia um movimento posterior ao pós-modernismo, especialmente olhando para a arquitetura e 56 
os seus resultados diante das mudanças teórico-conceituais fundamentadas em objetos fractais, na não linearidade, em ondas e torções, superposições, entre outros. As modificações estão baseadas nos dois conceitos de complexidade do início dos anos 1960: a primeira de Robert Venturi, que define a complexidade como uma colagem do pré-existente, como soluções conhecidas e manipulação do modernismo, e a segunda versão na complexidade como emergência, a partir do desenvolvimento da ideia cibernética, como um arranjo de uma colônia de formigas que tem uma conexão e comportamentos próprios, organizados como um superorganismo com propriedades não lineares. É com esse olhar que Jenks se detém no livro.

As inspirações teóricas que balizam a produção da arquitetura defendida por Jenks como o salto da arquitetura são baseadas em organismos vivos, tais como o padrão de disseminação de musgos, ou o desenho de asas de insetos, ou a forma da estrutura de ossos de animais etc. A compreensão desses objetos, traduzidos em padrões matemáticos, é a informação inicial para uma máquina matricial, utilizada como inspiração para o projeto em arquitetura. Verifica-se aí uma valorização do leque de pos- 
sibilidades que a numerização proporciona no processo de projeto e produção de edifícios com superfícies complexas.

Neste olhar, Jenks indica o estudo dos seres vivos e a sua associação com padrões de comportamento que podem ser estudados para a utilização na arquitetura. Também propõe o aprofundamento da emergência, que pode ser a transmutação de determinados procedimentos ou condutas em novos parâmetros produzidos na natureza ou por linguagem algorítmica, que cria novos padrões, e essas situações também são possíveis de serem aplicadas nos conceitos de arquitetura.

A produção de arquiteturas com formas complexas é um dos resultantes dos processos digitais de projetação, em que diversos métodos de desenvolvimento geram superfícies antes pouco imagináveis na produção da construção civil. Entende-se por arquiteturas com superfícies complexas aquelas defendidas por Jenks (1997), dentro de um processo que utiliza as ferramentas de Mitchell; McCullough (1996), mas também os métodos descritos por Oxman (2006), que categoriza os vários métodos desenvolvidos para a elaboração de projetos com o uso de fer- 
ramentas digitais.

Como defende Klinger (2010), os programas utilizados para o desenvolvimento de projetos contribuem na administração de complexidades, articula projetos em modelos mestres que facilitam a comunicação e a troca de conhecimentos e colaboração em diferentes especialidades durante o processo. $\bigcirc$ modelo final é uma base de informações que agrega valor através do processo interativo e da reflexão criativa, o que resulta em informações. $\bigcirc$ projeto é essencial e deve ser privilegiado no desenvolvimento de soluções, aumentando o retorno da realidade de produção para a construção final. Portanto, a informação gerada pelas tecnologias digitais é o agente essencial para a inovação em um processo total da arquitetura.

Na fabricação digital, os elementos e os dados da produção informam o processo de construção e fornecem parâmetros e restrições para o processo de projeto (GRAMAZIO; KOHLER; OESTERLE, 2010). De acordo com Oosterhuis et al. (2004), o processo começa com um modelo digital de forma livre, que pode ser fabricado em um equipamento CNC (Computer Numeric Control - Comando Numérico Computadorizado) para ajuste da forma ou rá- 
pida avaliação de suas proporções ou o processo inverso através da captação da imagem por um scanner e posterior manipulação do modelo. O modelo pode ser manipulado, torcido e deformado através da superfície NURBS ${ }^{1}$, para a definição espacial através de uma nuvem de pontos.

O escritório de Oosterhuis trabalha com programação matemática, manipulação do modelo e parametrização para intervenção no objeto. No projeto da Barreira Acústica em Utrecht, Holanda, desenvolvido por essa equipe, foram utilizadas 3 etapas de programação: a primeira traduz a estrutura, definindo a forma e a posição dos painéis de vidro, a segunda gera um modelo 3D detalhado da estrutura de aço e vidro e a terceira aplica as restrições. Após esse processo, os dados são enviados para as etapas de fabricação.

Na descrição de Sass (2007a), para a produção de uma casa mínima com a utilização de equipamentos digitais de

1Superfícies NURBS significa Non Uniform Rational Basis Splines, tem origem na representação matemática de uma linha ou superfície curva com diferentes tipos de raios distribuídos na entidade. A equação matemática foi desenvolvida por Pierre Bézier que trabaIhou em um polígono de controle para a manipulação do objeto através de pontos fora do mesmo (SOUZA \& ULBRICH, 2009). 
cortadora subtrativa, ele descreve que o processo passa por dois tipos de máquina: uma para a elaboração do projeto e o desenvolvimento da espacialidade e outra para a fabricação. E o processo de fabricação digital é constituído, basicamente, por 3 etapas: 1. A partir do volume do objeto, criam-se superfícies planas que compõem o mesmo; 2 . A segunda etapa é a elaboração de placas-componentes que formam os planos iniciais, 3. A terceira é a tradução dessas placas componentes para as máquinas que efetuarão o corte no material, processo de organização para o corte conhecido como nesting.

A partir dessa elaboração das arquiteturas contemporâneas geradas por utilização de equipamentos digitalizados e do uso comum de programação para a sua obtenção, considera-se que superfícies complexas podem ser definidas como segue abaixo.

Os primeiros autores são o prof. Adriano Fagali e Cristiane Brasil Lima Ulbrich, no livro Engenharia Integrada por Computador e Sistemas CAD/processo de organização para o corte/CNC: Princípios e Aplicações, publicado em 2009, que trata uma superfície complexa como o desenvolvimento de uma equação matemática, com base nos 
estudos de Pierre Bézier na década de 1950. Neste livro, eles desenvolvem alguns conceitos sobre tecnologias de manufatura auxiliadas por computador e definem superfície complexa como:

[...] quando o raio de curvatura se altera, ao decorrer da entidade, de forma não uniforme. Cada ponto da geometria possui um raio de curvatura distinto e independente dos adjacentes (SOUZA \& ULBRICH, 2009, p. 59).

Já Paoletti (2006), compreende por superfícies complexas aquelas existentes em edifícios, que apresentam uma superfície fluida, formadas por sólidos esféricos para formar volumes curvos ou que possuem um nível de complexidade do sistema ou do componente em sua morfologia ou tecnologia e uma complexidade do módulo em relação à sua geometria e material e que têm uma íntima relação com as tecnologias da informação, mas, acima de tudo, a junção de um grande número de responsabilidades, competências e de acordo com a organização dos processos construtivos.

A frequência de edifícios com superfícies complexas no Brasil ainda é escassa, e alguns exemplos dessas tipologias foram desenvolvidos no exterior, como é o caso do 
Museu do Amanhã, do espanhol Santiago Calatrava, que foi detalhado pelo escritório Arup, de Milão, ou a Arena das Dunas, em Natal-RN, que foi criada pelo escritório Populus e executada pela empresa Bemo, de origem alemã.

Um exemplo brasileiro que tem grande vocação para a utilização da fabricação digital é a cobertura do Museu de Arte do Rio (MAR) (Figura 3), do escritório Bernardes + Jacobsen Arquitetura. O Museu é formado pelo Palacete Dom João VI (1916) e o Hospital da Polícia Civil do Rio de Janeiro e faz parte do plano de revitalização da zona portuária do Rio de Janeiro. Foi inaugurado em 2013, após sua adequação para se tornar um museu-escola. Os arquitetos tinham como preocupação criar um ícone para a região e integrar os dois edifícios através das passarelas e de uma cobertura fluida que remetesse ao mar.

A superfície nasceu de um desenho digital a partir de um modelo líquido em movimento no programa 3DMax (Figura 5). Nesse modelo, a frequência das ondas foi acertada de acordo com a intenção projetual dos arquitetos e com a malha de pilares de $15 \mathrm{~cm}$ de diâmetro, que definia as alturas, sempre coincidindo as cotas mais baixas da superfície com a posição dos pilares para a saída das águas 


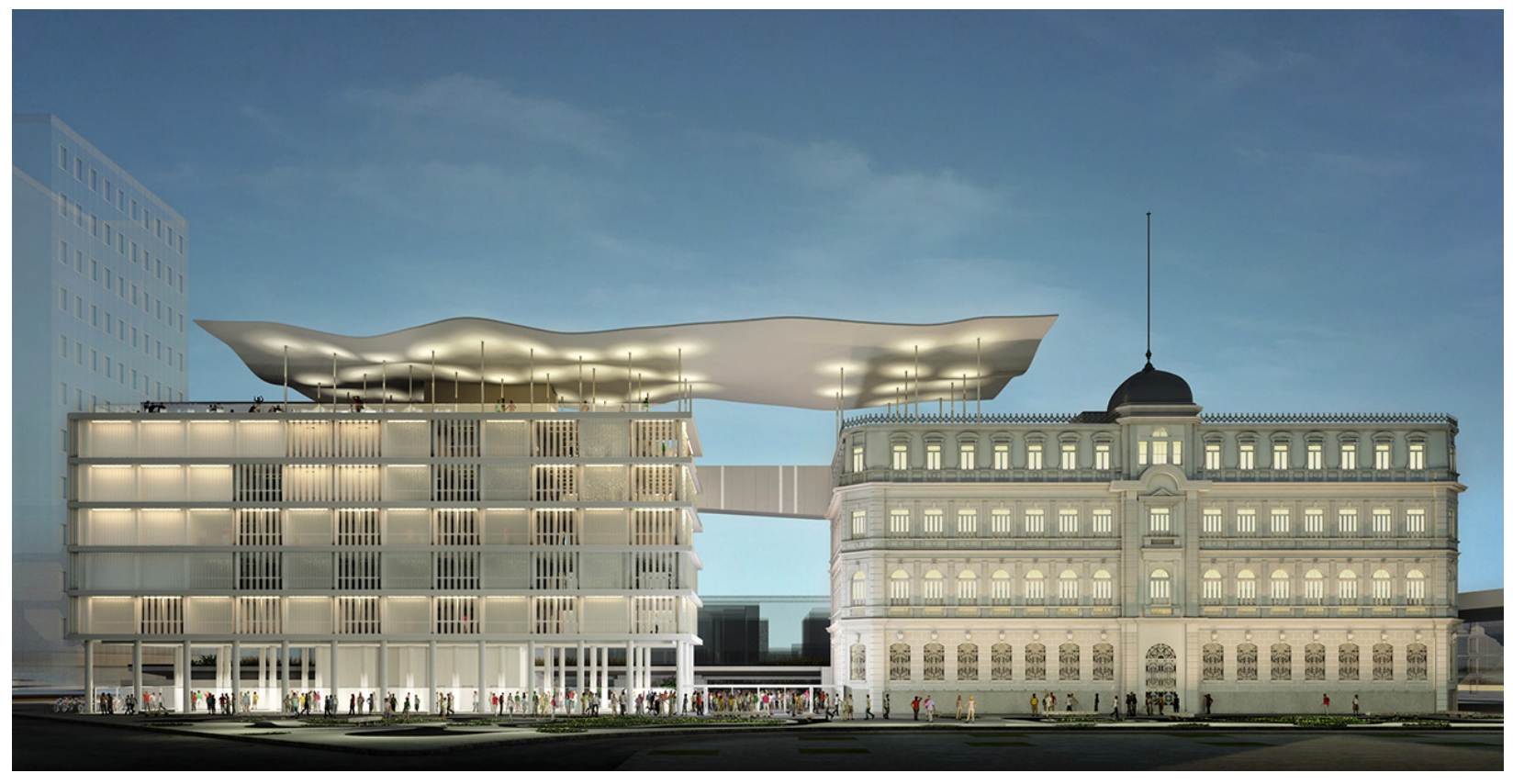




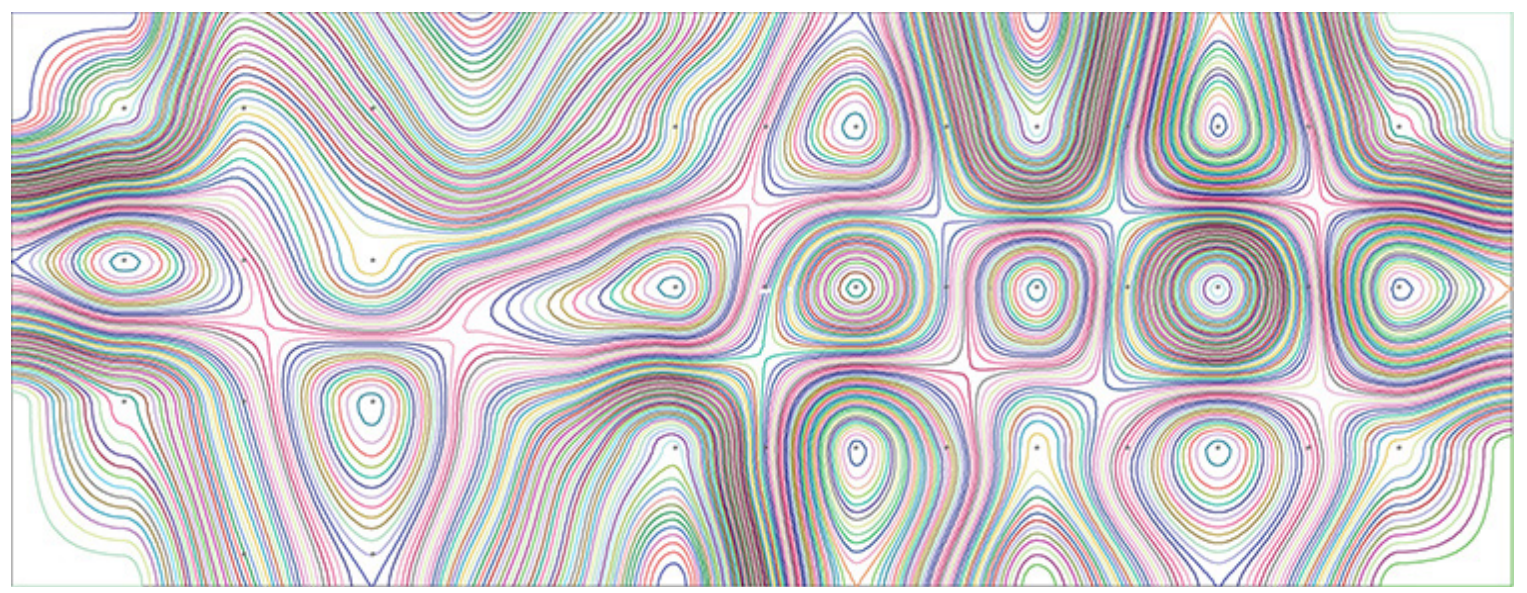

Figura 3: Maquete do Museu de Arte do Rio (MAR). Fotos: Andres Otero, Leonardo Finotti. Fonte: Imagens cedidas por Bernardes + Jacobsen Arquitetura.

Figura 4: Modelagem gráfica da cobertura que foi impressa em papel para recorte das formas. Nos pontos centrais, estão localizados os pilares para saída de águas pluviais. Execução da estrutura de ferro, concretagem da laje. Fonte: Imagens cedidas por Bernardes + Jacobsen Arquitetura.

pluviais (Figura 4).

Para a cobertura, foram utilizados $320 \mathrm{~m}^{3}$ de concreto e 70 ton. de aço (MC-BAUCHEME, s/d). A superfície possui as dimensões de $25 \mathrm{~m}(\mathrm{~L}) \times 67 \mathrm{~m}(\mathrm{C}) \times 19 \mathrm{~cm}(\mathrm{E})$, totalizando $1.650 \mathrm{~m}^{2}$ de área e peso de 800 toneladas. A superfície está posicionada a 30 metros de altura do solo, possui desníveis de até $1,5 \mathrm{~m}$ e é apoiada sobre 37 pilares que se distribuem no topo dos dois edifícios (MIYASAKA et al., 2017).

A equipe técnica tinha como desafio criar uma forma que suportasse o peso do concreto e que fosse capaz de preservar o caráter fluido do projeto. Inicialmente, foi cogitada 


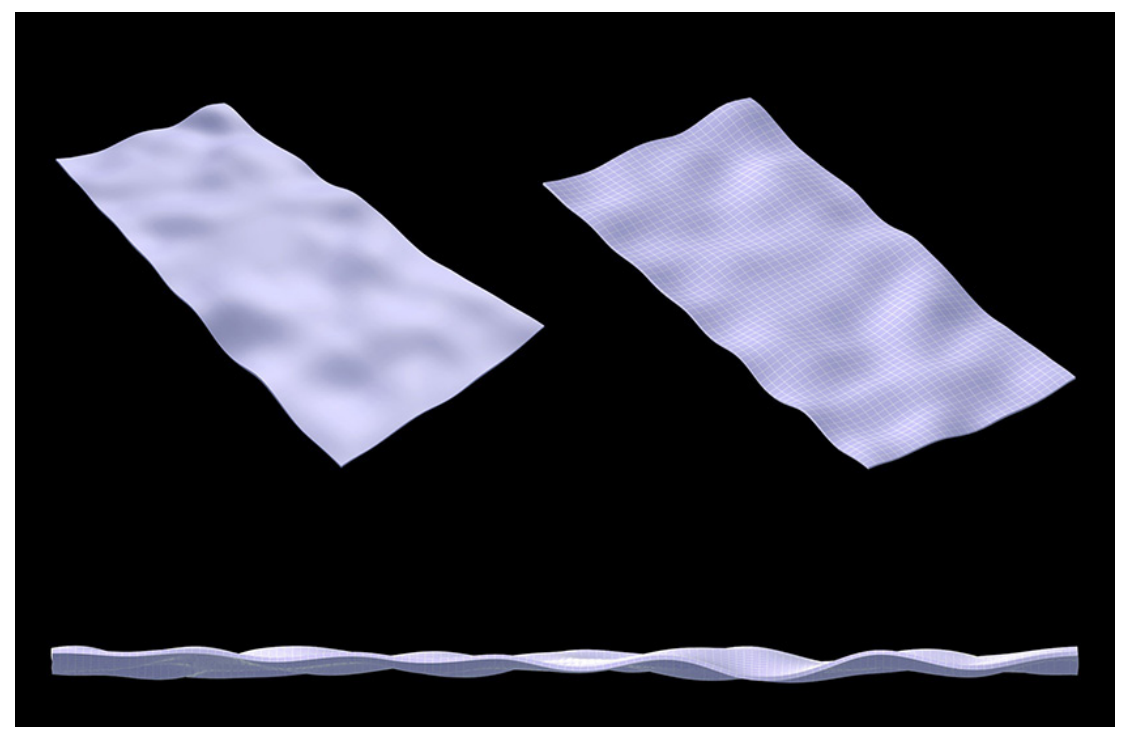

a utilização de técnicas de fabricação digital para confecção das formas. Carlos Lopes, artista plástico especialista em carros alegóricos carnavalescos, propôs que os 1.800 $\mathrm{m}^{3}$ de isopor fossem esculpidos em formas inferiores por artesãos da Escola de Samba Acadêmicos do Salgueiro (MC-BAUCHEME, s/d), que têm a habilidade de trabalhar com objetos orgânicos a partir de plantas e intimidade com o material. As peças de EPS (Expanded Polystyrene), com altura variável entre 0,6 e 1,0 m, foram executadas no galpão da escola em módulos de aproximadamente $5 \times 5$ metros, a partir de um modelo geométrico impresso em papel (Figura 4) e com acompanhamento topográfico. As formas foram levadas por caminhões e içadas para uma

Figura 5: Renderização da cobertura idealizada a partir de ondas do mar. Fonte: Imagens cedidas por Bernardes + Jacobsen Arquitetura.

Figura 6: Montagem das formas sobre a plataforma para posterior concretagem. Fonte: Imagens cedidas por Bernardes + Jacobsen Arquitetura. 66 


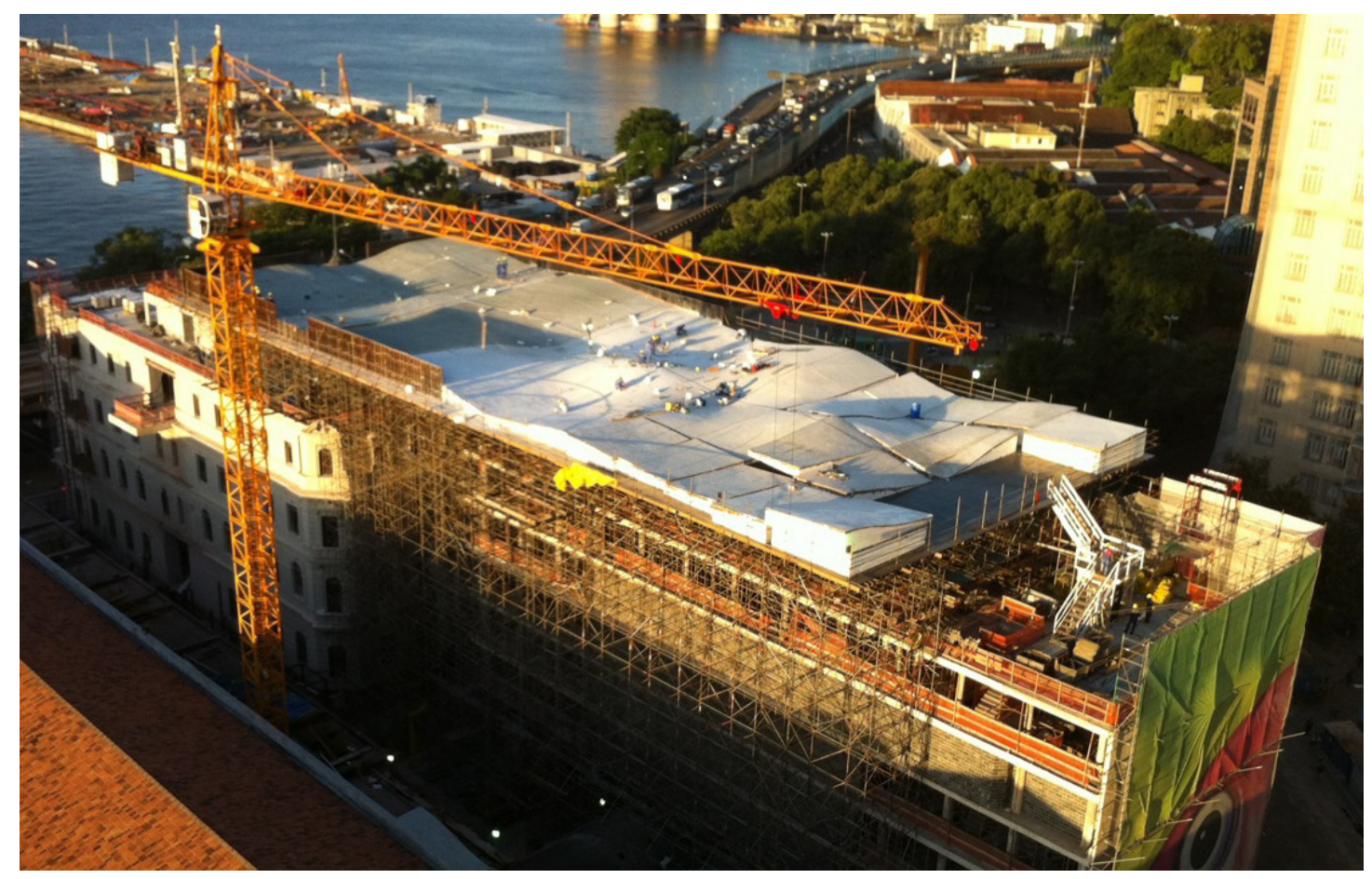



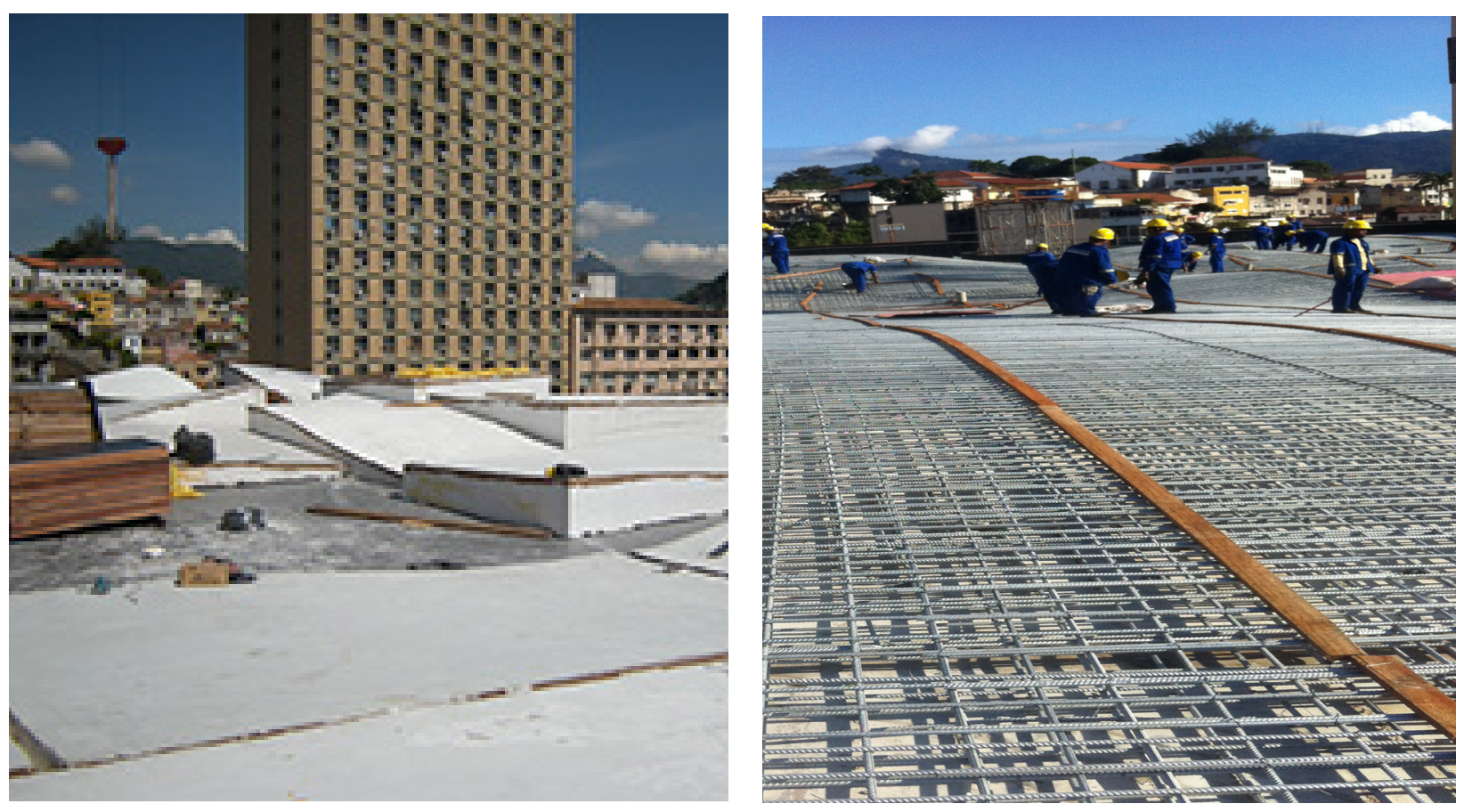

plataforma plana de madeira estruturada sobre andaimes (Figura 6). A partir daí, os blocos foram nivelados para a construção da armação e posterior concretagem (Figura 7/8).

A utilização da habilidade de profissionais acostumados a produzir carros alegóricos foi o melhor meio encontrado para a viabilização e produção das ondulações da superfície da cobertura através de uma adaptação ao trabalho, a partir de uma habilidade pertencente a esses produtores.
Figura 7: Formas de blocos de isopor moldados por carnavalescos a partir de planta impressa em papel. Fonte: Imagens cedidas por Bernardes + Jacobsen Arquitetura.

Figura 8: Execução da estrutura de ferro para concretagem da laje. Fonte: Imagens cedidas por Bernardes + Jacobsen Arquitetura 
A idealização do projeto, com o uso da modelagem, impressão digital em papel, associada ao trabalho artesanal dos trabalhadores, fez com que o processo se completasse, obtendo-se os resultados esperados pelos arquitetos.

Essa é uma breve ilustração de como os processos com potencial para o uso das tecnologias digitais são encaminhados no Brasil: com muita criatividade, é certo, mas que talvez mostrem outras potencialidades, se o mercado contar com esses serviços e equipamentos disponíveis a um custo compatível. Ademais, como citaram os vários autores, os protocolos apresentam grandes possibilidades para serem alterados; situação que pode proporcionar novas criações e atuações em arquitetura. Esta constitui, portanto, uma lacuna no processo de fazer e produzir os edifícios com superfícies complexas no Brasil, perspectiva de interesse para a pesquisa, que busca, de forma crítica, o conhecimento para o preenchimento do espaço teórico.

Em pesquisa apresentada em 2015 por Miyasaka \& Fabricio, Digital Fabrication in Brazil, Academic Production in the last decade ${ }^{2}$, os autores descrevem que a discussão

2 Fabricação Digital no Brasil, Produção Acadêmica na última década. 
sobre fabricação digital e prototipagem rápida é crescente no Brasil, principalmente nas universidades, e a utilização das ferramentas aumenta nas escolas de arquitetura. A preocupação principal é em relação ao processo de projeto paramétrico. Os objetos produzidos são na escala do corpo, mobiliários e pavilhões, e as máquinas adquiridas são as cortadoras a laser e fresadoras CNC. Este artigo demostra que a literatura produzida a respeito de edifícios em escala real é escassa, reafirmando a necessidade de pesquisas que olhem para esse campo.

O conhecimento aprofundado e detalhado sobre as tecnologias e os processos utilizados para a construção de superfícies complexas através de projetos de pesquisa é um dos pontos importantes para que essas estruturas sejam viabilizadas. Estudar e compreender esses métodos pode contribuir para o desenvolvimento dos projetos para a produção, deixando mais claras as necessidades tanto em nível de recursos quanto em relação à cadeia de produção que envolve tais elementos.

Apropriar-se de um conhecimento tecnológico e do seu "saber fazer" possibilita a utilização do mesmo associado a outros repertórios, e não necessariamente à reprodu- 
ção de tipologias recorrentes nos processos de ocupação, mas, sim, à sua implementação voltada para necessidades tipicamente brasileiras ou latino-americanas que valorizem nossa cultura e história. Significa, em última instância, um desejo de que a indústria da construção civil absorva equipamentos de alta performance e tenha a flexibilidade de utilização em diferentes setores voltados para a sociedade.

Dessa forma, a pesquisa desenvolvida se centra no levantamento e na análise da etapa depois do projeto elaborado, salientando que estas etapas não são lineares e se integram entre si, como mostra o diagrama 1. Quanto maior a simultaneidade entre elas, maior será a probabilidade de sucesso, minimização de tempo e custos. 


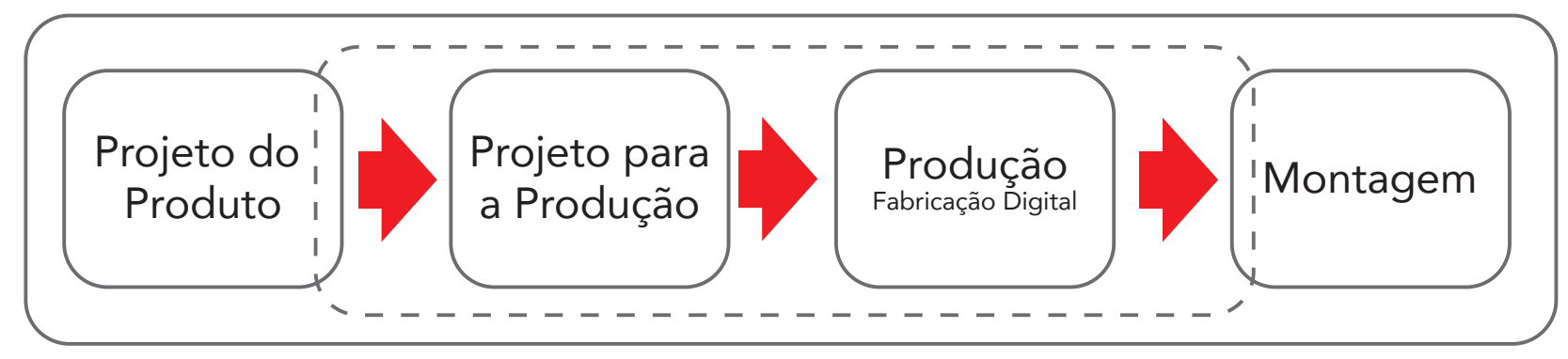

Diagrama 1: Esquema do processo de projeto com a definição do tema de estudo. Fonte: Autor. 
Visualizar o problema do projeto para a produção de superfícies complexas implica compreender as etapas necessárias para que os dados do projeto sejam transformados em componentes para a montagem; nesse caso, mais do que a visualização dos procedimentos que serão adotados no canteiro, pois o arquiteto necessita verificar e analisar o processo de fabricação muito antes da fase de execução do objeto (DUNN, 2012).

Acredita-se que tratar do projeto para a produção de superfícies complexas envolva certas especificidades no que se refere à criação de componentes relacionados a parâmetros diferentes de produção, bem como à utilização de equipamentos digitais específicos para a elaboração e manufatura dos componentes. Nesse sentido, esse trabalho se preocupa em se aproximar desses processos, na tentativa de desvendá-los e esclarecer os rumos pelos quais a construção civil e, especificamente, a manufatura tem escolhido para as soluções desse objeto. 
Diante disso, temos como:

\section{Objetivo Geral}

Descrever e discutir como se dão os Projetos para a Produção de superfícies complexas de edifícios contemporâneos reais, pouco descritos na literatura brasileira, e propor um modelo do processo de Projeto para a Produção de superfícies complexas.

\section{Objetivos Específicos}

- Verificar como são desenvolvidos e como se dão os processos decisórios;

- Compreender o processo de transformação do projeto de arquitetura para a produção e como são determinadas as escolhas;

- Identificar os pontos-chave do processo para a viabilização da superfície complexa,

- Verificar os maquinários utilizados para a produção dos componentes em fábrica. 
Diante desses objetivos, estes são os Pressupostos da Pesquisa:

1. A viabilização das formas complexas está centrada nas soluções de projeto, apoiado no comportamento dos materiais e nas técnicas utilizadas, isto é, para o desenvolvimento do produto, são necessárias equipes específicas que trabalharão nas diversas disciplinas e necessidades para a viabilização do edifício.

2. São necessários profissionais especializados com habilidades específicas para a definição da geometria e dos polígonos da superfície, pois, para a construção da superfície em partes que se agregam, é necessário que a mesma seja segmentada em pequenas peças para serem fabricadas e, posteriormente, montadas no edifício.

3. As plataformas BIM são fundamentais para a gestão do empreendimento, utilizadas para realizar a compatibilização das diversas disciplinas e a previsão de problemas.

4. O Projeto para a Produção de superfícies é uma atividade complexa, que envolve diferentes disciplinas e o planejamento minucioso de etapas subsequentes. 
Como será exposto a seguir, esses pressupostos partiram da literatura pesquisada e tratarão, nos dois primeiros capítulos teóricos, de como desenvolver as bases para o entendimento do problema, abordando, inicialmente, os modos de produção, as tendências contemporâneas e a construção civil e, depois, o Projeto para a Produção no contexto digital. A partir disso, será relatado como foram feitas as buscas de dados para a construção das informações para se descreverem dois casos pesquisados e, finalmente, tirar considerações sobre esse processo, com a análise da literatura apresentada. 
Figura 10: Imagem ilustrativa editada das revoluções de acordo com o grau de automatização no modo de produção. Fonte: Roser (2015). 
O Capítulo 1 realiza uma contextualização em relação à situação dos instrumentos computacionais através de uma análise dos processos industriais de produção, associados ao nível de automatização técnica em uma divisão temporal. Utiliza como referência Schwab (2016), que subdivide didaticamente entre as $1^{\text {a. }}$ e a $4^{\text {a. }}$ Revoluções Industriais (Figura 10) e exemplifica essa produção em relação à construção civil.

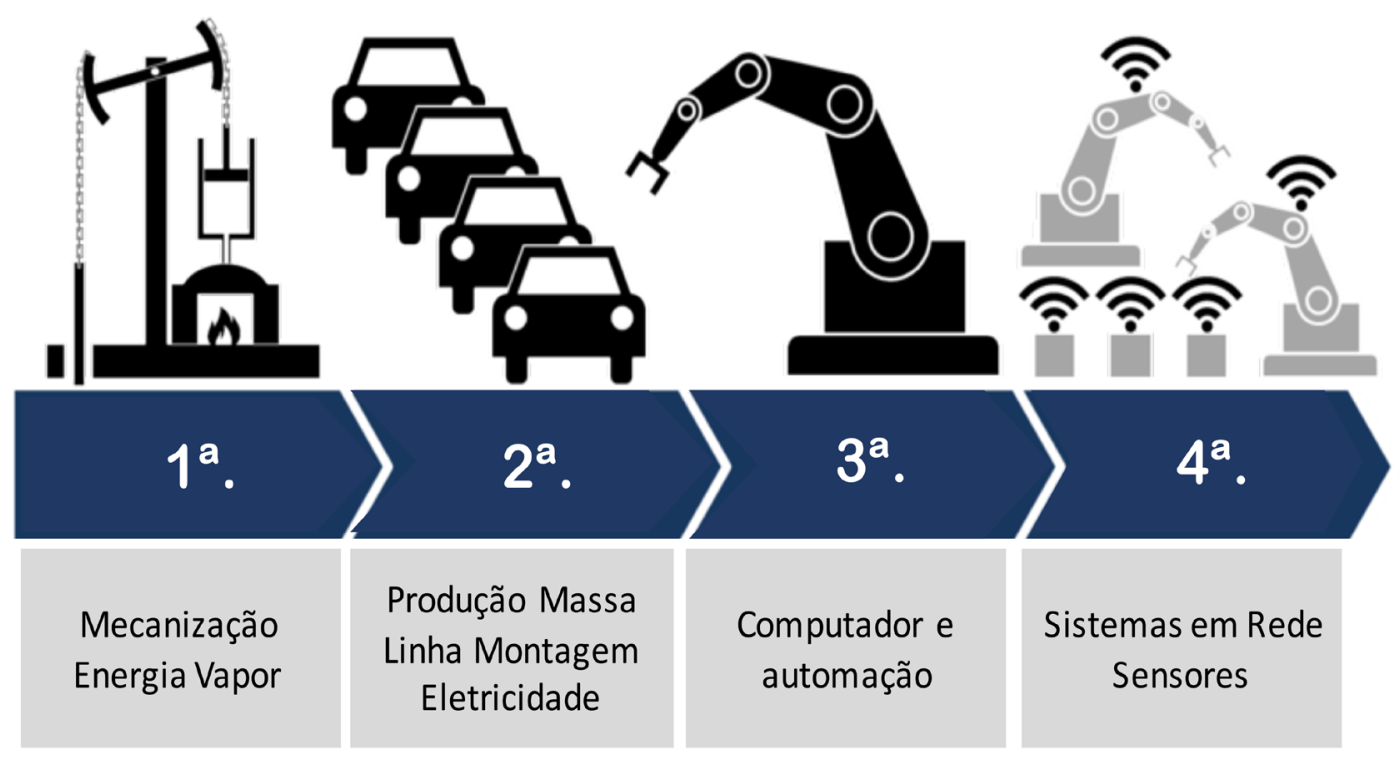


O termo "automatizar" é entendido como tornar-se independente de algum processo. A palavra foi diminuída para automação, que vem do grego automotos, de movimento, e ion, do latim, que significa estado; é a substituição do trabalho físico e mental do homem pelas máquinas (KATSUNDO, 1994). A automação, pelo dicionário Britânica', significa a aplicação de máquinas em tarefas executadas por seres humanos. Atualmente, é aplicada para um conjunto de técnicas com a finalidade de tornar automática a realização de tarefas, substituindo a força humana, física e mental, por dispositivos eletromecânicos computacionais (SILVEIRA; LIMA, 2003).

A vontade de substituir o trabalho humano pelas máquinas sempre esteve presente, especialmente quando associada ao aumento da produtividade e à diminuição dos custos. As mais antigas máquinas-ferramenta ${ }^{2}$ foram as mandriladoras de canhão dos séculos 16, 17 e 18. São má-

1 https://global.britannica.com/technology/automation. Data de acesso: 15/out/2016.

2 Definição: máquina estacionária, não portátil, acionada por uma fonte de energia externa - não humana nem animal -, que modifica a forma de peças metálicas sólidas ou de materiais alternativos com finalidades similares, por deformação plástica ou por corte de natureza mecânica, abrasiva, eletrofísica, eletroquímica ou fotônica, com decorrente remoção de massa (MORAES \& ABREU, 2006). 
quinas flexíveis que permitem a adaptação de diferentes ferramentas, utilizadas para usinagem, perfurações, fresagem, mandrilagem ${ }^{3}$ e torneamento, sem a necessidade da retirada do objeto. Este equipamento era movido por um eixo ligado a uma roda d'água externa, que movimentava os trilhos, polias e cordas (MORAES; ABREU, 2006).

O início da utilização da máquina industrial para a transformação em escala no século 18 está vinculado à utilização do vapor como fonte de energia, à mecanização da produção e à disseminação das estradas de ferro para a distribuição de mercadorias, principalmente têxteis. Essa etapa da industrialização é conhecida como:

\section{A 1. Revolução Industrial}

A idealização da bomba a vapor é muito anterior à reconhecida Revolução Industrial - data de 1706 por Newcome (ADDIS, 2009) -, mas foram as máquinas desenvolvidas por James Watt que fizeram a grande diferença no movimento industrial. Eram aquecidas com grandes quantidades de água e com a utilização de carvão até que o vapor

3 Definição: ato de igualar ou aumentar as bordas internas ou orifícios. 
se expandisse e contraísse dentro de um cilindro de metal com um pistão que fazia girar a engrenagem (MORAES; ABREU, 2006).

A transformação do processo produtivo para a fábrica foi gradativa e lenta e dependia da reorganização da antiga produção, da criação de mercados de consumo e de sistemas de distribuição das mercadorias (CARDOSO, 2008). O crescimento urbano, com o aumento da população, dos bens e serviços, as reformas urbanas, com o intuito de limpar a cidade, e os novos sistemas de comunicação (BENEVOLO, 1993) compõem o cenário cotidiano, impregnado por valores burgueses, que têm seus modos de vida e pensamentos próprios, com um comando, essencialmente, sob domínio moral masculino e com a célula da família como núcleo do lar (PERROT, 2009).

O pensamento hegemônico do final do século 19 era aquele que acreditava em situações ideais. Os pensadores realizavam pesquisas sobre como se obterem maiores rendimentos em tarefas específicas a partir de homens fisiologicamente perfeitos. O trabalho "Os Princípios da Administração Científica", de Frederick Winslow Taylor (1911), é o exemplo de como a produtividade podia ser 
aumentada a partir da divisão do processo de trabalho em organização de tarefas e de acordo com o estudo do meIhor movimento e tempo dispendido (HARVEY, 1989).

Mattelart (2002) chama a atenção para a sociedade tratada como indústria, voltada para a administração das coisas, através de uma filosofia positivista, industrial e científica.

O organismo social da era positiva ou industrial tem como princípio estrutural a hierarquia das funções. A rede, quer seja material ou imaterial, quer seja de transporte, bancária ou vetor de símbolos, é arquétipo da organização [...] (MATTELART, 2002, p. 35).

O anseio por invenções era corrente, na Inglaterra, em 1760. Essa vontade passava por todas as classes sociais, desde tecelões, artesãos, filhos de fazendeiros, construtor de pontes, membros da nobreza ou duques. Assiste-se a um movimento com a criação de bonecas mecânicas ${ }^{4} \mathrm{com}$ mecanismos autômatos capazes de desenhar, andar e tocar instrumentos musicais (GIEDION, 2004).

O francês Joseph Marie Jacquard, no início dos anos 1800,

4 Os primeiros autômatos, segundo o historiador Silvio Bedini, são do antigo Egito (séc. 17). Eram máquinas complexas que desafiavam a vontade de voar como as aves e de nadar como os peixes, como uma extensão do controle humano; possuíam princípios mecânicos e dispositivos complexos de engenharia que seriam utilizados posteriormente (NOBLE, 2011). 
inventou o tear mecânico, com uma leitora de cartões perfurados metálicos; um sistema de comando automático para operações repetitivas e sequenciais. Uma fita contínua que avançava sobre uma estação de leitura, onde um conjunto de agulhas atravessava o cartão nos locais perfurados, que constituíam o código para a execução da operação (MORAES; ABREU, 2006).

Herman Holerith trabalhou nas tabelas de cálculo de logaritmos ou desenvolvimento de leis do pensamento. Aproveitou os cartões perfurados de Jacquard para interpretar, classificar e manipular as somas aritméticas nas perfurações, combinando com dispositivos eletromagnéticos (FONSECA FILHO, 2007).

Normal, padrão, média, tempos e movimentos, mecanização, mulheres, crianças, longas jornadas, insalubridade em todos os níveis, divisão do trabalho, mínima personalização dos produtos são as palavras de ordem da 1 $^{\text {a. }}$ Revolução Industrial, marcada pela utilização da energia produzida pelo vapor, do tear mecânico e, pela distribuição de produtos pelas estradas de ferro. 


\section{A industrialização da Construção Civil na 1. Revolução Industrial}

A produção industrializada de um edifício pressupõe a fabricação de sistemas, que são o conjunto de partes e regras solucionadas na fase de projeto e podem ser utilizados em outras edificações. Essa produção pressupõe 5 graus de industrialização 5 . Os dois primeiros podem ser associados aos modos de produção da $1^{\text {a. }}$ Revolução Industrial e são: a pré-fabricação, que é fazer um componente ou peça similar e com o mesmo processo e materiais construtivos dos tradicionais, feitos em canteiro de obras, em ambiente controlado de fábrica. Esse sistema reduz até $15 \%$ do custo da construção quando a produção está em alta capacidade. O segundo tipo é a mecanização, que é a utilização de máquinas para facilitar o processo de trabalho (RICHARD, 2005).

A produção da engenharia civil e da arquitetura no período da 1' Revolução Industrial estava principalmente voltada para a apropriação dos conhecimentos do ferro fundido e para as potencialidades e aplicações de acordo com

5 Os 5 graus de industrialização: 1. Pré-fabricação, 2. Mecanização, 3. Automatização, 4. Robotização e 5. Reprodução (RICHARD, 2005). 
o comportamento em grandes vãos de edifícios, além de pensar como um elemento de sistemas compostos pré-fabricados e que poderiam ser montados e desmontados. O processo produtivo do período aparece na arquitetura com a reprodução de várias peças elaboradas em série e como uma engrenagem sincronizada que constitui o edifício e é capaz de suportar as adversidades em relação à sua estrutura em áreas extensas, proteção etc. e no domínio dos materiais capazes de serem pré-fabricados, com o uso de máquinas e equipamentos apropriados.

Um exemplo desse período é o Hungerford Fish Market (1831-1833) (Figura 11), de Londres, do arquiteto Charles Fowler. Construído para abrigar um mercado de peixes, foi desenvolvido em ferro fundido, em uma estrutura independente, sem paredes. Sua estabilidade é conseguida a partir de estruturas entre os pilares e vigas, ou o uso do travamento em " $x$ " ou em " $k$ " (ADDIS, 2009). O edifício é composto por alguns elementos idênticos organizados de forma padronizada e repetitiva, formando as tipologias correntes nesse período, em que foram construídas muitas fábricas, estações e edifícios com grandes vãos.
Figura 11: Hungerford Fish Market evidencia as peças de pilar, vigas, travamentos em ferro fundido montadas e encaixadas. Fonte: www.studyblue. com/notes/note/n/1-fair-review/ deck/6480891. Data de Acesso: 06 jun 2017. 


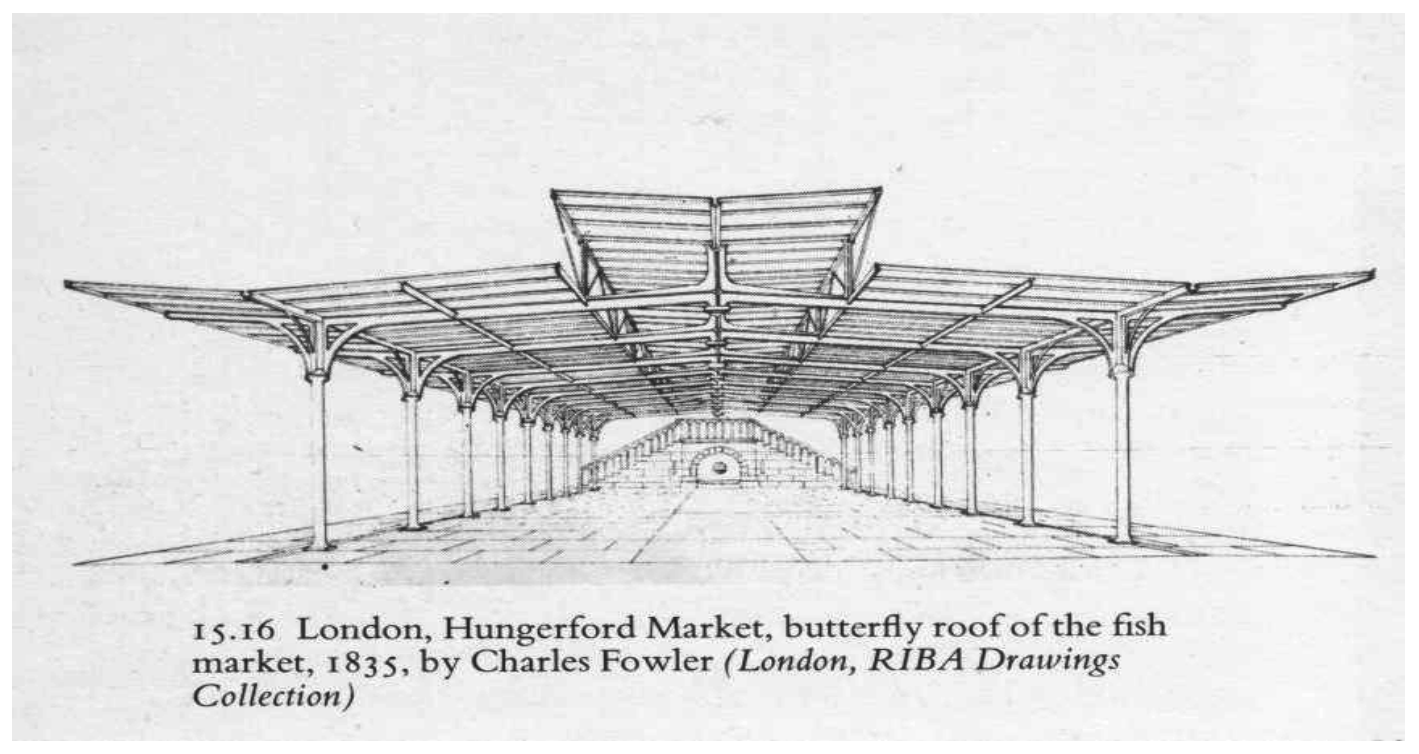




\section{A 2. Revolução Industrial}

Um século depois da 1ª Revolução industrial, em Cincinati - Ohio, a produção dos automóveis Modelos T de Henry Ford atingiu seu ápice, baseada nas linhas de produção contínua, na divisão do trabalho e na introdução de correias transportadoras que movimentam o produto, e não mais no trabalhador. Usava a eletricidade como elemento fundamental para o funcionamento da engrenagem e da produção em massa e foi reconhecida como o primeiro esforço de automação de fluxo de material, chamada de Detroit Automation ou Hard Automation (VISWANADHAM, 2002).

A filosofia de Ford era de que qualquer pessoa é capaz de consertar seu carro. Para isso, fornecia um manual especificado com detalhes para solucionar os problemas com o veículo (SCHWAB, 2016).

Ford tinha 3 princípios:

1. Diminuir o tempo de produção com o emprego imediato dos equipamentos e matéria-prima e a rápida colocação do produto no mercado; 
2. Reduzir o estoque de matéria-prima ao mínimo, vender o produto antes de seu vencimento,

3. Aumentar a capacidade de produção através da especialização da linha de montagem.

Para atingir esses objetivos, Ford estipulou 8 horas de trabalho, impôs o ritmo de produção, estabeleceu a divisão do trabalho através da linha de montagem, colocou os estoques junto à engrenagem e as peças que não encaixavam eram descartadas. Estabeleceu uma coordenação organizacional com integração vertical, determinando todas as etapas e peças com menor tolerância e cronograma de entrega minucioso. Montou fábricas no local do mercado de consumo. Os operários tinham apenas uma tarefa e nenhuma qualificação, não necessitavam sair do seu local, o que causava enorme desinteresse pelo trabalho; no final da linha de montagem, o ajustador era responsável por realizar os reparos. Criou o Engenheiro de Produção e o Engenheiro Industrial. As ferramentas eram peças intercambiáveis pouco versáteis, com máquinas para corte, capazes de trabalhar com metais pré-endurecidos (WOMACK; JONES; ROSS, 1992).

O projeto do carro foi elaborado com peças de fácil ajuste 
e com um mesmo sistema de medidas usado em todos os componentes no processo de fabricação. A etapa de projeto era fundamental e com alta especialização, como mostra o trecho abaixo:

Primeiro a concepção global do novo modelo é especificada pela equipe projetista de produtos e revisada pela gerência sênior. A seguir, o produto é projetado em detalhes, até níveis milimétricos, e o tipo de material específico de cada peça. Desenhos detalhados de engenharia são feitos para cada peça, especificando os materiais exatos a serem empregados. Somente nesse ponto as organizações que realmente produzirão as peças são acionadas [...] (WOMACK; JONES; ROSS, 1992, p. 135).

A criação dos relés ${ }^{6}$ modificou a rotina das indústrias, através de um dispositivo simples que conecta dois pontos de contato. Em 1909, a General Motors (GM) possuía máquinas automatizadas na linha de montagem com esse dispositivo. De acordo com Katsundo (1994), o termo automação surgiu em 1936, por D. S. Harder, da GM. Sua intenção era ter um processo de produção sem a necessidade do trabalho humano, e, em 1946, ele criou um setor de auto-

6 Dispositivo eletromecânico, composto por um ímã móvel, que funciona como um interruptor de dois contatos metálicos. É considerado o precursor dos transistores; tinha um custo considerável, com tamanho relevante, mas lentos para completar o circuito. Fonte: http://www.hardware.com.br. Data de acesso: 30/mar/2017. 
mação na Ford Motor Company.

De acordo com Noble (2011), o controle integrado apareceu pela primeira vez nas indústrias de processo contínuo. O desenvolvimento de controles industriais automáticos, a partir da década de 1920, modificou a produção de várias indústrias. A produção necessitava de dispositivos para monitorar e ajustar operações complexas de controle manual, como sensores e atuadores, que foram elaborados na indústria de laticínios para o monitoramento de temperaturas de pasteurização e, posteriormente, na manufatura de produtos químicos como o álcool etílico e o etileno glicol. Na indústria de energia elétrica, na década de 1930, Gabriel Kron, da General Electric, trabalhou na modelagem matemática dinâmica de redes e outros sistemas complexos, que seriam os precursores da eletrônica para analisar, controlar e otimizar sistemas de comunicação e servomecanismos ${ }^{7}$. Em meados do século 20, surgiram

$7 \bigcirc$ servomecanismo é uma combinação de hardware mecânico e de controle que utiliza um retorno para influenciar o controle de um sistema. O retorno está na forma de erro ou da diferença entre o parâmetro monitorado e seu valor desejado. Os servomecanismos operam com base no princípio do retorno negativo, no qual o erro é subtraído da saída. Um servomecanismo é conhecido como um sistema em malha fechada [...]" são capazes de controlar posição, velocidade, torque, temperatura, pressão ou outro tipo de variável que possa ser medida (LAMB, 2015). 
nas indústrias de energia elétrica e refinarias de petróleo as primeiras operações controladas por computador analógico, que era utilizado para monitorar o desempenho, cadastrar informações e indicar ações.

Na refinaria de Port Arthur, da Texaco, a produção passou a ser controlada por computador digital em 1959. Um ano depois, a Monsanto passou a controlar o computador digital de sua planta de amônia na Louisiana, assim como B. F. Goodrich com sua instalação de vinil plástico em Calvert, Kentucky. Logo, os laminadores de aço, os altos-fornos e várias fábricas de processamento químico em todo o país passaram a ser controlados por computador (NOBLE, 2011, p.60).

\section{A industrialização da Construção Civil na 2. Revolução Industrial}

De acordo com Richard (2005), outro grau de industrialização na construção civil é a Automatização, em que as ferramentas substituem o trabalho e o papel dos programadores é fundamental no processo. Representa $27 \%$ de economia, comparada com os métodos tradicionais de construção.

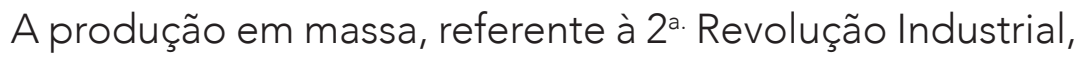
associa-se, principalmente, à produção de Le Corbusier 
(Sistema Dom-ino), Buckminster Fuller (Dymaxion), Konrad Wachsmann (módulos) e John Habraken (Sistemas Abertos), em que a linha de produção é o ponto-chave para a sua fabricação e os conceitos de Ford aparecem refletidos na elaboração desses arquitetos (AGREN; WING, 2014). A produção de Le Corbusier e Buckminster Fuller certamente estava preocupada em atender à grande demanda por habitações em relação às exigências colocadas pelas guerras e conflitos e, para Wachsmann e Habraken, como resultado da forte movimentação de pessoas para as cidades.

Os sistemas sugeridos têm como pano de fundo a produção em massa de edificações. Le Corbusier encontrou no concreto armado a solução para a produção, tendo sugerido a utilização da argamassa armada pelo baixo custo e pela agilidade de produção. Buckminster Fuller associa sua produção com a produção dos Ford T e, com isso, elabora o sistema Dymaxion, chegando até o detalhamento de seu banheiro pré-fabricado e a coordenação modular de Wachsmann, que vai ao limite de atender às necessidades dos usuários e ao sistema aberto industrializado idealizado por Habraken. 
Evidentemente que a lógica que coordenava a produção desses edifícios tinha a fabricação em massa como base de seus conceitos e, apesar de estarem distribuídos em um longo período no século 20, possivelmente tinham como forma de organização do trabalho a linha de produção em massa de Ford, com uma administração hierarquizada e produtos estandardizados.

\section{A $3^{\text {a. }}$ Revolução Industrial}

A cada 100 anos têm ocorrido grandes modificações no processo de produção industrializada; no final de 1700, a fase mecânica; no final dos anos 1800, a fase elétrica, com a produção em massa, e, no final de 1900, a etapa da informação (TIEN, 2012). A nova fase da produção é uma associação da produção em massa e os conceitos inicialmente colocados por Eiji Toyoda e Taichi Ohno para o Sistema Toyota de Produção (STP).

Os dois princípios básicos de Toyoda e Ohno são:

1. a produção a partir da demanda, que está ligada ao plano agressivo de vendas vinculado entre montadora, revendedora e cliente e; 
2. uma linha de montagem com um acionamento que pode ser ativado por qualquer operador quando houver algum problema e todos os operários são responsáveis por solucionar a situação.

Com essa estratégia, conseguiram que a produção tivesse um alto envolvimento dos profissionais e, a médio prazo, praticamente todos os problemas eram solucionados na linha de produção (SCHWAB, 2016).

O sistema utilizava menores espaços e ferramentas, planejamento em menor tempo e estoque mínimo. A produção flexível era uma das principais características, podendo alterar os produtos a partir da rápida modificação das máquinas. Seus estoques foram reduzidos praticamente a zero. As peças com defeitos retornavam ao controle de qualidade, que verificava onde estavam os erros e os reparava (WOMACK; JONES; ROSS, 1992).

A produção se baseava em conceitos como: utilização de medidas para o melhor processo, produção de peças para cada etapa, visualização imediata de defeitos, estoque para 1 hora de trabalho, fornecedores em níveis funcionais, altos volumes e variedade de produtos tendendo à perfeição, automatização, flexibilidade, trabalho em 
equipe, com liberdade para controlar o próprio trabalho, solução de problemas na linha de montagem de forma coletiva, os trabalhadores agregavam valor e eram multiqualificados, eram estimulados à produtividade crescente, tinham empregos vitalícios e eram comprometidos. Os líderes realizavam trabalho em grupo, o que tendia a um rendimento de $100 \%$, e custo zero, alta capacidade de disseminação da informação, com desenvolvimento simultâneo, utilização de robôs na área de soldagem e pintura (SCHWAB, 2016).

O Sistema Toyota de Produção estava em plena produção nos anos 1960 e tinha as máquinas automatizadas com equipamentos controlados numericamente em sua produção. Um importante passo para as máquinas controladas numericamente ocorreu em 1949 na Força Aérea Americana (FAA) que trabalhava na fabricação de aviões e material de guerra. A Parsons e a FAA centraram os investimentos em uma máquina-ferramenta para a Cincinati Lamb, que foi apresentada no MIT (Massachussetts Institute of Technology) em 1953 (MORAES; ABREU, 2006).

Em 1958, a Kearney \& Trecker Corporation, nos Estados Unidos, possuía ferramentas automáticas avançadas e cen96 
tros automatizados (KATSUNDO, 1994). A década de 1960 foi ainda mais frutífera. Em 1968, a BedFord Association (USA) desenvolveu o MODICON (Modular Digital Controler), dispositivo para substituir os relés. Foi o primeiro controlador lógico programável ativado por programação digital de sistemas autônomos, tornando-o mais flexível econômico e eficiente (DRATH; HORCH, 2014).

A indústria associada a esse período do século 20 conta com linhas de montagem que movimentam o produto, braços articulados que auxiliam na montagem dos equipamentos e uma produção voltada para a customização em massa acionada a partir da venda programada, que está diretamente ligada à produção.

\section{A industrialização da Construção Civil na 3. Revolução Industrial}

Após os anos 1960, a tentativa era automatizar diversos processos da construção: de casas, edifícios ou serviços urbanos, no acabamento interno, na colocação de tijolos, nas construções modulares, na pavimentação de rodovias, no controle de escavadeiras, na inspeção de infra- 
estruturas, na construção de túneis, pontes e outros, diferentemente das atividades atuais, que estão mais focadas em programação e tecnologias da informação, incluindo sensores, coleta de dados, análise, segurança e armazenamento, controle de processos e monitoramento automatizado (BALAGUER; ABDERRAHIM, 2008).

O Japão há 40 anos tem sido um dos mais bem-sucedidos produtores da indústria pré-fabricada na construção civil, com uma produção de aproximadamente 150.000 unidades habitacionais por ano, com uma qualidade crescente e agregando tecnologias inovativas. No processo de produ-

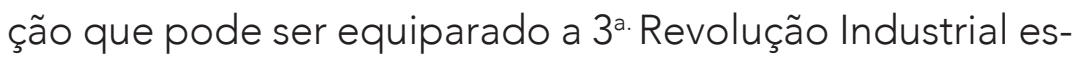
tão a Sekisui Heim, a Toyota Home (Figura 12) e a Misawa Homes (Hybrid). No projeto, dividiram o edifício em três partes, que são realizadas sobre uma estrutura principal, em aço, com dimensões que podem ser enviadas a uma linha de produção e montadas com instalações técnicas, acabamentos, cozinha, banheiros e eletrodomésticos. A primeira etapa da montagem é automatizada; as fábricas produzem de 80 a $90 \%$ do trabalho, além da execução de ajustes e fixações (BOCK; LINNER, 2015).

Na fábrica da Toyota Home, a planta de fábrica é basea-
Figura 12: Linha de montagem Toyota House, trabalhadores em montagem das unidades habitacionais. Disponível em: www. contemporist.com/2008/07/05/ did-you-know-toyota-builds-houses. Data de acesso: 02 nov 2016. 

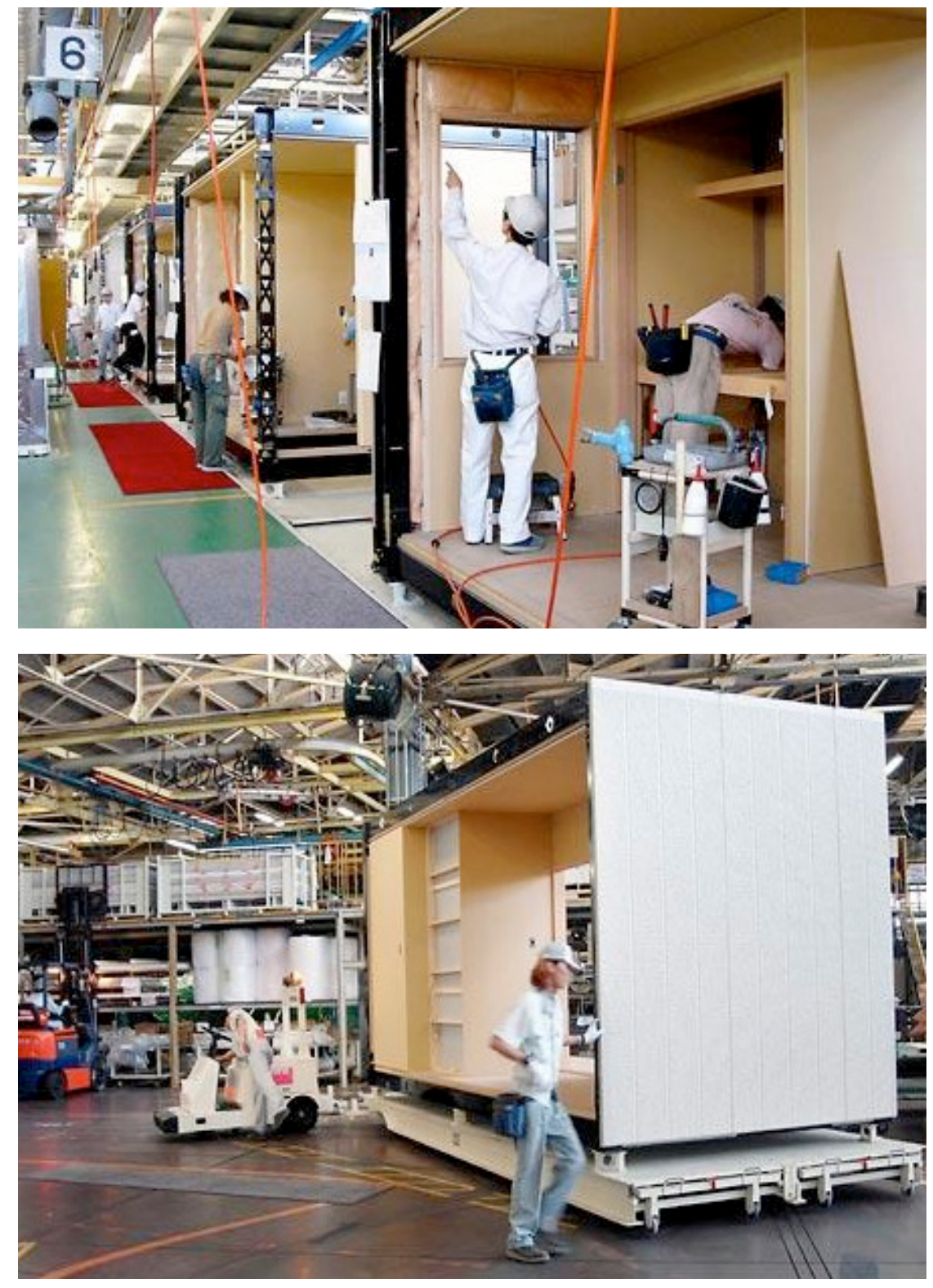
da na linha de produção; o tipo de organização aplicado é uma combinação de elementos da linha de fluxo. Os serviços oferecidos têm unidades de crescimento, com rearranjos e recustomização do espaço, garantia de manutenção, soluções de energia e assistência tecnológica personalizada para o dia a dia, além de adaptações para idosos (BOCK, 2015).

O Japão mostra uma forte vocação para a utilização inovativa de tecnologias e apresenta boa aceitabilidade em relação a produtos industrializados, cuja tendência é resultado de diversos fatores históricos e físicos. Esse povo tem em suas raízes a utilização dos tatames, que são um tipo de módulo organizacional e que têm em sua essência a coordenação modular para o processo de industrialização. Ao lado disso, foi um dos únicos países que colocou em prática os conceitos de cápsulas desenvolvidas pelos arquitetos da década de 1960, o que abre caminhos para o desenvolvimento e a utilização de unidades industrializadas, adicionadas aos modos de vida contemporâneos, que utilizam espaços cada vez menores, e a frequência de pessoas morando sós tem crescido a cada ano. O país tem um território equivalente ao estado de São Paulo, com 
uma alta densidade populacional, o que induz à utilização de casas minúsculas, em que os usuários se adaptam com maior facilidade. Assim, as unidades habitacionais industriais se adequam naturalmente a essa população.

\section{A 4. Revolução Industrial}

O processo de digitalização ou de numerização dos sistemas analógicos para uma codificação em matrizes organizadas por 0 (zero) e 1 (um) ainda é a base para a lógica que transformou toda a racionalidade para o sistema digital e que deu o salto na tecnologia, modificando os paradigmas nos vários setores da sociedade (BRETON; PROUX, 2006; MATTELART, 2002). O computador é a "máquina universal" utilizada em todas as áreas e disciplinas; desempenha tarefas mentais, realiza mudanças nos processos e nas organizações. Essas mudanças se retroalimentam, ampliando ainda mais as possibilidades oferecidas (BRYNJOLFSSON; MCAFEE, 2011).

No contexto atual, é possível utilizar a tecnologia de sensores aplicados em locais estratégicos, que verificam a umidade do ambiente e decidem quanto e como irrigar 
plantações em diversas regiões; sistemas urbanos que podem ser organizados a partir de dispositivos que informam quando e onde coletar lixos, abastecimentos de energia, água e esgotos, monitoramento de trânsito etc. Microprocessadores incorporados a objetos e máquinas possibilitam a sua programação para que se tornem autossustentáveis e inteligentes, máquinas recebem pedidos e podem confeccionar o produto, tais como medicamentos ou vestiários, e enviar diretamente para a entrega ao cliente; a internet possibilita o compartilhamento de trabalhos de qualquer ponto geográfico em tempo real.

Para estudar, pesquisar e propor encaminhamentos, diversos países têm encaminhado estratégias e programas, desde o final dos anos 1990, para atuarem no crescimento do mercado contemporâneo, desenvolvendo políticas e pesquisas voltadas para os ramos da automação, com robôs inteligentes, informação ubíqua, segurança de informações, gestão de ciclo de vida de produtos, administração de grande quantidade de dados e digitalização em geral (FEDERAL MINISTRY OF EDUCATION AND RESEARCH, 2014). Exemplos disso são a Internet of Things (IoT) - Internet das Coisas -, Cyber-Physical Systems (CPS) 
- Sistemas Ciber-Físicos - e Internet + na China.

A iniciativa da Alemanha Industry 4.0 (14.0) - Indústria 4.0 -, em 2011, impulsionou os territórios Europeus às oportunidades tecnológicas, aos desafios científicos relacionados com a entrada de novas gerações de tecnologias, de comunicação e serviços nos sistemas de produção industrial. Nos Estados Unidos, a Internet Industrial foi introduzida em 2012 pela General Eletric e foi considerada a terceira onda de inovação depois da revolução industrial (SILVEIRA; LIMA, 2003; POSADA et al., 2015). Na busca de compreendê-la, propõe-se discutir algumas dessas políticas com o intuito de examinar e avaliar o seu conteúdo e, a partir disso, verificar como é o rebatimento destes na construção civil.

Um dos primeiros movimentos foi a Internet of Things (IoT) - Internet das Coisas -, o termo que foi utilizado, em 1999, por um britânico que trabalhava no MIT, Kevin Ashton. Em uma palestra, ele introduziu a ideia de utilizar códigos de frequência em produtos para facilitar o controle e a logística na cadeia de produção.

No cenário das tecnologias, a Internet das Coisas é forma- 
da por uma teia de elementos compostos pela conectividade em tempo real, por dispositivos e uma quantidade imensa de equipamentos que captam informações entre si, processam e retroalimentam plataformas que disparam novas ações de forma inteligente. Esse processo ocorre em uma grande rede no espaço com vários loopings simultâneos tomando decisões e encaminhando novas ações, a partir da análise dos dados recebidos (ASHTON, 2015).

As definições a respeito da loT presentes na literatura classificam-se em 3 tipos de atuação (ATZORI; IERA; MORABITO, 2010):

- Ubíqua, capacidade de estar presente em toda parte, com os dados transferidos para a rede, e a prestação de serviços na captura, transferência e interoperabilidade dos mesmos ${ }^{8}$.

- As voltadas para o desenvolvimento de produtos, com objetos conectáveis indiscriminadamente', com

8 A. Dunkels, J.P. Vasseur, IP for Smart Objects, Internet Protocol for Smart Objects (IPSO) Alliance, White Paper \#1, September 2008, $<$ http://www.ipso-alliance.org $>$.

9 ITU Internet Reports, The Internet of Things, November 2005. 
identidade e personalidade virtual em espaços inteligentes intercomunicados ${ }^{10}$.

- Aquelas que verificam o significado e as interpretações, preocupam-se com os dados e em como representar, armazenar, interconectar, pesquisar e organizar as informações.

Desde que a Internet das Coisas foi citada pela primeira vez, na década de 1990, vários grupos têm desenvolvido diversas pesquisas para avançar e ampliar na aplicabilidade do conceito, dos equipamentos, das tecnologias e dos potenciais nessa teia de elementos da realidade. Essa vertente está ligada, principalmente, aos meios de comunicação e em como estes podem contribuir na extensa captação de dados, análise, retroalimentação e no controle de dispositivos inteligentes.

Outro conceito utilizado para referir o contexto da digitalização é o Cyber-Physical System (CPS) - Sistema Ciber-Físico. Foi apresentado por Hellen Gill, da National Science Foundation, em 2008, na $4^{\text {a }}$ Conferência Anual de Carne-

10 INFSO D.4 Networked Enterprise \& RFID INFSO G.2 Micro \& Nanosystems, in: Co-operation with the Working Group RFID of the ETP EPOSS, Internet of Things in 2020, Roadmap for the Future, Version 1.1, 27 May 2008. 
gie Mellon para a Indústria de Eletricidade - Sistemas de Energia do Futuro: Eficiência, Segurança, Controle ${ }^{11}$.

A autora define CPS como ${ }^{12}$ sistemas físicos, biológicos e de engenharia integrados, monitorados e controlados por um núcleo computacional em tempo real. Componentes em todas as escalas e em rede com altos graus de automação e retroalimentação, ações não convencionais, organização e reconfiguração dinâmica e operações certificadas (GILL, 2008). Este grupo defende uma visão sistêmica e integrada, com objetos e artifícios articulados. Fazem parte desse processo os objetos como computadores, sensores, atuadores, internet e a programação de aplicativos ou tarefas específicas.

CPS está na intersecção entre o físico e o cibernético, com comunicação e capacidade avançada, com requisitos de desempenho e sistemas de armazenamento, monito-

11 Fourth Annual Carnegie Mellon Conference on the Electricity Industry _ FUTURE ENERGY SYSTEMS: EFFICIENCY, SECURITY, CONTROL

12 Cyber-physical systems are physical, biological, and engineered systems whose operations are integrated, monitored, and/or controlled by a computational core. Components are networked at every scale. Computing is deeply embedded into every physical component, possibly even into materials. The computational core is an embedded system, usually demands real-time response, and is most often distributed (GILL, 2008). 
ramento e controle da gestão eficiente, com protocolos específicos e tomada de decisões a partir da retroalimentação dos dados (LEE; BAGHERI; KAO, 2012; LEE; KAO; YANG, 2014; MA, 2011; SHAFIQA et al., 2015; FALLERA; FELDMÜLLER, 2015). Entre a Internet das Coisas e os Sistemas Ciber-Físicos, ambas estão ligadas à rede, a dispositivos e componentes inteligentes. A loT está focada nas redes abertas, enquanto o CPS está focado nos aspectos de engenharia e sistemas físicos de retroalimentação fechada (JESCHKE, 2013).

Exemplo do CPS são os aplicativos de automóveis programados para escolher a melhor rota, conforme a situação de tráfego. Nesse caso, os usuários fornecem dados através de dispositivos móveis que alimentam uma plataforma e esta é capaz de indicar o percurso mais curto utilizando o menor tempo e a rota que esteja menos congestionada. A plataforma conta com uma base de metadados, como sentido e localização de ruas, clima, hora, localização de acidentes, policiamento, condições físicas das vias, entre vários outros que formam uma rede de informações enviadas, analisadas autonomamente e que são alimentadas constantemente pelos próprios usuários em tempo real. 
Desde que o conceito de Sistema Ciber-Físico foi mencionado pela primeira vez, a Alemanha adaptou o conceito para a iniciativa da Indústria 4.0 (14.0), o que foi feito posteriormente pelos Estados Unidos, no seu programa de pesquisa H2020. A informatização e automação são processos crescentes em praticamente todos os territórios, nas Industri du Fur, na França, Fàbrica 4.0, na Itália, e posteriormente será demonstrado o movimento que impulsionou vários outros países, a Indústria 4.0.

A primeira versão da Indústria 4.0 foi criada na feira de Hannover (2011), para anunciar uma estratégia do governo alemão para o desenvolvimento de alta tecnologia que promove a digitalização da indústria "Estratégia High-tech 2020" (ANTONIO, 2016). Os autores consideram que é a 4. Revolução Industrial e inserem o movimento à modificação dos meios de produção. $O$ conceito da 14.0 integra várias iniciativas como Internet das Coisas, Sistemas Ciber-Físicos, serviços - Internet of Services - aplicados na gestão de indústrias inteligentes ou das chamadas Fábricas do Futuro (GRANGEL-GONZÁLEZ et al., 2016; DRATH; HORCH, 2014; HADDARA; ELRAGAL, 2015).

A Indústria 4.0 descreve um projeto de sistemas inteligen- 
tes e autônomos de fábricas e máquinas robóticas, com uso da nanotecnologia e produção aditiva, conectados em rede e com o consumidor. Os processos de produção são descentralizados nos locais de consumo, com dispositivos para avaliar problemas de desempenho, disseminando o conhecimento, e não somente o produto (LEE; KAO; YANG, 2014) (LASI et al., 2014) (LARIZZA, 2016) (TRENTESAUX, BORANGIU; THOMAS, 2016) (SOMMER, 2015) (SHAFIQA et al., 2015) (WANG et al., 2015).

A Indústria 4.0 tem como alvos principais: 1. Produzir de forma customizada, atendendo cada vez mais às necessidades de personalização dos objetos de acordo com a demanda; 2. Adaptar a manufatura de forma flexível, para atender à cadeia de produção; 3. Reconhecer de forma inteligente informações a respeito de objetos e máquinas em rede; 4. Apropriação da interação com as máquinas contemporâneas como robôs e máquinas autônomas e 5. Adequação dos serviços oferecidos que contribuam na cadeia de valor (SHAFIQA et al., 2015).

Para a obtenção da personalização em massa ou Customização Avançada (NABONI; PAOLETTI, 2015), há a necessidade da diminuição das hierarquias e de descentralização 
dos comandos. Um sistema de logística inteligente para manufaturar o produto em diferentes partes e algoritmos potentes que permita administrar os fluxos de informações internas e externas (ANTONIO, 2016). Da mesma forma, cada vez mais as atenções estão voltadas para os contextos ecológicos e sociais, fazendo com que as indústrias se preocupem com os temas relativos à eficiência energética e à sustentabilidade (LASI et al., 2014).

Essa configuração propicia às indústrias um alto grau de autonomia, em que componentes adquirem comportamentos independentes, processam informação, aprendendo com isso, e reagem em tempo real para o autocontrole e a organização. A rede é aberta para firmar novos parceiros e criar novos modelos de acordo com os custos e riscos (ABRAMOVICl; GÖBEL; NEGES, 2015).

Em sequência à política, em 2014, o governo alemão publicou uma nova estratégia de alta tecnologia desenvolvida pelo segundo plano para a Indústria 4.0. Agora, a inovação é vista não somente no setor da tecnologia, mas também na sociedade. Nesse olhar, a estratégia se volta para a qualidade de vida, as condições de comunicação em rede e a sua transferência de dados, a inovação dos 
sistemas de produção e o entendimento extenso da inovação, para que mais pessoas possam atuar no processo (FEDERAL MINISTRY OF EDUCATION AND RESEARCH, 2014).

A política se volta para o aprimoramento dos setores envolvidos diretamente com a economia e para a melhoria do cotidiano, investindo em educação digital, vida ambiental, utilização, armazenamento e geração de recursos energéticos eficientes, pesquisas e incentivo social para inovações, novas formas de organização do trabalho de acordo com o desempenho e investimento em qualificação com aumento da digitalização, vida saudável com medicina individualizada, combate contra doenças importantes e inovação em tecnologia médica.

Dentre os principais instrumentos para essa constelação de relações entre consumidores, empresas, equipamentos, tecnologias de ponta, estão os dispositivos digitalizados, a comunicação via internet habilitada, as nuvens de dados, máquinas inteligentes das fábricas com alta capacidade tecnológica e, evidentemente, os trabalhadores responsáveis pelo desenvolvimento, captura, análise, armazenamento e resposta dos dados. 
A partir dessas iniciativas comentadas anteriormente da Internet das Coisas, Sistemas Ciber-Físicos e Indústria 4.0, verifica-se no quadro comparativo:

Tabela 1: Comparativo das iniciativas contemporâneas comentadas anteriormente. Fonte: autor.

\begin{tabular}{|c|c|c|c|}
\hline & $\begin{array}{c}\text { Internet of Things } \\
\text { Internet das Coisas } \\
\text { loT }\end{array}$ & $\begin{array}{c}\text { Cyber-Physical Systems } \\
\text { Sistemas Ciber-Físico } \\
\text { (CPS) }\end{array}$ & $\begin{array}{c}\text { Industry 4.0 } \\
\text { Indústria 4.0 } \\
\text { (I4.0) }\end{array}$ \\
\hline $\begin{array}{c}\text { Origem } \\
\text { Autoria }\end{array}$ & $\begin{array}{c}\text { 1999 - Kevin Ashton } \\
\text { (MIT) }\end{array}$ & $\begin{array}{c}2008 \text { - Hellen Gill } \\
\text { (National Science Foun- } \\
\text { dation) }\end{array}$ & $\begin{array}{c}2011 \text { - Governo Ale- } \\
\text { mão, França, Itália, } \\
\text { China, entre outros }\end{array}$ \\
\hline Definição & $\begin{array}{c}\text { União de redes conecta- } \\
\text { das e interagindo entre si } \\
\text { de forma inteligente }\end{array}$ & $\begin{array}{c}\text { Sistemas monitorados } \\
\text { e controlados por um } \\
\text { núcleo computacional }\end{array}$ & $\begin{array}{c}\text { Rede de fábricas } \\
\text { inteligentes em } \\
\text { interação }\end{array}$ \\
\hline $\begin{array}{c}\text { Eixo de } \\
\text { Atuação }\end{array}$ & Cadeia de Produção & Sistemas & Rede de Fábricas \\
\hline Objeto & $\begin{array}{c}\text { Pessoas e Dispositivos } \\
\text { conectados }\end{array}$ & Controle de Sistemas & $\begin{array}{c}\text { Reorganização da } \\
\text { Produção }\end{array}$ \\
\hline
\end{tabular}


Diante do quadro ao lado, verifica-se que os dois primeiros estão focados em processos informacionais que atendem a um determinado ramo: na loT, a comunicação das pessoas através de dispositivos e, na segunda, o controle de sistemas monitorados. Já as políticas da 14.0 propõem uma reorganização do modo de produção tendo como parceiros as fábricas e utiliza, para isso, os dispositivos, a tecnologia, a conectividade e a reorganização da gestão e dos parceiros.

Outro aspecto é que as duas primeiras iniciativas partiram de ambientes de pesquisa, diferentemente da Indústria 4.0, que incorpora a pesquisa como parte de sua estratégia, juntamente com a sociedade e as indústrias. $\bigcirc$ primeiro se preocupa mais com o desenvolvimento de dispositivos de comunicação, enquanto o segundo está voltado para a gestão da informação, com olhos principalmente no controle dos sistemas. No terceiro, a estratégia busca meios para aumentar a produtividade e atingir novos mercados de consumo e utiliza, para isso, o envolvimento do setor industrial e a rede de parcerias, desde o consumidor até os equipamentos utilizados na produção.

Dessa forma, o setor da produção tem se organizado com 
equipes de trabalho na área de desenvolvimento, análises, detalhamentos, gestão associada ao objeto oferecido, bem como ações que aumentem a qualidade das atividades prestadas. A tendência de servitização tem avançado no decorrer dos anos e representa um ramo em que novas oportunidades de negócios surgem no mercado.

Após verificação dos conceitos, pesquisas e teorias discutidas e que tendem a direcionar as complexas relações entre produção, mercado e consumo, o trabalho se voltará ao ramo da construção civil, na tentativa de compreender a sua dinâmica e as articulações entre os vários participantes do processo dentro do contexto contemporâneo da $4^{\mathrm{a}}$. Revolução Industrial.

\section{A industrialização da Construção Civil na 4. Revolução Industrial}

A temática Indústria 4.0 ainda não tem ganhado relevância nas fábricas da construção civil, ainda mais quando se fala nas possíveis redes de conexões entre clientes, produção, máquinas com retroalimentação de dados e programação especializada (OESTERREICH; TEUTEBERG, 2016). 
Em geral, a indústria da construção é mais conservadora. Em muitos casos, quando os novos produtos automáticos não são complementares aos antigos, são dificilmente implementados e seu uso é mínimo (BALAGUER; ABDERRAHIM, 2008).

O conceito de 14.0 para construção compreende uma multiplicidade de tecnologias interdisciplinares no sentido de permitir a digitalização, automação e integração do processo de construção em todas as fases da cadeia de valor da construção. Várias tecnologias de comunicação e informação estão em diferentes níveis de maturidade, como, por exemplo, as plataformas BIM (Building Information Modeling), que consiste em um sistema de tratamento de informações utilizadas desde a modelagem, as simulações, a gestão de custos, as soluções para pré-fabricação, análises de consumo energético, certificação, análises pós-ocupação, a gestão de informações até as nuvens de dados, que possibilitam o desenvolvimento do projeto em suas várias disciplinas, com possibilidades de compartilhamento dos processos e, também a incorporação dos dispositivos móveis como verificadores com GPS utilizados em terraplanagem, os drones, etc. 
A pesquisa para o desenvolvimento de fabricação aditiva com metais, realidade aumentada virtual ou híbrida ainda está em fase de experimentação, essencialmente nos centros de pesquisas. Na construção civil, as tecnologias de comunicação e os dispositivos avançados como tablets já são empregados em pequena escala, e aos poucos, ocupam espaços em serviços de montagem, automação do processo de fabricação e construção.

Para atingir plenamente o contexto da 14.0 no setor da construção civil, há a necessidade de se enfrentarem os desafios com plataformas independentes de fabricação, aumento dos níveis de automação, melhorias nos equipamentos de produção para benefício dos ambientes de chão de fábrica, componentes com melhores eficiências energéticas e implantação de fibras óticas para melhoria da capacidade de comunicação interna e externa da manufatura (LEONARD, 2015).

Por exemplo, as empresas têm que lidar com mudanças organizacionais e de processos, com elevados custos de implementação e a previsão pouco clara de redução de investimentos ou com a crescente necessidade de segurança e proteção de dados. Do ponto de vista técni- 
co, existem vários problemas a serem enfrentados, como a falta de padrões para tecnologias, os requisitos para equipamentos ou necessidades crescente de redes de comunicações avançadas, incertezas jurídicas e contratuais (BRYNJOLFSSON; MCAFEE, 2014).

A automação interferindo no projeto considera as diversas etapas, tais como a integração, organização, aspectos informais e tecnologia das máquinas, que melhoram a eficiência, qualidade e complexidade do produto. São verificados também a logística, a montagem, o grau de estruturação de automação na fábrica e no local, o desenvolvimento a partir da coordenação modular, o controle de variações e a relação da fabricação com as necessidades do cliente.

Os processos de automatização e suas aplicações na construção civil, como descrevem Balaguer; Abderrahim (2008), podem ser divididos em dois grandes grupos: o primeiro caracteriza-se pela utilização de robôs em ambientes externos para a área de infraestrutura, como pavimentação e compactação de estradas, túneis e construção de pontes, escavações, dragas, inspeção e manutenção de setores urbanos etc. O segundo grupo está na área de construção 
de moradias, na construção e montagem de estruturas, montagem de painéis de vedação, compactação de concreto, acabamentos finais internos ou montagem do edifício completo.

A maior dificuldade da Robótica e Automação em Construção (RAC) está relacionada com o ambiente de trabaIho, que, em geral, é pouco estruturado. Trabalhar nesses locais envolve objetos pesados, elementos com grande tolerância, baixos níveis de padronizações, insuficientes níveis de industrialização e pré-fabricação, além do número de atores. Há que se fazer um esforço para aumentar o nível de automação envolvendo processos nesse importante setor econômico com a finalidade de incrementar sua produtividade (BALAGUER; ABDERRAHIM, 2008).

Para a consolidação da automatização na construção civil, são necessários diferentes esforços (BALAGUER; ABDERRAHIM, 2008):

1.Integração entre os vários processos do desenvolvimento do edifício, com retroalimentação de dados que alimentam outros estágios, diversificação dos projetos, utilizando-se elementos similares unificados, e padronização dos programas para uma rápi- 
da alteração entre as diversas disciplinas.

2.Pré-fabricação de novos materiais que não só o concreto. Customização em massa com a utilização do conceito CIM (Computer Integrated Manufacturing), que significa o entrelaçamento entre a flexibilidade de um produto com a produtividade na manufatura.

3.Robôs e máquinas automatizadas: é um ponto-chave para aumentar a produtividade, para o desenvolvimento de equipamentos robotizados com menor custo e para o aumento do nível de automação das máquinas existentes.

4. Investimentos em programas internacionais, com mudança da cultura dos operadores envolvidos diretamente no processo de construção. 
No diagrama 2 de Oesterreich; Teuteberg (2016), eles apresentam alguns aspectos de intervenção das tecnologias na cadeia de produção da construção civil.

Nesse quadro, verifica-se que, diante do processo de projeto da construção, as áreas voltadas à execução, montagem e manutenção são as que têm as maiores possibilidades de utilização das tecnologias, incluindo automação, dispositivos com sensores e identificadores, comunicação em tempo real, maquinário com tecnologias avançadas e sistemas de fábricas com máquinas inteligentes em rede.

As etapas que antecedem a fase de execução, como atividades de gestão geral, desenvolvimento do projeto e de suas especialidades, bem como planejamento, utilizam-se de equipamentos e programas para a detecção e verificação de simulações em estruturas, qualidade de conforto térmico e acústico, compatibilização das disciplinas através dos softwares BIM, além dos ambientes de armazenagem, transferência e análise de dados com as nuvens, maquinários robustos para trabalhabilidade de dados, dispositivos móveis, processo de digitalização total do edifício, que propicia uma visão ampla do mesmo. 


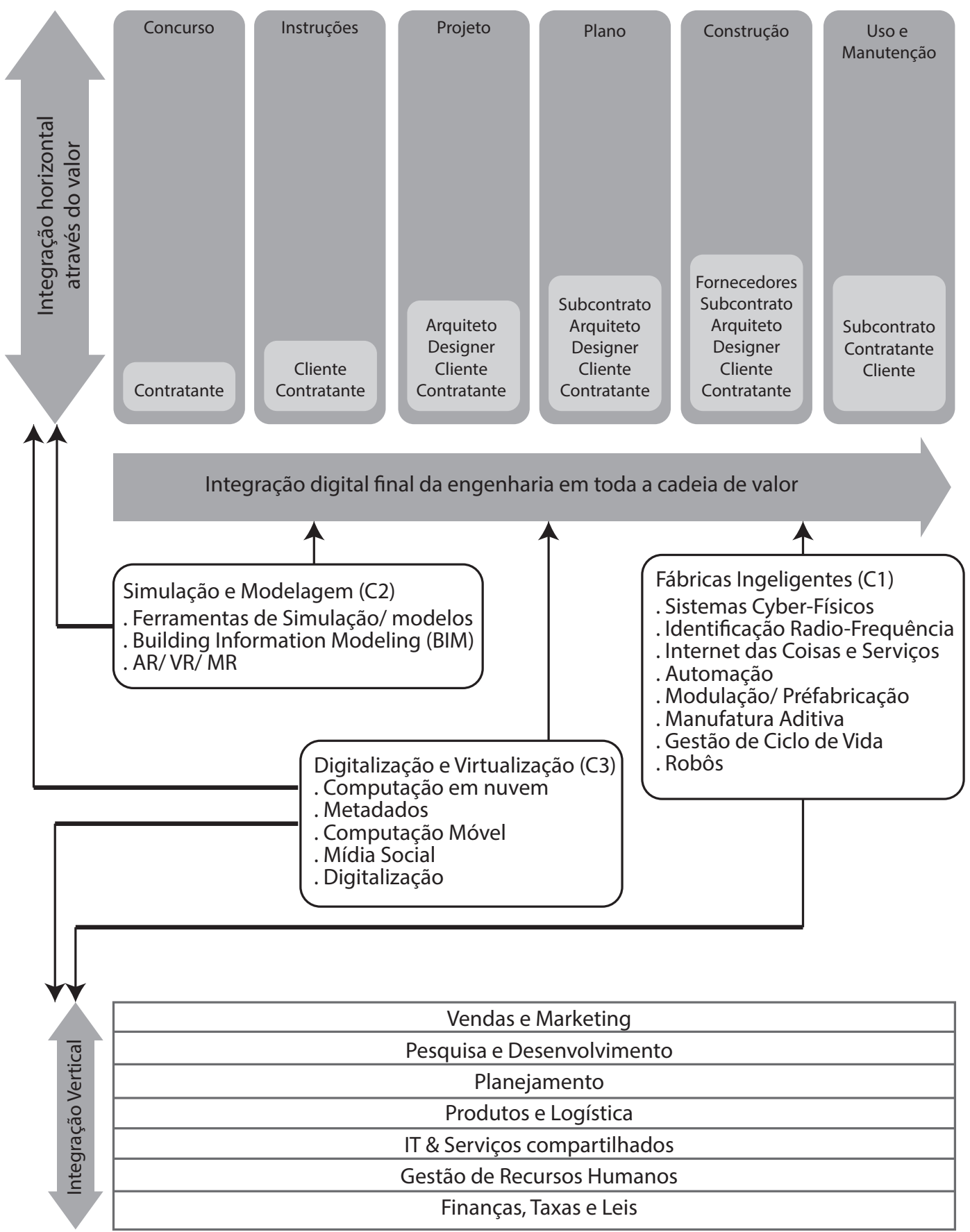

Diagrama 2: Impacto das tecnologias da Indústria 4.0 na cadeia de valor da construção civil. Fonte: (OESTERREICH; TEUTEBERG, 2016). 
Diante desse cenário, os aspectos importantes para a implementação da automatização na área da construção civil são:

- Mudança de atitude nas empresas, nas máquinas da indústria, nos centros de pesquisa e nos direcionamentos governamentais, no sentido de se desenvolverem novos produtos comerciais com tecnologias de ponta;

- Implementação de novas tecnologias de informação, mudando os processos de trabalho em todos os segmentos,

- O mercado da globalização e, consequentemente, a adaptação da estrutura comercial no setor da construção civil introduzem um alto nível de competitividade, o que força as empresas a adotarem técnicas automatizadas e mais eficientes. 
As tecnologias avançadas de pesquisa têm utilizado vários meios para a elaboração de operações computadorizadas na construção civil. Esses equipamentos robóticos podem ser altamente flexíveis, uma vez que podem trocar a função a partir da troca da ponta que define diferentes ações, como processos aditivos com argamassa, subtrativos como fresadoras, transformação, com modificação de materiais e montagem, com posicionamento de componentes.

Conforme Caneparo (2014), algumas máquinas disponíveis no mercado são para: 
Tabela 2: Processos de transformação de metais utilizados na indústria contemporânea. Fonte: Caneparo (2014).

\begin{tabular}{|c|c|c|c|}
\hline MATERIAL & FUNÇÃO & TIPOS & OBJETO \\
\hline \multirow{14}{*}{ METAIS } & Torno & $\begin{array}{l}\text { Rotação sobre um eixo } \\
\text {-circular externo: paralelo ao eixo da revo- } \\
\text { lução; } \\
\text { - faceando: perpendicular ao eixo da revo- } \\
\text { lução } \\
\text {-complexo: paralelo ou perpendicular ao } \\
\text { eixo de revolução. } \\
\text { - Interno: combinação de circular, faceado } \\
\text { e complexo }\end{array}$ & Cônicos ou circular \\
\hline & Perfuração & $\begin{array}{l}\text { Remove material rotacionando sobre a } \\
\text { peça imóvel }\end{array}$ & Cilíndrico ou cônico \\
\hline & Fresamento & $\begin{array}{l}\text { Remove material por rotacionamento de } \\
\text { uma ponta móvel }\end{array}$ & $\begin{array}{l}\text { Peças multifacetadas, planas, } \\
\text { helicoidais e curvas }\end{array}$ \\
\hline & Moagem & Remove material na forma milimétrica & $\begin{array}{l}\text { Polimento ou precisão do obje- } \\
\text { to }\end{array}$ \\
\hline & $\begin{array}{l}\text { Centros de } \\
\text { Usinagem }\end{array}$ & $\begin{array}{l}\text { Multifuncionais - fresagem, perfuração, } \\
\text { medição, rosqueamento. }\end{array}$ & Diversos \\
\hline & Erosão & $\begin{array}{l}\text { Retirada de material por força mecânica, } \\
\text { térmica, elétrica, química ou magnética }\end{array}$ & Peças escala nano ou micro \\
\hline & Fundição & $\begin{array}{l}\text { Metal aquecido e colocado em molde para } \\
\text { solidificação }\end{array}$ & $\begin{array}{l}\text { Moldagem de metais, plásticos, } \\
\text { madeira, }\end{array}$ \\
\hline & Deformações & Aquecimento do metal & $\begin{array}{l}\text { Formas variadas com aplicação } \\
\text { em áreas específicas do material }\end{array}$ \\
\hline & Laminação & Aplicação de dois cilindros em um metal & $\begin{array}{l}\text { Progressão do metal ativo, com } \\
\text { alteração das características do } \\
\text { material }\end{array}$ \\
\hline & Deformações & Por compressão do material & $\begin{array}{l}\text { Melhora propriedades estrutu- } \\
\text { rais da peça }\end{array}$ \\
\hline & Forjamento & $\begin{array}{l}\text { Deformação do metal antes do ponto de } \\
\text { fusão, }\end{array}$ & $\begin{array}{l}\text { Melhores propriedades mecâni- } \\
\text { cas. }\end{array}$ \\
\hline & Extrusão & $\begin{array}{l}\text { Deformação por compressão, usada prin- } \\
\text { cipalmente para peças semiacabadas }\end{array}$ & Seções de janelas ou portas \\
\hline & Consolidação & $\begin{array}{l}\text { Montagem de partes diferentes por solda- } \\
\text { gem, }\end{array}$ & Em peças reversíveis \\
\hline & Robôs & $\begin{array}{l}\text { Braços mecânicos controlados numerica- } \\
\text { mente }\end{array}$ & $\begin{array}{l}\text { Planos cartesianos, cilíndricos, } \\
\text { antropomórficos, }\end{array}$ \\
\hline
\end{tabular}


Tabela 3: Processos de transformação de madeira utilizados na indústria contemporânea. Fonte: Caneparo (2014).

\begin{tabular}{|c|c|c|c|}
\hline MATERIAL & FUNÇÃO & TIPOS & OBJETO \\
\hline \multirow{4}{*}{ MADEIRA } & \multirow{2}{*}{$\begin{array}{l}\text { Processos } \\
\text { de Massa }\end{array}$} & $\begin{array}{l}\text { Corte com uma serra: motosser- } \\
\text { ra, serra de fita, serra circular }\end{array}$ & $\begin{array}{l}\text { Corte flexível da madeira: alar- } \\
\text { gamento, rosqueamento, Fresa- } \\
\text { mento, perfuração e medição. }\end{array}$ \\
\hline & & $\begin{array}{l}\text { Lâmina ao longo do plano para } \\
\text { corte da seção. }\end{array}$ & Corte de folha \\
\hline & Deformações & $\begin{array}{l}\text { Por imersão em água quente, } \\
\text { vapor ou amônia }\end{array}$ & $\begin{array}{l}\text { Curva em madeira - cadeiras } \\
\text { escadas }\end{array}$ \\
\hline & $\begin{array}{l}\text { Juntas e } \\
\text { Consolidação }\end{array}$ & $\begin{array}{l}\text { Madeira compensada } \\
\text { Chapas laminadas } \\
\text { Painéis X-Lam }\end{array}$ & $\begin{array}{l}\text { Folhas coladas transversalmente } \\
\text { Estruturas extensas } \\
\text { Camadas coladas cruzadas - cha- } \\
\text { pas }\end{array}$ \\
\hline
\end{tabular}


Um exemplo na área de arquitetura e urbnismo que utilize os instrumentos digitais, como na 4. Revolução Industrial, pode ser a implantação das Smart Cities (cidades inteligentes). O termo smart usualmente está associado a inteligente ou digital, foi usado pela primeira vez na década de 1990 e fazia referência às modernas infraestruturas das cidades. A intenção era a implementação das tecnologias de informação nas cidades e, como as comunidades poderiam se tornar mais inteligentes (ALBINO; BERARDI; DANGELICO , 2015).

Em casos recentes, os autores referem que as políticas de planejamento que utilizam o conceito das smart cities estão voltadas para o emprego da tecnologia na integração para a educação, na comunicação entre comunidades, nos sistemas de infraestrutura, no acesso amplo à internet, na gestão de uma rede de cidades, na mobilidade controlada e informada, no monitoramento climático, dentre outros projetos, integrando uma diversidade de informações para a maior previsibilidade e busca de soluções de problemas de forma antecipada, que resultem em uma qualidade de vida superior dos moradores e que atente para a manutenção do meio ambiente (MONZON, 2015). 
Um outro exemplo nesse caminho é a fabricação de conexões metálicas de diferentes formatos e pontos de uniões. Em pesquisa a ARUP desenvolveu um componente complexo estrutural de aço impresso em 3D para projeto estrutural, com a intenção de reduzir custos e descarte de material. O processo comporta formas fluidas e geometrias complexas desejadas pelos arquitetos e com maior eficiência estrutural (JONES, 2014).

De acordo com esse projeto liderado pela ARUP de Amsterdã, e que teve a participação da InsideLab, empresa de consultoria e design em engenharia de software; CRDM/3D Systems, especialista em fabricação aditiva; EOS empresa de manufatura com aditivos; o processo é baseado em aquecimento e fundição a laser aditiva com derivados de aço ultra resistente desenvolvido para o componente. Essa solução reduz 40\% da emissão de carbono ao longo do ciclo de vida em relação aos métodos tradicionais e redução de $30 \%$ do peso e diminuição das dimensões sem alterar as propriedades estruturais (NABONI; PAOLETTI, 2015).

Ren; Galjaard (2015) referem que para a construção dessas conexões em aço em sistema aditivo, este processo tem 

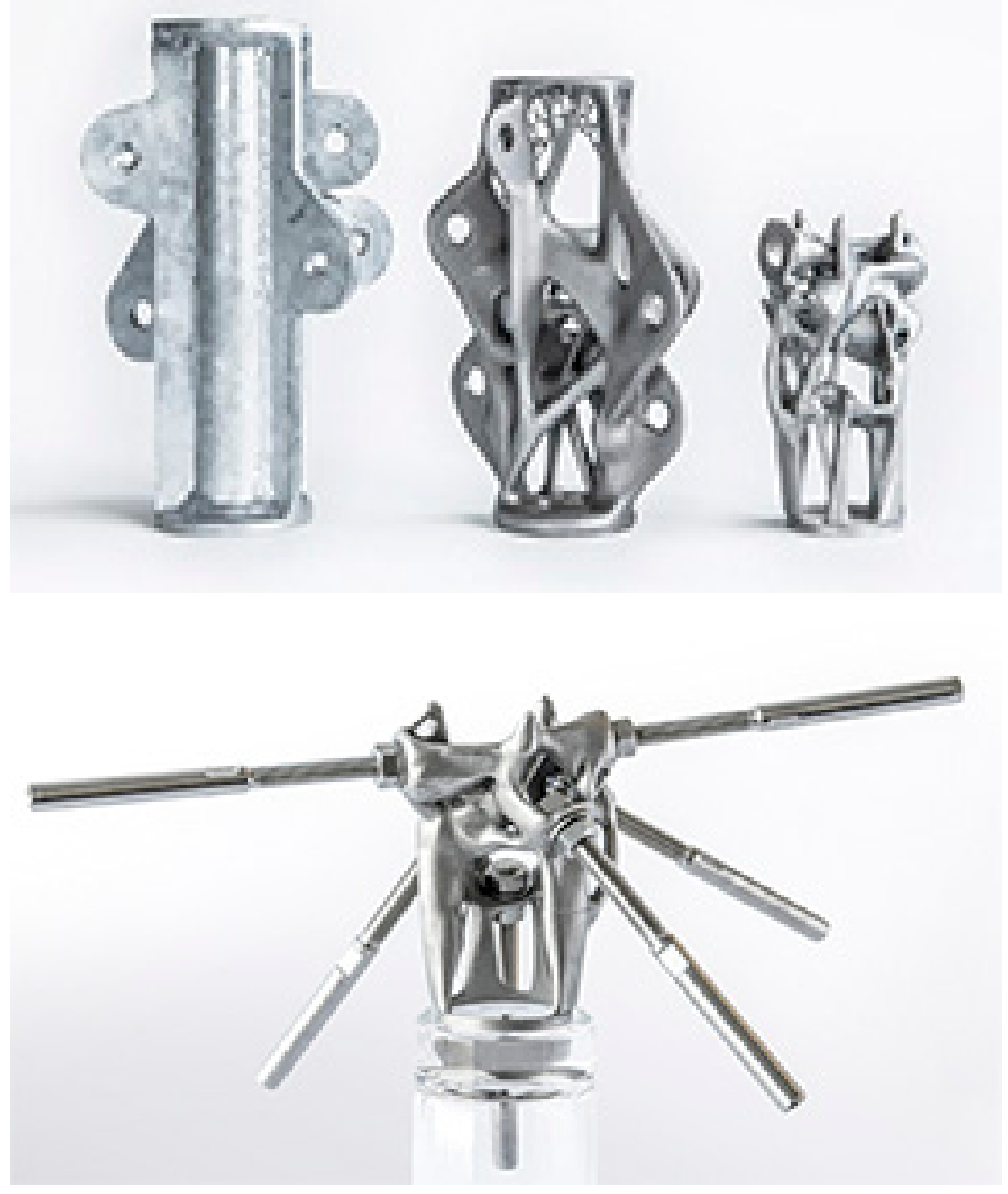
como potencial aumentar a eficiência com a diminuição das etapas, do uso de material e ainda proporcionar uma solução para peças estruturais com geometrias complexas. De acordo com os resultados demonstrados na figura 13/14, a peça da esquerda apresenta $20 \mathrm{Kg}$, com $14 \mathrm{Kg}$ da segunda e $5 \mathrm{Kg}$ na imagem da direita, sendo todas com o mesmo desempenho.

Diante do caminho percorrido para a automatização da construção civil, verifica-se que este se encontra em processo e, que talvez tenham áreas que já utilizam a tecnologia com a participação dos clientes e com flexibilização da produção, como provavelmente ocorre na produção de tintas. Mas em diversos outros ramos, ainda se tem que avançar, no sentido de adaptar e adequar o setor para a produção industrializada para atingir a 4. Revolução Industrial.

Figura 13: Conexões: 1. Tradicional, 2. e 3. Impressas em 3D. Disponível em: 3dprint.com/64376/ cutting-edge-3d-printing/. Data de Acesso: 10 abr 2017.

Figura 14: Conexão confeccionada em impressora 3D. Foto: David Galjaard. Disponível em: www.architectmagazine.com. Data de acesso: 10 abr 2017. 
Figura 15: Grelha base para fabricação dos painéis de argamassa armada. Fonte: Imagens cedidas por Gary Tortona Canbuild. Data: 2015. 


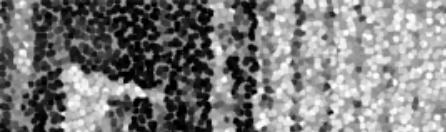

WW $\quad$ Hx

Hrov

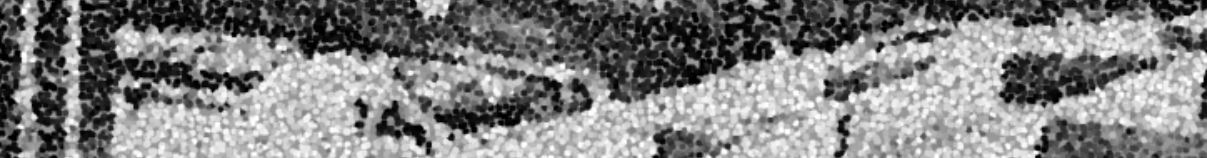
in $i j$ i in, i i i l. $T=1$

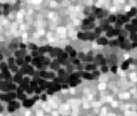
3 If If $\therefore$ i j

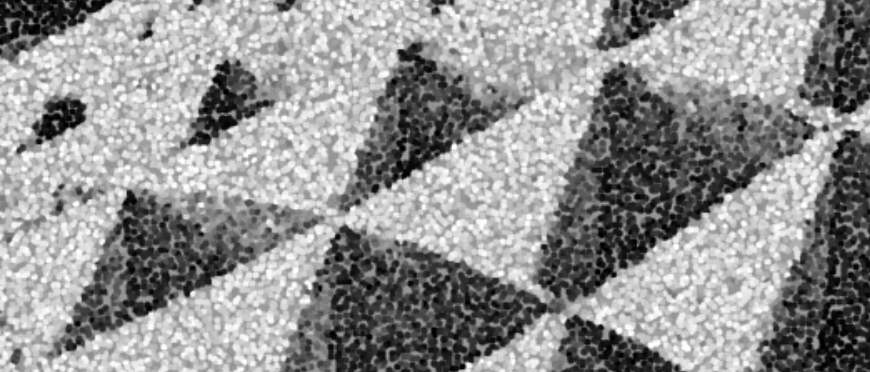
s.
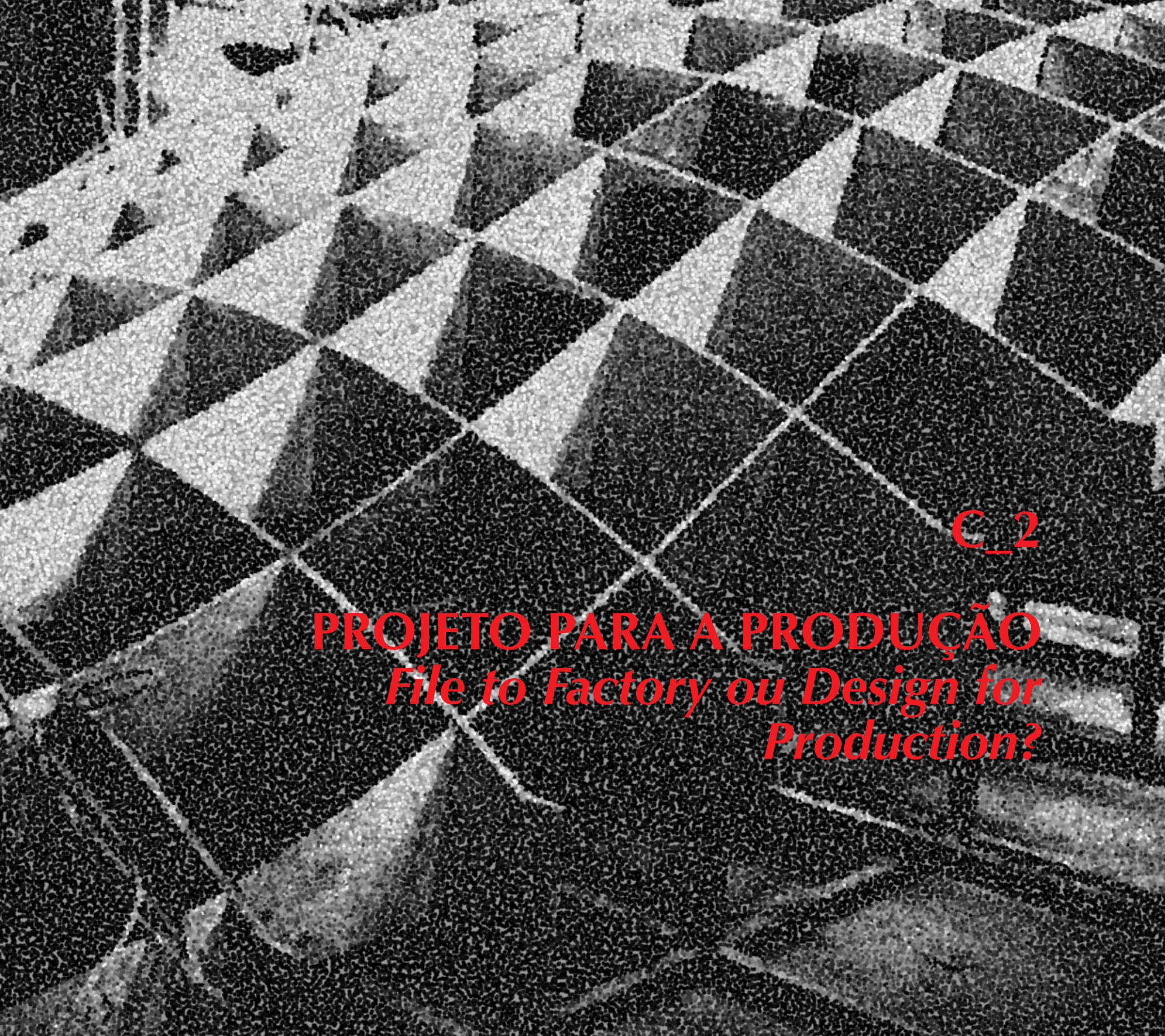
C)

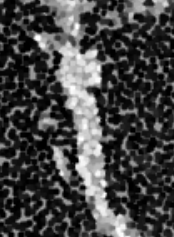

1) 



\section{Projeto para a Produção}

Este capítulo tem a intenção de discutir o Projeto para a Produção, inicialmente em relação ao seu conceito e definição, e depois de analisar dois aspectos da literatura: o processo Arquivo-Fábrica (File to Factory), que considera o arquiteto ligado diretamente à fabricação, e outro em que o processo é desenvolvido em etapas distintas na construção das superfícies complexas, o Projeto para a Produção (Design for Production).

Um dos primeiros relatos de participação conjunta para a solução de problemas da manufatura da construção civil é do início dos anos 1930, no trabalho conjunto entre Ove Arup e Tecton, na construção do prédio residencial, ao norte de Londres, Highpoint (Figura 16), do arquiteto Berthold Lubetkin. O projeto foi idealizado para ser construído em concreto tradicional, aspecto que limitava a flexibilidade e poderia apresentar patologias como fissuras. Arup sugeriu que as paredes fossem construídas de concreto armado, que seria mais econômico, diminuiria as fissuras e melhoraria o espaço interno. Com esse projeto, Arup introduziu o conceito de projeto total, em que os 


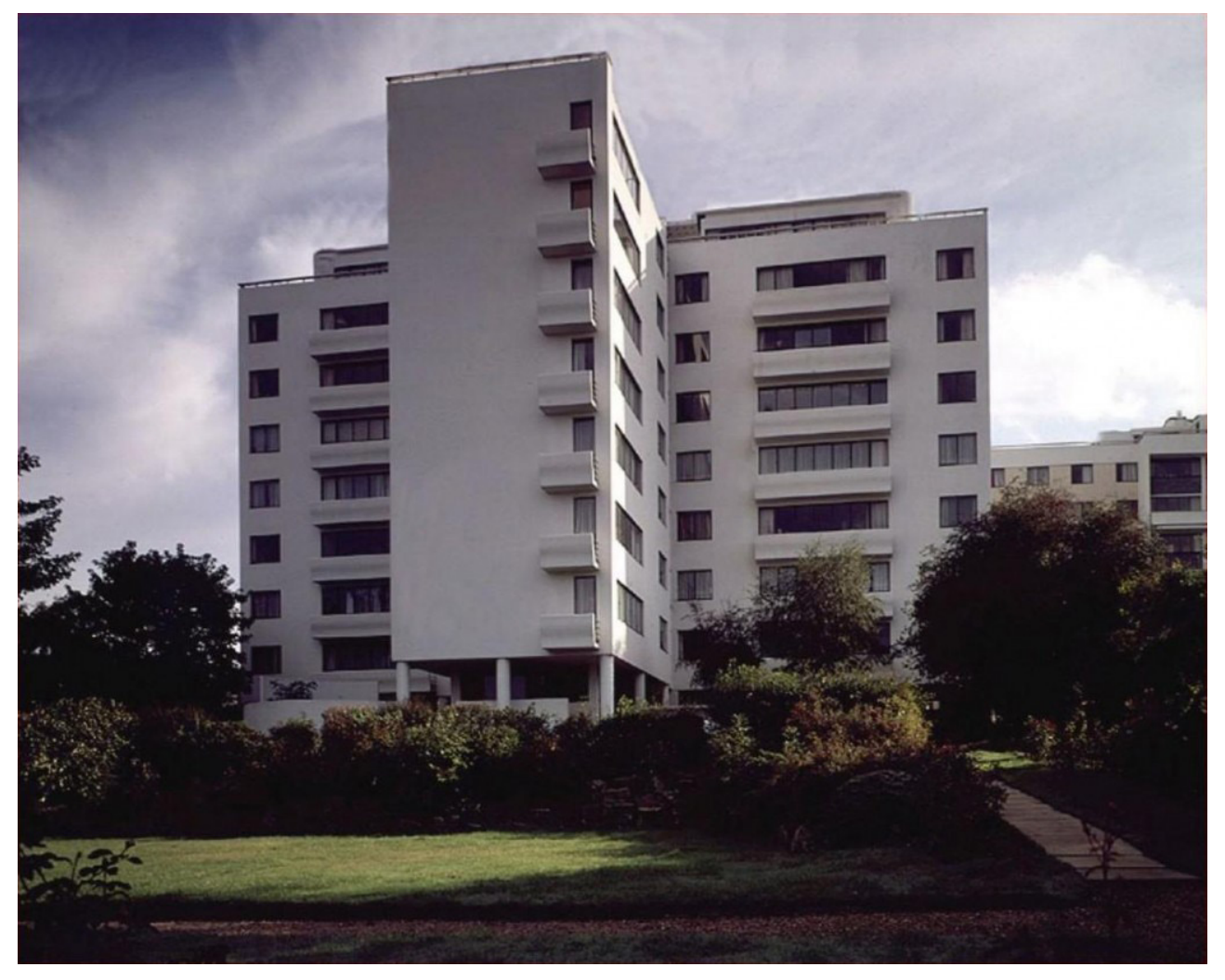


Figura 16: Edifício residencial Highpoint do arquiteto Berthold Lubetkin e Tecton ao norte de Londres. Fonte: www.kristerbladh.co.uk/blog/?p=1153. Data de Acesso: 06 jun 2017. arquitetos trabalham em colaboração para o desenvolvimento do empreendimento, desde as etapas iniciais até o detalhamento, unindo o domínio da técnica com a concepção do projeto (ADDIS, 2009).

tema Projeto para a Produção é mais tratado na literatura desde o início dos anos 1960, quando várias companhias voltadas para a indústria publicaram guias de manufatura do projeto do produto. No início dos anos 1970, análises discutiam métodos para o projeto para a montagem e, no final dos anos 1980, o conceito de projeto para a manufatura aparece considerando todos os aspectos do projeto e suas restrições para o produto. A implantação desses projetos trouxe como benefícios a simplificação dos produtos, a redução dos custos de montagem e manufatura, o aumento da qualidade e a redução do tempo para colocação do produto no mercado (KUO; HUANG; ZHANG, 2001). Em outras palavras, o Projeto para a Produção trabalha, em vários aspectos, para a concretização do empreendimento com a expectativa de desenvolver tecnicamente a produção para a melhoria da eficiência, como na organização logística da produção do edifício, com a sequência racionalizada da execução e a adequada 
escolha dos processos produtivos.

Algumas iniciativas no Brasil (Apêndice 1) especialmente ligadas à construção civil são as de Bruna (1976), que citava o planejamento da produção como um exercício de visualização antecipada do canteiro de obras, de simulação de todas as opções para a sequência de execução. Rosso (1990) trabalhou sobre a racionalização do processo de produção como um conjunto de recursos e métodos sistemáticos; Martucci (1990), discute a previsão da execução como instrumento de tomada de decisões; Barros (1996), trabalha com as etapas físicas, desde os estudos de viabilidade até a utilização do empreendimento; Novaes (1997), trabalha o tema como processo, com soluções elaboradas e compatibilizadas e a orientação das informações necessárias para as atividades a serem realizadas durante a produção; Ferreira (1998), comenta sobre a implantação da normatização que atenta para a necessidade do arranjo físico inicial do canteiro de obras; Sabatini (1998), define "Como Fazer" a partir da especificação de materiais, do planejamento da execução e da gestão do processo de produção; Melhado (1994), discute o conceito de Projeto Simultâneo; Melhado; Fabricio (1998), colocam o Projeto 
para a Produção como uma sequência de métodos de execução em projeto; Fabrício; Baía; Melhado (1998), pontuam que o projeto para a produção faz parte da etapa de desenvolvimento do produto dentro das etapas de projeto na construção de edifícios; Santos; Moccellin (1999), incluem o planejamento da produção, projeto de canteiro de obras, projeto de usinas, gerenciamento da produção com processos de trabalho e da organização com o planejamento da produção; Costa; Formoso (2006), colocam o Projeto para a Produção como um sistema de alternativas para a produção e Chalita (2010), coloca como o projeto deve conter informações sobre o sistema construtivo, processo com características dos materiais, componentes, planejamento da produção com estratégias, normas, procedimentos, sequência de produção, equipamentos, logística, relação entre os subsistemas, metas de produtividade, métodos de controle e parâmetros de gestão e controle do processo de produção.

Da literatura estrangeira, temos Herrmann; Chincholkar (2000), que discutem o tema como métodos que determinam o sistema de produção, requerem informações sobre o produto (projeto), planejamento do processo, quantida- 
de de produção e informações sobre o sistema de produção que vai fabricar o produto e avaliar a capacidade de saída de acordo com o tempo.

No final dos anos 1970, outros focos foram incorporados ao processo (BOOTHROYD; DEWHURST; KNIGHT, 2011), com a ideia de Design for $X$ de excelência, que é uma metodologia de elaboração de instrumentos para a decisão de projeto, voltada para o desempenho da produção das diferentes etapas da cadeia produtiva, como manufatura, produção, montagem, reciclagem, eliminação e prototipagem. Kuo; Huang; Zhang (2001), também trabalham o conceito e as aplicações de Design for $X$, discorrendo sobre os conceitos e definições.

Hermann (2003), cita que o Projeto para a Produção se refere às tecnologias de produção, aos materiais, à facilidade de montagem do produto e à avaliação do desempenho do sistema de produção e distribuição do produto, à logística e aos fornecedores e também analisa o Design for $X$ como uma metodologia para o desenvolvimento de ferramentas de apoio à decisão de projeto e preocupa-se com o desempenho do sistema de produção nos diferentes níveis da cadeia produtiva. Egan (s.d.), e Warwick Ma- 
nufacturing Group (2007), consideram como uma metodologia específica, analisável sob diferentes perspectivas, e Lehto et al. (2011), verificam os vários benefícios sob a utilização do projeto nas diferentes etapas do processo.

O Projeto para a Produção é um meio sistemático de pensar a manufatura como método de avaliação do desempenho dos sistemas de produção, sendo importante atentar que as equipes de projeto afetam diretamente 0 desempenho da fabricação, pois implicam no não retrabaIho para solucionar problemas de fabricação ou de tempo de produção (CHINCHOLKAR; HERMANN; WEI, 2003). O Projeto para a Produção determina que cerca de $70 \%$ dos custos do produto (materiais, processamento e montagem) são apontados por decisões do projeto, enquanto $20 \%$ é determinado por decisões da produção (como planejamento dos processos, escolha das máquinas e instrumentos) (CHANG; WYSK; WANG, 1998) e tem como objetivo reduzir os custos de acordo com os requisitos e as funções aceitáveis de eficiência, confiabilidade e segurança (NAVY, 1999).

O Projeto para a Produção considera a tecnologia e o sistema de produção para a manufatura e distribuição do 
produto. O tempo de produção ou tempo do ciclo de produção se refere a todos os tempos dos ciclos das estações de trabalho (MARWAH; THAKAR, 2013). O Projeto para a Produção é usado para 3 atividades prioritárias: 1. Como base para a engenharia simultânea, orientando a equipe de projeto, para a simplificação da montagem e melhoria do produto; 2. Como ferramenta de avaliação em relação aos produtos concorrentes e para superar dificuldades de manufatura e montagem e 3. Como instrumento de negociação com fornecedores (BOOTHROYD; DEWHURST; KNIGHT, 2011).

Algumas regras ou diretrizes para os encaminhamentos do Projeto para a Produção são (CHANG; WYSK; WANG, 1998):

1. Redução do número de partes, o que interfere no manuseio, tempo de processamento, desenvolvimento, nos equipamentos, na engenharia, na montagem, nos testes etc.;

2. Projeto modular;

3. Peças com múltiplas funções;

4. Peças com diferentes usos; 
5. Projeto com fabricação fácil, em relação ao material e processo, com diminuição do número de operações;

6. Poucas fixações;

7. Minimizar direções de montagem, com direção preferencial para a gravidade;

8. Facilitar encaixes de elementos externos e,

9. Minimizar o manuseio. 
No aspecto da informação que envolve o Projeto para a Produção, verifica-se que o conceito de Computer Integrated Manufacturing (CIM) é um termo utilizado desde 1973, inicialmente por Harrington, para indicar funções do controle total da fábrica através de informações que comandam máquinas e sistemas inteligentes. É uma estratégia de manufatura flexível que integra projeto, produção e gestão através de um sistema de informação, ao mesmo tempo em que atua na produção, venda e tecnologia. Tem o objetivo de diminuir o tempo de espera e a rápida adaptação diante das diferentes variedades de produção em pequenos lotes, através de um sistema integrado de produção (IMS - Integrated Manufacturing System - Sistema Integrado de Manufatura) (KATSUNDO, 1994).

O CIM constitui um sistema integrado em um banco de dados comum, que atua no desenvolvimento e planejamento do produto desde os estágios iniciais até a sua colocação no mercado, organizado como mostra no esquema ao lado (KATSUNDO, 1994):

1. CAM (Computer Aided Manufacturing) - auxilia na produção, na gestão e no controle de custos, na qualidade e no controle, na distribuição e nas 


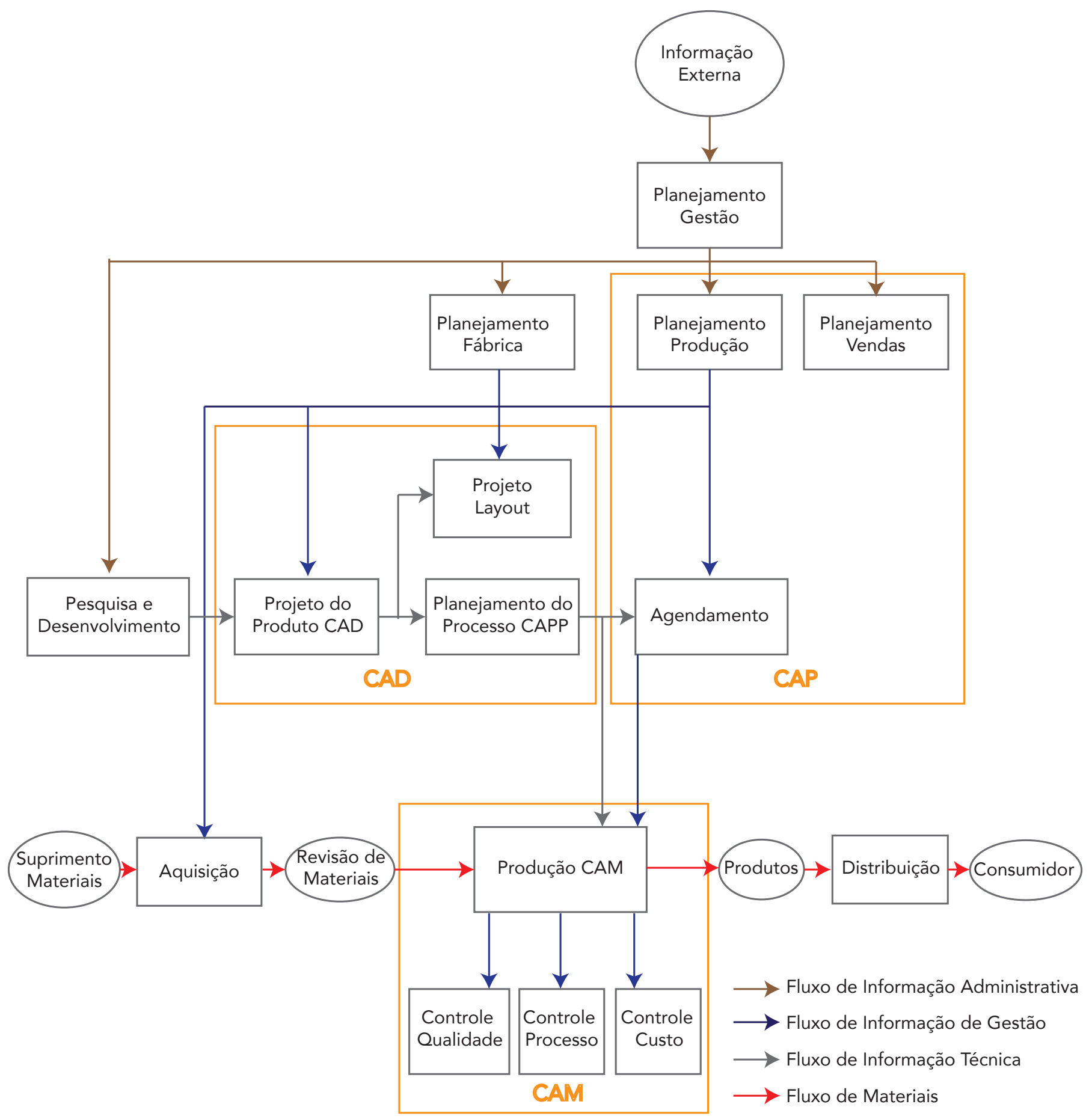

Diagrama 3: Fluxo de informações para a manufatura. Fonte: (KATSUNDO, 1994) 
rendas, com a estratégia de não ter trabalhadores diretos e capacidade de produzir vários produtos em lotes pequenos;

2. CAD (Computer Aided Design) - auxilia no projeto, na pesquisa de desenvolvimento, no projeto do produto, no processo do projeto e layout e, com agilidade no projeto e na eficiência no produto, com uma variedade de partes para atender às necessidades do mercado, pode ser considerado um CAE (Computer Aided Engineering), que auxilia no aprimoramento do projeto em relação a análises estruturais, otimização, programação, sistemas teóricos e outros,

3. CAP (Computer Aided Planning) - com fluxo automatizado de informações para plano de vendas, planejamento e produção e estabelecimento de uma agenda de produção para a manufatura que responde rapidamente às demandas do mercado.

Estes são os encaminhamentos que determinam os fluxos de produção da manufatura, com a utilização de equipamentos com alto grau de complexidade e programação nos campos de projetação, planejamento e manufatura do produto.

Nesse fluxograma, Katsundo (1994), expôs 3 núcleos prin- 
cipais de utilização dos computadores, que são o desenvolvimento do projeto, o planejamento da produção e a manufatura propriamente dita. No estágio de projeto (CAD), verifica-se que o Projeto para a Produção faz parte da etapa de design, sendo que, na pesquisa e no desenvolvimento, faz parte a escolha dos materiais, com suas respectivas análises, custos, disponibilidades e adequação à produção. Na etapa de planejamento (CAP), este está mais voltado para o fluxo de produção da fábrica e a organização estratégica para a colocação do objeto no mercado. E, na etapa de manufatura, (CAM) os projetos se voltam para os suprimentos e os controles de gestão da produção propriamente dita. Este diagrama ilustra os diversos encaminhamentos e desenvolvimentos diante da produção do produto, apesar de não detalhar de forma mais aprofundada como são utilizados os computadores e nem as funções de cada ponto no processo de manufatura do objeto. Este artigo de 1994 tinha como intenção dar um panorama geral e uma breve história da automação. Outro ponto interessante apontado pelo diagrama é a utilização dos computadores e a sua relação com os fluxos de informação. Aqui separados em informações administrativas, de gestão, técnica e de materiais, demonstram as 
conexões entre as diversas disciplinas e como os dados devem ser incorporados nas diferentes etapas de manufatura, desde as fases iniciais até a distribuição e o consumo.

Diante das discussões, considera-se que o Projeto para a Produção é um projeto do processo de produção, que desenvolve soluções para a viabilização do objeto desde a proposta conceitual até a sua montagem em canteiro de obras. Articula tecnologias disponíveis, análise e utilização de potenciais dos materiais, distribuição, logística, requisitos legais e de eficiência energética, fornecedores e mão de obra. É orientado para a busca da simplicidade e padronização do produto de forma modular, com o intuito de diminuir o número de partes, com peças multifuncionais, com desenhos facilitados para a fabricação, montagem e manipulação. 
Em relação ao Projeto para a Produção de superfícies complexas, verificam-se duas correntes: uma que é conhecida como Processo Arquivo-Fábrica (File to Factory), citada hegemonicamente, e defende que os arquitetos participam integralmente do processo, desde a criação do edifício até a sua produção nas máquinas. É defendida por vários autores como (KOLAREVIC, 2001), (KOLAREVIC, 2003), (OOSTERHUIS et al., 2004), (OOSTERHUIS, 2012), (AFIFY; ELGHAFFAR, 2007), (SASS, 2007b), (ROCHA; CELANI; PUPO, 2010), (MENGES; SHWINN, 2012), e muitos outros. E a outra vertente do Projeto para a Produção (Design for Production), defendida por este trabalho, considera a elaboração de superfícies complexas de edifícios contemporâneos com o processo de produção, que inclui etapas e envolve conhecimentos e habilidades específicas, e que raramente são realizadas pelos arquitetos autores do projeto, mas por equipes que desenvolvem e detalham o objeto. Essa linha de trabalho é defendida por poucos autores, como: (SHEIL, 2012), (SCHEURER, 2008), (NORMAN, 2004), (LARSEN; SCHINDLER, 2008), e (RASPALL, 2015). A partir dessa breve apresentação, o trabalho encaminhará no sentido de abordar as duas correntes e depois discutir os processos nos estudos de caso. 


\section{Processo Arquivo-Fábrica (File to Factory)}

A primeira corrente que compreende como Processo Arquivo-Fábrica (File to Factory) também é representada por Mitchell \& McCullough (1996), que já falavam sobre uma conexão direta entre projeto, construção e fabricação de um modelo digital, com a utilização de base de dados conectados e softwares CAD/CAM.

Um dos autores mais citados da literatura é Branco Kolarevic e, provavelmente, um dos maiores defensores do processo Arquivo-Fábrica. Ele diz que:

... a era digital possibilitou a conexão direta entre o que pode ser representado e o que pode ser construído através de processos "File to Factory" com a fabricação controlada numericamente por computador (CNC). Existe uma franqueza sem precedentes com a qual a informação do projeto digital pode ser usada na construção de edifícios. A consequência é que os arquitetos estão se tornando muito mais envolvidos na fabricação, pois podem criar de forma eficiente a informação que é traduzida diretamente aos dados de controle do equipamento de fabricação digital [... ${ }^{1}$ (KOLARE-

1 ... the digital age enabled a direct digital link between what can be represented and what can be built through "file-to-factory" processes of computer numerically controlled (CNC) fabrication. There is an unprecedented directness with which digital design information can be used in the construction of buildings. The consequence is that architects are becoming much more directly involved in the fabrication, as they can efficiently create the information that 
VIC, 2003, p. 46).

E considera que, a partir do envolvimento dos arquitetos em disciplinas como materiais e fabricação digital, aparecerão novos desafios nas formas de projetar a partir dos métodos de produção, fabricação e construção, o que, a médio prazo, tende a alterar os protocolos dos processos de projeto e fabricação da construção civil (KOLAREVIC, 2003).

Estes autores advogam que a Fabricação Digital liga os profissionais aos processos de fabricação, nos quais o designer desenvolve o projeto de forma paramétrica a partir das restrições das tecnologias de fabricação, que são limitantes do processo de projeto, mas, ao mesmo tempo, oferecem instrumentos palpáveis para a produção do objeto (DRITSAS, 2012).

Processo Arquivo-Fábrica (File to Factory) se refere à conexão direta entre o processo de projeto e o de fabricação, em que os dados são transferidos diretamente dos softwares de modelagem para as máquinas CNC (Computer Numerically Controlled), com base em conceitos comfabrication equipment (KOLAREVIC, 2003, p. 46.). 
putacionais. $O$ processo se inicia com um modelo digital manipulado através de uma rede de pontos deslocáveis que apresenta uma estrutura inicial em sua superfície. Os conceitos empregados para a definição da forma no projeto são (OOSTERHUIS et al., 2004):

1. Utilização de geometrias curvas contínuas;

2. Elaboração a partir de um projeto parametrizado;

3. Programação;

4. Conceito de movimento e dinâmica.

E como estratégia:

1. Pele estrutural;

2. Geometria da Arquitetura ou tessellation;

3. Busca de uma estrutura em famílias genéricas, com o maior número de polígonos iguais,

4. Associação e combinação de diferentes materiais para a melhoria do desempenho.

Com esse novo modo de fazer arquitetura, os componentes do edifício são peças "ativas", sendo alterados pelo polígonos planos (OOSTERHUIS, BIER, AALBERS \& BOER, 2004). 
processo de projeto, pela fabricação e interação entre os vários participantes, como fala Oosterhuis:

... O novo tipo de edifício baseia-se na invasão de tecnologias digitais para a indústria da construção e no processo de design, como design paramétrico, componentes generativos, processo de produção em fábrica para customização em massa e agentes inteligentes incorporados. ${ }^{3}$ (OOSTERHUIS, 2012, p. 412).

A informação é o tronco que se transformará nos diversos processos de desenvolvimento, agregando técnicas, conhecimento específico e programação. Assim, as ideias da criação, juntamente com as decisões de projeto, são produzidas de acordo com a máquina utilizada para a fabricação (AGKATHIDIS; BROWN, 2011).

A concepção do projeto para a fabricação explora as potencialidades criativas dos equipamentos de modelagem digital e as máquinas de produção (RASPALL, 2015). Como falam Anderson; Tang (2011), a criação de novos modelos de fabricação é graças à aproximação da linguagem das máquinas através do código $G$, que expressa a precisão

3 [...] The new kind of building is based on the invasion of digital technologies into the building industry and into the design process, such as parametric design, generative components, file to factory production process of mass customization, and embedded intelligent agents [...] (OOSTERHUIS, 2012, p.412). 
do modelo na escala da fabricação, além das tecnologias como CNC, corte a laser, jato de água ou fresadoras, que podem ser aplicadas para diferentes tipos de materiais. Atualmente, as impressoras aditivas têm maior acessibilidade aos usuários e apresentam vantagens, especialmente na manufatura de objetos fluidos. A fabricação digital pode ser representada em maquetes físicas de estudo contendo informações antes difíceis de serem confeccionadas. Essas novas formas de análise são uma oportunidade de aprendizado para os processos construtivos e para a transferência de informação à fábrica, que envolve a exatidão das informações de projeto.

Os arquitetos podem projetar um modelo 3D e fabricar sem a necessidade de construtores convencionais, utilizando ferramentas de fabricação digital, como braços robóticos, eliminando outros profissionais no processo, com a utilização de softwares avançados capazes de interpretar o desempenho dos elementos propostos. As informações anteriormente fornecidas pelos engenheiros devem ser consideradas nas fases iniciais do projeto. A partir dessa incorporação das análises mais abrangentes, a elaboração do projeto parte da verificação das possibilidades de 
acordo com as necessidades requeridas. Assim, no processo Arquivo-Fábrica (File to Factory), o projeto pode ser analisado com maior confiabilidade e segurança, com o planejamento da eficiência energética, o desempenho estrutural e o ciclo de vida, mesmo antes de ser concluído e enviado para a fábrica, a partir do modelo 3D, sem submetê-lo a qualquer modificação do desenho digital (NEUMAN, 2014).

Esse conceito foi utilizado por Rocha; Celani; Pupo (2010), para a produção de um elemento de concreto, com a utilização de formas de madeira desenvolvidas com planos não ortogonais. O objeto tinha aproximadamente $50 \mathrm{~cm}$ de altura por 60 de largura. Como vantagens, obteve-se um processo sem desenhos e formas intermediárias e sem perda de material ou dados.

Além desse, vários exemplos podem ser nomeados, nos trabalhos da Professora Gabriela Celani (CELANI; PICCOLI, 2010); (BARBOSA; CARVALHO; CELANI, 2006); (ROCHA; CELANI; PUPO, 2010) e também nos trabalhos de Larry Sass, que desenvolve abrigos (SASS; MICHAUD; CARDOSO, 2006), (SASS, 2007b); (SASS; BOTHA, 2006); (SASS, 2007a) etc. ou o elemento urbano de Schimek et 
al., (2013), os elementos urbanos de Oosterhuis; Bier; Aalbers; Boer (2004) e Oosterhuis (2012), os vários pavilhões e mobiliários desenvolvidos pelo professor Achim Menges (MENGES ; SHWINN, 2012); (MENGES, 2007); (MENGES, 2013) ou o Pavilhão Elytra Framen, construído em 2016 pela Universidade de Stuttgart, no Institute for Computational Design and Construction (ICD), com cobertura idealizada para o Victoria and Albert Museum, de Londres, tecida com fios de fibra de vidro por braços robóticos. De acordo com esses autores, os protocolos se alteraram e os arquitetos estão mais próximos dos ambientes de produção; o produto projetado pode ser encaminhado diretamente para as máquinas de execução, como cortadoras, fresadoras e impressoras 3D ou robôs, subtraindo intermediários como empreiteiros e engenheiros.

Verifica-se que um aspecto fundamental a ser considerado é a informação que nasce do criador e deve chegar ao produto final, como determinado no conceito do projeto. Caso essa informação tenha partido de scripts na sua criação, esse dado determina um dos parâmetros que deverá absorver o processo de produção do produto, mas aparentemente não significa que muitas das complexidades 
que contêm o processo de detalhamento e construção do objeto estejam resolvidas nas etapas de criação e que sejam capazes de serem encaminhadas diretamente para as máquinas.

Os dados de criação constituem fator determinante para o desenvolvimento do projeto para a produção, mas não são, em si, o produto final da produção. A utilização da programação no processo de projeto é uma realidade que se dissemina nos vários territórios, através dos instrumentos de linguagem de programação mais facilitada para a criação de parâmetros para a manipulação das superfícies.

Outro ponto importante é a etapa da Geometria da Arquitetura, geometrização, panelização ou tessellation, que é considerado um aspecto decisivo para as próximas etapas, pois é nesse momento que os técnicos determinarão os polígonos que constituem a superfície, de acordo com os materiais escolhidos e as capacidades para a sua utilização. Nos exemplos citados acima, a transformação da superfície de curva para facetada permite a sua confecção em placas planas. Esse processo é feito a partir de algoritmos e códigos parametricamente controlados que definem os polígonos da face trabalhada (ANDERSON; 
TANG, 2011).

Os componentes geralmente têm graus de complexidade solucionados em modelagem 3D; as máquinas de fabricação digital podem cortar e curvar placas metálicas na medida proposta e as soldas podem montar os componentes, em equipamentos que posicionam o material original, com a ajuda de um laser (SZALAPAJ, 2005).

Considera-se, portanto, que a informação desenvolvida na criação do projeto que abarca o conceito do mesmo deve estar presente nos produtos finais ou nos componentes fabricados para a superfície complexa, mas as etapas intermediárias para a elaboração deste são de alto detalhamento e provavelmente incluirão o desenvolvimento de perfis, conexões, encaixes entre os diferentes materiais, estruturação e estudos de desempenho, além de conhecimento aprofundado a respeito dos comportamentos dos materiais e as potencialidades para utilização dos equipamentos de fabricação, sem considerar os aspectos de montagem que serão desenvolvidos minuciosamente quando se atribui componentes ou sistemas parametrizados, mas diferentes entre si, o que não significa a exclusão de construtores por maquinário automatizado. 
O processo Arquivo-Fábrica (File to Factory) será efetivo quando os designers se apropriarem das potencialidades dos materiais do processo de construção, das possibilidades dos equipamentos de fabricação digital e dos conhecimentos sobre o processo de montagem (NORMAN, 2004), além de conexões, apoios, articulações, fixações, parametrizados para a fabricação em massa (ANDERSON; TANG, 2011). O que parece mais viável no contexto de mercado é que equipes especializadas na viabilização sejam incorporadas ao processo para a elaboração do Projeto para a Produção da superfície complexa. 


\section{Projeto para a Produção (Design for Production)}

grupo da segunda vertente que desenvolve o processo por etapas e equipes com funções distintas tem um alto conhecimento sobre programação de computadores e sobre os processos de produção contemporâneos; aspectos que facilitam na busca das melhores alternativas para a confecção dos componentes.

$\bigcirc$ crescente aumento dos laboratórios, das iniciativas em centros de pesquisa e da elaboração de pavilhões experimentais em escala real tem reforçado a ideia de que os arquivos são encaminhados diretamente para as máquinas de fabricação digital. Essas iniciativas de construção de pavilhões são descritas como proto-arquiteturas e fazem parte de uma categoria maior do que os protótipos, mas "fora das noções convencionais da construção" (SHEIL, 2013, p. 381). São um tipo particular de construções que busca avaliar pesquisas voltadas para a fabricação digital, para o desempenho estrutural, o material, a produção, a montagem, entre outros. De acordo com o autor, essas atividades são resultantes de laboratórios implantados 
nas universidades, com equipamentos de fabricação digital, e têm incentivado o trabalho conjunto entre diferentes disciplinas como a engenharia civil e a computação, criando práticas e culturas híbridas e, ao mesmo tempo, abrindo campos para novas iniciativas com a exploração da produção a partir da modelagem. Essas proposições também dão abertura para o florescimento de disciplinas associadas entre a indústria e a criação, como computação, fabricação, gestão e concepção.

É evidente que alguns arquitetos possuem as habilidades e ferramentas para o desenvolvimento do produto, desde sua proposta inicial até a materialização do seu processo, no entanto parece que a prática na construção civil passa por um caminho diferente, principalmente em edifícios de escala real.

Para o desenvolvimento do projeto em um produto, são necessários alguns conhecimentos sobre o processo de construção real, sobre os métodos e as ferramentas envolvidos e sobre a codificação dos dados para os equipamentos, que devem considerar os requisitos práticos do ciclo de vida, além de aspectos como drenagem de águas pluviais, segurança dos usuários, necessidades estrutu- 
rais e padrões legais de construção. $\bigcirc$ autor do projeto em relação à fábrica deve considerar as potencialidades dos equipamentos, que, por um lado, a partir do seu conhecimento, possibilitam novas formas criativas e, por outro, apresentam um campo de atuação que necessita da adequação do projeto em objetos fabricáveis (LARSEN; SCHINDLER, 2008.).

Embora hoje possamos «imprimir» o modelo de um edifício digitalmente como na prototipagem rápida, ainda existem alguns obstáculos importantes antes de enviar dados do projeto diretamente para um produtor e esperar um resultado impecável, tal como imaginado no projeto que o projetista tinha em mente (ou no computador)... ${ }^{4}$ (LARSEN \& SCHINDLER, 2008, p. 399.).

Nesse processo para a elaboração da cadeia digital, são necessários (SCHEURER; SCHINDLER; BRAACH, 2005):

1. Definir os requisitos geométricos, funcionais e construtivos a partir da forma proposta;

2. Definir os materiais e detalhes construtivos, com participação ativa dos técnicos de produção, que têm o objetivo de utilizar ao máximo os potenciais

$4[\ldots]$ Although we today may 'print' the model of a building digitally as in rapid prototyping, there is still some major obstacles before we can send design data directly to a producer and expect a flawless result just as imagined in the designer's mind (or computer)... (LARSEN \& SCHINDLER, 2008, p. 399). 
dos materiais e diminuir detalhes diferentes dos componentes;

3. Definir a geometria da estrutura, o que pode ser feito através do modelo da forma, do conceito ou do algoritmo,

4. Determinar a geometria de cada peça:

a. otimizar para a produção e para o detalhamento específico para produção,

b. gerar código de produção (código G), a linguagem para atuação do equipamento $\mathrm{CNC}$, normalmente a partir de um script para a produção das peças,

Atentando para o desenvolvimento específico das junções, dos encaixes, apoios, das análises mecânicas e de tantos outros tópicos importantes para o seu desenvolvimento.

No caso do Complex Doubly Curved Exhibition Plataform (Figura 17), criado pelo escritório Instant Architects, as etapas de elaboração do objeto foram:

etapa 1: Atendimento aos requisitos do projeto, utilizando o software Maya, com elaboração de peças com facilidade para a montagem e o transporte; 


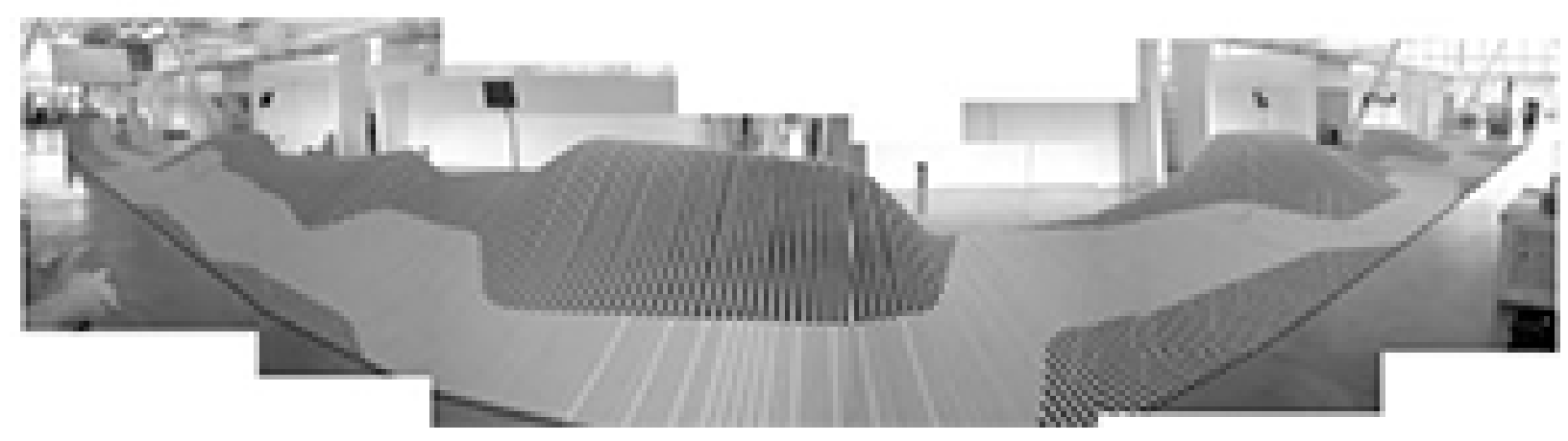


etapa 2. Respeitar as capacidades da CNC de 5 eixos e das ripas de MDF,

etapa 3. Criação da modelagem.

A definição da geometria é um ponto fundamental que contém a informação da superfície, a divisão dos polígonos e o script que determina a alteração paramétrica de cada componente. A partir da geometria, o próximo passo é transferir os dados para cada parte, com perfurações para montagem e encaixes. $\bigcirc$ processo passa por uma programação de corte das placas e geração do código específico da máquina que dá as coordenadas de movimento da CNC para o corte da madeira (SCHINDLER; BRAACH; SCHEURER, 2006.).

De acordo com Raspall (2015), o projeto para a fabricação é composto por 3 etapas:

1. Estudo sobre os materiais, ferramentas para a sua transformação, testes para verificação dos seus

Figura 17: Complex Doubly Curved Exhibition Plataform, elemento de $40 \mathrm{~m}$ de extensão. Viabilizado pelo escritório Design to Production. Fonte: www.generativeart.com/on/cic/ papers2005/36.ScheurerSchindlerBraach_final.htm. Data de Acesso: 08 jun 2017. comportamentos, proposição de geometrias com o material escolhido;

2. Desenvolvimento e sistematização do processo, garantindo que a construtibilidade e a montagem dos componentes sejam viáveis; no caso de auto- 
matização, análise e previsão dos processos de fabricação;

3. Construção de protótipos em escala real, para verificação do processo de construção, como tempo, sequência de montagem, detalhes de junção, tolerâncias e outros.

Para componentes com dimensões e geometrias variadas, são necessárias técnicas para garantir a fabricação a custo viável. A decomposição da superfície em partes pode facilitar a sua fabricação, sendo posteriormente unidas para formar sistemas de fachada para a sua montagem (SZALAPAJ, 2005).

Esse processo de busca pela melhor célula para compor a superfície é conhecido como Rationalization (Racionalização), e está voltado para o estudo da superfície através de análises algorítimicas para encontrar um modelo que possa ser fabricado e construído a um custo viável. Como cita o autor:

... é uma ferramenta que integra diretamente a consciência de fabricação permite que o designer explore e escolha um modelo final de forma com um maior número de informações. Panelização é uma instância da racionalização e refere-se à aproximação de uma superfície por um conjunto de componentes da forma, os chamados painéis, 
produzíveis a um custo razoável (DEUSS, 2015, p. $5)^{5}$.

Outro trabalho descrito por Williams et al. (2011), como no diagrama para componentes de concreto mostrado abaixo, demonstra que é preciso preocupar-se com as restrições do processo de fabricação, do planejamento e da proposta indicadas no conceito do projeto, com uma atuação do conhecimento fornecendo informações no ir e vir.

Verifica-se que as informações produzidas e necessárias ocorrem de forma contínua, gerando e retroalimentando o processo, com o intuito de atingir o objetivo final, que é o produto finalizado. Nesse caminho, são necessárias algumas habilidades como: ter conhecimento de programação, com descrições formais bem definidas, sintaticamente corretas dentro da linguagem executada; encontrar soluções que acolham os diferentes detalhes da superfície para a modularização, ser preciso de acordo com os equipamentos e máquinas digitais de alta tecnologia e com pequenas tolerâncias e ter conhecimento aprofundado sobre geometria na forma de vetores normais, medidas

5 ... a tool that directly integrates fabrication-awareness lets the designer explore and choose a final model in a more informed manner. Paneling is a instance of rationalization and refers to the approximation of a surface by a set of surface components, so-called panels, producible at reasonable cost (DEUSS, 2015, p. 5). 
Geometria da estru- . Geometria detalhada tura de concreto de formas

Diretrizes para padrões de superfície e configuração

. Detalhes das quantidades de material

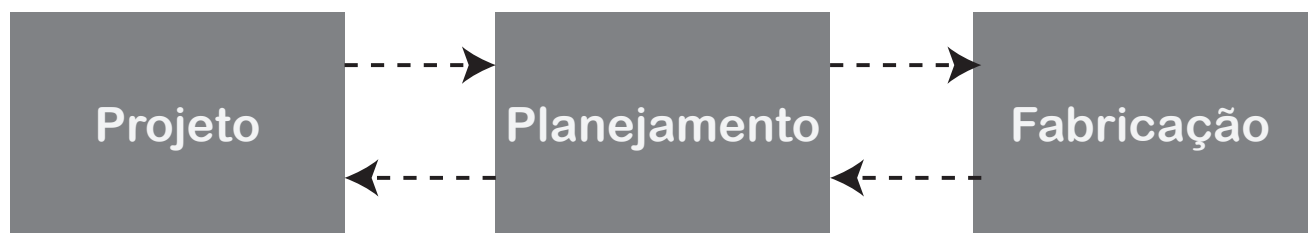

. Detalhes das quantida- . Detalhes de restrides de formas

. Detalhes sobre restrições de planejamento

- Detalhes do ajuste proposto 
de curvas e coordenadas. A produção do algoritmo define as propriedades dos componentes, a partir de parâmetros programados específicos, que traduzem todos os detaIhes da superfície e dos componentes (SCHEURER, 2009).

As informações são parte das definições nas diversas etapas, desde o processo de projetação, planejamento até a fabricação, que necessita dos dados sobre as restrições dos equipamentos, mas que também contribui para a definição da geometria, os detalhes e levantamentos de insumos. O processo é retroalimentado constantemente e o planejamento ocorre de forma simultânea em todas as fases.

Considera-se que em ambos os grupos, tanto no processo Arquivo-Fábrica (File to Factory) como no Projeto para a Produção (Design for Production), o conhecimento e as habilidades no desenvolvimento da programação são correntes; no entanto, os aspectos diferenciados situam-se no detalhamento mais específico, quando se utilizam diversos materiais e a montagem de componentes em sistemas para a formação da superfície complexa.

Como exemplificam Anderson e Tang: 
[...] O projeto de junção de conexão é uma esfera simples que se ramifica para receber as hastes de conexão que abrangem ponto a ponto. Esses superconectores são definidos por parâmetros que são determinados pelas necessidades de fabricação em massa, como diâmetro externo de uma haste, taxa de dilatação do material, espessura mínima da parede para resistência e comprimento de suporte em relação ao peso e comprimento da haste de conexão. A remoção de um dos artefatos de conexão do projeto faz com que o quadro perca a quantidade apropriada de deslocamento estrutural e pode causar as falhas de toda a estrutura6 (ANDERSON; TANG, 2011a, p. 95.).

Esse parágrafo mostra a multiplicidade de variáveis que envolvem a construção de um elemento de superfícies complexas, que devem atender a todas as especificações legais de segurança e conforto.

Pensar na superfície complexa implica entendê-la como parte integral do conceito, da composição do espaço e da organização das funções do projeto, bem como a elaboração estrutural, definição dos materiais, da superfície

$6[\ldots]$ The connection joint design is a simple sphere that branches off to receive the connecting rods that span point to point. These super connectors are defined by parameters that are determined by the needs of mass manufacturing such as outside diameter of a rod, material shrinkage, minimum wall thickness for strength, and length of support compared to weight, and length of connecting rod. Removing one of the connection artifacts from the design causes the frame to lose the appropriate amount of structural displacement and may cause the entire structure to fail [...] (ANDERSON; TANG, 2011a) 
e da estrutura, com a aplicação no edifício. O seu detaIhamento é o desenvolvimento do conceito arquitetônico, em uma escala particular, que acompanha o conceito do projeto. A superfície faz parte da estrutura, influencia o espaço interno, externo e ao redor do edifício, interfere na vista, iluminação, ventilação, conforto, serviços e carga, o que intervém e determina o projeto (KNAACK et al., 2007).

No projeto do Rolex Learning Center, em Lausane, desenvolvido pelos arquitetos japoneses do SANAA, o escritório Design to Production elaborou uma solução específica para a grande laje curva de concreto. $O$ desafio era manter a superfície de construção em uma posição específica e segura até a conclusão da concretagem (SCHIMEK et al., 2013).

Outro exemplo de processo de projeto é o trabalho descrito por Agkathidis; Brown (2011), que constrói uma marquise para um hotel (Figura 18). Os detalhes foram desenhados em 3D; devido à geometria complexa da cobertura, não poderiam ser detalhados em desenhos 2D, da mesma forma que todos os desenhos 3D foram utilizados para o projeto e a fabricação dos componentes. As informações foram produzidas no Rhinoceros, Autocad, Freefem++, e 


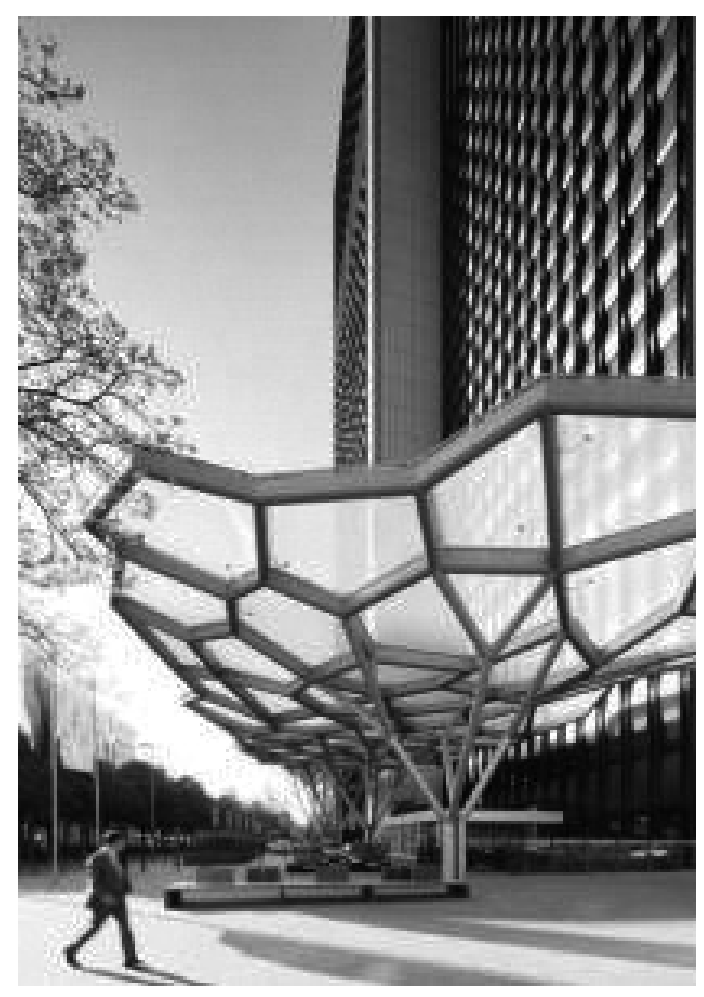


a manufatura contou com o uso de uma máquina $\mathrm{CNC}$ com corte a plasma. Todos os tubos foram calculados, numerados e usados como dados de fabricação, pré-montados na fábrica e, posteriormente, levados para o local para finalização.

No projeto publicado por Hudson; Shepherd; Hines (2009) sobre o Aviva Stadium, eles afirmam que são necessárias habilidades especializadas, com equipes multidisciplinares e um alto nível de colaboração e comunicação. $\bigcirc$ desenvolvimento envolveu uma equipe de engenheiros mecânicos e uma equipe de controle estético, representada pelo grupo de concepção de projetos. Protótipos foram desenvolvidos para o estudo dos comportamentos, a verificação das trocas climáticas da fachada e a verificação das deformações dos componentes.

Figura 18: Tree-Structure Canopy, estrutura em aço, para o Marriott Tower (2011) Foto: Eibe Sönnecken. Disponível em: asteriosagkathidis.wordpress. com/2011/04/10/tree-structure-canopy/. Data de Acesso: 07 jun 2017.
No artigo Materialising Complexity, de Scheurer (2009), ele descreve vários trabalhos desenvolvidos: a estrutura do Centro Pompidou, em Metz (França); o Resort Nove Pontes Golfe, em Yeju (Coreia do Sul), do arquiteto Shigeru Ban; a Cobertura para Quatro Novas Estações Metropolitanas, em Hungeburgbahn, em Insbruck, Áustria, e a Superfície de Vedação da Building Workshop, Peek \& Clo- 
ppenburg Wltstadhaus, em Cologne, do arquiteto Renzo Piano. Nesses projetos, o escritório foi contratado para desenvolver o Projeto para a Produção e acompanhar até a etapa de montagem do edifício. A atenção foi dada fundamentalmente para a definição algorítmica que acolhe as propriedades das superfícies, transferindo o conteúdo para a programação das máquinas de manufatura, que produziram peça a peça diferenciadamente, com a modificação do script.

Sheil (2013) coloca que o termo mais apropriado e menos simplificado para o processo seja File through Factory arquivo através da fábrica -, pois demonstra a transformação dos dados através de um percurso. Nesse processo, o profissional que elabora a produção do produto necessita de conhecimentos sobre os processos das ferramentas, as coordenadas e variações das máquinas, a orientação dos materiais e as habilidades necessárias para a elaboração da produção.

O Projeto para a Produção de superfícies complexas envolve, portanto, o desenvolvimento de vários projetos que pensem especificamente: no sistema que compõe a superfície; na fabricação desses sistemas; na montagem em 
canteiro de obras, na desmontagem e em vários outros aspectos não menos importantes (LARSEN; SCHINDLER, 2008).

No projeto para a elaboração dos sistemas da superfície, as diretrizes são dadas pelo projeto de arquitetura, que, a partir disso, definirá a geometria dos polígonos para a fabricação dos componentes. Habitualmente são utilizados programas capazes de modelar e definir os parâmetros que absorvem o conceito arquitetônico. Técnicos capazes de manipular a linguagem de scripts estão na linha de frente desses trabalhos, que adequarão os parâmetros e as informações necessários para a definição de componentes e o consequente detalhamento das células. Os equipamentos disponíveis na fábrica que produz a superfície complexa são um aspecto restritivo e de oportunidade para a definição do projeto, ditando parâmetros de medidas de peças e capacidades para a fabricação digital.

O material utilizado é determinante na definição do projeto, que emprega todas as suas potencialidades, com o intuito de facilitar a fabricação e a montagem do objeto 
e também aproveitar a eficácia e a eficiência do produto, com o menor custo nos diversos processos produtivos. Diante do conhecimento do comportamento e das capacidades do material, são desenvolvidos os detalhamentos de projeto, que envolvem desenhos de conexões entre os sistemas, conexões entre a estrutura do edifício e conexões entre a superfície e seu suporte ou subestrutura, além de se considerarem os requisitos legais de ventilação, insolação, segurança e necessidades em casos de incêndio, e, finalmente, os estudos sobre a eficiência energética de acordo com o projeto proposto.

O projeto para a fabricação foca na materialização dos componentes; elabora desde os desenhos de peças, perfis e montantes até a sua montagem em sistemas e, da mesma forma, atenta para avaliação dos custos, pedidos de insumos, análises mecânicas de segurança, atendimento aos requisitos legais e compatibilização com a estrutura do edifício e a gestão para a construção. A mão de obra utilizada para essa etapa geralmente é de engenheiros, que realizam a modelagem do produto, fazem a gestão do projeto, coordenam a produção, o chão de fábrica, além do pessoal administrativo. 
No processo do Projeto para a Produção estão incluídos desde a elaboração do projeto para a fabricação até a montagem em fábrica e posterior entrega com elaboração logística. Os sistemas têm que ser identificados para a localização na obra a partir de um mapa da devida localização de montagem. A logística envolvida planeja o transporte dos elementos, considera o acondicionamento em páletes, o tipo de veículo que será utilizado, quais as suas dimensões, qual o tempo para chegada do material, onde será armazenado no canteiro de obras e quais os equipamentos necessários para o seu carregamento e descarregamento.

O projeto para a montagem em canteiro de obras é outro ponto crucial no planejamento do empreendimento. Está no cronograma e é sincronizado com as etapas subsequentes: o preparo do terreno; a locação de áreas administrativas, almoxarifados, gruas, áreas de descartes; as instalações necessárias para receber a superfície complexa de montagem da superfície, além da execução da estrutura do edifício, já pensada para acolher a subestrutura dos painéis; o planejamento do equipamento e mão de obra para a montagem dos componentes, a sequência de 
montagem, o cuidado com a fragilidade dos elementos e a organização do trabalho associado com as outras disciplinas envolvidas na construção, tais como ar-condicionado, revestimentos, elevadores, elétrica, hidráulica etc.

Fazer o desmonte implica elaborar um projeto desde o início voltado a este intuito, além da necessidade de planejamento de toda logística pensada para esse objetivo, tal como a identificação das peças; a ordenação racionalizada para a remontagem; o transporte; a coordenação do acondicionamento para o transporte e para o novo canteiro de obras, a organização das planilhas para a nova montagem e, finalmente, o cuidado com os elementos após a chegada no novo canteiro. Importante salientar que, apesar de todo cuidado aplicado nesse processo para a remontagem, talvez seja necessária a confecção de peças danificadas durante o processo. Por esse motivo, a fábrica deve estar preparada para esses eventos, não descartando as formas utilizadas e os documentos com as informações para a manufatura.

Para melhor compreensão, a tabela 4 a seguir mostra de forma resumida os diferentes processos citados anteriormente. 
Tabela 4: Etapas do processo de Projeto para a Produção de Superfícies Complexas.

\begin{tabular}{|c|c|}
\hline $\begin{array}{l}\text { Projeto do } \\
\text { Sistema da } \\
\text { Superfície } \\
\text { Complexa }\end{array}$ & $\begin{array}{l}\text { - Requisitos arquitetônicos } \\
\text { - Definição da Geometria e polígono da superfície } \\
\text { - Considerações sobre as potencialidades do material } \\
\text { - Associação com equipamentos disponíveis } \\
\text { - Técnicos desenvolvedores de scripts } \\
\text { - Desenvolvimento das conexões entre os sistemas da superfície, a estrutura do edifício, a subes- } \\
\text { trutura e o painel propriamente dito - BIM de projeto } \\
\text { - Detalhamentos de peças e conexões } \\
\text { - Atendimento aos requisitos legais de ventilação, insolação, segurança e incêndios } \\
\text { - Análises sobre eficiência energética }\end{array}$ \\
\hline $\begin{array}{l}\text { Projeto } \\
\text { para a } \\
\text { Fabricação }\end{array}$ & $\begin{array}{l}\text { - Modelagem do painel e da subestrutura - BIM para fábrica } \\
\text { - Análises mecânica, de vedação, comportamento dos materiais, dos requisitos legais e de se- } \\
\text { gurança } \\
\text { - Equipe para gestão de custos, insumos, controle de chão de fábrica, gestão de projeto etc. } \\
\text { - Encaminhamento da confecção das chapas, metalon, montantes etc. - utilização de equipa- } \\
\text { mentos digitais para corte, moldagem, montagem } \\
\text { - Produção das curvaturas, texturas etc. } \\
\text { - Produção das formas e subestruturas } \\
\text { - Produção das peças, painéis e sistemas } \\
\text { - Montagem dos sistemas com identificação } \\
\text { - Mapas de localização dos componentes } \\
\text { - Logística para acondicionamento dos componentes, tempo de chegada no local, carregamen- } \\
\text { to, transporte, recebimento e armazenamento }\end{array}$ \\
\hline $\begin{array}{l}\text { Projeto } \\
\text { para a } \\
\text { Montagem }\end{array}$ & $\begin{array}{l}\text { - Preparo e modificação do canteiro de acordo com as etapas da obra } \\
\text { - Armazenamento em canteiro de obras de forma a não prejudicar a construção e com espaço } \\
\text { suficiente para colocação dos componentes, que devem estar acondicionados e não podem } \\
\text { sujar } \\
\text { - Previsão de equipamentos necessários para o içamento, a montagem e a fixação dos painéis, } \\
\text { com mão de obra especializada para tal; } \\
\text { - Planejamento para a sequência de montagem dos sistemas } \\
\text { - Cuidados com a fragilidade dos painéis } \\
\text { - Utilização de mapas para a localização dos componentes } \\
\text { - Cronograma minucioso }\end{array}$ \\
\hline $\begin{array}{l}\text { Projeto } \\
\text { para o } \\
\text { Desmonte }\end{array}$ & $\begin{array}{l}\text { - O projeto inicial já prevê o desmonte. } \\
\text { - Os componentes têm que ser reidentificados, organizados de acordo com a remontagem e } \\
\text { acondicionados com a racionalidade da remontagem. } \\
\text { - Acompanhar planilhas de identificação dos componentes. } \\
\text { - Os páletes para o transporte são confeccionados desde o transporte da fábrica para o canteiro } \\
\text { e aqui podem ser reutilizados. }\end{array}$ \\
\hline
\end{tabular}


Algumas decisões realizadas no Projeto para a Produção são determinantes no processo de construção do edifício. Por exemplo, o material a ser trabalhado no projeto determina o equipamento de produção para chegar à forma desejada. No caso da madeira, os equipamentos indicados são as fresadoras com diversos eixos e a utilização de tecnologias específicas para a madeira, como aquecimento a vapor, que altera a sua curvatura, madeiras laminadas e coladas, que aumentam a resistência e possibilitam a confecção de longos componentes. Nos casos de metais, cortadoras a laser, plasma e jato de água provavelmente são as ferramentas preconizadas, além de calandras para obtenção de curvas e/ou até as impressoras 3D, capazes de obter componentes de conexão. Finalmente, nos casos com a utilização de concreto ou seus derivados, o processo geralmente prevê a construção de formas, que podem ser de isopor ou de outro material de baixo custo e baixa durabilidade, já que possivelmente só serão utilizados em uma oportunidade; nesse caso, as máquinas indicadas são as fresadoras de vários eixos, já que o trabalho provavelmente será de subtração de partes para a modelagem do objeto. 
A definição do polígono que forma a superfície é fundamental, pois, a partir de sua indicação, este interferirá em todas as etapas subsequentes, facilitando ou dificultando a sua produção, atuando diretamente nas tecnologias e nos custos necessários para o desenvolvimento do sistema que forma a superfície complexa.

As escolhas e possibilidades de confeccionar sistemas para montagem da superfície sugerem a concentração maior ou menor do trabalho, que pode se deslocar mais para a fábrica ou para o canteiro de obras. Os aspectos positivos de se montarem os sistemas são a menor interferência das condições adversas do canteiro e o controle rígido do ambiente de fábrica, que pode ser administrado em todas as etapas e condições para a obtenção de uma boa qualidade do objeto. Por outro lado, isso interfere nos custos, além de ser necessária a adequação dos transportes e da montagem, sendo, provavelmente, imprescindíveis maiores cuidados, veículos apropriados e equipamentos mais potentes para o içamento do material semipronto com maiores dimensões e peso.

O processo é dinâmico; envolve inúmeros atores, entre técnicos e operários; agrega uma diversidade de discipli- 
nas e especialidades que trabalham sincronizadas a partir da gestão geral, que, em regra, planeja o Projeto para a Produção do empreendimento e coordena os momentos de entrada das equipes de acordo com o andamento da obra.

Após a discussão das duas vertentes de pensamento, o quadro ao lado faz uma breve síntese entre os processos, mas compreende que, apesar de se apresentarem como duas correntes de pensamento, podem não ser contraditórios, mas grupos complementares que atuam em áreas distintas: uma investigando novos conhecimentos, como é o caso dos grupos de pesquisa, e outra trabalhando na aplicação concreta dos edifícios finais. 
Tabela 5: Quadro comparativo entre as correntes conceituais de processo de produção do objeto.

\begin{tabular}{|c|c|c|}
\hline & $\begin{array}{l}\text { Processo Arquivo-Fábrica } \\
\text { File to Factory }\end{array}$ & $\begin{array}{l}\text { Projeto para a Produção } \\
\text { Design for Production }\end{array}$ \\
\hline Processo & $\begin{array}{l}\text { 1. Projeto, Geometrização } \\
\text { 2. Protótipo/Modelo } \\
\text { 3. Planificação (Nesting) } \\
\text { 4. Adequação ao programa da máquina } \\
\text { 5. Elemento final }\end{array}$ & $\begin{array}{l}\text { 1. Projeto Arquitetônico } \\
\text { 2. Geometrização } \\
\text { 3. Projeto dos painéis e conexões } \\
\text { 4. Detalhamentos } \\
\text { 5. Projeto da Fabricação } \\
\text { 6. Projeto da Montagem } \\
\text { 7. Projeto da Desmontagem }\end{array}$ \\
\hline Material & $\begin{array}{l}\text { Potencialidade para utilização na escala } \\
\text { desejada }\end{array}$ & $\begin{array}{l}\text { Análise profunda das potencialidades que } \\
\text { são aplicadas no componente final }\end{array}$ \\
\hline Escala & Objeto, mobiliário, Pavilhão & Estádios, edifícios altos, institucionais \\
\hline $\begin{array}{l}\text { Desenvolve- } \\
\text { dores }\end{array}$ & $\begin{array}{l}\text { Grupos de pesquisa com novos desafios, } \\
\text { experimentando novos protocolos para a } \\
\text { projetação } \\
\text { Arquitetos ligados diretamente às máqui- } \\
\text { nas de produção }\end{array}$ & $\begin{array}{l}\text { Escritórios de Gestão do empreendimento } \\
\text { Etapas e equipes distintas }\end{array}$ \\
\hline Construtores & $\begin{array}{l}\text { Indica a eliminação de construtores substi- } \\
\text { tuídos por equipamentos robóticos. }\end{array}$ & $\begin{array}{l}\text { Considera o projeto com maior complexida- } \\
\text { de e segue o modelo tradicional de produ- } \\
\text { ção. }\end{array}$ \\
\hline $\begin{array}{l}\text { Aplicação da } \\
\text { programação }\end{array}$ & $\begin{array}{l}\text { Desenvolvimento da superfície com indi- } \\
\text { cação dos polígonos }\end{array}$ & $\begin{array}{l}\text { Desenvolvimento da geometria e definição } \\
\text { dos polígonos }\end{array}$ \\
\hline $\begin{array}{l}\text { Elemento da } \\
\text { superfície }\end{array}$ & Componentes & Sistemas \\
\hline $\begin{array}{l}\text { Requisitos } \\
\text { estruturais }\end{array}$ & De menor complexidade & $\begin{array}{l}\text { Devem atender às normas legais de segu- } \\
\text { rança, desempenho e eficiência energética. }\end{array}$ \\
\hline Montagem & $\begin{array}{l}\text { De forma geral, executada pelos próprios } \\
\text { desenvolvedores. }\end{array}$ & Requer planejamento minucioso. \\
\hline $\begin{array}{l}\text { Equipamen- } \\
\text { tos }\end{array}$ & Baixa capacidade & Alta capacidade \\
\hline Objeto & Proto-Arquiteturas & Edifício Real \\
\hline
\end{tabular}


Os pontos semelhantes entre os grupos estão, principalmente, na aplicação da programação e na definição da forma, apesar de o primeiro estar mais focado no volume e o segundo estar preocupado com a utilização dos scripts para a definição dos componentes, que, em última instância, darão os parâmetros para a confecção das placas. As duas vertentes trabalham as potencialidades dos materiais, aplicados em análises de resistência e como artifício para a fabricação dos elementos.

Os pontos divergentes são a escala dos objetos confeccionados e seus detalhamentos específicos para a construtibilidade, o aprofundamento das equipes que atuam em diferentes disciplinas e o envolvimento das diversas empresas especializadas que colaboram entre si para a construção do edifício. A partir dessa diferença de escala, os objetos necessitam atender aos requisitos construtivos, que requerem equipamentos com capacidades específicas para as dimensões do empreendimento e o devido planejamento para a construção do edifício.

Os grupos de trabalho são equivalentes à escala do produto, que conta com equipes experimentais ou a participação de diferentes empresas que fazem a gestão e a 
organização da cadeia produtiva do edifício, tais como desenvolvimento dos componentes, produção fabril, canteiro e desmonte. Da mesma forma se equivalem as necessidades estruturais, os tipos de equipamentos utilizados, a montagem e a necessidade de profissionais especializados para a construção.

Apesar de o processo para a construção do edifício ser um processo contínuo, o projeto do produto elaborado por escritórios de arquitetura está mais focado em determinar os conceitos e as diretrizes para o desenvolvimento do edifício, tais como forma, distribuição e definição das espacialidades, definição dos fechamentos, escolha da estrutura principal, entre outros.

A partir do momento que o processo junto às outras disciplinas se inicia, os trabalhos voltados ao Projeto para a Produção são articulados com os estudos para viabilizar as propostas. Nesse ponto, participam os especialistas em estruturas, hidráulica, elétrica, lógica e, ao mesmo tempo, há a preocupação de proceder as compatibilizações dos projetos, que trabalham em parceria até a finalização da construção. 
Os projetos executivos determinados pelas diferentes disciplinas são específicos de cada setor, isto é, o projeto executivo de arquitetura traz informações relativas à organização espacial, a alturas, materiais e outros, assim como as demais áreas que explicitam o seu tema específico, como estruturas, conforto térmico, entre outros. O Projeto para a Produção da superfície complexa envolve todas as disciplinas além do projeto executivo de arquitetura, compatibiliza e realiza a gestão para concluir a construção do edifício. 
(7)

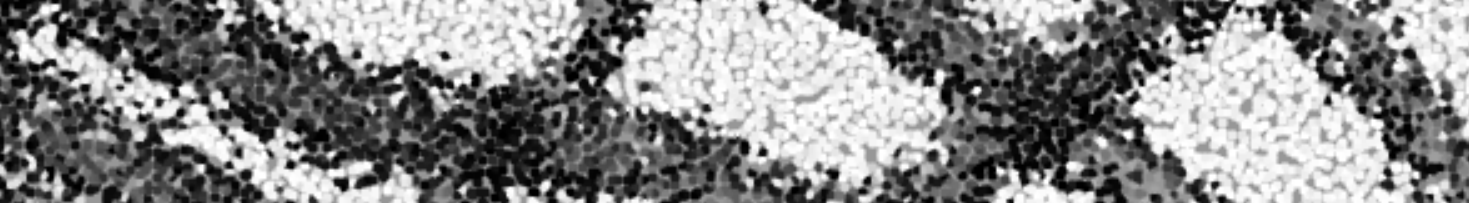

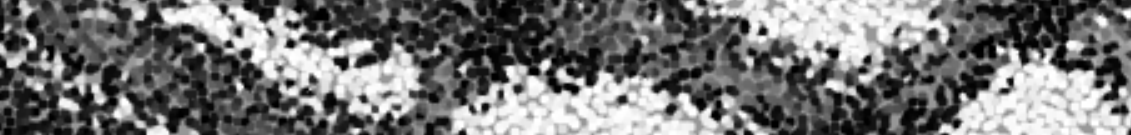

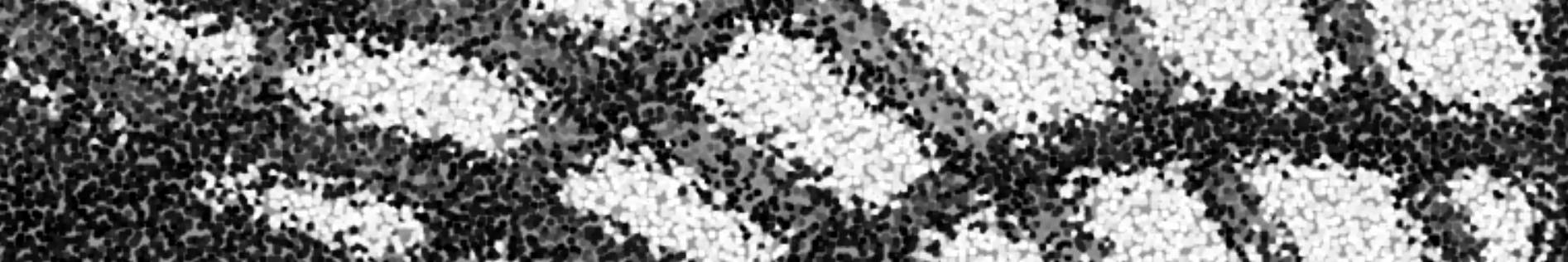

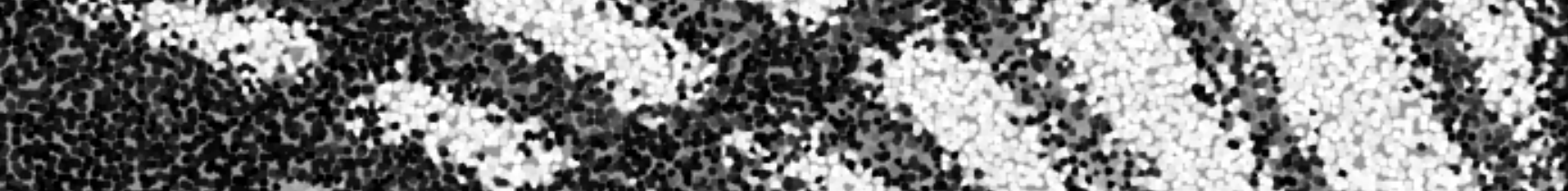

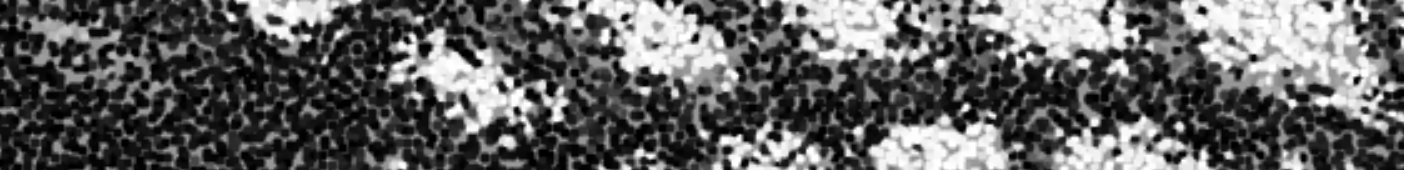

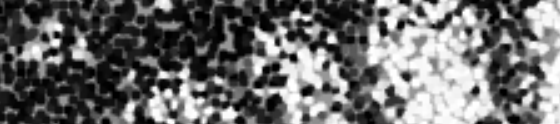

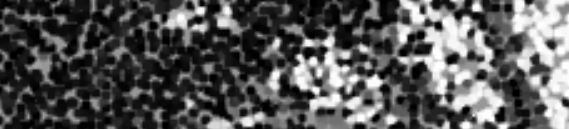

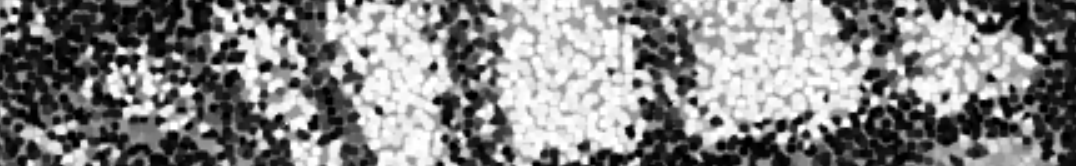

is

is: ह)

$\cos ^{2} \sin ^{2}$

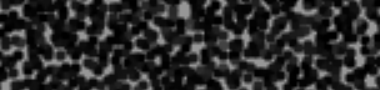

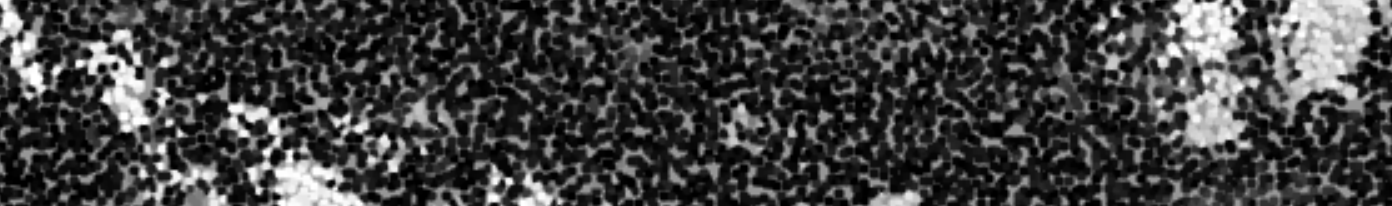

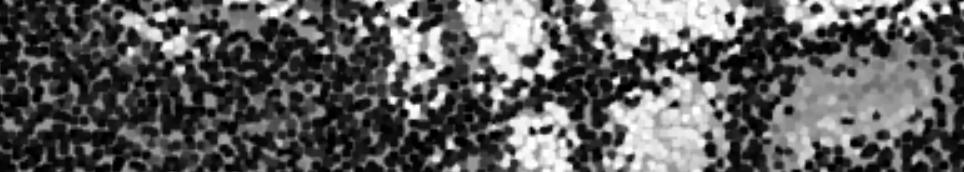

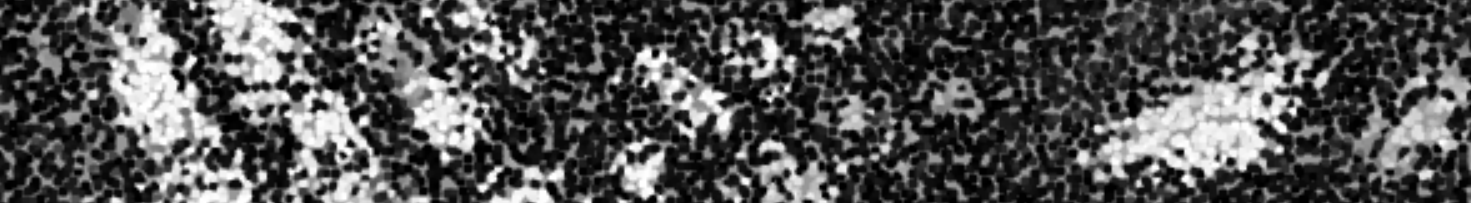

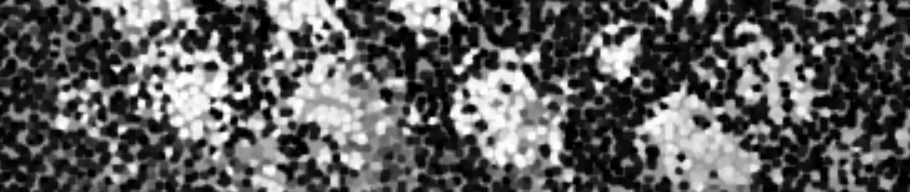

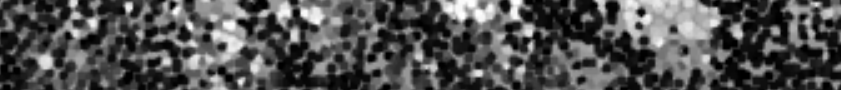

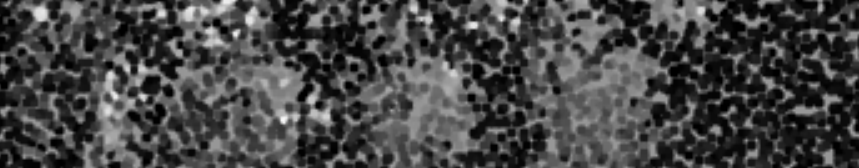

(a)

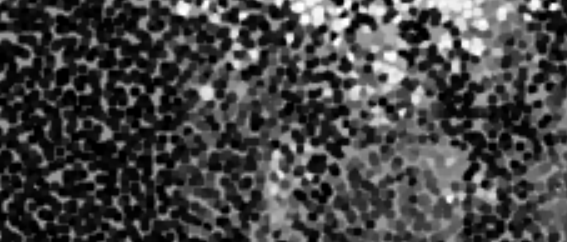

$7 y^{\circ}$

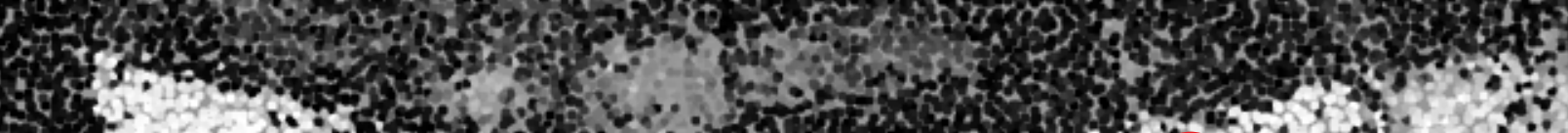

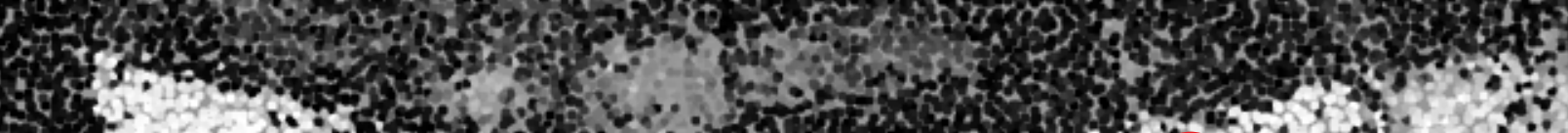

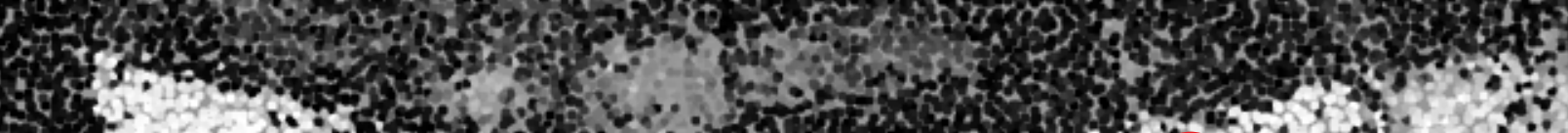
top? 9. 3 . bitis $x^{2}$

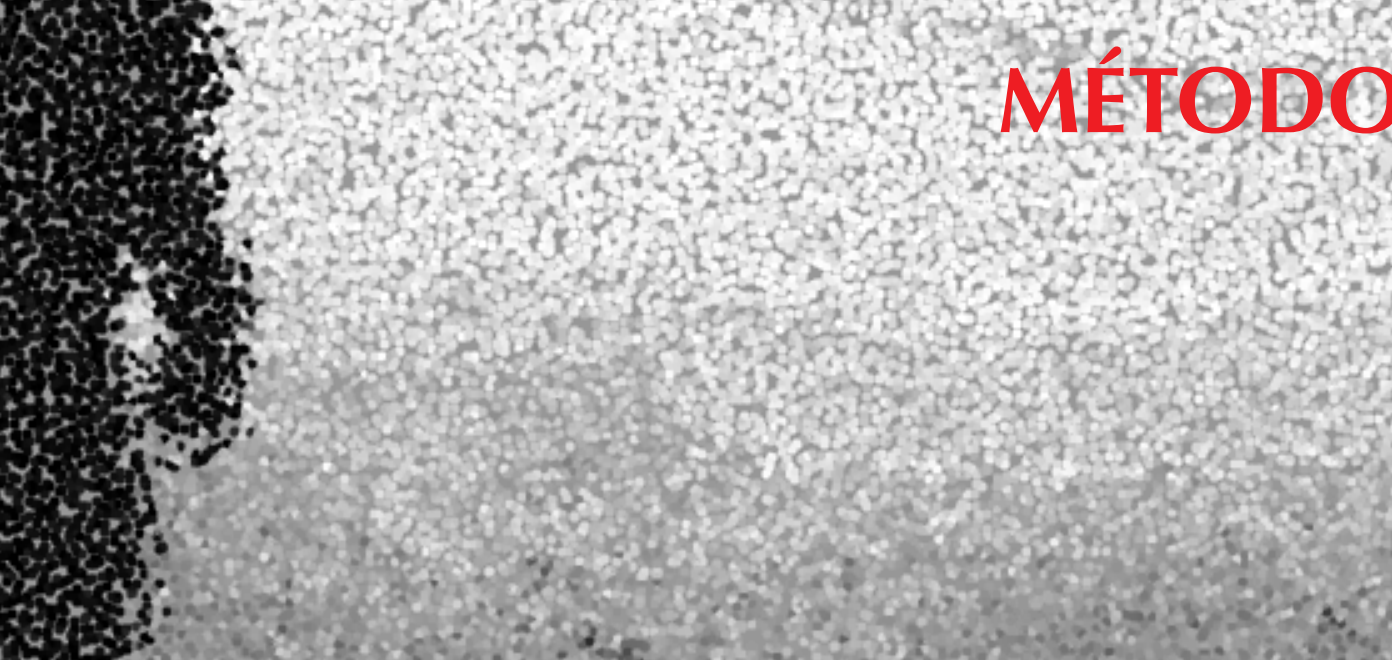
4 

Neste capítulo serão descrtitos os caminhos pelos quais a pesquisa trilhou na busca dos dados empíricos de acordo com as informações disponíveis, a organização e sistematização da base documental.

A pesquisa tem a natureza de ser aplicada, pois propõe gerar conhecimentos para o emprego na prática da construção civil voltada para os processos industrializados, orientados para a solução de problemas específicos. Possui uma abordagem qualitativa, visto que a interpretação dos fenômenos e o seu entendimento são aspectos básicos para o processo de pesquisa, dentro de seu ambiente natural da coleta de dados. O pesquisador é o instrumento-chave para o processo e envolve o estudo aprofundado de poucos objetos para a obtenção do conhecimento amplo e detalhado (SILVA; MENEZES, 2005).

A estratégia utilizada para a pesquisa foi o estudo de caso que tem como característica tentar absorver a complexidade de casos simples. Possui caráter contemporâneo, com pouco controle ou possibilidade de manipulação sobre o evento, e se encontra dentro do seu contexto dinâmico. Trabalha com a coleta de dados com múltiplos métodos combinados, focados através de diferentes ângulos e, 
posteriormente, combinados através da triangulação para a obtenção de resultados válidos e consequentes generalizações. A triangulação evidencia uma forma de obtenção da validade do estudo de casos, através da coletânea de dados combinados, somados a outras fontes, teorias e investigações. A combinação de diversas informações pode, muitas vezes, indicar diferentes questionamentos, que são positivos para a pesquisa, pois mostram a rede de variáveis que intervém no problema (JOHANSSON, 2003).

Nesta pesquisa, a preocupação recai essencialmente sobre a busca da indagação Como?, em situações em que o pesquisador tem pouco controle sobre o evento (WANG; GROAT, 2002) (YIN, 2001). Na tentativa de compreender "Como" são viabilizadas as superfícies complexas através do Projeto para a Produção. O problema da pesquisa é um fenômeno contemporâneo e busca olhar uma prática do fazer e como são os personagens envolvidos no processo, de acordo com suas habilidades e especialidades formais. Trabalhar com situações contemporâneas requer estratégias que sejam capazes de absorver, problematizar, participar do evento para, posteriormente, realizar o distanciamento e avaliar de forma crítica as questões que 
envolvem o contexto e a situação da pesquisa, para, no final deste processo, obter respostas e conclusões de pesquisa.

Existem 5 aplicações para a utilização dos estudos de caso (YIN, 2001):

1. Explicar os vínculos em intervenções contemporâneas complexas;

2. Descrever intervenções no contexto real;

3. Elucidar situações de forma descritiva ou para avaliação;

4. Pode ser usado quando o evento não apresenta resultados simples e claros,

5. Pode ser uma avaliação da avaliação.

É fato que, quando se analisa um evento contemporâneo, corre-se o risco de tirar conclusões equivocadas; no entanto, com os devidos cuidados, com as análises de dados cruzados e a verificação com outros pesquisadores e trabalhadores do mesmo ramo, pode-se trazer inúmeros benefícios para as inovações da tecnologia brasileira, no sentido de compreender e, posteriormente, construir um modelo de Projeto para a Produção de superfícies com- 
plexas pouco comuns em nosso país.

Essa estratégia de pesquisa apresenta alguns pontos fortes (WANG; GROAT, 2002):

1. O fenômeno ocorre dentro de seu contexto;

2. Possui capacidade para explicar ligações causais;

3. Rica em múltiplos dados;

4. Habilidade para generalização em teoria,

5. É conclusiva quando bem encaminhada.

E os pontos fracos são:

1. Tem potencial para complicações;

2. A causalidade é multifacetada e complexa;

3. Apresenta o desafio por integrar várias fontes de dados de forma coerente;

4. É importante replicar em outros casos,

5. Possui poucas regras e procedimentos determinados, assim como em outras estratégias de pesquisa.

Esta pesquisa faz parte do grupo de pesquisa ArquiTec, que possui estudos no setor de desenvolvimento e ges- 
tão de projetos contemporâneos e, em especial, no setor de pesquisas voltadas às industrializações das construções. Também foi desenvolvida em parceria com o grupo Actlab, da Universidade Politécnica de Milão - Itália, que possui pesquisas no ramo de fabricação digital e vasta produção de literatura a respeito de processos construtivos contemporâneos.

A pesquisa foi viabilizada com o Programa de Doutorado-sanduíche no Exterior, da CAPES - Coordenação de Aperfeiçoamento de Pessoal de Nível Superior -, processo no. 99999.003519/2015-05, que possibilitou a estadia da estudante, que vivenciou as atividades do laboratório e se aprofundou na temática durante 1 ano do processo de pesquisa.

A profa. Ingrid Paoletti, docente da Universidade Politécnica de Milão, que acolheu a candidata, é da área de Tecnologia da Arquitetura, estuda processos industrializados e, em especial, os processos construtivos de superfícies complexas desde seu doutorado, em 2005, e tem conhecimento profundo sobre tecnologias inovativas da construção civil, tem parcerias diretas com indústrias do setor na Itália e atua, inclusive, como conselheira de algumas 
instituições representando a universidade.

A escolha dos casos se deu pelos edifícios possuírem superfícies complexas, o que constituiu primeiro aspecto de sua seleção. Inicialmente, a pesquisa buscou 5 casos:

1. Pavilhão da União dos Emirados Árabes (Milão) Norman Foster Associates

2. La Nuvola (Roma) - Massimiliano Fuksas

3. Fundazioni Feltrinelli (Milão) - Herzog De Meuron

4. Aeroporto Internacional de Fuimicino (Roma) - Studio Muzi

5. CityLife (Milão) - Zaha Hadid Architects

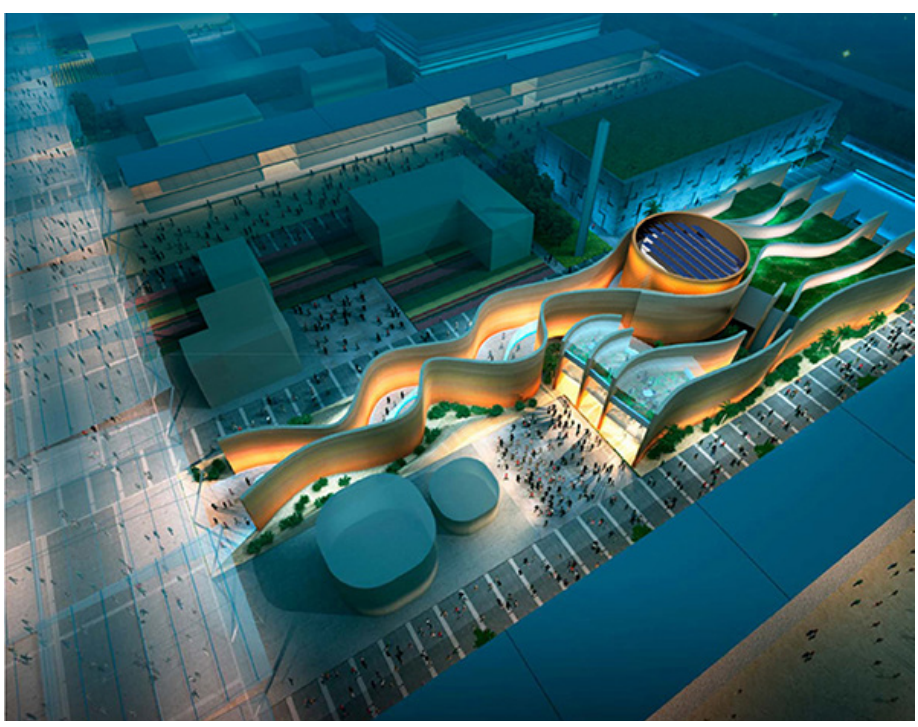

Figura 20: Renderização do Pavilhão da União dos Emirados Árabes. Escritório Norman Foster AssociatesFonte: Foster \& Partners. Data 2014.

Figura 21: La Nuvola. Fonte: http://www.fuksas.com/it/Progetti/Nuovo-Centro-Congressi-Roma-EUR-e-Hotel-Rome. Escritório Massimiliano Fuksas. Data de Acesso: 3 ago 2017.

Figura 22: Fundazione Feltrinelli - Milano. Fonte: www. dezeen. com/2010/03/15/porta-volta-fondazione-feltrinelli-by-herzog-de-meuron-2/. Escritório Herzog \& De Meuron. Data de Acesso: 25 ago 2015. 

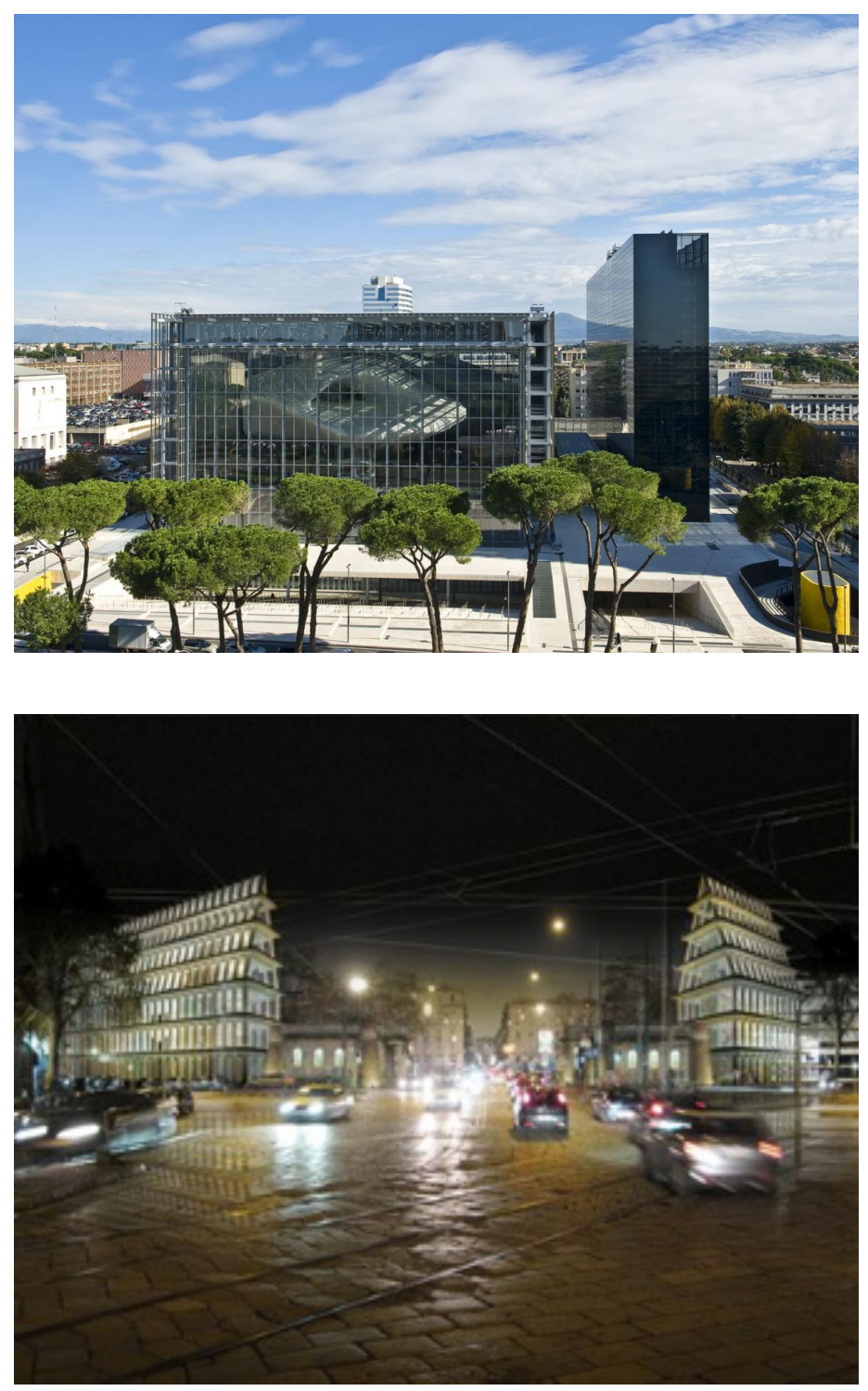

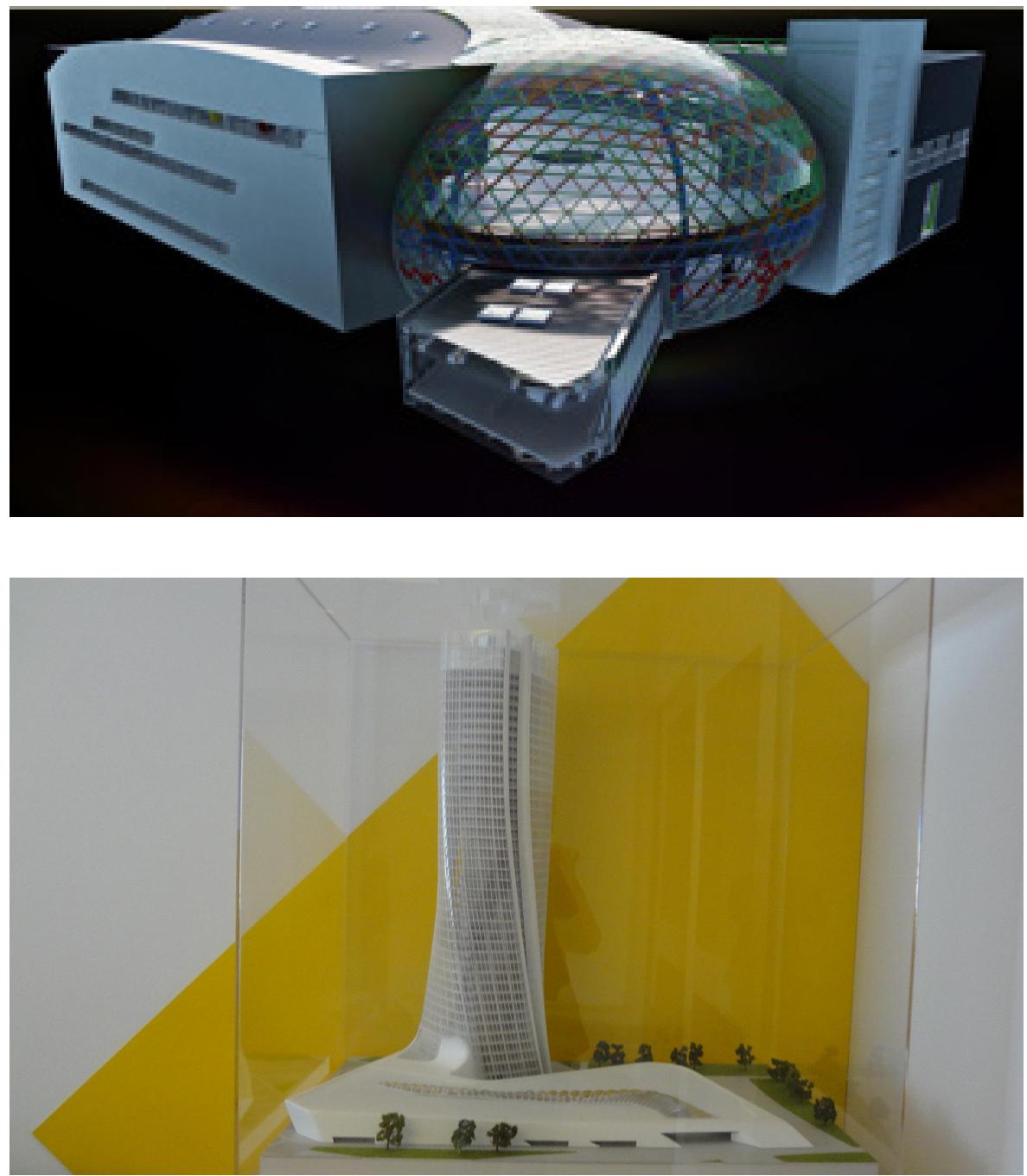
A escolha pelas opções iniciais se deu devido à facilidade de localização, por estarem na cidade de Milão, ou pelos contatos com os escritórios que desenvolviam a gestão dos projetos desses empreendimentos. A partir dessa seleção, os contatos foram convidados a participar da pesquisa e autorizaram a publicação das imagens e do projeto.

Alguns escritórios de arquitetura descartaram a possibilidade dos estudos; outros não responderam aos inúmeros contatos realizados e outros, mesmo disponibilizando os dados, não autorizaram a sua publicação, o que inviabilizaria a sua inclusão na pesquisa. Diante disso, foram escolhidos os dois casos já mencionados anteriormente, o de Norman Foster \& Associates e o de Zaha Hadid Architects, que foram solícitos e atenderam prontamente aos pedidos de publicação do material e do estudo sobre os objetos.

Figura 23: Aeroporto Internacional Fuimicino - Roma. Escritório Studio Muzi. Fonte: Rimond. Data: 2016.

Figura 24: Maquete do empreendimento CityLife - Milano. Zaha Hadid Architects. Foto: autor. Data 2016.
Tendo como foco o Projeto para a Produção das superfícies de vedação dos dois estudos de caso, a pesquisadora se debruçou sobre as diversas possibilidades de busca de dados e prosseguiu na investigação para compreender como foram desenvolvidos os objetos a partir do projeto 
inicial.

Diferentes caminhos foram abertos para a compreensão do fenômeno e serão mostrados a seguir.

Acompanhamento em canteiro de obras:

1. Observação direta, com visitas periódicas ao canteiro de obras para verificação do desenvolvimento da construção ou da desmontagem do edifício, acompanhamento do trabalho, verificação dos modos de fazer dos trabalhadores, assim como levantamento dos equipamentos utilizados e da quantidade de operários necessária para as atividades desenvolvidas.

2. Captação de séries fotográficas do processo de montagem ou desmonte, para o entendimento do processo construtivo, estudo da materialidade, estrutura e subestrutura dos painéis utilizados, bem como compreensão sobre as soluções e os detaIhamentos encontrados para fixação e a relação entre os diversos sistemas e a montagem do objeto.

3. Anotações sistemáticas com descrição de dúvidas para posterior apreciação. Essas ações possibilitaram o entendimento do processo de montagem, da materialidade e das conexões entre os compo- 
nentes do sistema, mais facilmente compreensível do que nos desenhos das peças gráficas.

As entrevistas com os atores-chave do processo talvez sejam uma das fontes de evidências centrais para os estudos de caso, já que as informações são de trabalhos e condutas em projetos que foram ou são desenvolvidos há pouco tempo e fazem parte da atividade contemporânea dos escritórios de arquitetura (YIN, 2001).

As entrevistas semiestruturadas ocorreram com os profissionais que atuam diretamente no Projeto para a Produção do objeto. A partir desse contato direto com os desenvolvedores e executores do projeto, foi possível esclarecer pontos obscuros e compreender o motivo da escolha das soluções encontradas para os problemas. Foram entrevistados os seguintes envolvidos com o Pavilhão da União dos Emirados Árabes:

- Arquiteto que realizou a compatibilização dos projetos do pavilhão;

- Arquiteto que desenvolveu o detalhamento dos painéis de vedação;

- Engenheiro de segurança do canteiro de obras; 
- Engenheiro coordenador de projetos;

- Coordenador da fábrica que produziu os painéis de vedação,

- Engenheiro coordenador da estrutura principal do edifício

Da CityLife - Milano, foram entrevistados:

- Engenheiro coordenador de projetos;

- Engenheira de Segurança do canteiro de obras;

- Engenheiro de estruturas do edifício (concreto),

- Arquiteto coordenador do projeto da superfície de vedação.

Além das entrevistas, foram organizadas aulas expositivas com os coordenadores dos projetos, que expuseram o conceito dos projetos, aspectos de organização e gestão, solução de problemas e coordenação em cooperação com as equipes envolvidas. Essas aulas foram gravadas e examinadas posteriormente, apreendendo aspectos relevantes para a pesquisa. 
Visitas às fábricas de desenvolvimento e execução de componentes:

1. Visitas à fábrica de estruturas metálicas

2. Visita à fábrica de produção da vedação em sistemas de vidro

3. Visita ao laboratório de testes com materiais tensionados Etileno Tetrafluoretileno (ETFE) - polímero

De acordo com Yin (2001), o estudo de caso é uma investigação empírica em que os limites do fenômeno e o contexto não estão claramente definidos; enfrenta situações particulares com múltiplas variáveis e utiliza-se de proposições teóricas para conduzir a coleta e a análise de dados.

Disciplinas e ambientes técnicos

- Participação como assistente nas disciplinas de Building Technology Studio - BTS -, ministradas para o segundo ano da graduação e o segundo ano do mestrado. O conteúdo é voltado para a projetação de um pavilhão de uma exposição que ocorrerá em Dubai, em 2020. A disciplina incentiva os alunos a utilizarem 
programas com script (Rhinoceros - Grasshopper) e o uso de tecnologias inovativas, associando-o à tentativa de desenvolvimento do cálculo estrutural e da adequação da eficiência energética - a disciplina de projeto é integrada com estas disciplinas.

- Participação das atividades do laboratório - desenvolvimento de maquetes 3D: a atividade proporciona o entendimento das restrições dos equipamentos, sua lógica de funcionamento e de produção com o material específico. Os equipamentos eram de origem italiana, Wasp e Makebot.

- Participação em workshops para o desenvolvimento de projetos para impressora 3D - atividade direcionada para a compreensão das etapas do processo de projeto e produção de modelos.

- Participação em reuniões para o desenvolvimento de projetos, de temas relacionados às exposições internacionais, de tecnologias inovativas e de sistemas industrializados contemporâneos.

- Participação de palestras temáticas voltadas para projetos contemporâneos, tais como geometria da 
arquitetura, obras de arquitetos etc.

- Participação de Simpósios e Seminários de pesquisa

- Visita a exposições de design, arquitetura e arte

- Produção de artigos para congresso e revista

Coleta de dados documentais:

Os instrumentos gráficos foram adquiridos a partir do contato com os escritórios que desenvolveram os projetos. Dentre os documentos, estão plantas, cortes, vistas, concursos, detalhamentos, documento de aprovação do projeto, documentos de aprovação das empresas, planilhas de produção, desenhos para a busca de soluções entre os parceiros, tabelas, organogramas, diagramas explicativos, registros administrativos, materiais de divulgação, fotos de Mockups e maquetes, imagens das compatibilizações, relatórios etc. Com esses dados, foi possível compreender a organização e a gestão das empresas participantes, bem como cruzar as demais informações disponíveis para a pesquisa.

Vale a pena salientar que o processo de coleta de dados não é fluido, pois depende das disponibilidades dos ato- 
res, o que nem sempre é fácil, uma vez que o trabalho nos escritórios é intenso e depende de alta produção para a sua manutenção. A participação dos coordenadores do laboratório que acolheu a pesquisadora foi fundamental para o sucesso da coleta de dados, pois contribuiu tanto nos contatos com as empresas dos empreendimentos quanto na orientação de como conduzir o processo.

Critérios de análise: a partir da coleta das informações, a pesquisa se preocupou em criar um banco de dados para o estudo de notas, documentos, tabelas, imagens e entrevistas, sempre realizando a interlocução com pesquisadores externos, na tentativa de atentar para outras interpretações diferentes do núcleo iluminado pelo pesquisador. Essa discussão com outros pesquisadores também teve a motivação de compreender de forma mais aprofundada o contexto do fenômeno, já que a pesquisadora é estrangeira e não está habituada à realidade local.

A análise dos dados partiu da categorização, da classificação e das combinações, tendo como meta os pressupostos da pesquisa, na busca de estabelecer conexões para a criação da teoria. A análise das generalizações dos casos não é estatística, mas analítica, a partir de combina- 
ções de princípios que podem ser de raciocínio dedutivo, indutivo ou abdutivo. No primeiro caso, os resultados correspondem às hipóteses propostas, verificando se são verdadeiras ou falsificando a teoria. No segundo caso, de raciocínio indutivo, são tiradas conclusões a partir de fatos verificados e, provavelmente, estas se apresentam de forma similar em outros casos. O terceiro raciocínio, abdutivo, é o enfrentamento de uma situação inesperada, com a aplicação de alguma regra (JOHANSSON, 2003). A presente pesquisa trabalha com o raciocínio indutivo, busca - levantamento das informações e verifica similaridades para a produção da teoria.

É sabido que um maior número de casos traria mais confiabilidade dos resultados; apesar disso, a pesquisadora preocupou-se constantemente em averiguar as situações com a literatura, em aconselhamentos com profissionais inseridos nos escritórios, na própria universidade e com os dados de outros casos que não fazem parte da publicação, mas que disponibilizaram as informações para a pesquisadora.

Para a definição da teoria, são necessários conceitos inter-relacionados para a explicação do fenômeno, resultantes 
de proposições observáveis; conexões lógicas; conclusões dessas proposições e conexões; relações com a realidade empírica, um conjunto de pressupostos subjacentes à teoria e a organização destes itens de forma a serem testados em princípio (WANG; GROAT, 2002).

Diante desses aspectos, o trabalho propõe o delineamento da pesquisa a seguir: 


\section{Revisão da Literatura}

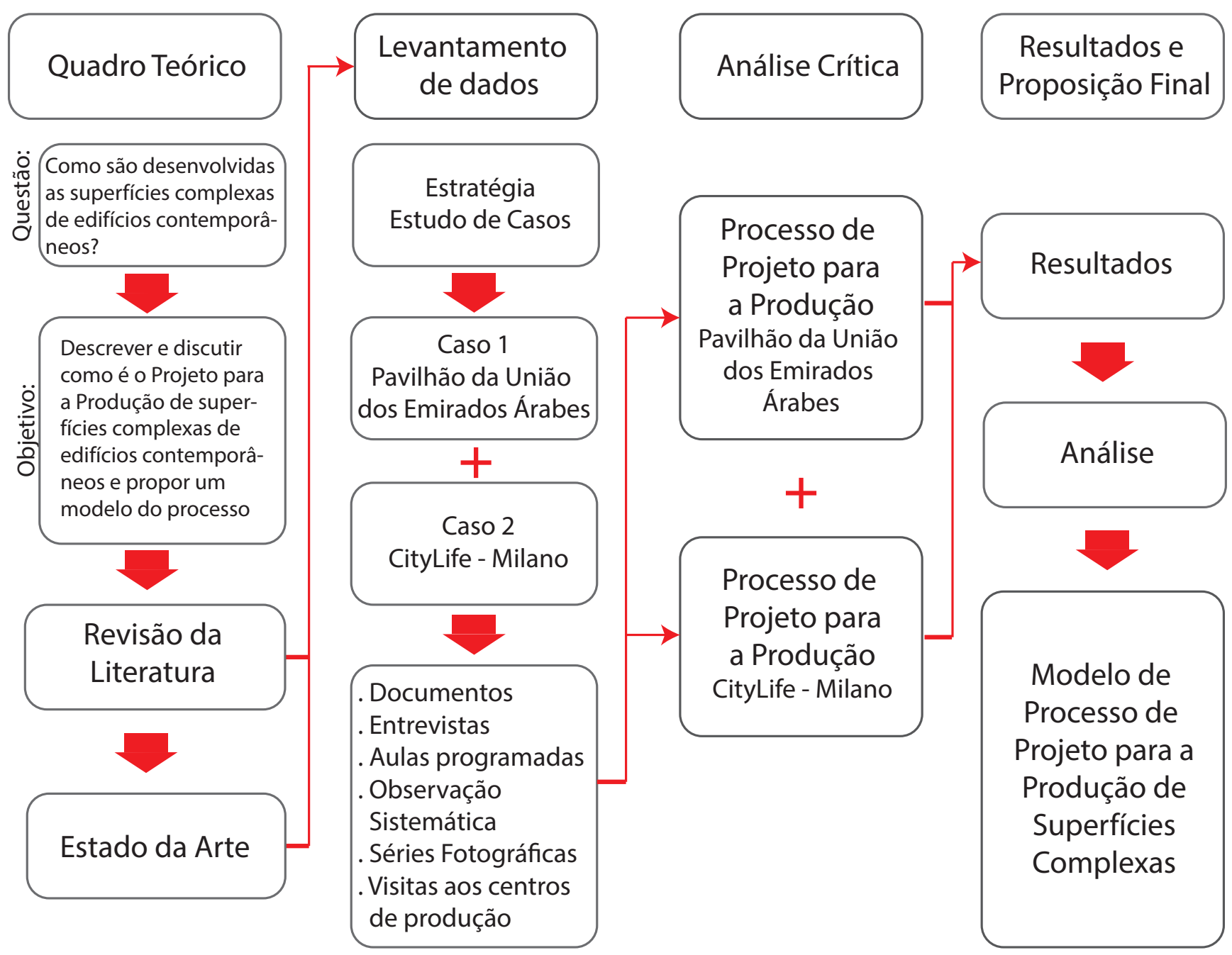


A revisão da literatura foi feita em todo o percurso da pesquisa, desde o início, com os questionamentos, até a sua finalização, na fase de escrita. A verificação e a formação do estado da arte foram o primeiro estágio para se esclarecer de forma um pouco mais ampla o problema, em que, era necessária a compreensão sobre quais são as possíveis variáveis que interferem no processo e quais os meios para a aproximação do fenômeno.

A estratégia a ser utilizada na pesquisa foi evidente desde os passos iniciais, pois se trata de um objeto contemporâneo e que deveria ser analisado no seu ambiente natural. A bibliografia sobre Projeto para a Produção de superfícies complexas não é extensa, mas situada em poucos exemplares da vasta literatura. Este tema faz parte da literatura sobre fabricação digital, mas aborda uma situação específica da produção real, e a literatura geralmente aborda experimentos em laboratórios de grandes universidades. A expectativa é trazer para o nosso conhecimento o modo de fazer uma tecnologia que é considerada de ponta e que já está estabelecida em edifícios de grandes centros econômicos.

A partir da obtenção dos dados, que foram diversos e va206 
riados, os pesquisadores se esforçaram com o intuito de compreender e descrever o processo a partir das informações coletadas por documentos administrativos, conversas com os atores, aulas, análises de outros processos etc. Partindo da análise dos conteúdos, foi possível verificar o processo de trabalho de ambos os casos, o que permitiu tirar algumas considerações e, finalmente, estruturar um Modelo de Projeto para a Produção de superfícies complexas, o que constitui o resultado deste processo de pesquisa.

No próximo capítulo, serão apresentados os estudos de caso da pesquisa, focando principalmente no Projeto para a Produção de superfícies complexas, mas apresentando também aspectos que envolvem a gestão, a produção e o projeto dos edifícios analisados. 
Figura 25: Conexão entre laje suporte e subestrutura do painel da torre CityLife. Foto: autor. Data: 2016. 
Figura 26: Renderização do paviIhão da União Emirados Árabes. Fonte: Foster \& Partners. Data: 2014. 


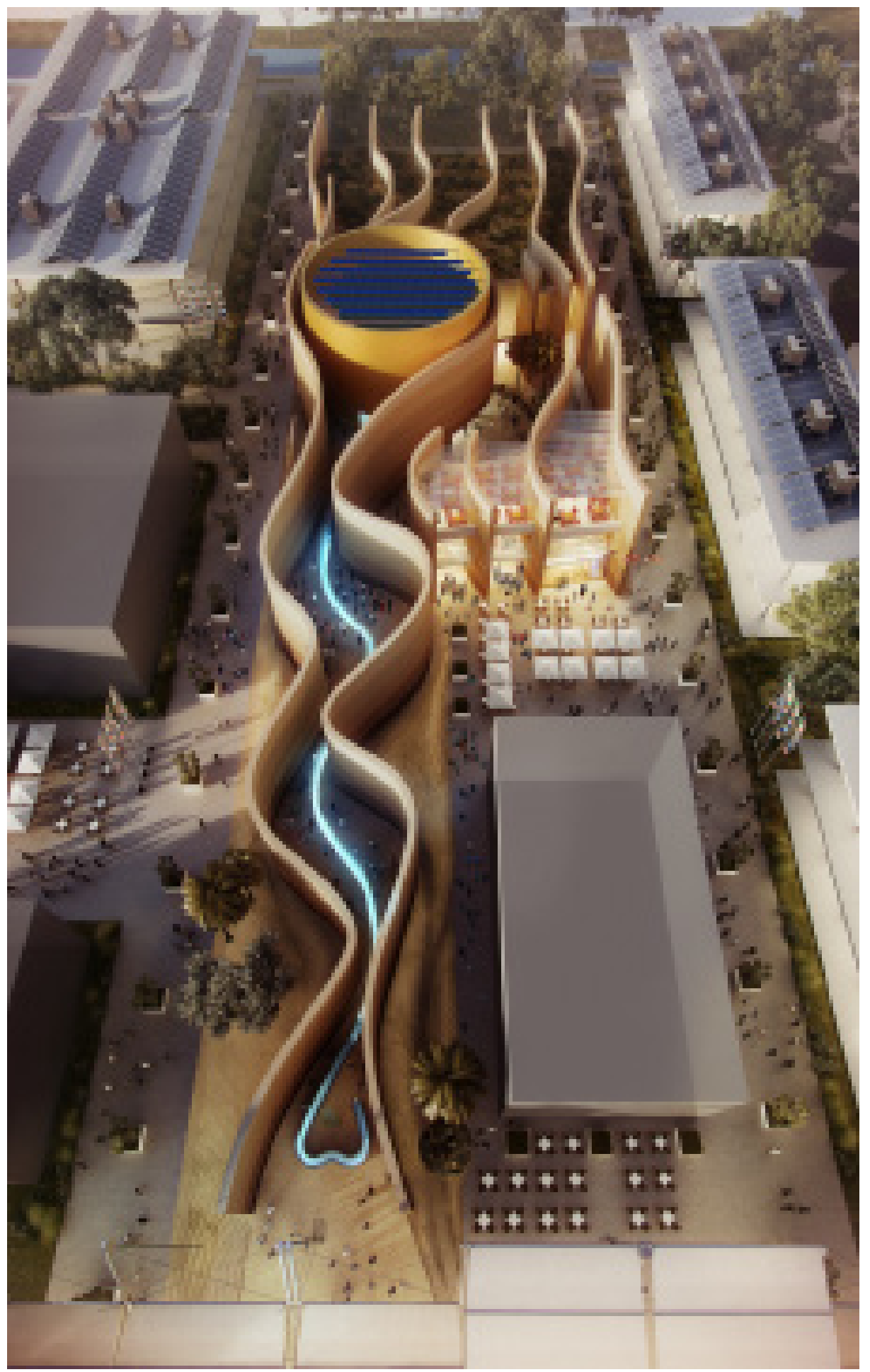

Pavilhão da União dos Emirados Árabes (UEA)

Expo Milão 2015 

A intenção desta etapa é apresentar e discutir o Pavilhão da União dos Emirados Árabes, focando especialmente nos painéis de vedação em argamassa armada com fibra de vidro (GRC - Glassfiber Reinforced Concrete), que foram construídos para a Exposição Universal de Milão, em 2015.

A União dos Emirados Árabes está situada no Oriente Médio e é composta por sete emirados: Abu Dhabi, Ajman, Dubai, Fujairah, Ra's al-Khaimah, Sharjah e Umm al-Quawain. O clima é árido tropical desértico, com temperatura média de $26,8^{\circ} \mathrm{C}$, variando de 12 a 40 graus. A base de sua economia é a produção e exportação de petróleo.

As exposições mundiais, como a Expo Milão 2015, são eventos históricos que ocorrem em diversas cidades do globo. Tiveram início no século 19 e o principal objetivo é mostrar o potencial tecnológico-científico e de desenvolvimento do país, associado à condição de industrialização que, desde o século 19, vinha em franco crescimento e desenvolvimento.

A primeira exposição ocorreu em 1851, em Londres, e 
teve como uma de suas estrelas a construção do Palácio de Cristal, de John Paxton, um edifício pré-fabricado em ferro fundido e vidro projetado com peças organizadas para ser montado e completamente remontável. Possuía 563 metros de comprimento, 124 metros de largura por 33 metros de altura. Este pavilhão demonstra domínio da elaboração, confecção e também do comportamento dos materiais utilizados.

Desde que ocorreram as primeiras exposições, já se somam mais de 50 acontecimentos em diversos países, como Estados Unidos (1876, 1884, 1893, 1901, 1904, 1907, 1909 etc.), Japão (1970, 1975, 1985, 2005), Brasil (1922), França (1855, 1878, 1889, 1900, 1937 etc.), Itália (1906, 1911, 1992 e 2015), dentre vários outros locais.

A Exposição Internacional de Milão de 2015 tinha como objetivo disseminar a cultura e os costumes dos diferentes países participantes. Teve como tema central:

Alimentar o Planeta, Energia para a Vida, em termos de conteúdo e abordagem, maximizando, assim, a participação na Exposição como uma oportunidade para mostrar os seus pontos de excelência (TEG TEMA WORKING GROUP, 2015).

A partir dessa iniciativa, várias discussões foram realizadas 
com os países participantes para travar um esforço mútuo com a intenção de diminuir a quantidade de malnutridos no globo terrestre.

A feira localiza-se na área metropolitana de Milão - Itália, a noroeste da cidade, e está ligada ao eixo rodoviário, ao Aeroporto Internacional de Milão, à linha de trem e de metrô. Fica a aproximadamente $18 \mathrm{~km}$ da Catedral de Duomo e da Galeria Vittorio Emanuelle, principais símbolos da cidade. 
A área da feira foi desenhada a partir de dois eixos ortogonais, denominados Cardo e Decumano. No eixo maior, Decumano, com aproximadamente 1,5 Km, estão os paviIhões dos países participantes, e no eixo Cardo, de aproximadamente 400 m, estão os representantes italianos, com alimentos e bebidas das cozinhas regionais.

O pavilhão da União dos Emirados Árabes tem um dos maiores lotes, com $4.386 \mathrm{~m}^{2}$, e, como mostra o desenho ao lado (Figura 27), está em um local privilegiado, no centro do eixo Decumano. Como não poderia deixar de ser, o tema foi a discussão dos problemas relacionados à nutrição em locais com climas quentes e quais alternativas para a sua solução.

A construção ocupa praticamente todo o lote, deixando somente áreas para o paisagismo, com pequenas dunas de areia, plantas e rochas do deserto. A entrada principal do pavilhão está voltada para a via central e, ao entrar no edifício, os visitantes se deparam com as paredes curvas, que têm a mesma textura da areia (Figura 28).
Figura 27: Planta da Expo Milano_2015. Fonte: TEG Tema working Group. Data: 2015. 


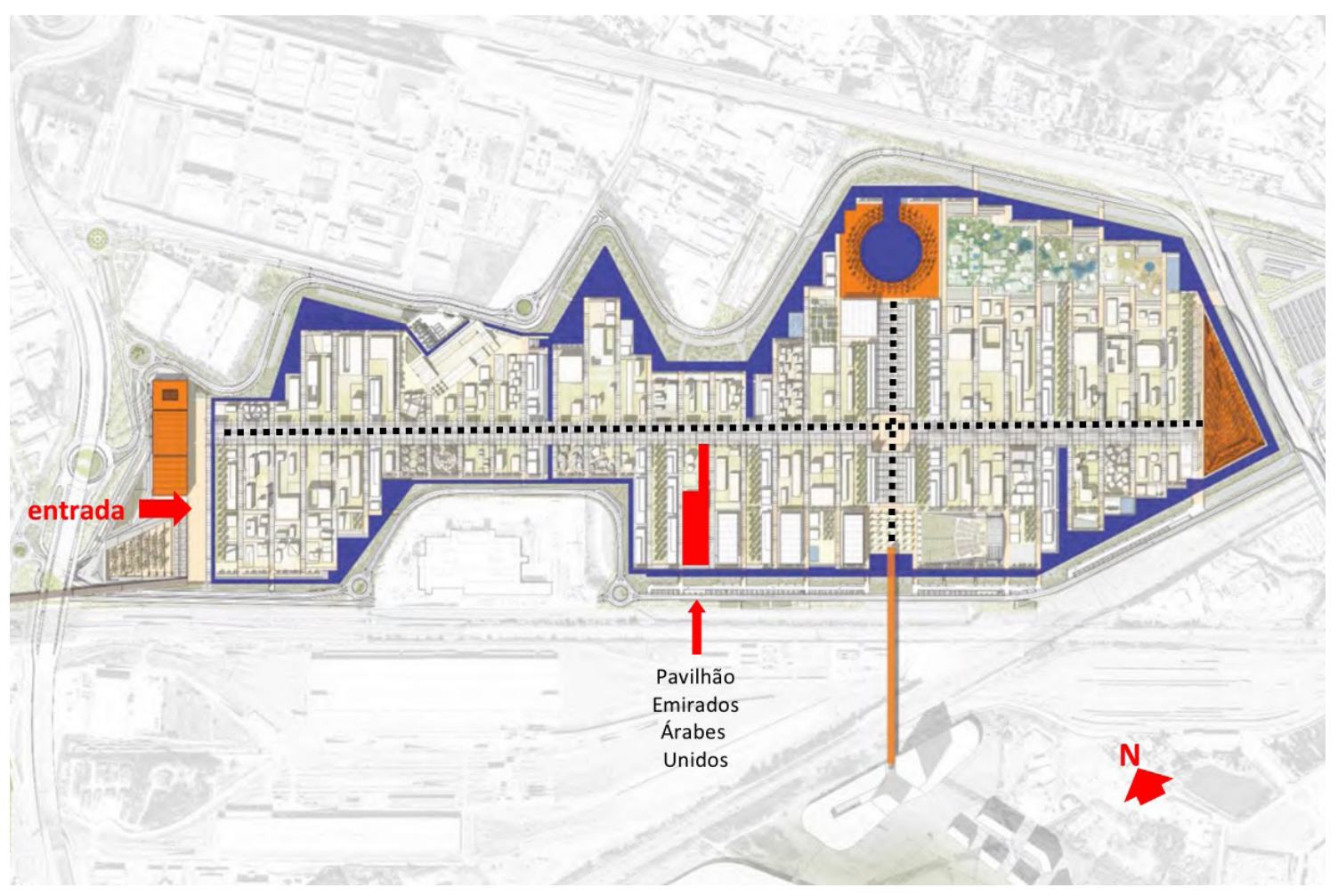


Durante a visitação, os participantes percorrem uma rampa que sugere a experiência de enclausuramento. $\bigcirc$ visitante só consegue ver o céu, tendo a sensação de estar no deserto entre as dunas. As paredes com 12 metros de altura foram inspiradas na arquitetura da cidade de Masdar, que utiliza a estratégia para criar áreas sombreadas e, assim, diminuir a temperatura do ambiente.

A experiência da visita oferece vários instrumentos digitais, realidade virtual, atividades informativas, interativas e de entretenimento, as propostas para a Exposição Internacional, que ocorrerá em Dubai no ano de 2020, além de degustação de comidas típicas dos Emirados e eventos com performances para os espectadores.
Figura 28: Entrada Principal do pavilhão. Foto: Nigel Young + Foster \& Partners, Data: 2016. 


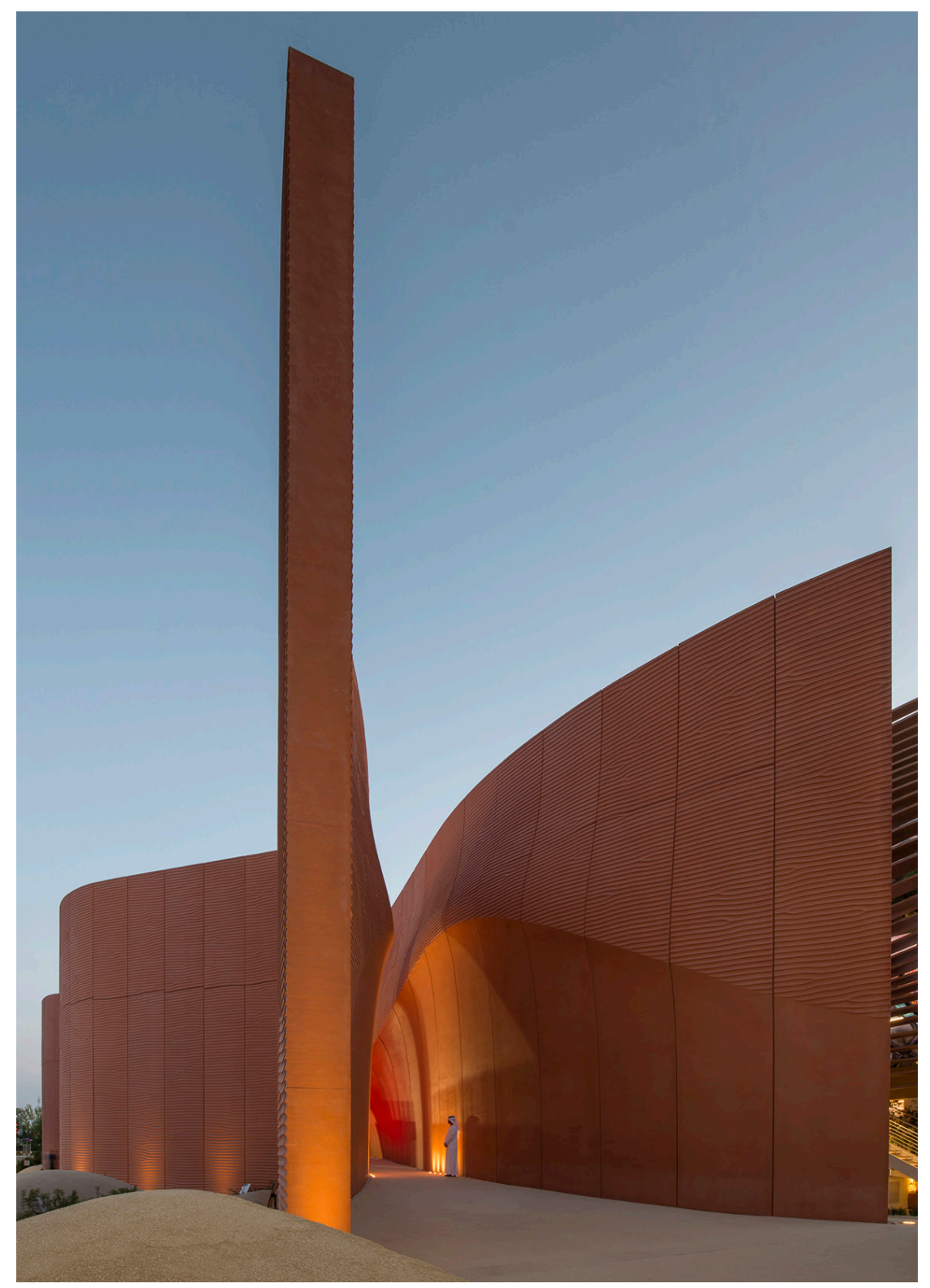




\section{Conceito}

O projeto foi desenvolvido pelo escritório Foster \& Partners e tem como conceito as paisagens do deserto, com as ondulações da areia (Figura 29/30), que foram utilizadas em planta e nos painéis. Diversas imagens foram captadas da paisagem para se chegar a um desenho que fosse semelhante ao cenário do país.

O edifício não tem um caráter temporário graças à tecnologia utilizada nos painéis com a estrutura metálica. $\bigcirc$ pavilhão foi projetado para ser montado para a feira em Milão, desmontado após o seu encerramento e remontado com algumas adaptações na área externa na cidade de Abu Dhabi, onde funcionará como um centro cultural de mídias.

Figura 29: Imagem das dunas do deserto referência conceitual para o projeto da União dos Emirados Árabes. Fonte: Foster \& Partners. Data: 2016.

Figura 30: Entrada do pavilhão com painéis altos e curvos que dão a impressão de estar no meio do deserto. Foto: Nigel Young + Foster \& Partners. Data: 2016. 

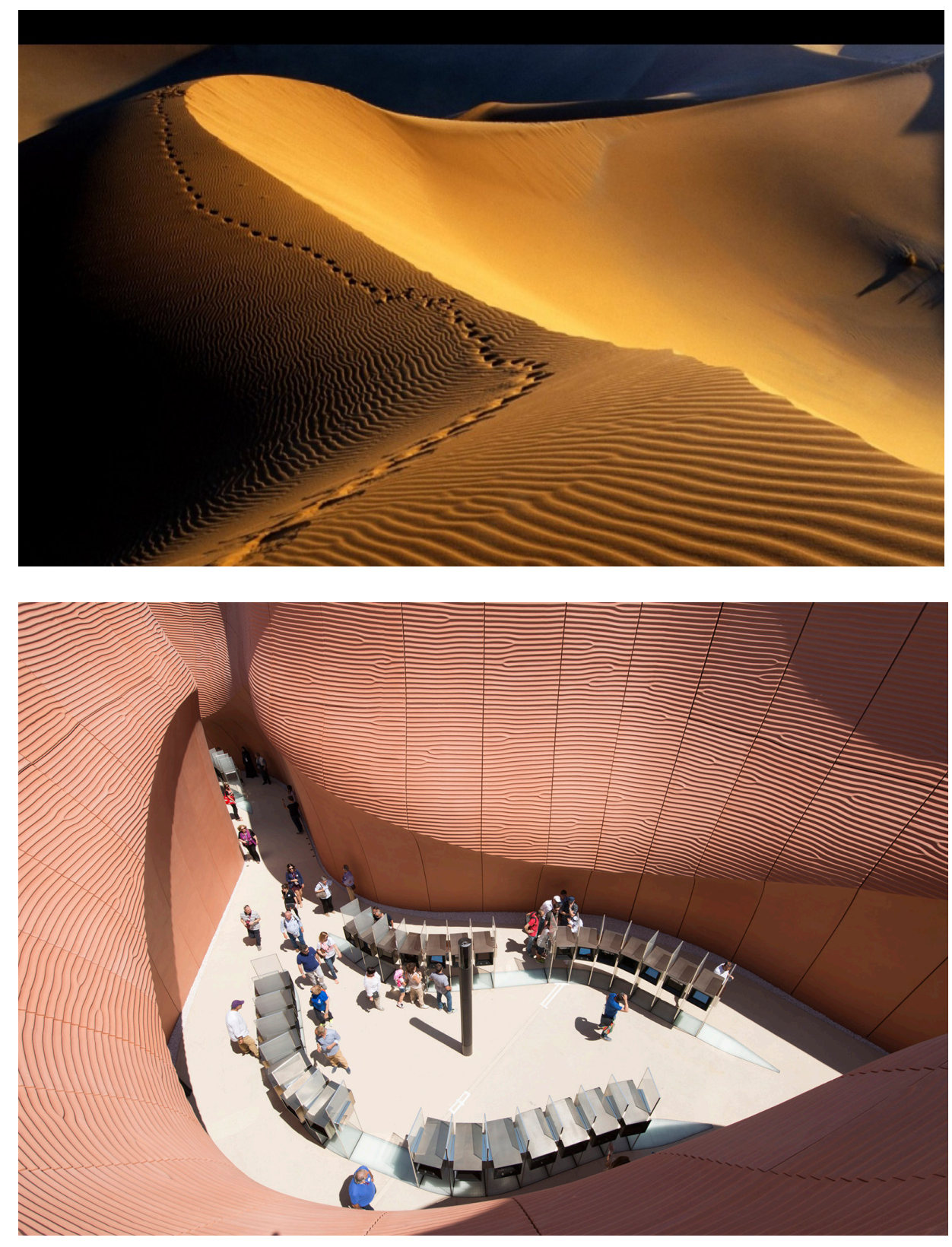


\section{Desenvolvimento}

Aqui serão colocadas questões de gestão, dados, organização, desenvolvimento do projeto etc. Para a execução do edifício, foram produzidos 1.148 desenhos. $O$ custo total do empreendimento foi de $60 \mathrm{Mi}$ de euros, enquanto o custo da construção foi de $18,5 \mathrm{Mi}$ de euros, o que significa 3.700,00 euros por $\mathrm{m}^{2}$. Os 930 painéis produzidos em Hong Kong demandaram 18 cargas para a Itália, com um planejamento complexo, de carregamento, transporte em água, terra e cronograma de montagem no edifício em 3 meses.

A qualificação das empresas para os trabalhos de detaIhamento, gestão, estruturas, instalações, montagem, segurança etc. foi aprovada a partir de um extenso questionário dividido em: 1. Informações básicas; 2. Qualificação da empresa; 3. Informações financeiras, volume de negócios, previsão de volume de negócios, contas auditadas, estrutura de grupo, número de certificados; 4. Estrutura e recursos da empresa para o projeto: número de funcionários, detalhes de pessoal, quantidades e qualificações de gerentes, organograma; 5 . Antecedentes em trabalhos 
semelhantes e 6. Referências de clientes.

A escolha das empresas está ligada às capacidades, competências, qualificações de trabalho em disciplinas específicas, experiências, outras obras em edifícios similares, tecnologia utilizada e também à confiança e ao relacionamento. O projeto do pavilhão foi contratado pelo ConseIho de Comunicação Social da União dos Emirados Árabes (National Media Council), que selecionou uma equipe específica para acompanhar o projeto. A empresa responsável pelo projeto de arquitetura elaborou o conceito central. O organograma a seguir mostra como cada empresa está situada para o desenvolvimento do trabalho. 


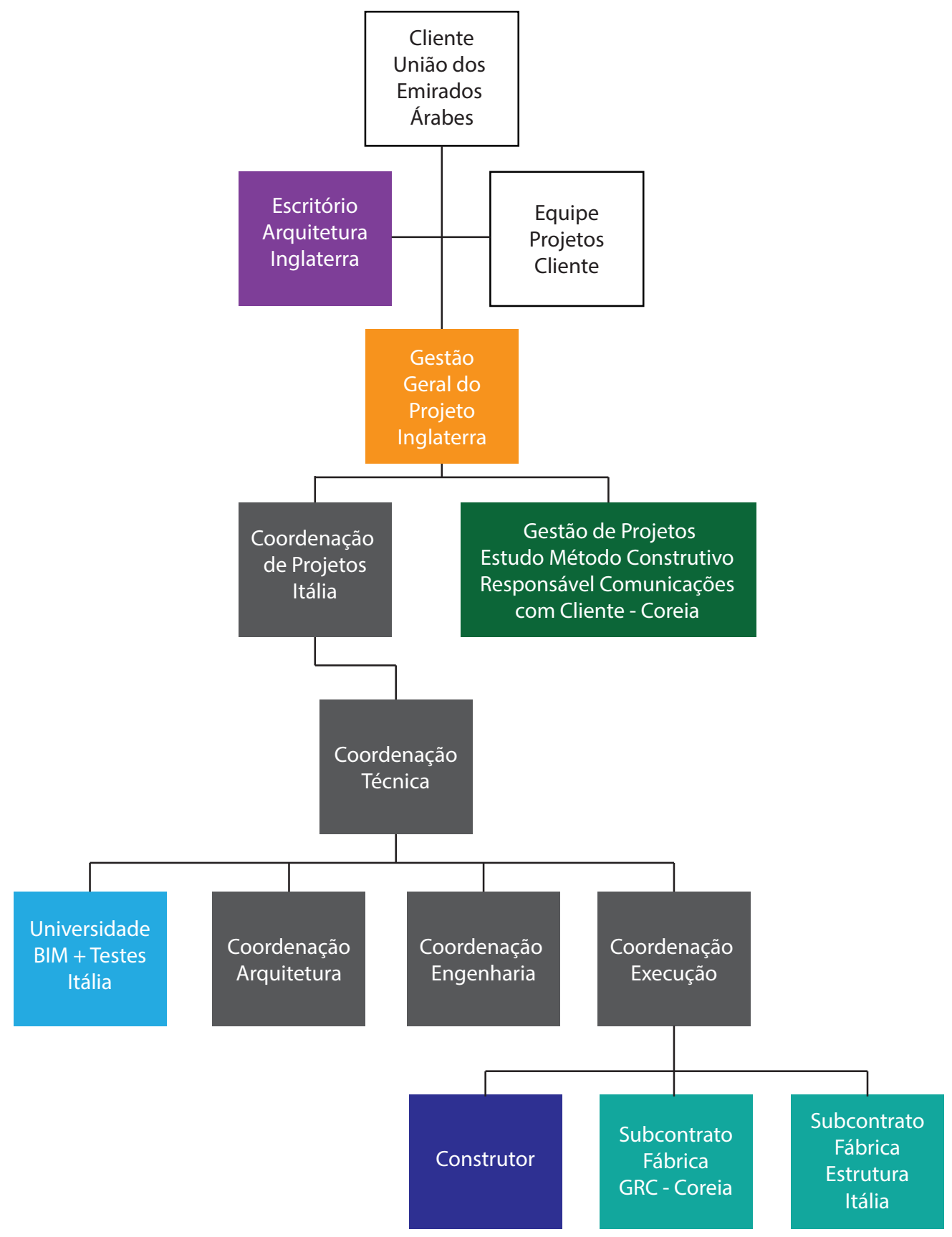

Diagrama 6: Organograma da organização do trabalho no projeto da União dos Emirados Árabes. Fonte: Rimond. Data: 2015. 
A partir disso, a equipe foi composta por 6 grupos:

- Gestão Geral do Projeto

Empresa inglesa Fraser and Randal, há mais de 25 anos no mercado, possui clientes na Europa, no Oriente Médio e nos Estados Unidos. Tem experiência na gestão de projetos, gestão de construções, busca de fornecedores, gestão de custos, supervisão, avaliação e levantamentos de qualidade, nas organizações de equipes, na revisão e aprovação de projetos, certificação, no acompanhamento de prazos e serviços. Nesse projeto, está diretamente conectada ao empreendedor e ao escritório de coordenação de projetos; realizou a gestão geral de todos os processos, parceiros, comunicação, seleção, controle do desenvolvimento e dos custos.

- Coordenação de Projetos

Foi realizada por duas empresas, uma coreana e outra italiana. A primeira, A \& A Company, atua desde 2000, oferece soluções e execuções de métodos de marketing, na área de informação e comunicação. Elaboração, desenvolvimento e aplicações de marcas; produção, execução e entrada de bens de mercado. No projeto do pavilhão, foi 
responsável pelo gerenciamento dos projetos, pela consultoria de métodos construtivos, pela logística e preparação de relatórios de processo.

A segunda, Empresa Rimond, realiza consultorias, gerenciamento de projetos e gestão de obras. Especializada em engenharia, aquisição e desenvolvimento de infraestrutura. No pavilhão, executou a compatibilização dos projetos, adequação de eficiência energética, as licenças, o estudo de métodos construtivos, a segurança, hidráulica, iluminação, ventilação e acessibilidade. São responsáveis pela gerência técnica, pelo planejamento e pela supervisão do canteiro de obras.

A universidade Politécnica de Milão é parceira no projeto e, com o escritório, faz a detecção de conflitos das disciplinas de arquitetura e engenharia no sistema de informações BIM e usa os laboratórios para testes e simulações.

\section{- Construtor}

A Tecton é italiana, trabalha com igrejas, escolas, edifícios públicos e privados, residências, comércio, interiores, restauração, arqueologia, edifícios históricos e monumentos. Neste projeto, são os construtores principais, na execução 
das fundações, lajes, instalações, gestão ambiental, logística, qualidade de segurança e saúde e na coordenação do controle da documentação. Fazem a supervisão dos projetos, a gestão de projetos, de custos, da arquitetura, da engenharia, das produções dos subcontratados e da solução de problemas urbanos.

Como construtores, também trabalharam a empresa encarregada pela estrutura de aço e a empresa dos painéis de vedação.

1. Fábrica de Estrutura Metálica: a Stahbau Picler é italiana e atua no mercado desde 1970, com especialização na concepção, fabricação e construção de estruturas de aço e sistemas Curtain Walls.

2. Fábrica de GRC: Canbuild, de Hong Kong, atua desde 1992, especializada em gestão e engenharia civil, tem experiência na fabricação de componentes pré-moldados. Neste projeto, fabricaram todos os painéis de GRC, subestrutura, montagem e desmontagem.

Existem 3 grupos principais: No $1^{\circ}$ Grupo, em branco, lilás e laranja, estão os principais coordenadores, incluindo o cliente, o escritório de arquitetura e os gerentes prin- 
cipais; no $2^{\circ}$ Grupo, em cinza, está o gestor de projetos de arquitetura e engenharia, incluindo a participação da universidade, e no $3^{\circ}$ Grupo, em verde e azul claro, são os gerentes de canteiro e gerentes de manufatura.

Para o desenvolvimento foram realizadas reuniões de acordo com a necessidade e o andamento do projeto, com o objetivo de realizar as compatibilizações entre os vários sistemas e encontrar as melhores soluções para os problemas. Os sistemas de informação BIM, internet e sistema de nuvem de dados são fundamentais para a gestão e troca de informações com todos os participantes, o que não seria possível com empresas em diferentes locais no globo.

Para a aprovação, os desenhos são desenvolvidos no escritório de arquitetura e detalhados pelo setor de coordenação de projetos, ao mesmo tempo que os sistemas e métodos construtivos. Quando finalizados, são encaminhados para o gestor e para o escritório de arquitetura, que analisa e faz as revisões de acordo com as observações. A partir disso, os desenhos são encaminhados para a manufatura ou para o canteiro ou, se reprovados, retornam à equipe de projeto, que trabalhará na busca de no- 


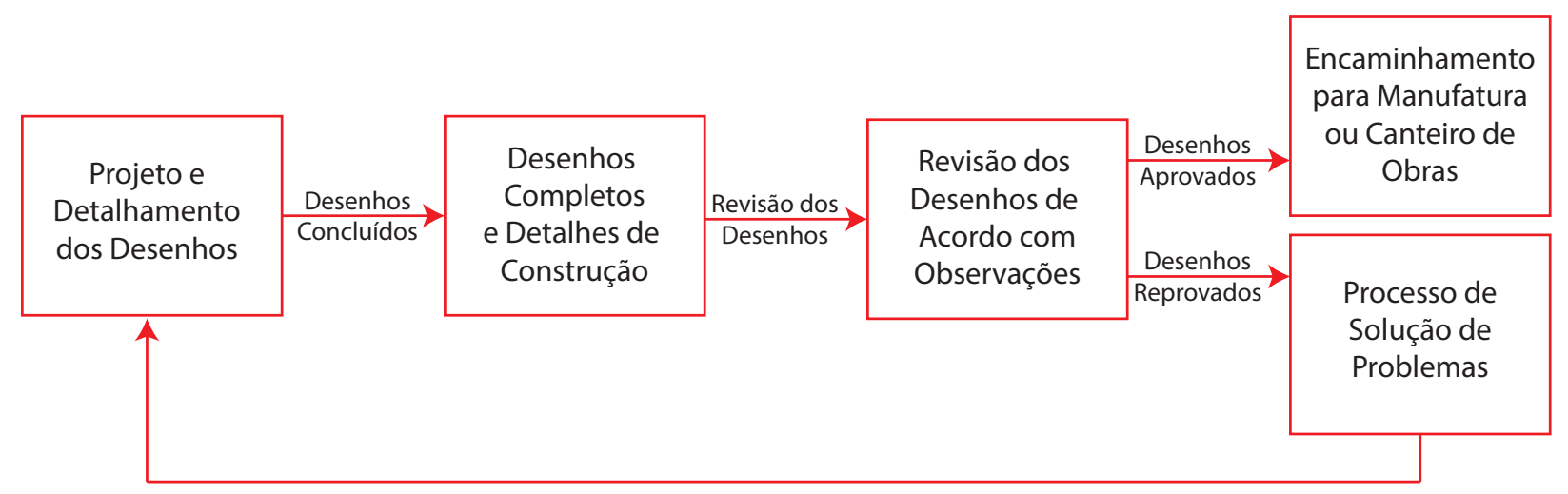

Diagrama 7: Fluxo de aprovação de projetos. Fonte: autor, baseado nos documentos pesquisados. Data: 2016.

vas soluções.

Os autores do projeto de arquitetura Foster \& Partners criaram o conceito geral, mas o desenvolvimento e o detalhamento do sistema construtivo são realizados pela rede de colaboradores. Por exemplo, as relações entre estrutura principal, subestrutura e painel são projetos desenvolvidos por outros atores do processo, que pensam sobre como será a estrutura, seus apoios, fixações, além da verificação de cargas, ventos, impermeabilizações etc. 
O escritório autor do projeto e o gestor principal verificam e aprovam todos os desenhos, soluções, protótipos etc., mas não faz parte das suas atribuições desenvolver e detalhar os projetos para a produção.

As normas e os procedimentos de comunicação, de desenvolvimentos dos projetos, as funções e os deveres de cada participante foram definidos nos primeiros encontros. Toda documentação estava disponível na nuvem de dados, que poderia ser acessada pelo pessoal autorizado. Todo o trabalho era relatado mensalmente para o cliente e para os líderes do projeto.

A organização do trabalho envolve diversas empresas, habilidades e trabalhadores com uma forte hierarquia, que demandam uma gestão minuciosa do empreendimento, que é complexo e de uma escala considerável. Os pontos-chave para que o projeto se desenvolva são a escolha de parceiros responsáveis e comprometidos com o trabalho, assim como a coordenação de projetos, que está na articulação de todo o processo e utiliza para isso os sistemas de modelagem BIM.

A utilização do sistema BIM no processo foi fundamental 
para coordenar os projetos e garantir a integração contínua no modelo, que assegurou a gestão individual de cada disciplina. Para o escritório que realizou a gestão, o BIM é um banco de dados compartilhado de sistemas que permite a monitorização contínua dos vários participantes. Admite a visualização de estimativas e filtros ativos de acordo com a necessidade, além de realizar a gestão cruzada e integrada e proporcionar um controle operacional rígido, que garante o cumprimento do cronograma e dos custos, graças aos modelos digitais.

As atividades de projeto seguiam a seguinte sequência:

1. Detalhamento de projeto, com as devidas especificidades de cada sistema;

2. Inserção no sistema BIM, para a compatibilização das disciplinas e o solucionamento de problemas;

3. Construção dos elementos ou componentes do edifício;

4. Fabricação e execução sistematizada de acordo com os projetos para a produção,

5. Planejamento minucioso do cronograma físico financeiro. 
O diagrama ao lado demonstra o processo de desenvolvimento dos projetos de acordo com o tempo, a aprovação e o encaminhamento e mostra os sistemas inseridos na plataforma BIM. Para um projeto que levou 263 dias para o seu desenvolvimento, o trabalho não seria possível sem a utilização do BIM na gestão.

A etapa branca representa a fase de desenvolvimento e detalhamento do projeto; em amarelo, está a fase de revisão da coordenação dos projetos; na etapa em azul, há a revisão com novas soluções de problemas e, finalmente, a fase de aprovação final dos projetos, que estão todos inseridos na plataforma BIM para serem analisados, verificados e enfim encaminhados para fabricação ou montagem.

As diversas atividades são elaboradas de forma simultânea ao projeto inicial. A partir da definição de cada área, esse projeto é colocado no sistema de modelagem 3D e, subsequentemente, os outros sistemas são inseridos. A aprovação e as alterações são realizadas ao mesmo tempo e, ao final, é possível verificar o cruzamento entre os vários sistemas e visualizar problemas entre eles. 


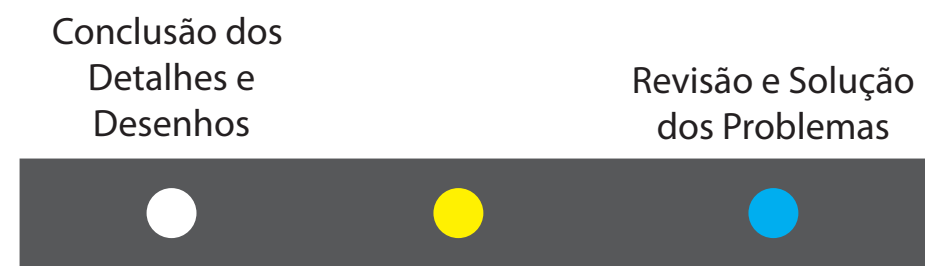

Submissão

para

Revisão

Aprovação dos

Detalhes e

Desenhos

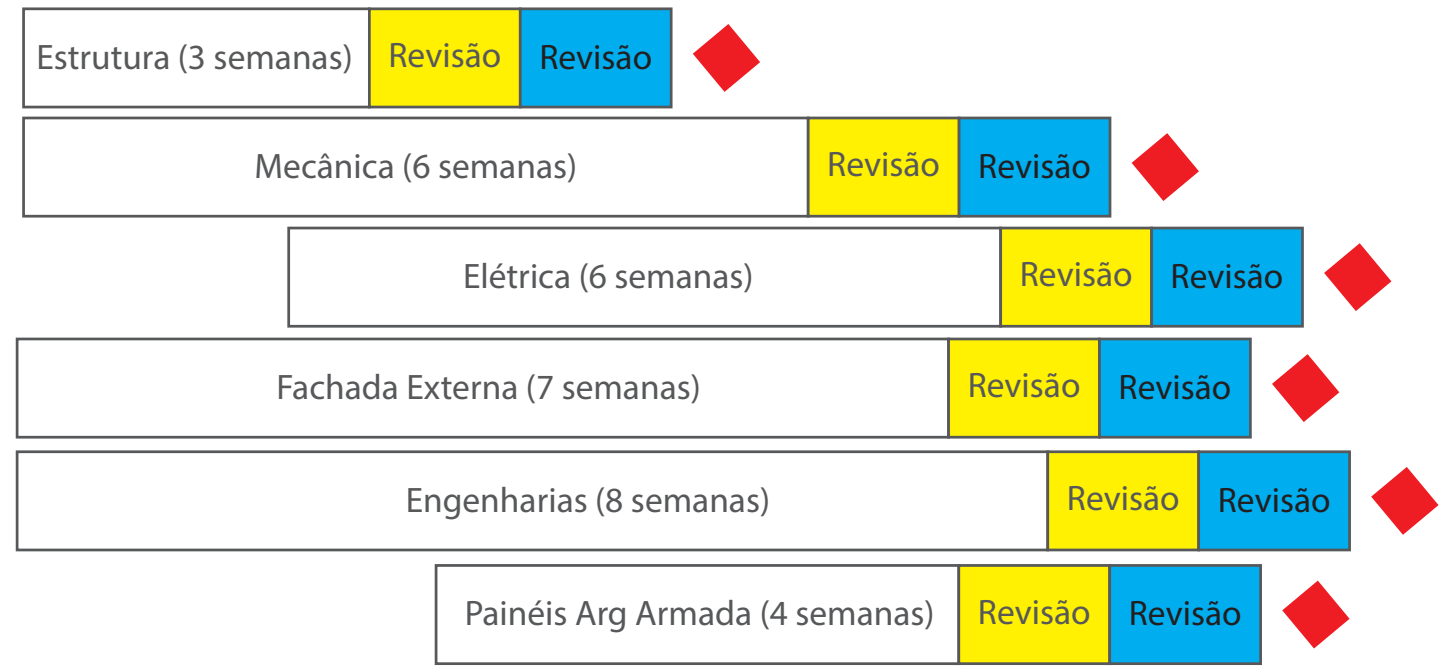

\section{Sistema BIM de Modelagem}

Diagrama 8: Distribuição dos trabalhos inseridos no sistema BIM. Fonte: Rimond. Data: 2015. 
De acordo com o diagrama, verifica-se que os trabalhos de compatibilização se somam a partir do meio do processo, quando os diversos projetos estão disponíveis para serem inseridos no programa. Os trabalhos se tornam ainda mais intensos a partir disso, visto que as demandas do ir e vir dos desenhos são constantes, acarretando maior quantidade de trabalho.

A compatibilização tem acontecido aos poucos nos diferentes países, mesmo que seus benefícios sejam incontestáveis. Apesar de alguns países colocarem a questão como compulsória, o que se vê é que o escritório responsável em gerir os projetos fica com o encargo de inserir os dados e acaba modelando os sistemas que não são desenvolvidos em BIM. Isso certamente ocasiona uma demanda intensa de trabalho, pois as atividades são executadas por apenas um profissional, que tem conhecimento das diversas disciplinas para fazer tal compatibilização.

A construção do pavilhão foi coordenada por uma gestão orientada pelas informações. De acordo com o coordenador dos projetos, a utilização do BIM possibilitou a otimização dos detalhes do projeto, a elaboração e execução complexa em relação aos prazos e fornecedores e resultou 
em $0 \%$ de erro na logística e montagem. As instalações do sistema audiovisual foram feitas nos ambientes, livres de poeiras e em tempo previsto. Os painéis de GRC foram instalados de acordo com o planejamento.

[...] o sistema BIM é uma fonte de informação para o cliente e para a equipe que acompanha o projeto, execução e montagem. Os investimentos de trabalho nas fases de projeto são intensos, no entanto o processo de construção é facilitado e influencia diretamente nos custos e na qualidade do empreendimento (CHIARANDÁ, 2016)1.

O sistema BIM proporciona uma estimativa precisa das quantidades de materiais, através do programa que tem todos os elementos utilizados na sua modelagem. Detecta antecipadamente problemas de projeto e torna possível a verificação de atividades que estejam fora das normas regulamentares. Através da modelagem do edifício nas plataformas, é possível verificar incompatibilidades de forma visual, como demonstrado (Figura 31/32/33) a seguir, a partir das imagens 3D; consequentemente, a comunicação é facilitada, melhorando o trabalho em relação aos atrasos e a execução de trabalhos adicionais. O entendimento do problema é imediato, se considerada a ativi-

1 Entrevista do engenheiro Giuseppe Chiarandá ao autor em 01/ jun/2016. 


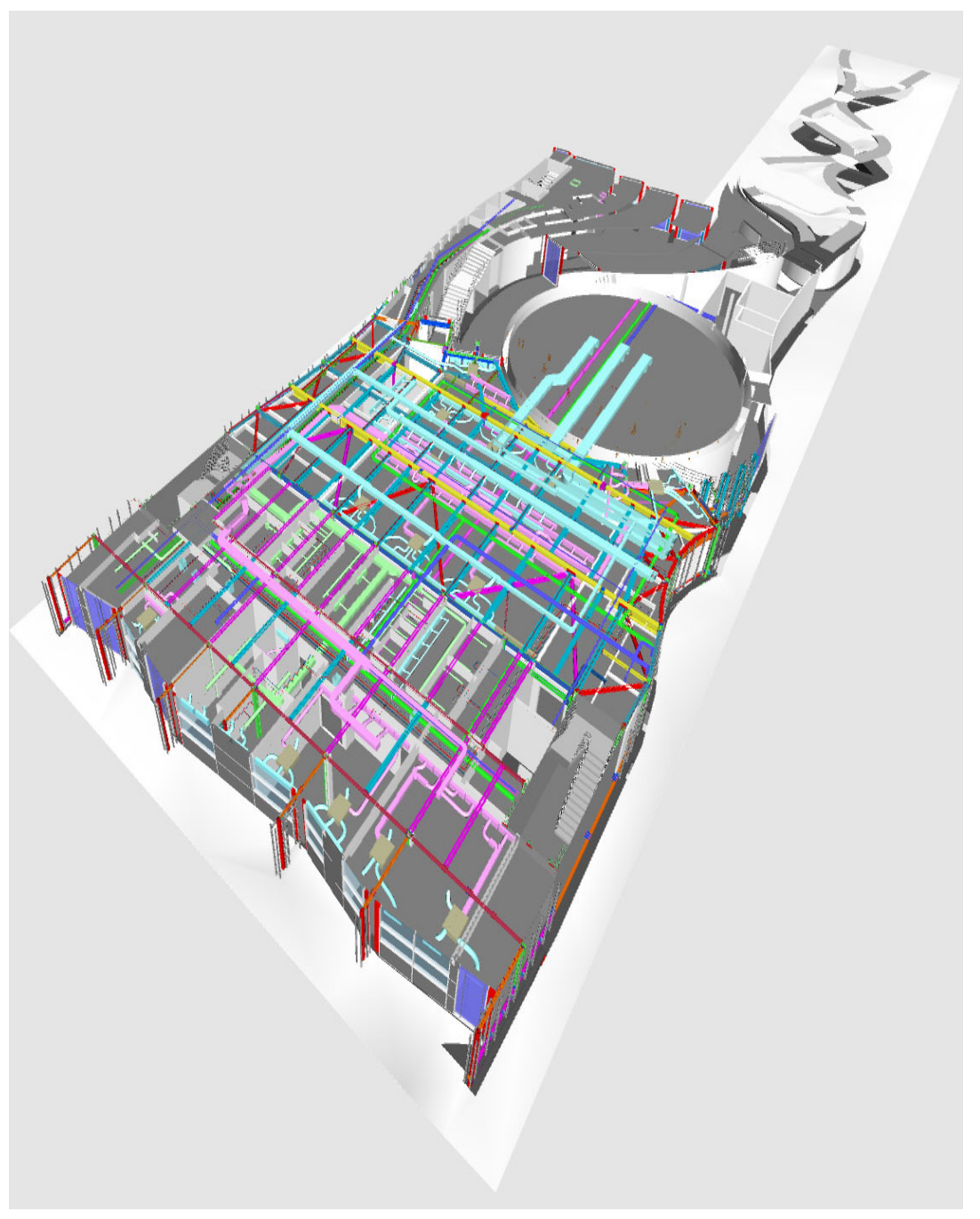

Figura 31: Projeto de Compatibilização dos diversos sistemas realizado na plataforma BIM.

Fonte: Rimond. Data: 2015. 


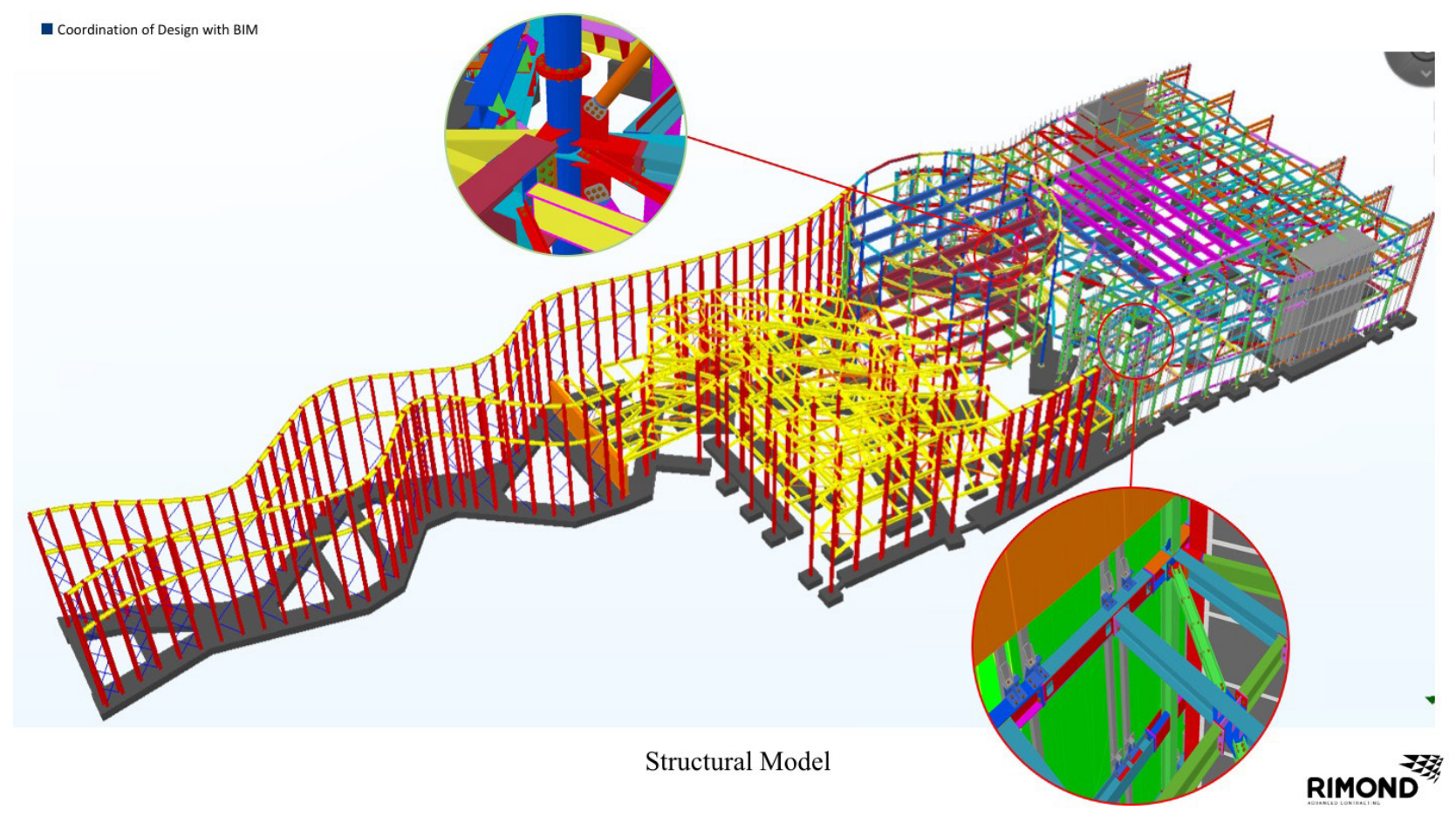

Figura 32: Imagem ilustrativa do equívoco entre estrutura principal e porta do edifício. Fonte: Rimond. Data: 2015.

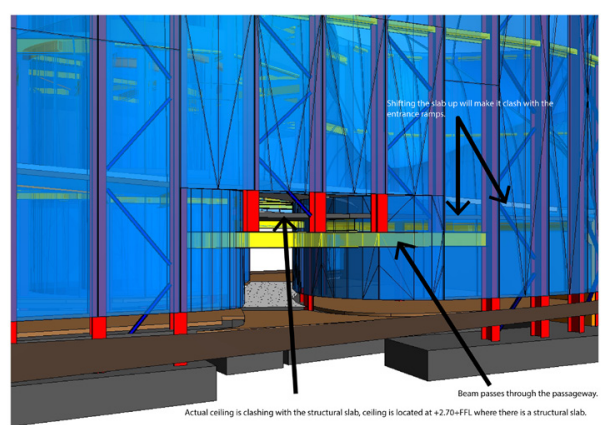

Figura 33: Exemplo de incompatibilidade de área de entrada e estrutura do edifício. Fonte: Rimond. Data: 2015. 
dade de várias pessoas com culturas e línguas diferentes (CHIARANDÁ, 2016).

Os painéis pré-fabricados foram elaborados desde o início, utilizando o sistema BIM, o que permite otimizar o desenho através da redução dos tipos e fornece as instruções precisas para a produção das placas e das subestruturas, além de controlar os sistemas de ajustes necessários para a instalação dos grandes elementos, mantendo as folgas de $5 \mathrm{~mm}$.

Diante dos inúmeros benefícios da incorporação dos sistemas BIM no processo de projeto, apesar dos investimentos necessários para a sua modelagem em todas as disciplinas, é evidente a sua contribuição para a coordenação, gestão e também nos resultados, que indicam uma economia no todo, já que ocasiões inesperadas são cada vez menos frequentes no canteiro de obras.

Os técnicos referem um aumento da colaboração entre os parceiros; minimização dos conflitos; atrasos; retrabalhos; desperdício de material; redução financeira e dos riscos de trabalho; maior eficiência; produtividade de campo e gestão de qualidade, documentação digital para remon- 
tagem e manutenção de instalações por todo ciclo de vida do edifício.

O projeto e a construção do pavilhão são um empreendimento de médio porte, com uma complexidade principalmente relacionada à elaboração, manufatura e construção dos painéis de argamassa armada, que possuem uma projeção em sua estrutura na rampa de entrada. $\bigcirc$ trabalho empregado é intenso, com uma gestão geral rígida e com diversas disciplinas envolvidas. Utilizaram-se sistemas digitalizados que foram fundamentais para a sua conclusão e sucesso, tanto no processo de desenvolvimento quanto na manufatura e na gestão. 


\section{Organização do Espaço - Plantas}

O pavilhão possui $5.085 \mathrm{~m}^{2}$, distribuídos em 3 níveis e 4 blocos (Figura 34). Em amarelo, está a entrada, que conduz o visitante através de um canyon para o auditório; o bloco B, em laranja, é o teatro onde ocorre o espetáculo principal, com cinema $360^{\circ}$, e nesse local é contada uma história sobre a sustentabilidade do país; no bloco A, em azul, estão os escritórios, sala de funcionários e o pós-show, um segundo teatro com tecnologia de projeção $3 D$, e, no bloco $C$, em verde, estão as instalações e o restaurante. 


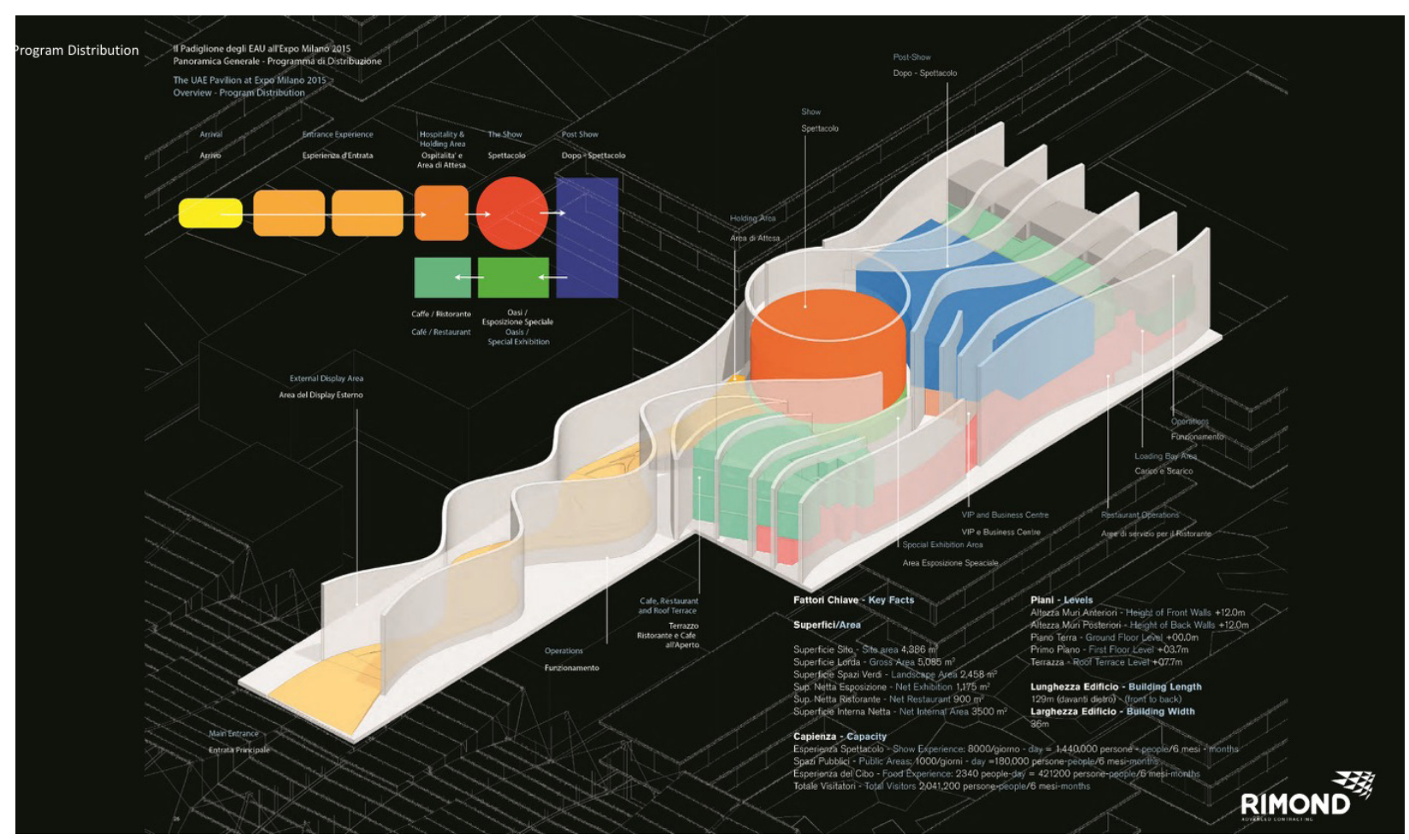

Entrada_canyon - Rampa

Bloco B_ Anfiteatro Principal

Bloco A _ Escritórios e Salas Funcionários, Pós-Show

Bloco C _ Oásis, Instalações e Restaurantes 


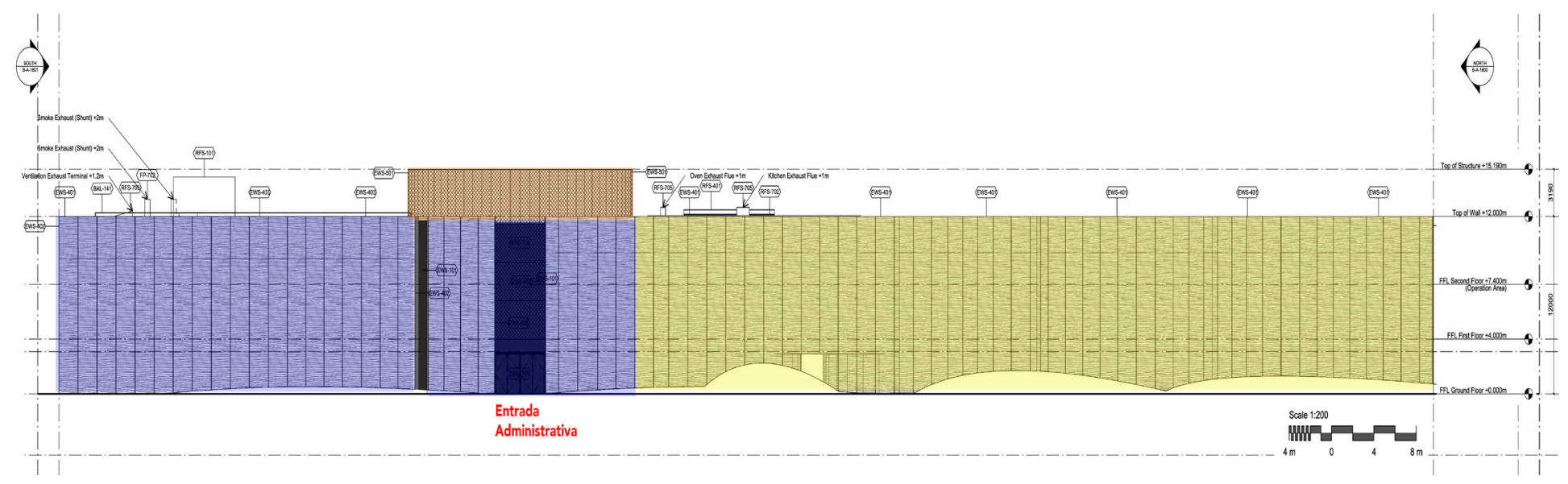

Entrada_canyon - Rampa

Bloco A _ Escritórios e Salas Funcionários, Pós-Show.

Bloco B_ Anfiteatro Principal

Figura 35: Vista Leste do Pavilhão da União dos Emirados Árabes.

Fonte: Rimond. Data: 2015. 


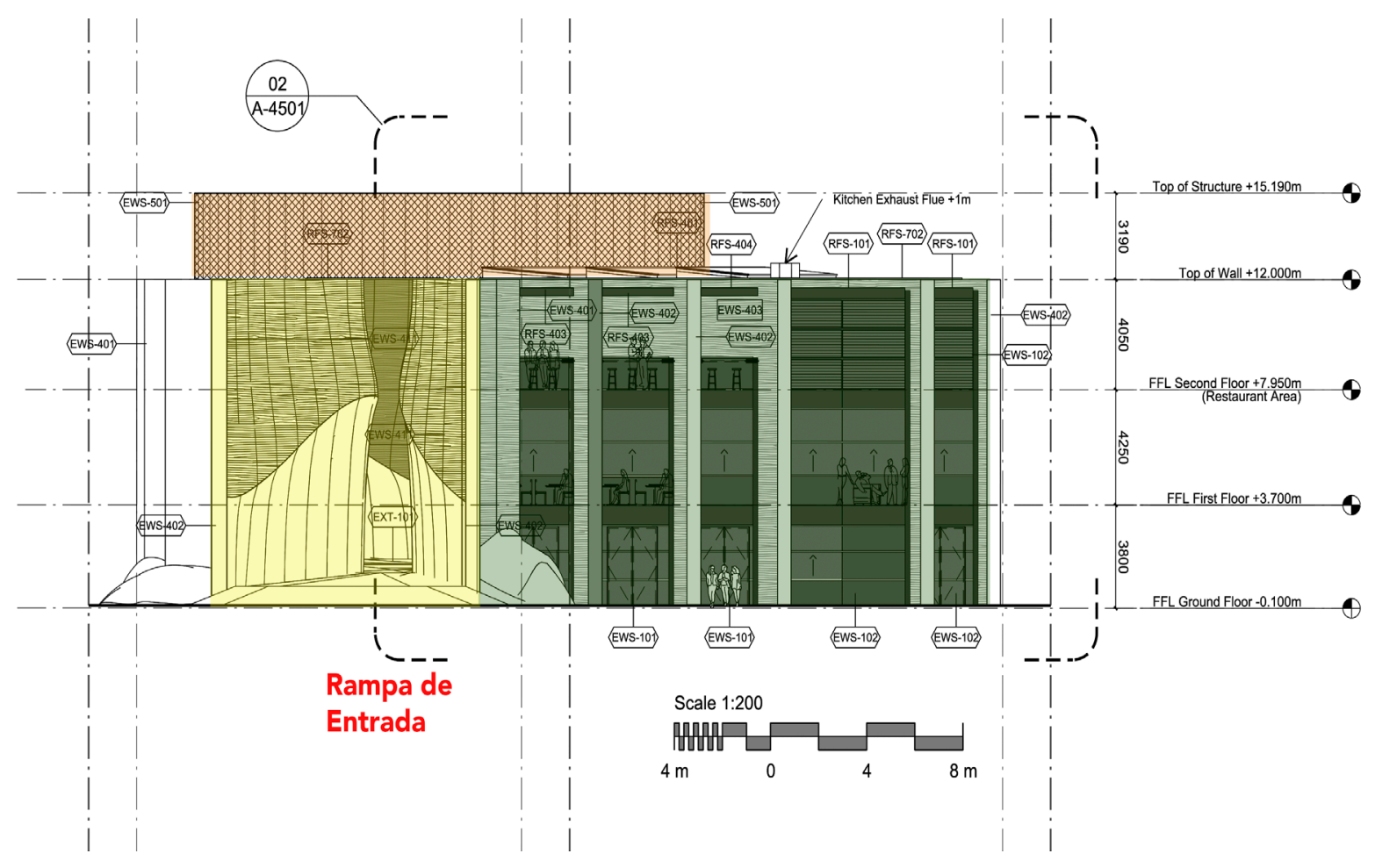

Entrada_canyon - Rampa

Bloco C_ Oásis, Instalações e Restaurantes

Bloco B_ Anfiteatro Principal

Figura 36: Vista Norte - Entrada principal para visitação do Pavilhão da União dos Emirados Árabes. Fonte: Rimond. Data: 2015. 


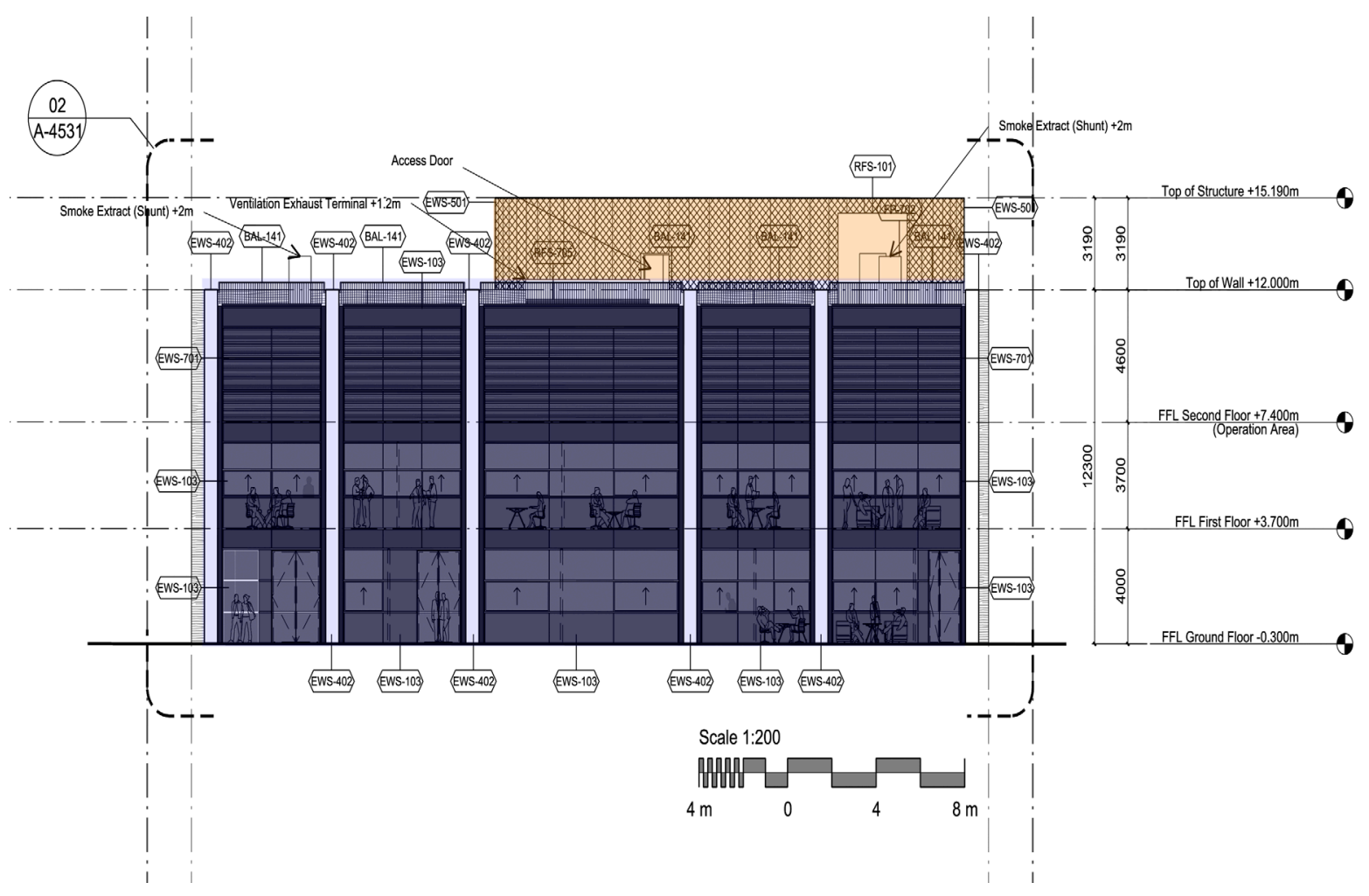

Bloco A_ Escritórios e Salas de Funcionários, Pós-Show.

Bloco B _ Anfiteatro Principal

Figura 37: Vista Sul do Pavilhão da União dos Emirados Árabes. Fonte: Rimond. Data: 2015. 
A planta é dividida em 3 setores (Figura 38/39/40/41):

1. as áreas de visitação e experiência, a rampa, o auditório principal, o auditório pós-show, áreas de exposições, o oásis e um restaurante;

2. o setor executivo, que tem uma entrada pela lateral e chega a um saguão, um anfiteatro, a área para reuniões, alimentação e descanso,

3. as áreas de apoio, destinadas à manutenção, à carga e descarga e à casa de máquinas.

No acesso pela rampa, existem representações digitais de aquedutos que abastecem a agricultura. Após o show, os visitantes interagem com plataformas e discursos, incluindo a Expo Dubai 2020. Depois dessa caminhada, a exibição leva a um oásis, com plantas e paisagem nativa, finalizando com a degustação de comidas típicas.

O pavilhão tem ambiente para orações voltado para a Meca e a planta também é norteada e tem a indicação de Meca. As áreas de circulação são as de visitação e seguem um fluxo direcionado e os outros setores são distribuídos a partir de corredores centrais. A circulação vertical acontece por escadas nas extremidades da área executiva e ao 
lado do anfiteatro.

O pavilhão tem 129 m de comprimento, 36 m de largura, $2.458 \mathrm{~m}^{2}$ de áreas verdes, $1.175 \mathrm{~m}^{2}$ de áreas de exposição, $900 \mathrm{~m}^{2}$ de restaurante, $3.500 \mathrm{~m}^{2}$ de áreas internas, uma capacidade de visitação de 8.000 pessoas/dia, capacidade de utilização de áreas públicas de 1.000 pessoas/ dia, capacidade de experiência na degustação de 2.340 pessoas/dia, totalizando uma visitação total de 2.041.200 pessoas em 5 meses. A seguir seguem peças gráficas do pavilhão:

A rampa chega ao nível 3,7 da exposição principal e visitação. Segundo as normas ${ }^{2}$ de construção da feira, não são permitidos níveis no subsolo, a não ser para a colocação das fundações ou instalações. Sob o nível 0,0, estão os ambientes privados executivos e as salas de máquinas. No nível 7,4, estão as casas de máquinas e cobertura. Para contribuir na eficiência energética, o edifício utiliza capta-

2 Dentre as normas da feira, o edifício não pode ultrapassar 12 metros de altura, sendo que elementos de comunicação visual ou brises podem atingir até 17 metros. Para o recuo frontal, devem ser respeitados 10 metros e, para os laterais, 2 metros em áreas livres e 3 metros quando há vizinhos. O programa sugerido pela organização da feira é: área de exposição e eventos, escritórios e cerimoniais, café, área de descanso e armazenagem. Além de aspectos inovativos, como arquitetura, materiais, gestão sustentável, interação com usuários e utilização de sistemas de comunicação. 


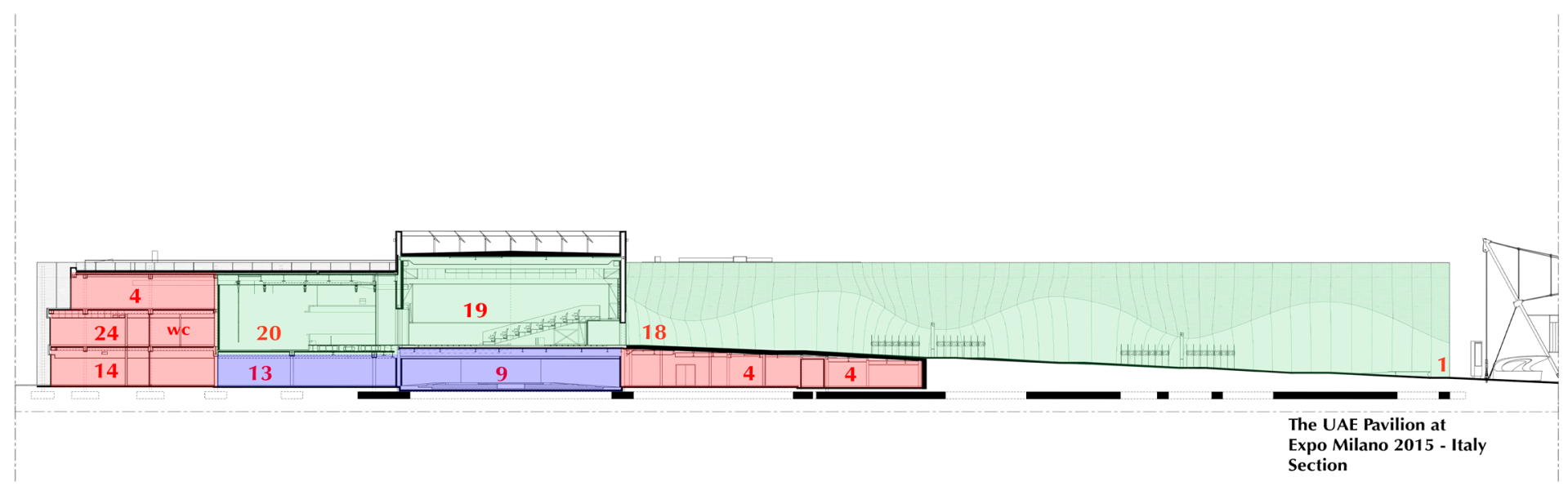

Legenda:

1. Entrada Principal;

4. Casa de máquinas;

9. Exibição Dubai 2020;

13. Centro de Exibição executiva;

14. Sala aula;

18. Recepção e acolhimento

19. Espetáculo principal - cinema;

20. Pós-show;

24. Escritório.

Figura 38: Corte Pavilhão em rampa do Pavilhão da União dos Emirados Árabes. Fonte: Rimond. Data: 2015. 


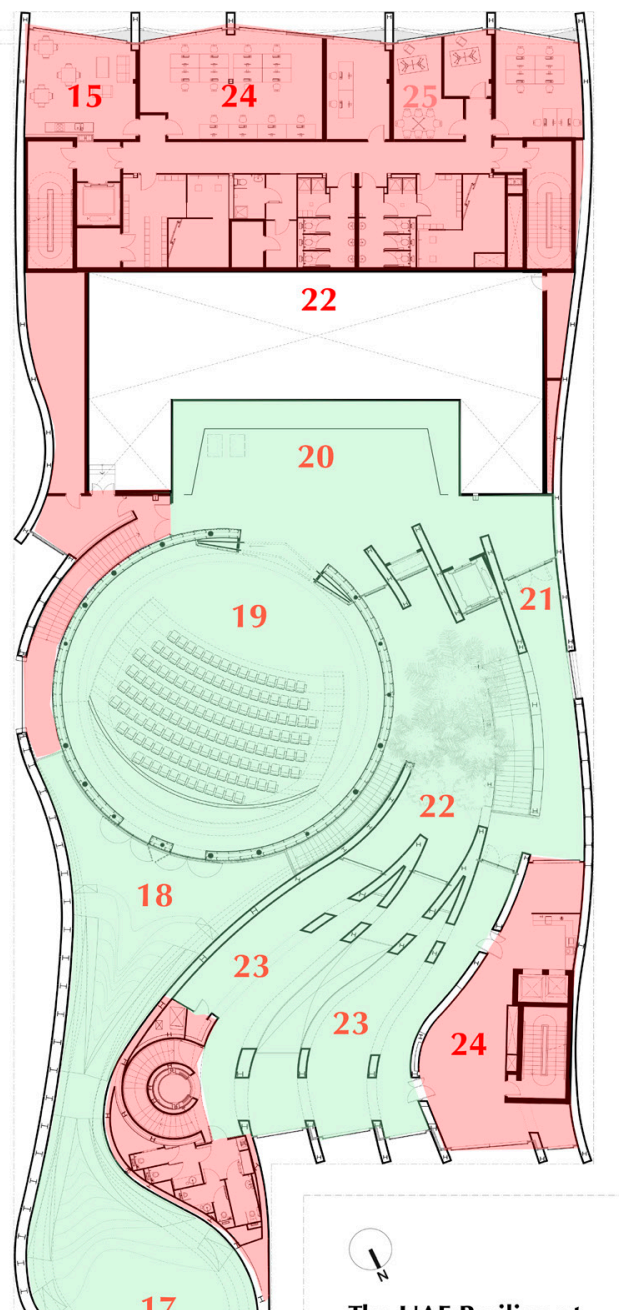

The UAE Pavilion at Expo Milano 2015 - Italy First Floor Plan

Figura 39: Planta nível 3,7 - Área de Visitação. Fonte: Rimond. Data: 2015.

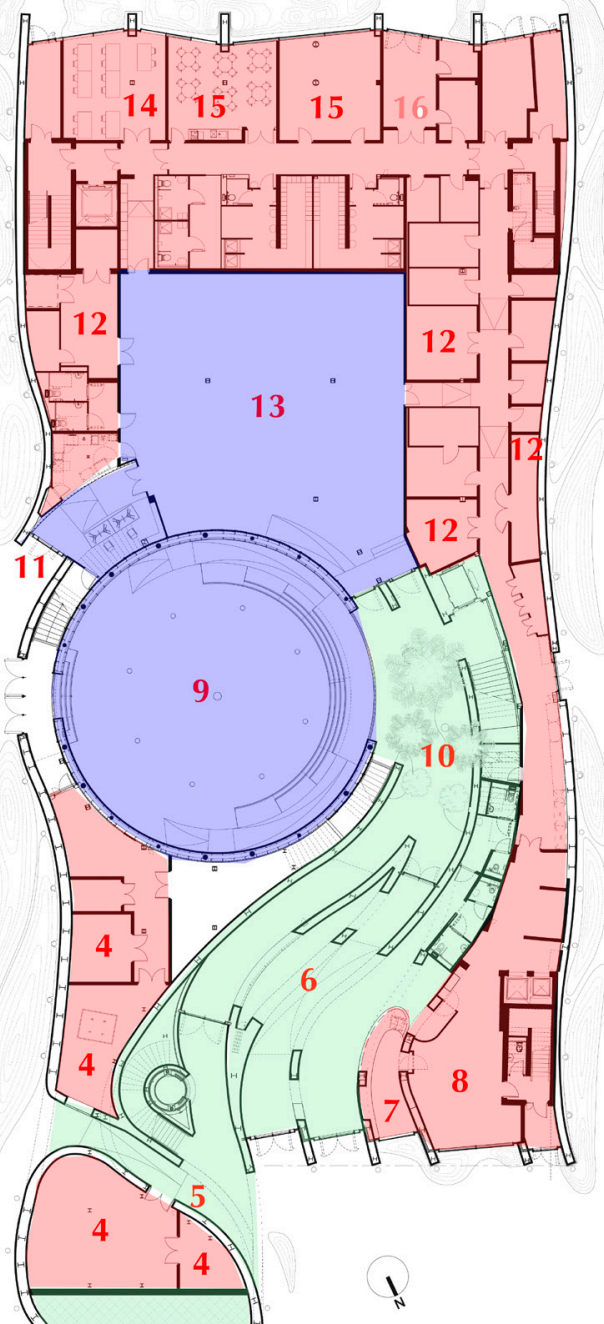

The UAE Pavilion at Expo Milano 2015 - Italy Ground Floor Plan

Figura 40: Planta nível 0,0 - Área Executiva e Administrativa. Fonte: Rimond. Data: 2015. 


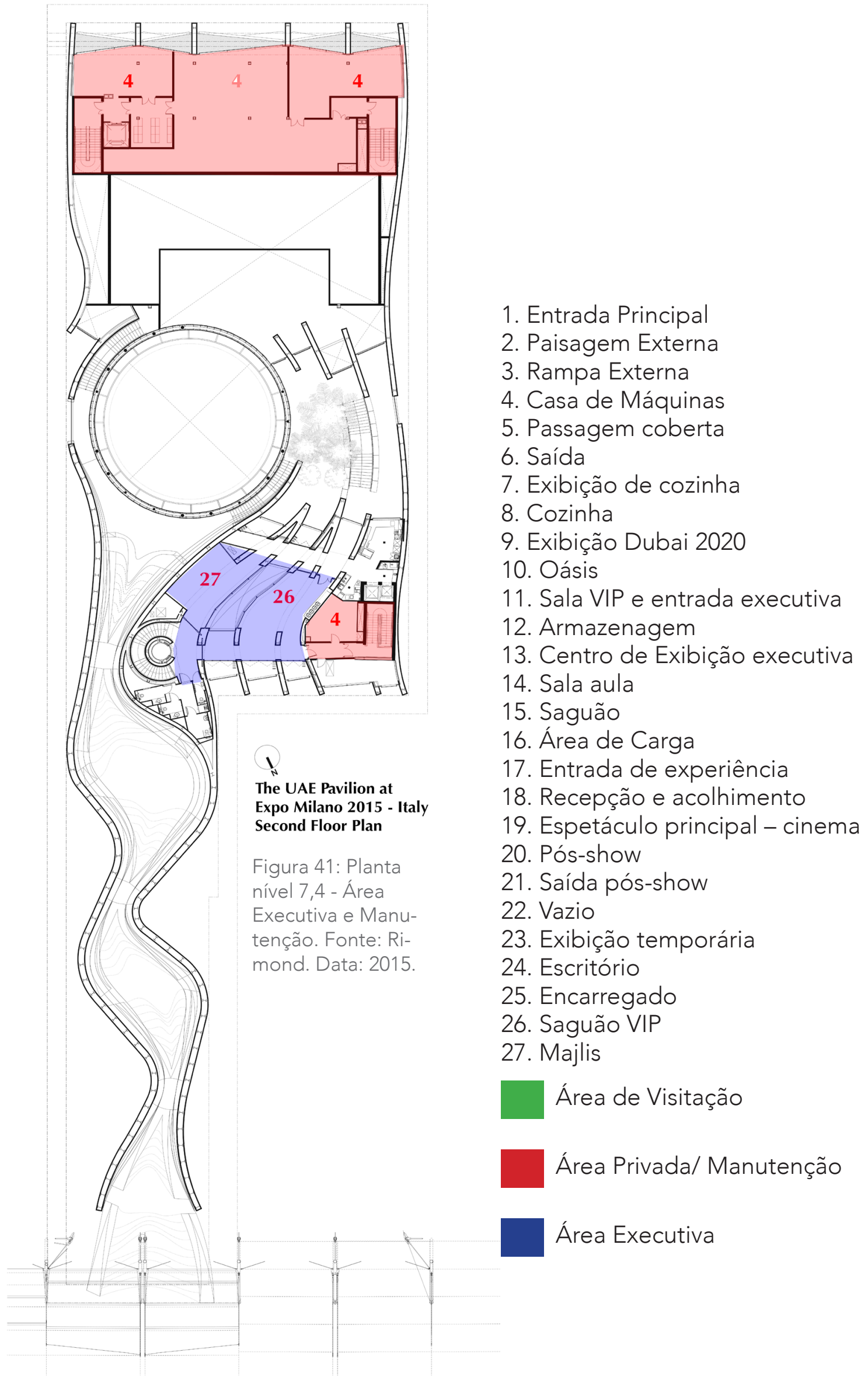


ção de energia solar com placas fotovoltaicas sobre o anfiteatro, captação de água de chuva e cobertura verde, com produção de plantas, que são utilizadas no restaurante.

O pavilhão utilizou estrutura metálica aparafusada, placas acopladas a esta estrutura que, posteriormente, serão utilizadas na remontagem, em Abu Dhabi. Apesar de o projeto ser desenvolvido com o intuito de reutilização, depoimentos descrevem que somente $60 \%$ do material será aproveitado, sendo que os $40 \%$ restantes são ambientes de concreto e materiais descartáveis como calhas, material elétrico, hidráulico, de vedação, de isolamentos, rufos, armações e impermeabilização.

Embora a reconstrução do edifício seja uma questão interessante em vários aspectos, como a reutilização dos mesmos materiais, remontar um edifício exige uma logística tão complexa quanto a sua elaboração. De acordo com os gestores do projeto, o custo de remontagem é em torno de 10\% menor do que o valor da construção, sem considerar o projeto e a fabricação do edifício.
Figura 42: Estrutura Pavilhão vista da desmontagem. Foto: autor. Data: 2016. 


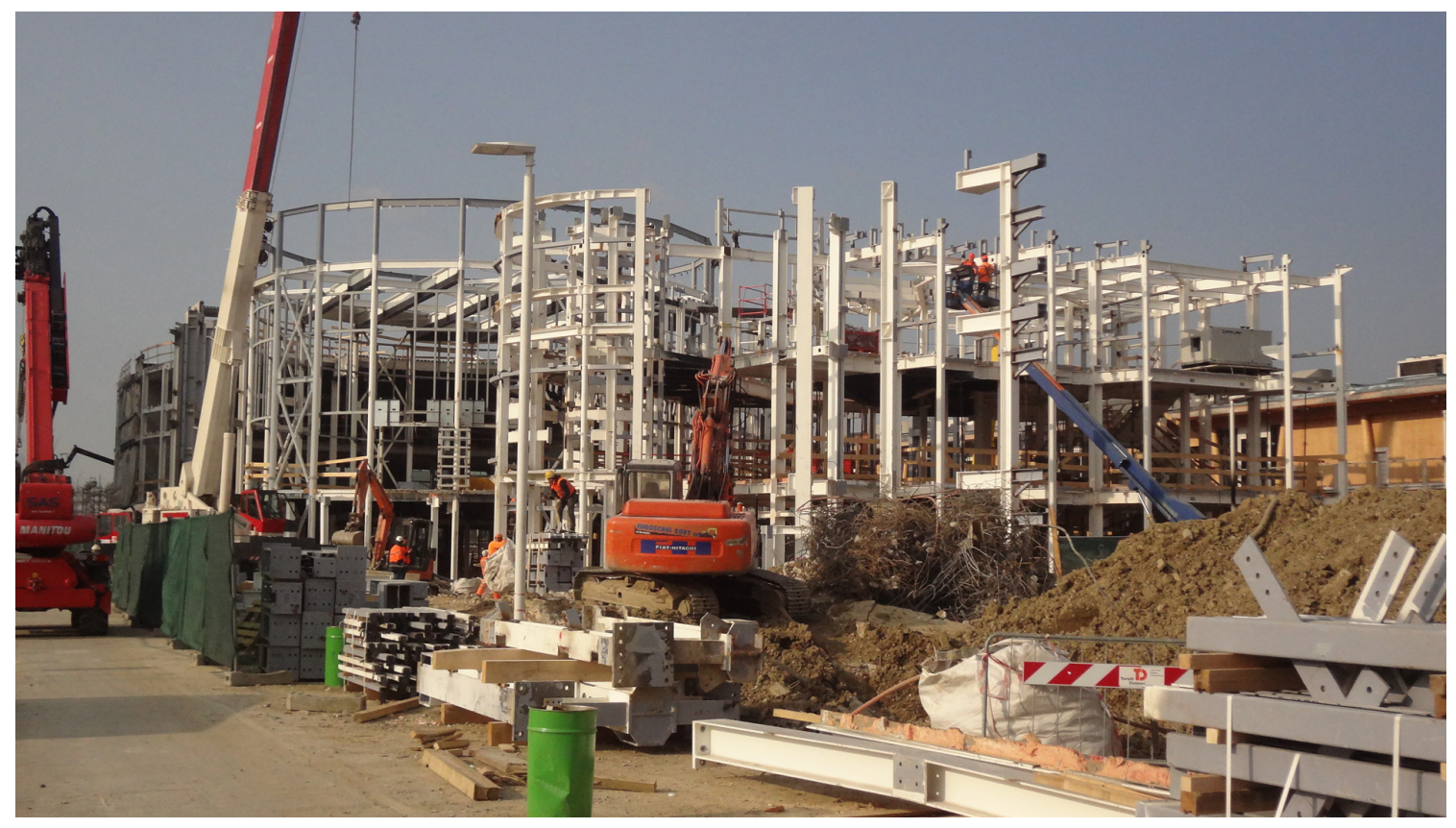




\section{Estrutura}

A estrutura principal (Figura 43) é uma grelha de aço que suporta os fechamentos com placas de argamassa fixadas a uma subestrutura dos painéis. A estrutura metálica foi desenvolvida na fábrica italiana Sthabau Picler, localizada na região de Trento, cidade de Bolzano, como citado anteriormente. Possui unidades em vários países, como Alemanha, Suíça, Áustria e Rússia. Já executou obras de Massimiano Fuksas (De Cecco - Pescara, 2008; Palazzo Ex Unione Militare - Rome, 2013), Zaha Hadid (Bergisel - Innsbruck, 2002), Sturchio Architects (Ferrari - Fiorano, 2002), Planungsburo Günther Weidner GmbH (Riedel - Kufstein, 2006), dentre muitos outros projetos de arquitetos renomados.

A empresa foi responsável pelo desenvolvimento do projeto de estrutura, a partir dos desenhos iniciais de Foster \& Partners, pela adequação dos sistemas com as demais equipes, pela montagem no canteiro, pelo acompanhamento da montagem da estrutura, desmontagem e remontagem em Masdar - Abu Dhabi.

Figura 43: Estrutura principal em grelha, setor de entrada. Foto: Filippo Poli. Data 2014/15 


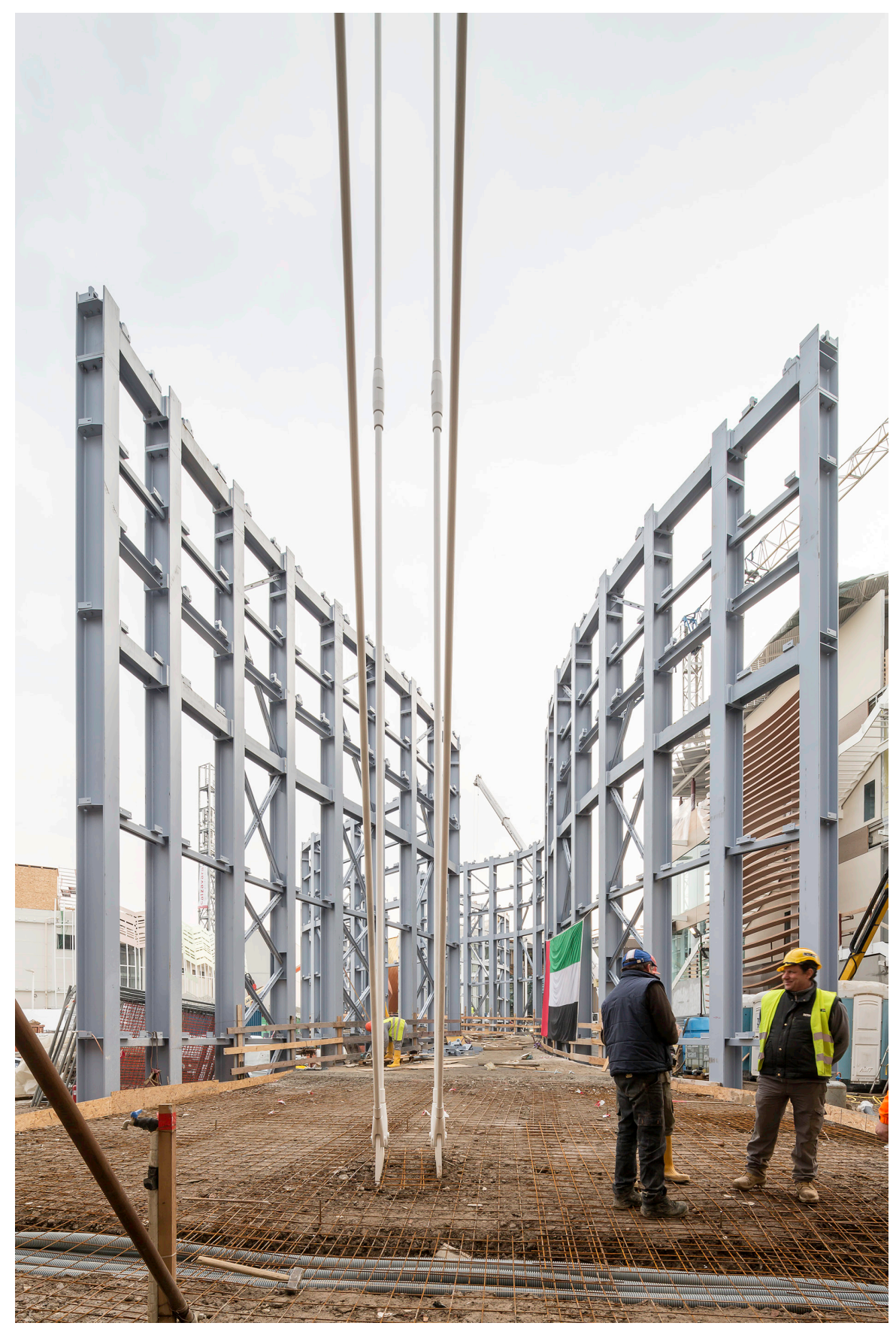


As peças para a produção desse edifício foram confeccionadas em Bolzano e, posteriormente, encaminhadas para Milão. Esta fábrica ${ }^{3}$ possui 30 projetistas, 6 engenheiros, 10 arquitetos, 60 funcionários em atividades administrativas, 80 funcionários em chão de fábrica e 30 funcionários de montagem em canteiro, ajustados dependendo da demanda de obras.

Para o desenvolvimento da estrutura, utiliza-se um programa apropriado para a área industrial chamado Tekla, da Trimble. Esse programa é utilizado nos setores de concreto, peças metálicas, pré-fabricados de concreto e armações. Na produção de estruturas metálicas, serve para modelagem, detalhamento, fabricação, gestão, levantamentos etc. É o programa BIM para o setor da produção.

A modelagem com a plataforma Tekla é feita em 3D. Cada peça é desenhada individualmente e visualizada na modelagem. As informações produzidas a partir do arquivo geram planilhas para a produção em 2D, com as informações de espessuras, furos, tipo de metal etc. O programa produz os desenhos de plantas, cortes, levantamentos de

3 Os dados foram levantados a partir de visita realizada a fábrica no dia 13 de maio de 2016. 
compra de material, contagem de peças e encaminhamento da informação diretamente para as máquinas de corte e montagem dos elementos em fábrica, além de documentos e mapas para o canteiro de obras e desenhos de instalações.

Os elementos como pilares e vigas com espessuras maiores são encomendados aos fornecedores no tamanho necessário e com os seus devidos cortes e furos. Na fábrica, são cortadas as chapas metálicas pequenas, em uma cortadora a laser (Figuras 44/45/46). Nesse caso, o arquivo é enviado diretamente do setor de projeto em extensão nwd. Após essa confecção, o setor de montagem reúne as partes com pequenos pontos de solda (Figuras 47/48) e, posteriormente, tudo é encaminhado para o setor de solda, que vai fixar efetivamente as peças. $\bigcirc$ ponto-chave é a montagem, que requer um funcionário cuidadoso e atencioso. Se alguma peça for confeccionada de forma equivocada, só será diagnosticada em canteiro de obras, acarretando danos no cronograma, nos materiais, na logística etc.

A organização da fábrica possui uma linha de produção - embora isso não constitua um processo contínuo - do 

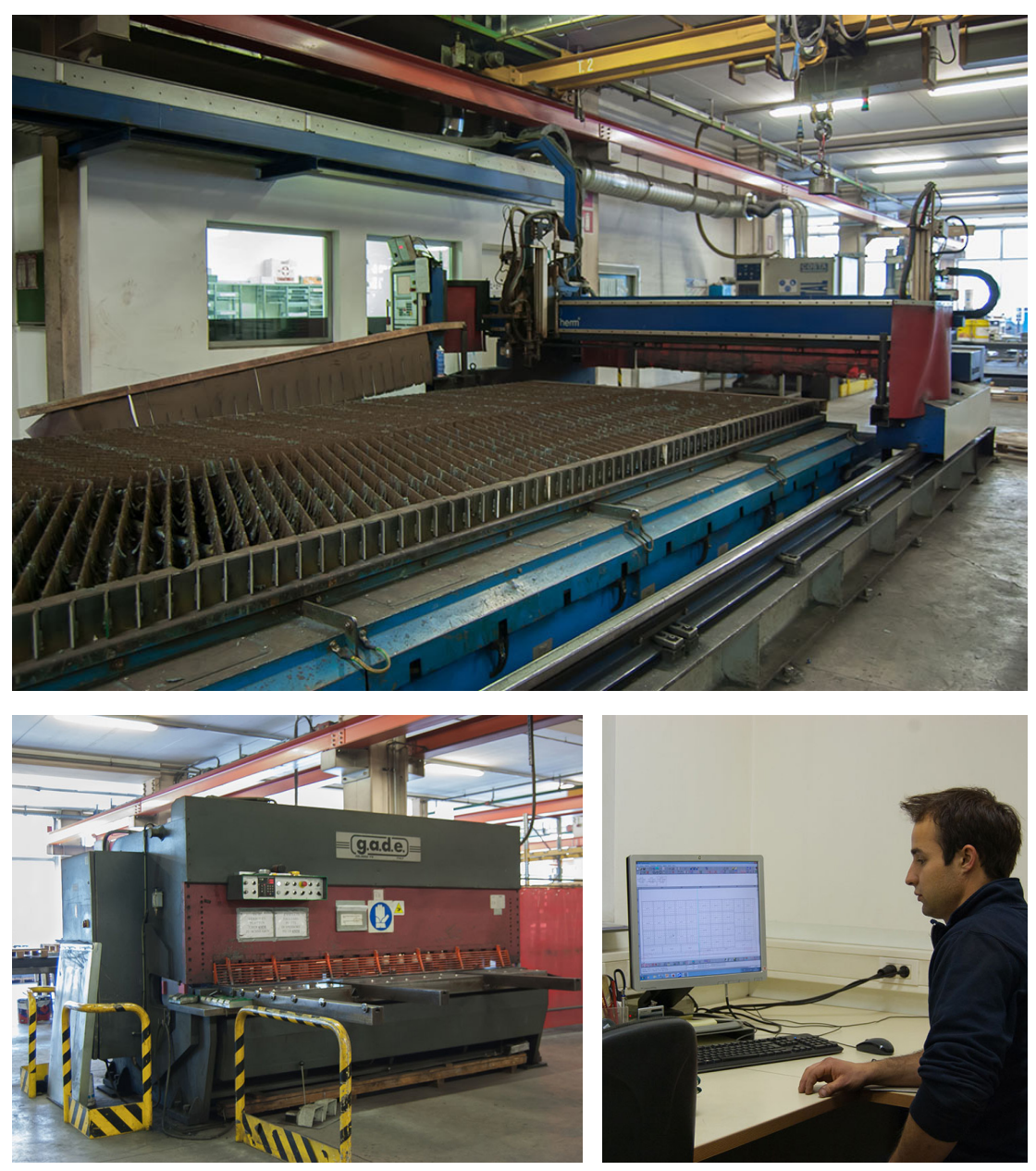

Figura 44: Máquina de corte a laser, esteira de colocação das chapas metálicas Foto: autor. Data: 2016.

Figura 45: Máquina de corte a laser, saída dos elementos seccionados. Foto: autor. Data: 2016.

Figura 46: Comando da máquina de corte a laser. Foto: autor. Data: 2016. 


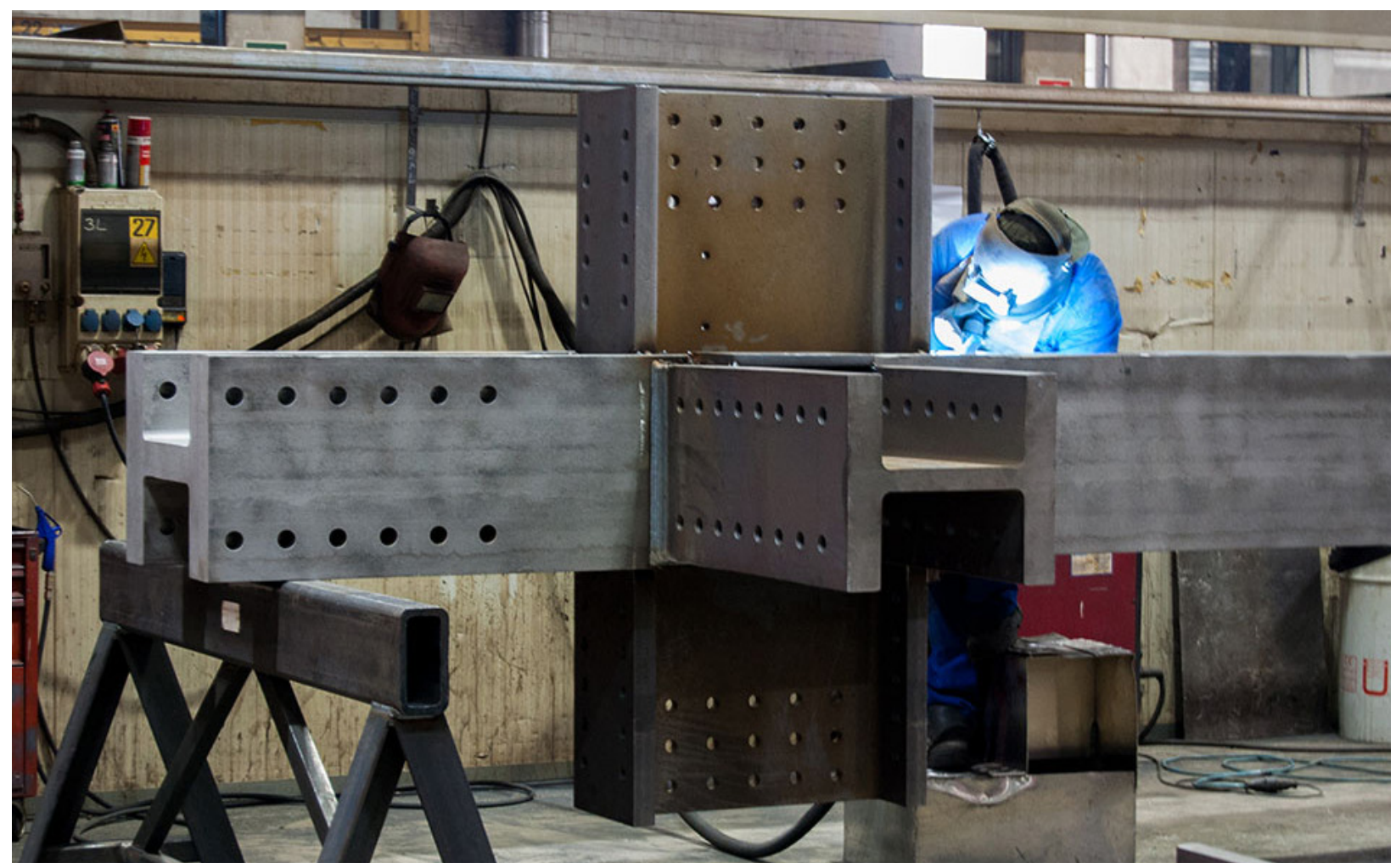

Figura 47: Peça metálica em fase de montagem em fábrica. Foto:

Davide Radogna. Data: 2016. 
tipo sistema Toyota de produção, devido às grandes dimensões das peças e ao desenho, que muda constantemente. A produção é sobre demanda, não possui grandes estoques, principalmente de elementos mais pesados de aço, e os processos de automação são pouco utilizados.

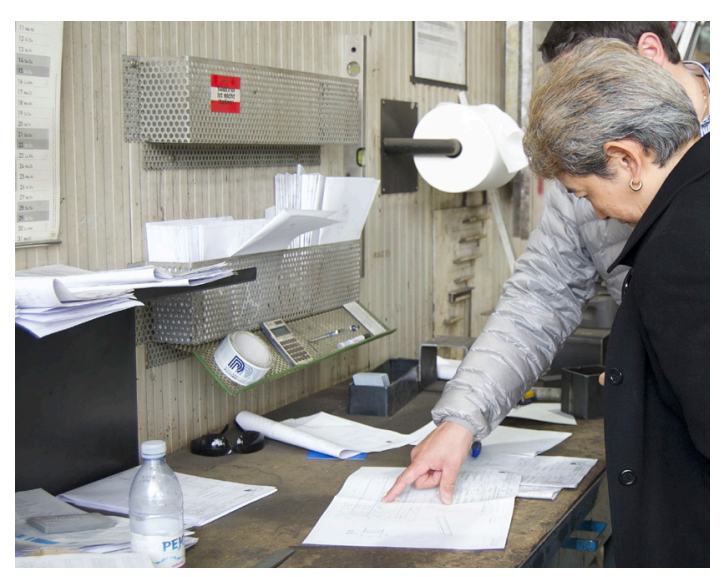

Figura 48: Planilhas para montagem da estrutura. Foto: Davide Radogna. Data: 2016. 
Nesse caso, o que se verifica em relação à digitalização da fábrica é a utilização de um software para a modelagem, gestão do projeto, de material e a utilização da máquina a laser para fabricação de pequenas peças comandadas digitalmente e cortadas com precisão e otimização das chapas. O trabalho de montagem, soldagem e transporte é realizado mecanicamente, com trilhos, guindastes, desenhos em 2D e identificação em planilhas e desenhos impressos.

Verifica-se, portanto, que a fábrica, apesar de estar à frente com os trabalhos realizados, apresenta poucos equipamentos digitalizados e automatizados em chão de fábrica e utiliza, principalmente, softwares para a modelagem e gestão de estruturas com programas BIM. A produção dos elementos é sob demanda, de acordo com os trabalhos firmados. A produção repetitiva se faz, principalmente, sobre elementos de um mesmo edifício e sobre o conhecimento desenvolvido, que segue a mesma lógica de elaboração e execução. 
Wall Tiling Strategies
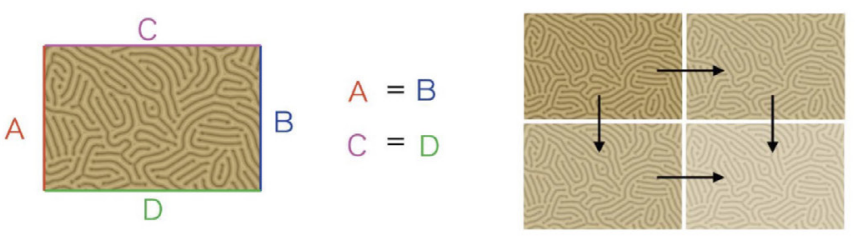

Tiling uses a periodic/

matching boundary to create continuous pattern
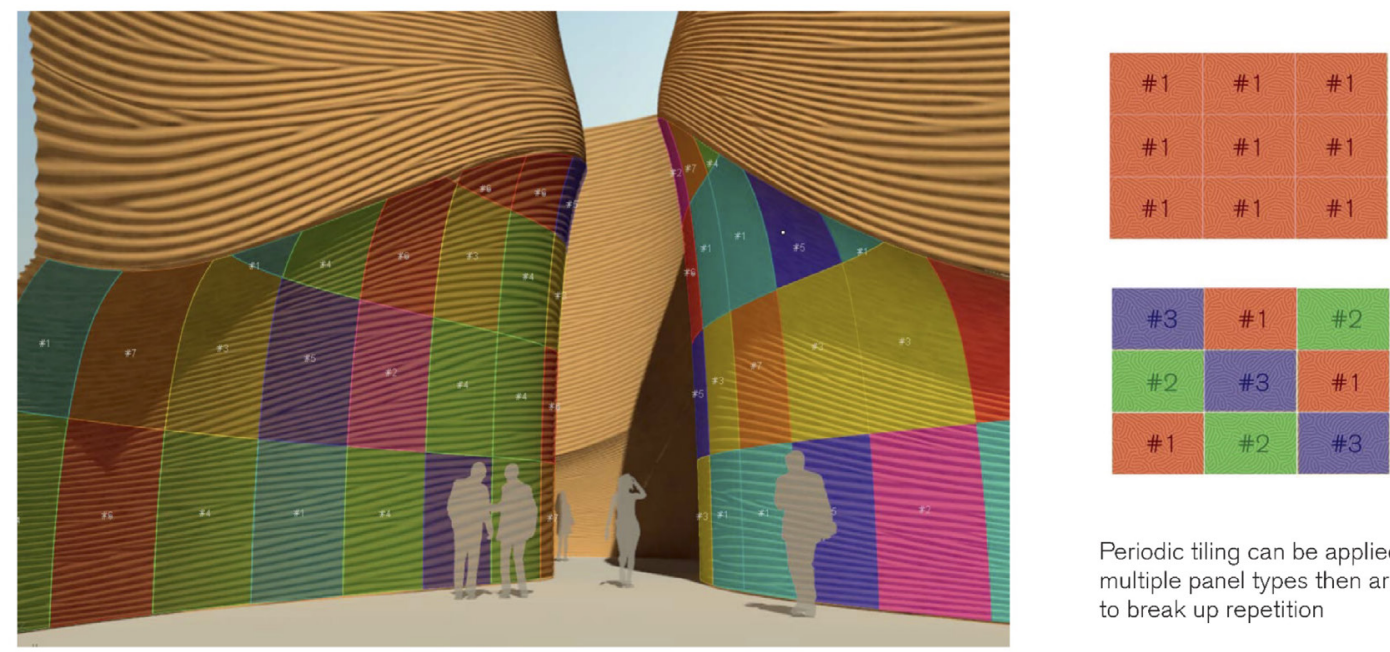

Periodic tiling can be applied on multiple panel types then arrayed to break up repetition

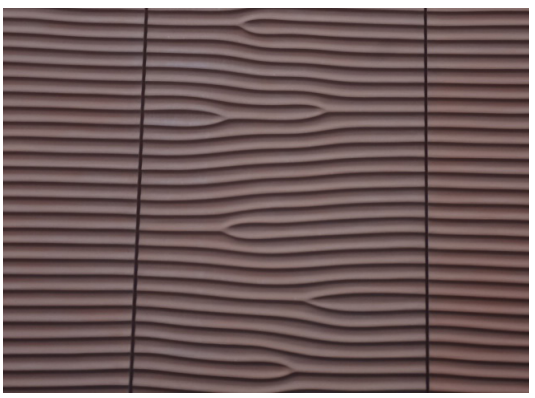




\section{Projeto para a Produção dos Painéis}

Os painéis foram elaborados a partir de um conceito em que todos os lados são idênticos (Figura 49), o que facilita a produção e a montagem no canteiro, em caso de painéis planos. De acordo com o escritório de arquitetura, esta estratégia reduz em $75 \%$ o trabalho na manufatura, possibilitando a fabricação de componentes idênticos para, depois, rearranjá-los na montagem.

Para o pavilhão da União dos Emirados Árabes, Foster criou duas tipologias de painéis: as placas planas de fechamento externo e as placas com curva, que estão ao longo da rampa de 140 metros. Os painéis da rampa são peças únicas, com a curvatura sobressaltada, e criam um movimento sobre o caminho percorrido. A argamassa armada já havia sido utilizada pelo arquiteto em um edifício educacional, o Masdar Institute, da União dos Emirados Árabes (2007-2015), com painéis ${ }^{4}$ vazados, painéis com

Figura 49: Estratégia para elaboração dos painéis de Argamassa Armada - GRC. Fonte: Foster \& Partners. Data: 2014.

Figura 50: Painéis planos externos com textura das dunas. Foto: autor. Data: 2016. curva simples, painéis com aberturas e painéis planos para fechamento.

4 http://www.fosterandpartners.com/projects/masdar-institute/ 


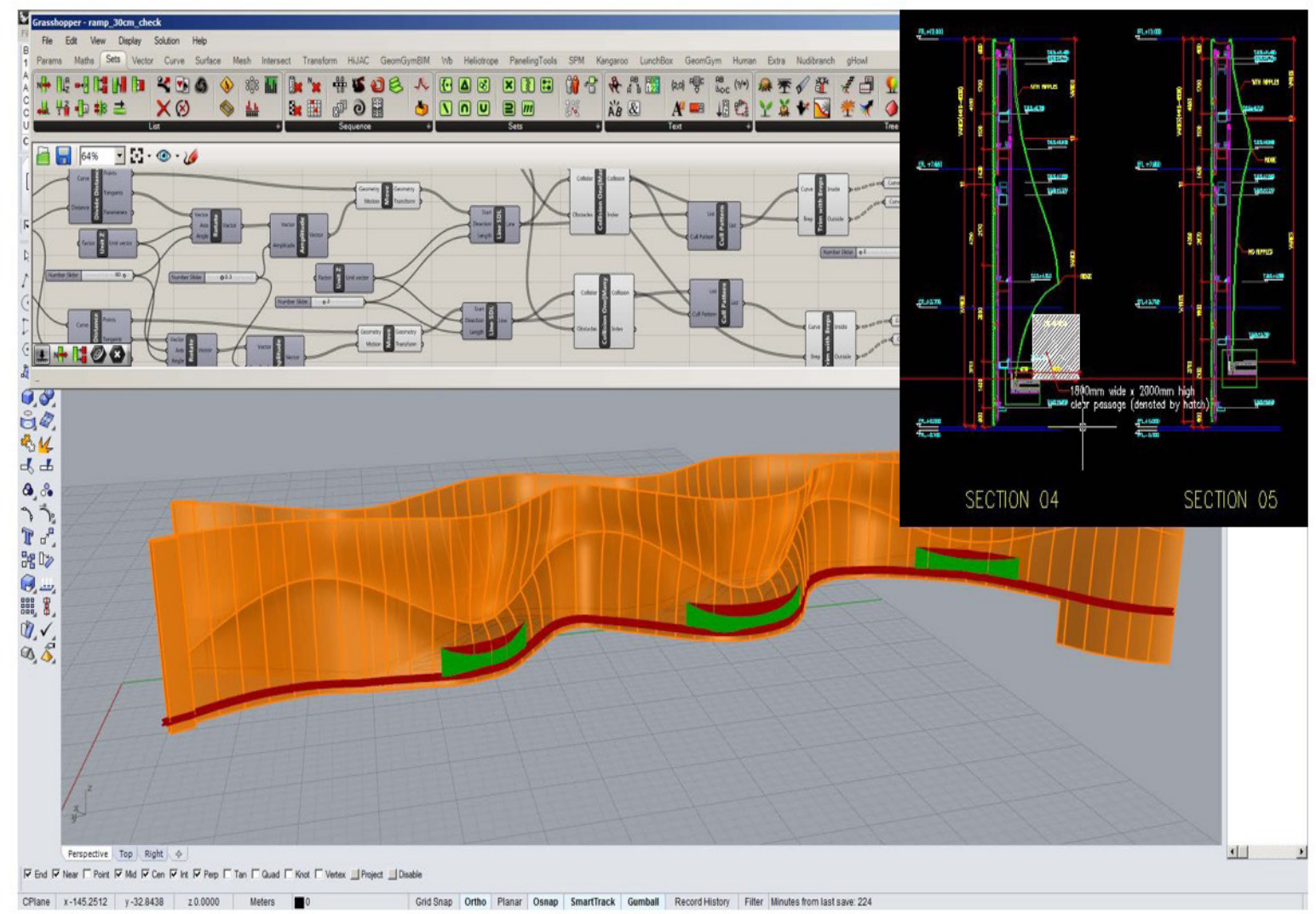


Para o projeto desses painéis, o escritório utilizou o programa Rhinoceros e o plug-in Grasshopper na definição das ondas, como mostra a figura 51.

Os aspectos determinantes para a definição das curvas são os pontos de estrangulamento do corredor de circulação, a altura dos visitantes contra acidentes e o aspecto estético das dunas de areia. A partir disso, foram criados padrões de curvas em modelagem, que ora são mais altos ou mais baixos e sua projeção, mais acentuada ou não, definida pelo caminho que lembra um canyon.

O Rhinoceros é uma ferramenta que possibilita ao usuário trabalhar com formas volumétricas e parametrizá-las, através de programação visual, de forma mais simples do que os scripts textuais, que exigem o conhecimento aprofundado de sua linguagem. A partir do desenvolvimento do projeto, foram elaborados vários testes para averiguação do desenho, da forma, da resistência, do desenho de subestrutura e montagem, demonstrados nas figuras 52 e 53.

Figura 51: Adequação das curvas dos painéis, de acordo com a escala humana. Fonte: Rimond. Data: 2016.
O próximo desenho é um corte no setor da rampa e mostra a estrutura principal, em aço, com uma subestrutura e 

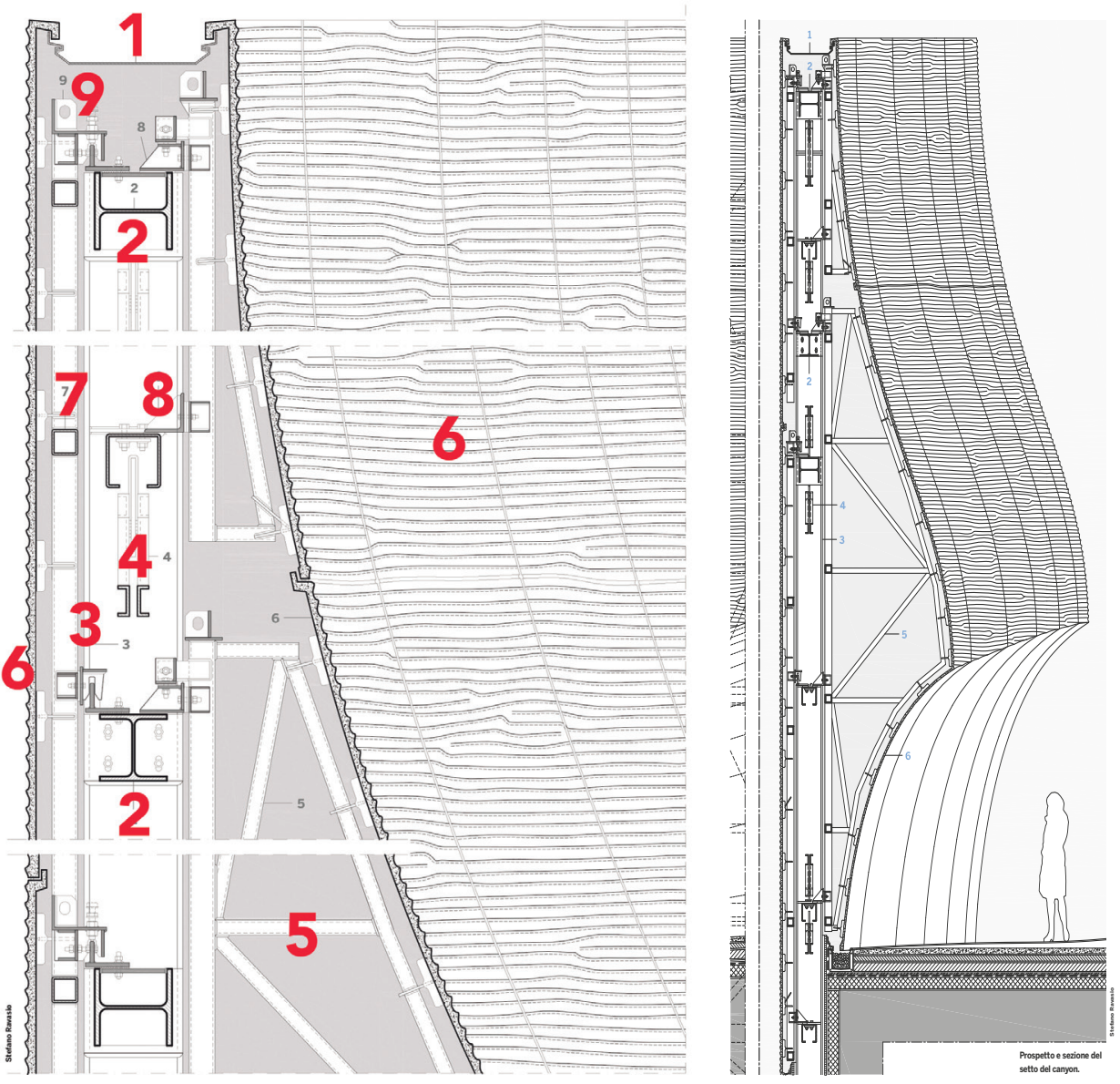

1. Fechamento de alumínio proteção para poeira

2. Viga de aço;

3. Pilar de aço;

4. Reforço diagonal;

5. Subestrutura de suporte;

6. Painel prefabricado de GRC;

7. Tubos de aço;

8. Suportes, cantoneiras e conexão;

9. Sistema de ajustamento deslizante

Figura 52: Desenho Painel em Argamassa Armada + Subestrutura + Estrutura. Fonte: Foster \& Partners. Data: 2014.

Figura 53: Vista de Painel em Argamassa Armada+ Subestrutura + Estrutura. Fonte: Foster \& Partners. Data: 2014. 


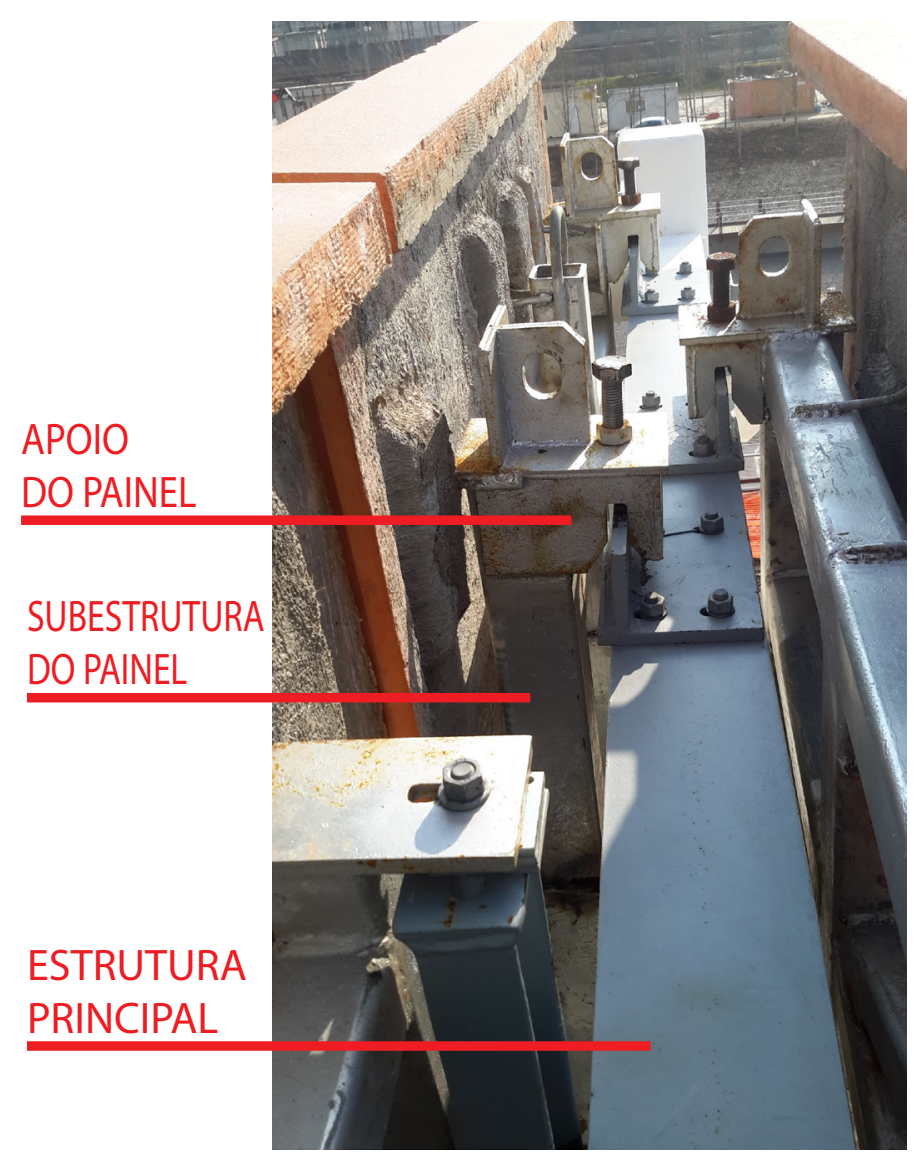

Figura 54: Detalhe de apoios entre painel, subestrutura e estrutura principal. Fonte: autor. Data: 2016. 


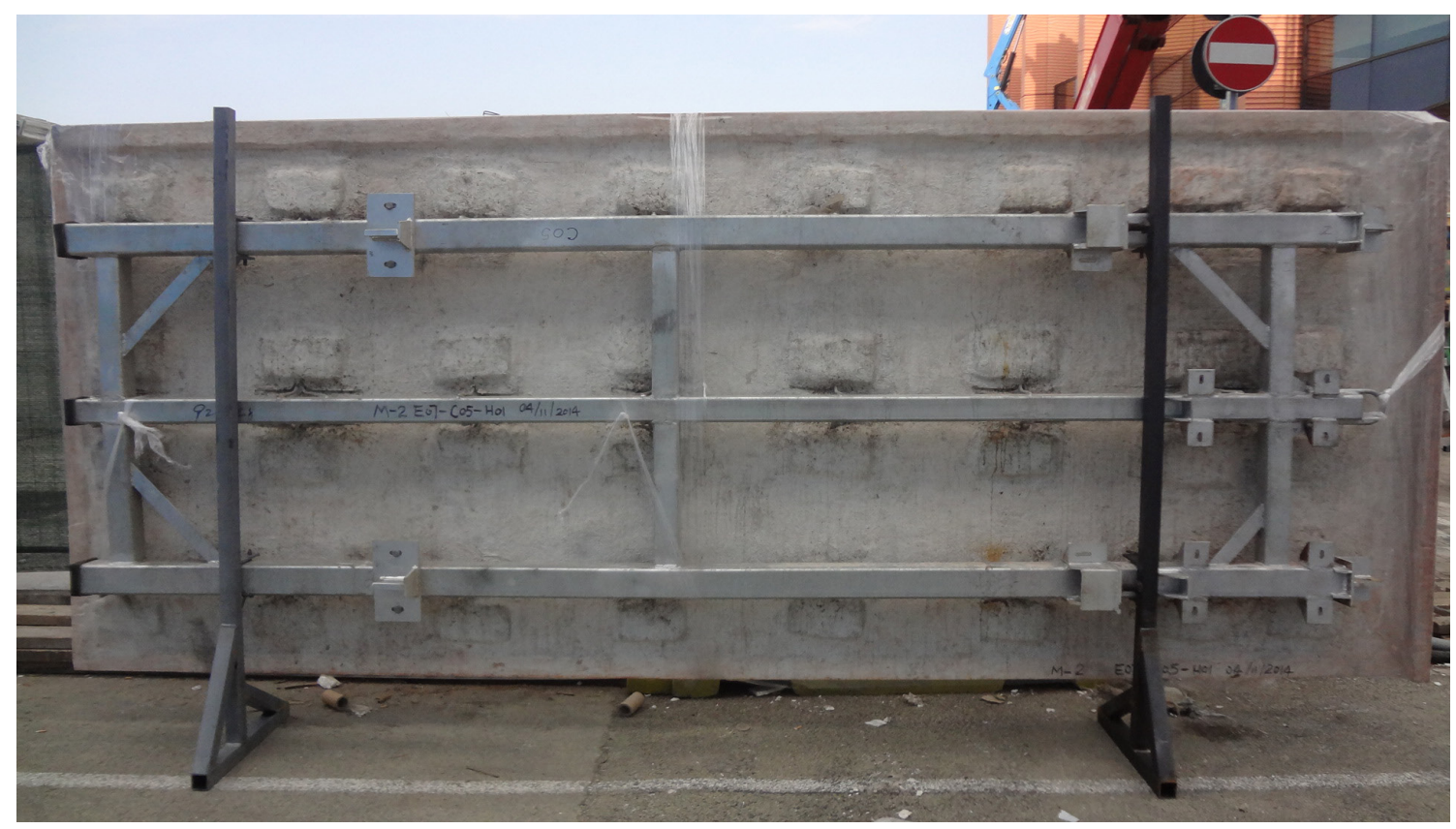

Figura 55: Relação entre estrutura, subestrutura e painel de argamassa armada. Foto: Rimond. Data: 2015. 


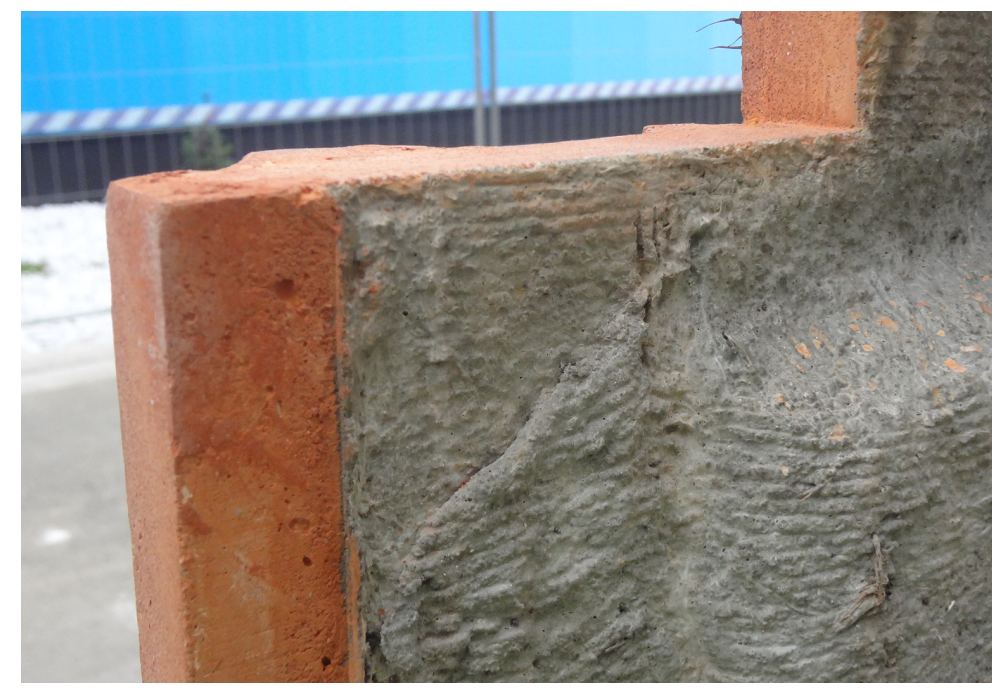

Figura 56: Detalhe de painel por trás. Foto: autor. Data: 2016. 

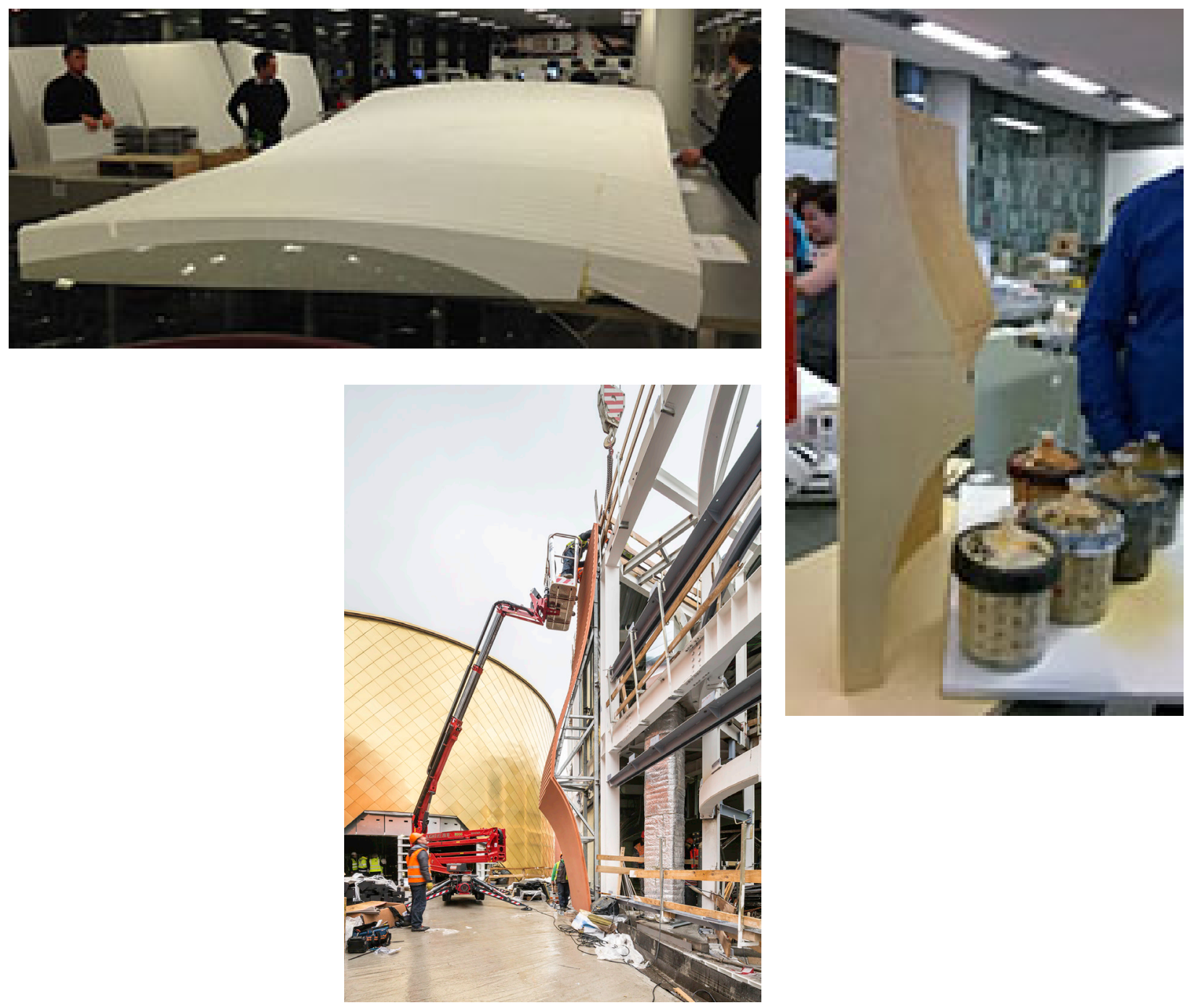
o painel de GRC. Os pontos de apoio são pequenas alças que se encaixam sobre a estrutura principal; estas distribuem o peso do painel ao longo da estrutura e o peso das placas sobre a subestrutura (Figura 54).

A argamassa armada com fibra de vidro é um material comum, aqui utilizado de uma forma diferente. De acordo com a International Glassfiber Reinforced Concrete Association $^{5}$, da Inglaterra, o GRC é um composto feito com cimento, agregado fino, plastificante, polímero, água e fibra de vidro. Pode ser usado como elemento de vedação, revestimento, componentes históricos ou como qualquer material que possa ser moldado, pintado, colorido ou na sua forma natural.

Após a definição da materialidade e do desenho dos painéis, foram realizados estudos para definição da textura, de maquetes e protótipos. Posteriormente aos testes e

Figura 57: Maquete do painel curvo. Fonte: Foster \& Partners. Data: 2014.

Figura 58: Parte da forma para produção do painel. Fonte: Foster \& Partners. Data: 2014.

Figura 59: Mockup e Montagem do painel de Argamassa Armada curvo. Foto: Filippo Poli. Data: 2015. simulações com peso, resistência e tipo de estrutura, os painéis foram encaminhados para desenho final e produção na fábrica da Coreia.

5 http://www.grca.org.uk/ 


\section{Fabricação}

Na manufatura, o fato de as laterais dos painéis serem idênticas contribuiu para que o molde fosse feito sobre pequenos segmentos de formas intercambiáveis e, a partir dessas matrizes, os moldes produzidos em uma fresadora podem ser trocados de posição, produzindo diferentes geometrias de textura, como mostra a imagem ao lado (Figura 60).

Os moldes foram pintados com tinta de resina epóxi, que dão a aparência de areia, e preparados para serem reutilizados até 10 vezes, o que significa que, dos 930 painéis, a produção em massa foi de menos de $10 \%$ do todo. De acordo com o produtor da fábrica, "a chave para o sucesso final dos painéis foi garantir o alinhamento perfeito das ondulações". Na produção, existiam diversos tipos de painéis: alguns planos, outros com recortes, em forma de "U", com dimensões diferentes, alguns curvos e praticamente todos com diferentes desenhos em superfície (Figuras 61/62/63/64/65).

Para a produção dos painéis da rampa, que tinham 2,2 m de largura por 7,5 a $10 \mathrm{~m}$ de altura, os moldes negativos
Figura 60: Base para a fabricação dos painéis planos de Argamassa Armada. Fonte: Fábrica Canbuild_Coreia. Foto: Gary Tortora, Data: 2014/15. 


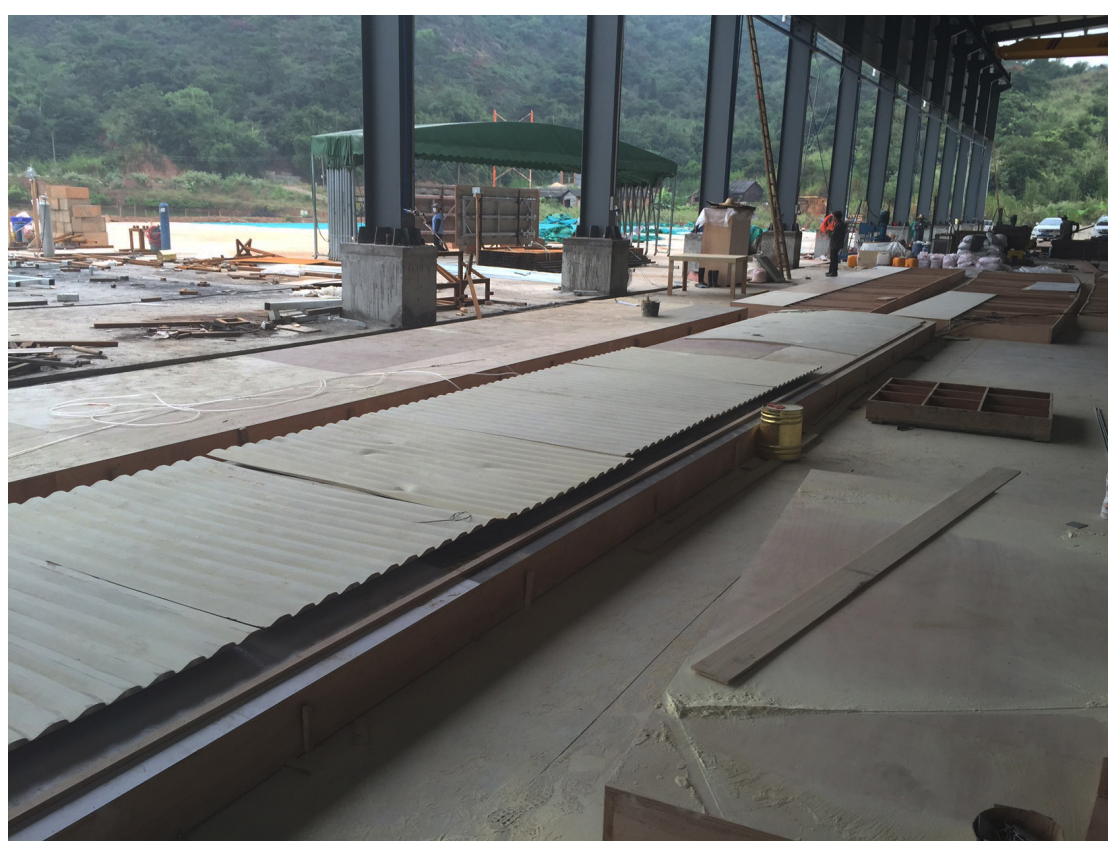



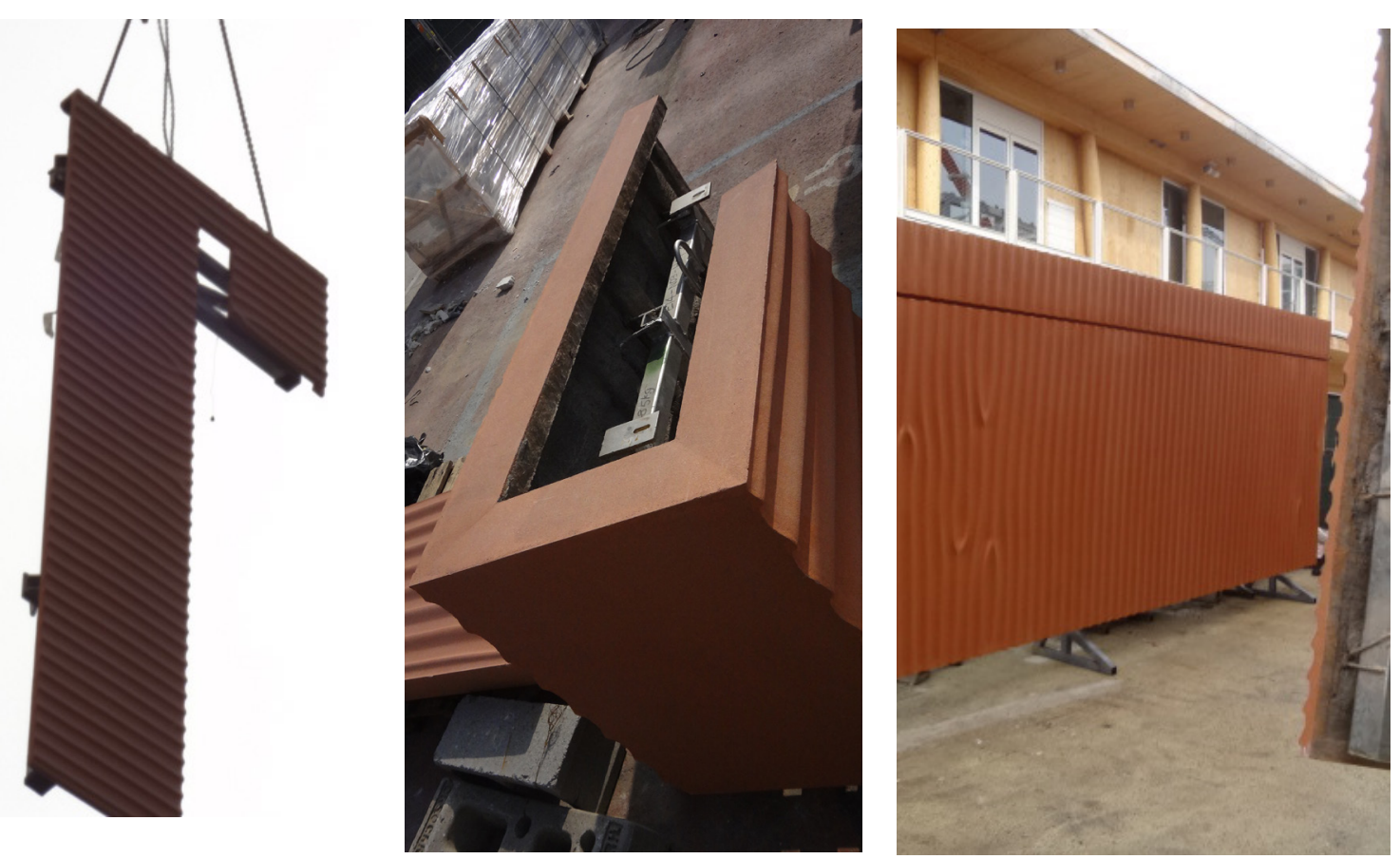

Figura 61: Painel de Argamassa Armada para fechamento de canto. Foto: autor. Data: 2016.

Figura 62: Painel de Argamassa Armada recortado para acabamento de canto. Foto: autor. Data: 2016.

Figura 63: Painel de Argamassa Armada com simulação de linha de emenda. Foto: autor. Data: 2016. 

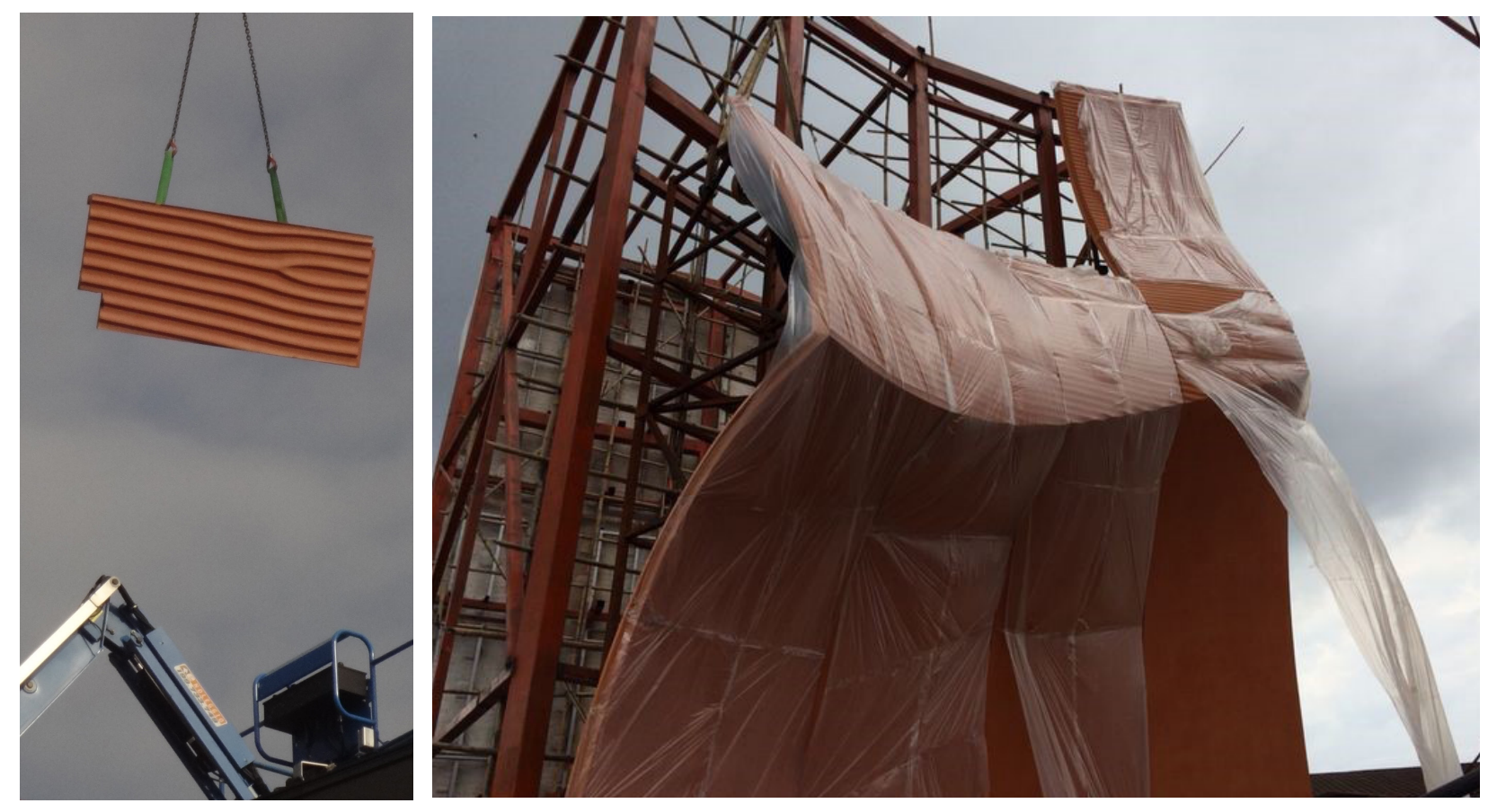

Figura 64: Painel de Argamassa Armada pequeno e com recorte. Foto: autor. Data: 2016.

Figura 65: Painel de Argamassa Armada com curvatura para o setor do Canyon. Foto: Rimond. Data: 2015. 

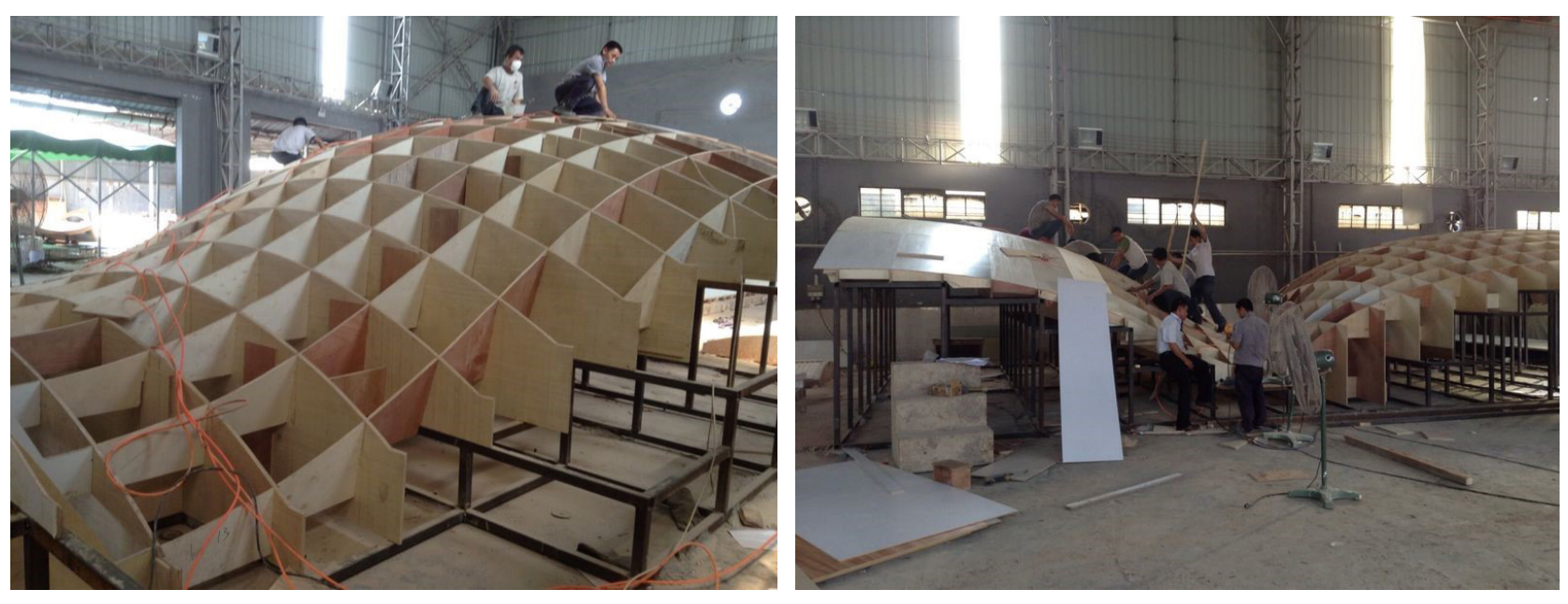

Figura 66: Grelha de madeira, base estrutural da forma do painel com projeção. Foto: Garry Tortona - Canbuild. Data: 2015.

Figura 67: Revestimento da base para molde dos painéis curvos do setor do Canyon. Foto: Garry Tortona - Canbuild. Data: 2015. 

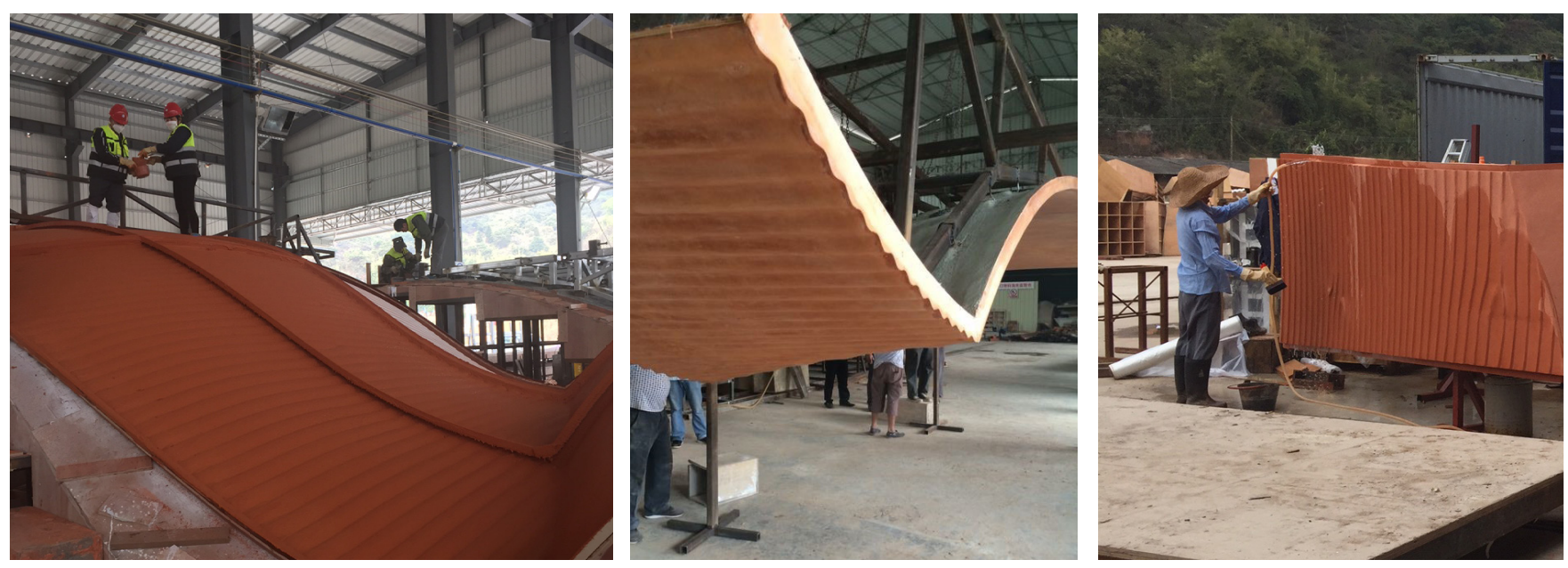

Figura 68: Confecção dos painéis curvos, com encaixe

entre eles. Foto: Garry Tortona -

Canbuild. Data: 2015.

Figura 69: Painel Curvo com subestrutura acoplada. Foto: Garry Tortona - Canbuild. Data: 2015.

Figura 70: Acabamento final com lavagem de ácido. Foto: Garry

Tortona - Canbuild . Data: 2015. 
curvos nas direções vertical e horizontal, com estrutura em madeira, foram construídos com uma fresadora, a partir de uma grelha tridimensional. Foi necessário o uso de um teodolito eletrônico no controle das curvas. A ligação entre os painéis tem um desenho com encaixe entre cada painel, o que garantiu a conexão entre eles. Na última etapa da produção para o acabamento, os painéis foram lavados com ácido, para ficarem com uma textura de areia.

A utilização das ferramentas computacionais foi essencial para a produção dos painéis, o que garantiu a precisão e a produção com desenho específico dos componentes. $\bigcirc$ escritório de arquitetura encaminhou os conceitos gerais, que foram ajustados para as máquinas de produção CNC e encaminhados para a fábrica. $O$ uso de equipamentos digitalizados é inovador, possibilitando diferentes configurações para o componente, como a produção deste caso. 


\section{Montagem}

A montagem dos painéis ocorreu da face sul para a norte; o canyon foi o último, com os painéis curvos. Apesar de sua colocação ser facilitada, graças ao desenho dos suportes na subestrutura, apoiados e aparafusados na estrutura principal, o trabalho é simples, embora cuidadoso, pela fragilidade do material.

A placa plana e a subestrutura pesavam em torno de 1,5 t. Os painéis pequenos das pontas pesavam em média 200 $\mathrm{kg}$ e os painéis curvos, aproximadamente 2 t. Foi necessário o uso de gruas e equipamentos para içar os componentes. A montagem foi coordenada de acordo com a chegada dos painéis no canteiro de obras e teve uma logística específica. Sua colocação necessitou de 2 ou 3 homens, que fixaram as cordas para levantar o módulo, e 1 ou 2 operários para colocá-lo no seu espaço.

As placas são identificadas, acompanhadas de um mapa que indica o seu nome e local de montagem. Cada painel tem seu número de elevação, curva, arco em famílias, tipo de curva especial, padrões de textura, data de chegada e data de montagem. 

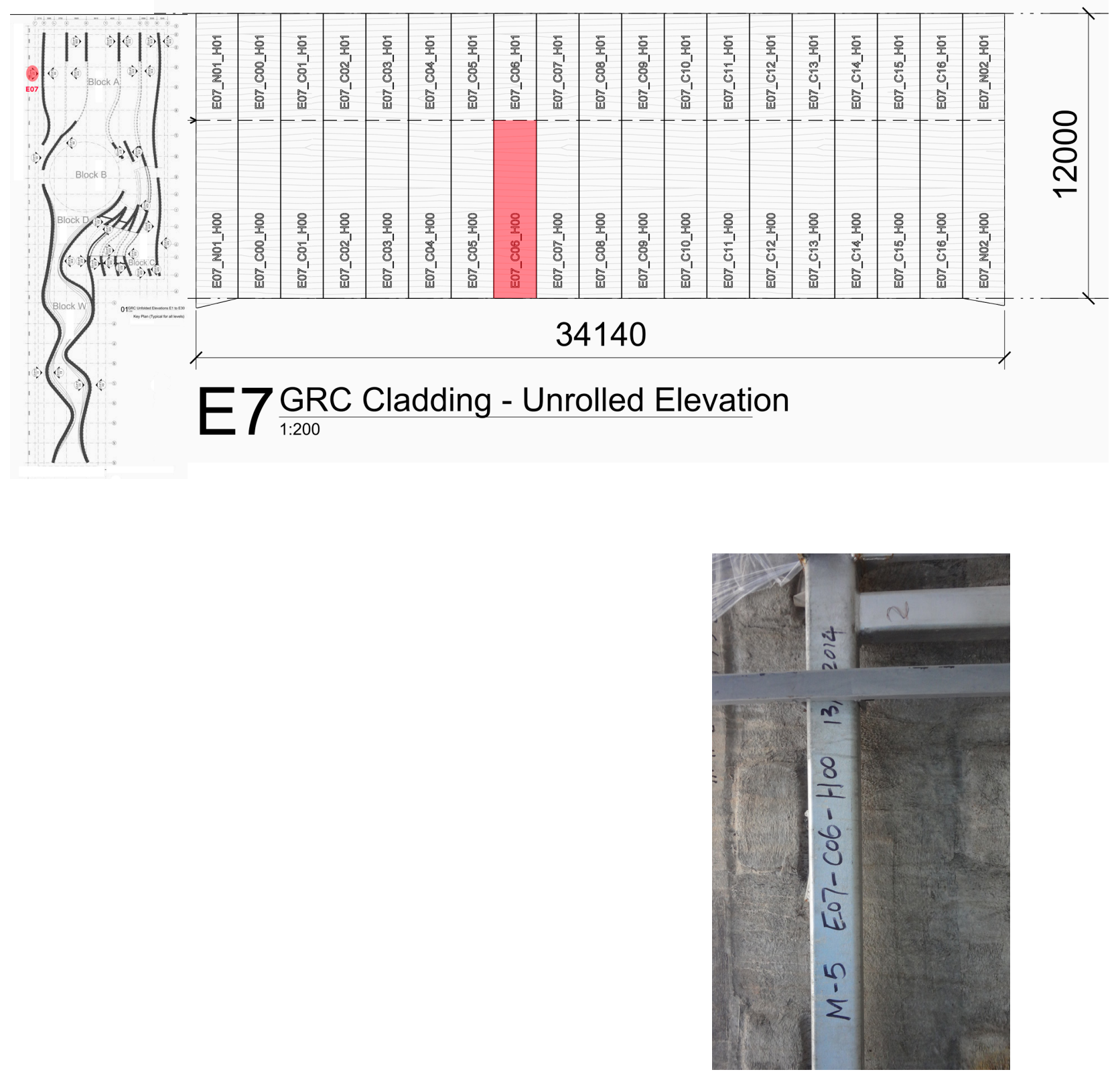
A montagem final ocorreu em 3 meses e os últimos acabamentos, como reparo de lascas, retirada de manchas, adequação da cor etc., foram feitos no momento da instalação, pela própria empresa coreana que fabricou os painéis.

O período da construção foi de julho de 2014 a abril de 2015. Uma construção de $5.000 \mathrm{~m}^{2}$ em 10 meses é ágil para o setor. Para atingir essa meta, foi necessário um planejamento minucioso para coordenar todos os sistemas, a logística de construção e de organização dos diversos parceiros envolvidos.

O canteiro de obras era praticamente todo ocupado pela edificação, sendo que poderia ter $3 \mathrm{~m}$ de recuo nas laterais e $10 \mathrm{~m}$ do recuo frontal. Para a montagem, foram utilizados guindastes, grandes caminhões que fizeram o transporte da estrutura metálica e dos painéis. $O$ canteiro foi organizado como mostram a figura 74 a seguir.

Figura 71: Planta Chave de Localização do Painel. Fonte: Foster \& Partners. Data: 2014.

Figura 72: Mapa de Localização do Painel. Fonte: Foster \& Partners. Data: 2014.

Figura 73: Identificação do Painel. Foto: autor. Data: 2016.
Da concepção ao final da construção, foram necessários 263 dias, com trabalho intensivo de colaboradores, encarregados, gestores em diferentes níveis, detalhamentos, logística, análises de montagem, aprovação de certifica- 


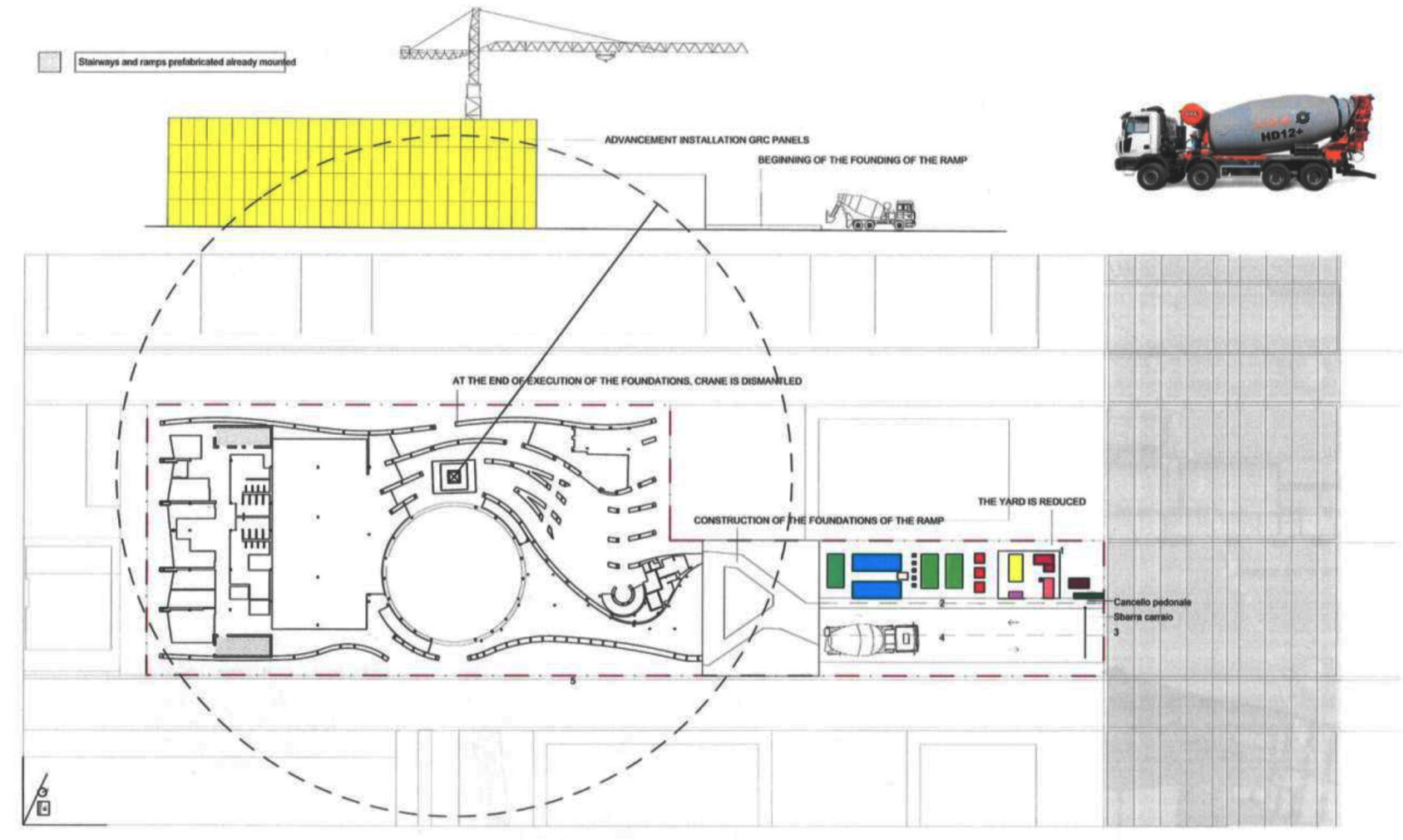


dos, elaboração e execução de protótipos, testes de comportamentos com materiais etc. Resultou em $129.426 \mathrm{~h}$ de homem/trabalho, que significa, para $5.000 \mathrm{~m}^{2}$,uma média de 492 homens por dia, com um alto grau de especialização para a produção do edifício. 
Figura 75: Torre Hadid e Pódio. Fonte: http://www.zaha-hadid. com/architecture/citylife-milano/. Escritório Zaha Hadid Architects. Data de Acesso: 21 jul 2017. 


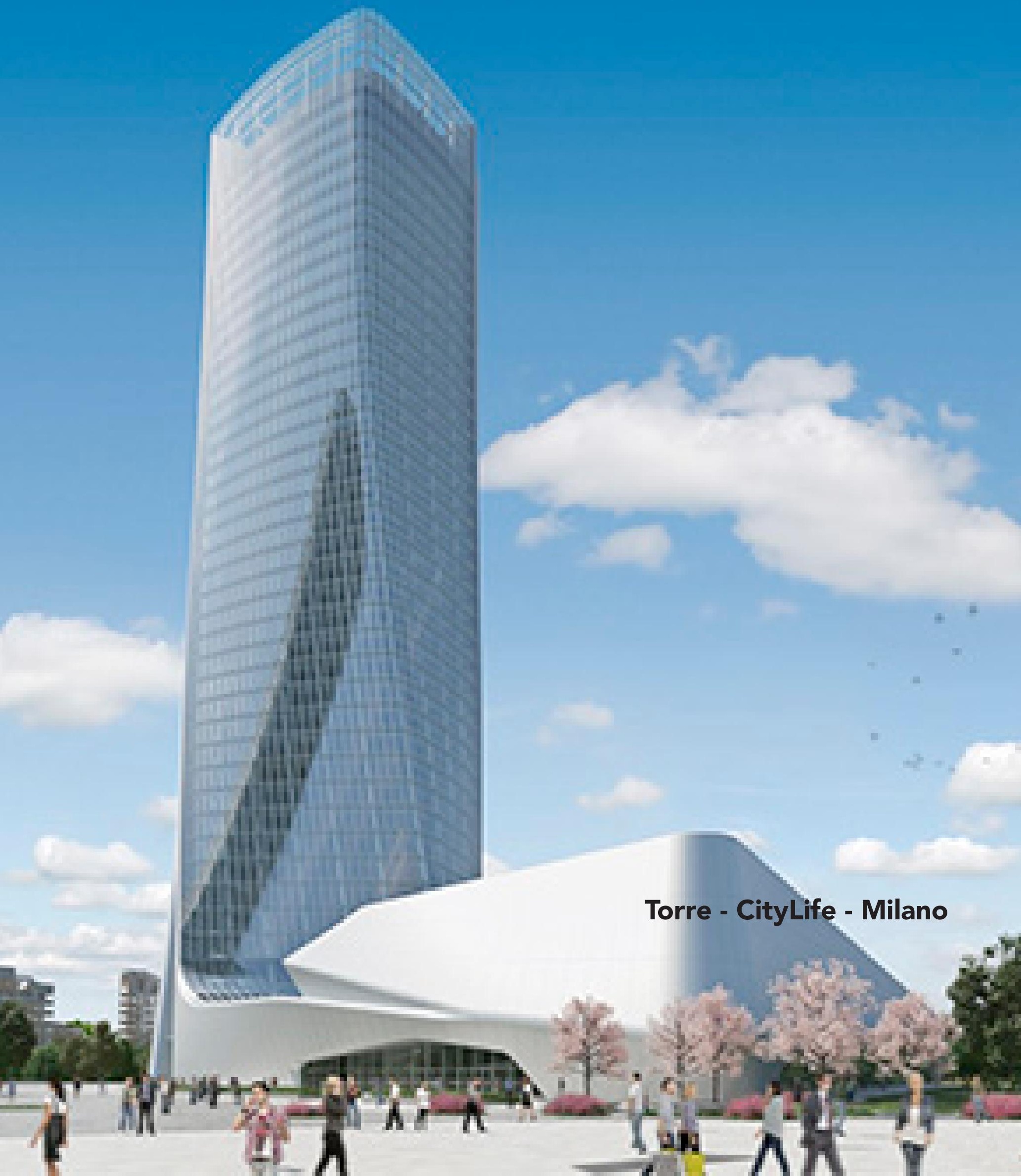



Essa etapa tem a intenção de apresentar o segundo estudo da pesquisa: uma torre de escritórios que faz parte de um complexo urbano com utilização mista entre área comercial, escritórios, parques e moradias. Está localizada a aproximadamente $5 \mathrm{~km}$ a noroeste da região central, na cidade de Milão - Itália.

O projeto urbano é resultado de um concurso realizado em 2004 em conjunto com os escritórios Studio Libeskind, Zaha Hadid Archtects e Arata Isozaki \& Associates, que desenvolveram o plano e reconectaram o tecido urbano existente a uma área abandonada onde eram realizadas as exposições e feiras desde 1920. A área da Feira mudou-se para a região periférica da cidade onde foi realizada a Expo Milão 2015.

O empreendimento de iniciativa privada, sob a coordenação da empresa Assicurazione Generali, de propriedade da Allianz Seguradora, está localizado no cruzamento de diversos eixos urbanos. $O$ projeto de aproximadamente $250 \mathrm{mil} \mathrm{m}^{2}$ conta com um parque de $100 \mathrm{mil} \mathrm{m}^{2}$, uma praça pública e uma estação de metrô no centro do empreendimento empresarial, duas grandes áreas residenciais de apartamentos e as três torres comerciais. Foi projetada 


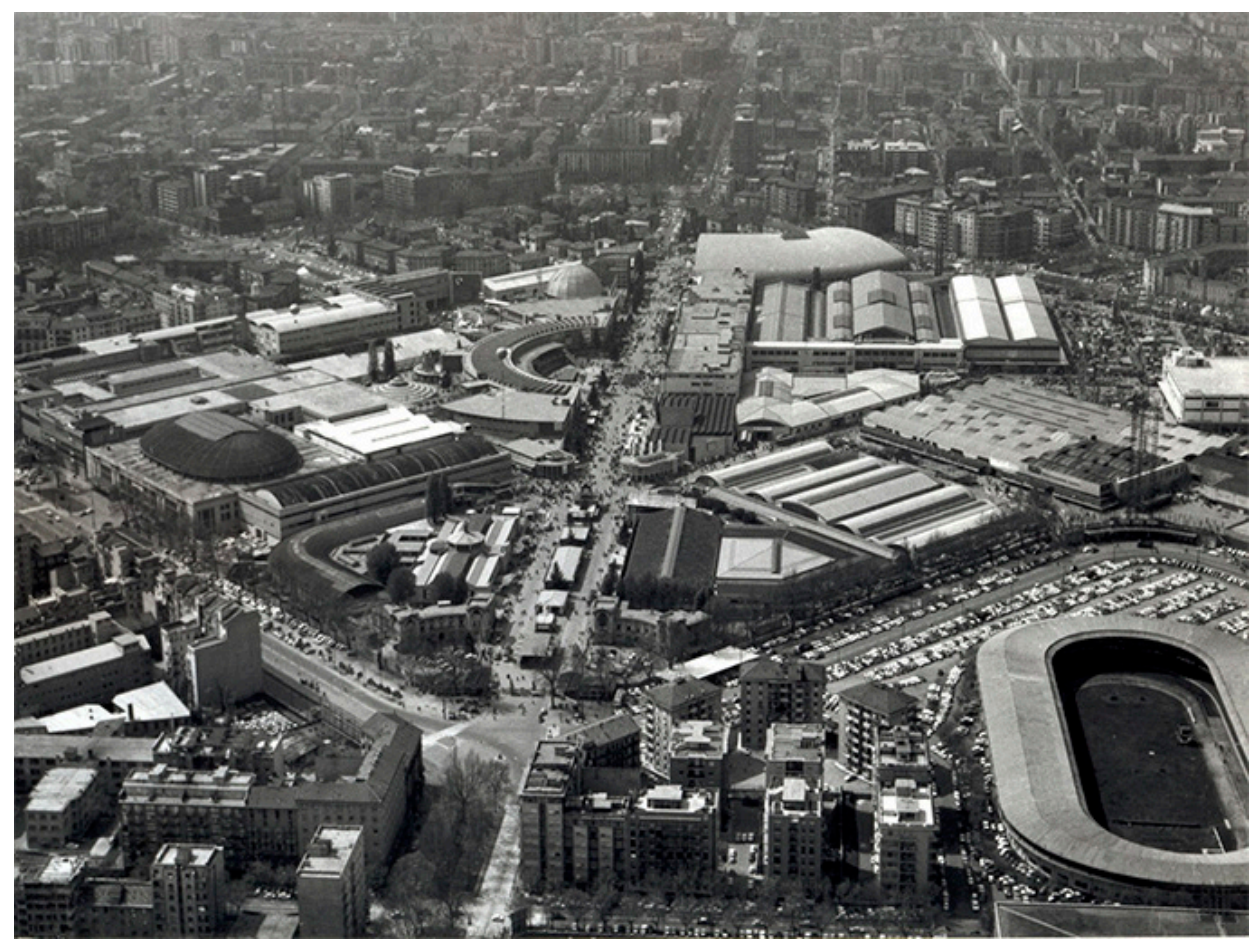

Figura 76: Local do empreendimento, antiga área de realização de feiras. Fonte: http:// www.city-life.it/en/project\#\&gi$d=1 \& p i d=1$. Data de Acesso: 21 jul 2017. 


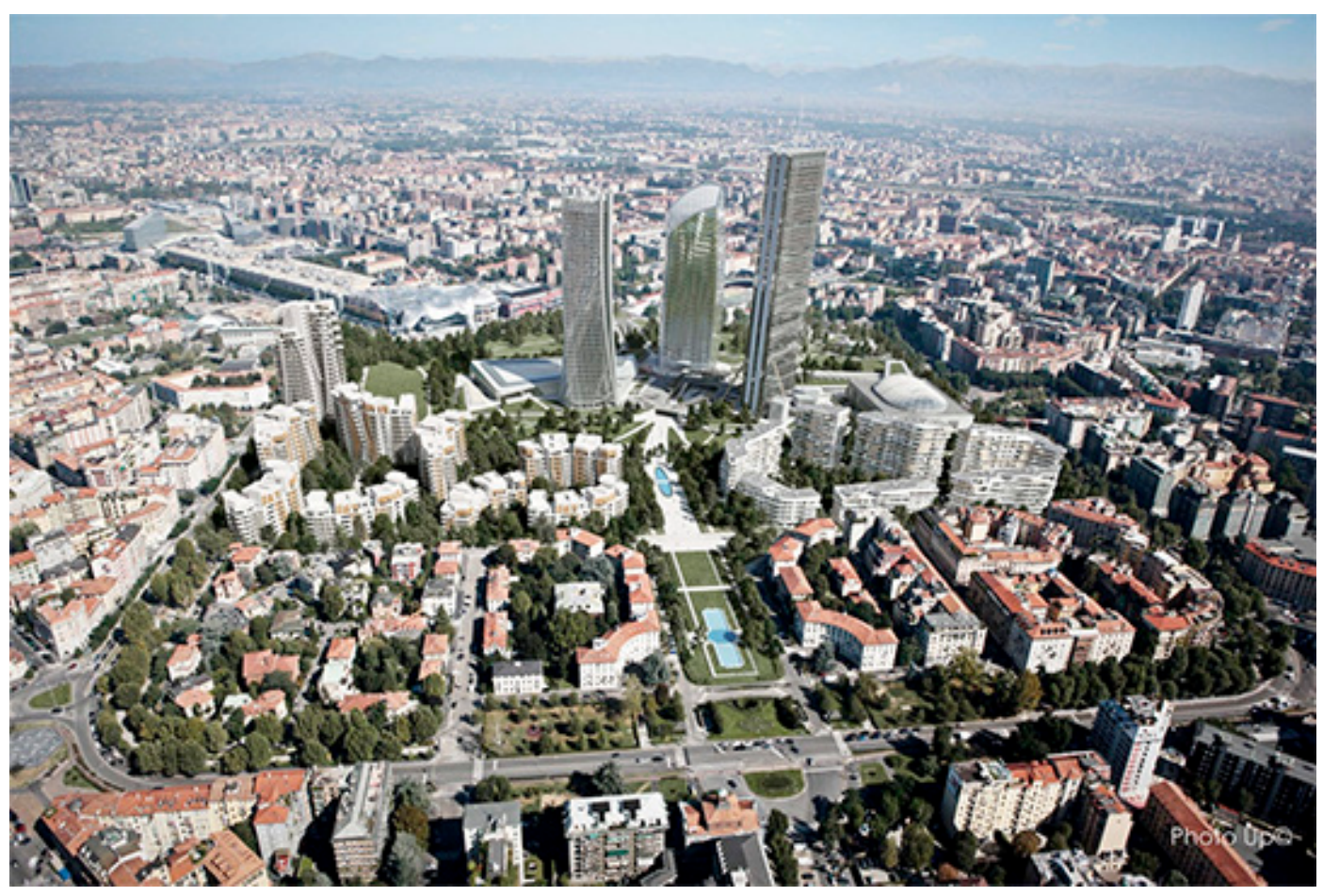

Figura 77: Vista aérea do empreendimento. Fonte: http://www.

zaha-hadid.com/architecture/

citylife-milano/. Data de Acesso:

21 jul 2017. 
uma grande área de estacionamento sob as torres, para deixar livres os espaços da cidade, que são ocupados com $5 \mathrm{~km}$ de ciclovias e um vasto caminho para pedestres.

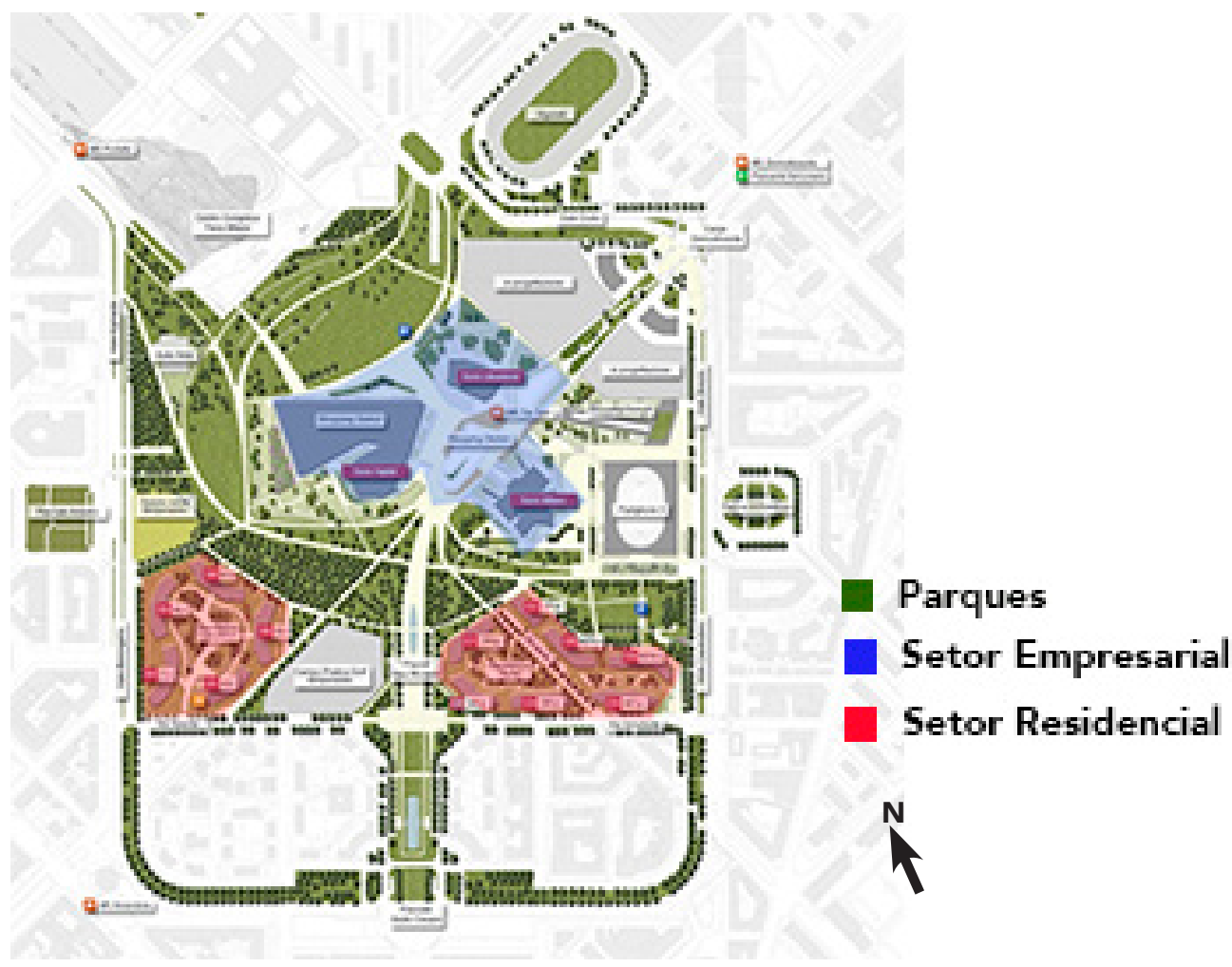

Figura 78: Projeto urbano. Área do empreendimento. Fonte: http://www.city-life.it/en/project. Data de acesso: 21 jul 2017. 
Além da participação no projeto urbano, o escritório Zaha Hadid Archtects elaborou uma das torres empresariais e um conjunto de residências, como mostra a figura 79 .

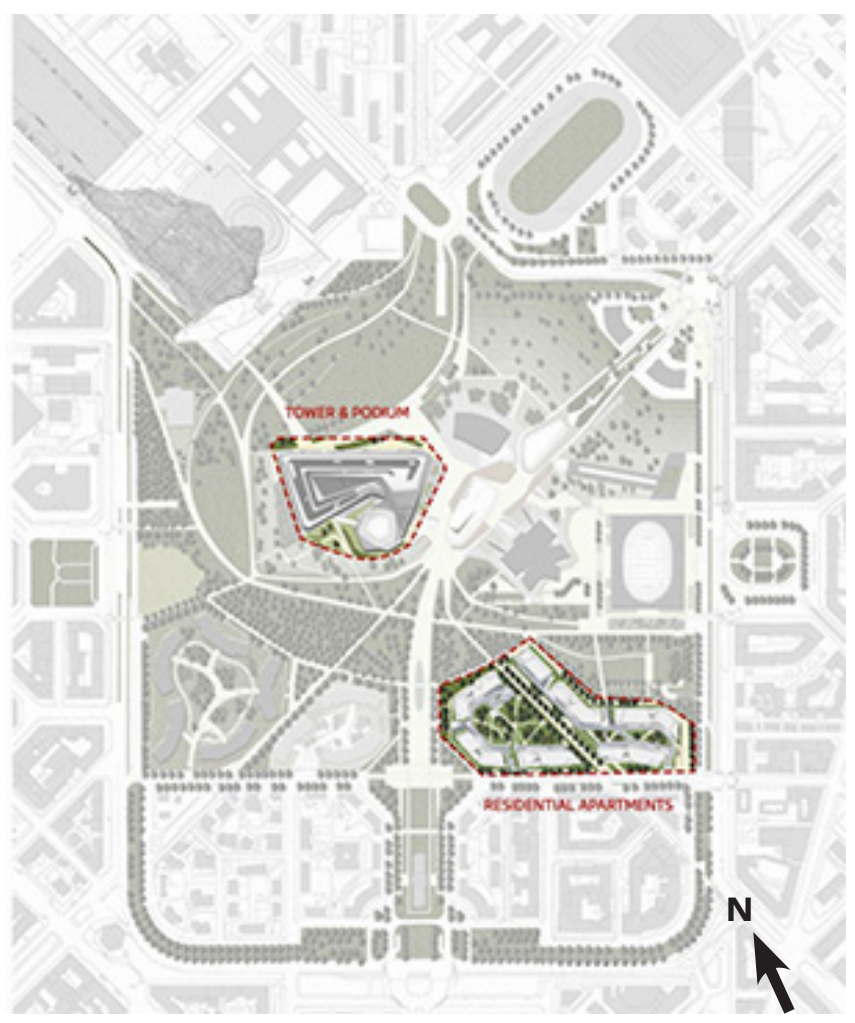

Figura 79: Localização da torre e do complexo residencial desenvolvidos pelo escritório Zaha Hadid Architects. Fonte: http:// www.city-life.it/en/project. Data acesso: 21 jul 2017. 
O complexo de moradias inclui sete edifícios lineares e se desenvolve em dois setores separados por uma grande via pública que se conecta ao parque e às torres. De acordo com os autores do projeto, o dinamismo do entorno fabril da região inspirou a geometria dos edifícios.

As torres, de autoria dos três escritórios que participaram do concurso, têm como intenção criar mais um centro empresarial para a cidade de Milão e, aos moldes dos empreendimentos norte-americanos, gerar ambientes que se transformem em ícones para a cidade, a partir de arquiteturas elaboradas por arquitetos renomados, que planejam monumentos urbanos.

Das 3 torres, a obra de Isozaki é uma lâmina fina recoberta com vidro duplo em forma curva. A torre de Libeskind é um edifício curvo nas duas faces voltadas para a praça central e a torre de Hadid apresenta um giro sobre o eixo vertical, como demonstra a imagem abaixo (Figura 81). Foi necessário 1 ano e 9 meses para o desenvolvimento do projeto das peles de vidro das torres.

As obras foram iniciadas em 2013, inicialmente pelas áreas urbanas, seguidas pelas residências e, atualmente, as
Figura 80: Vista aérea das residências de Zaha Hadid Architects. Foto: autor. Data: 2016. 


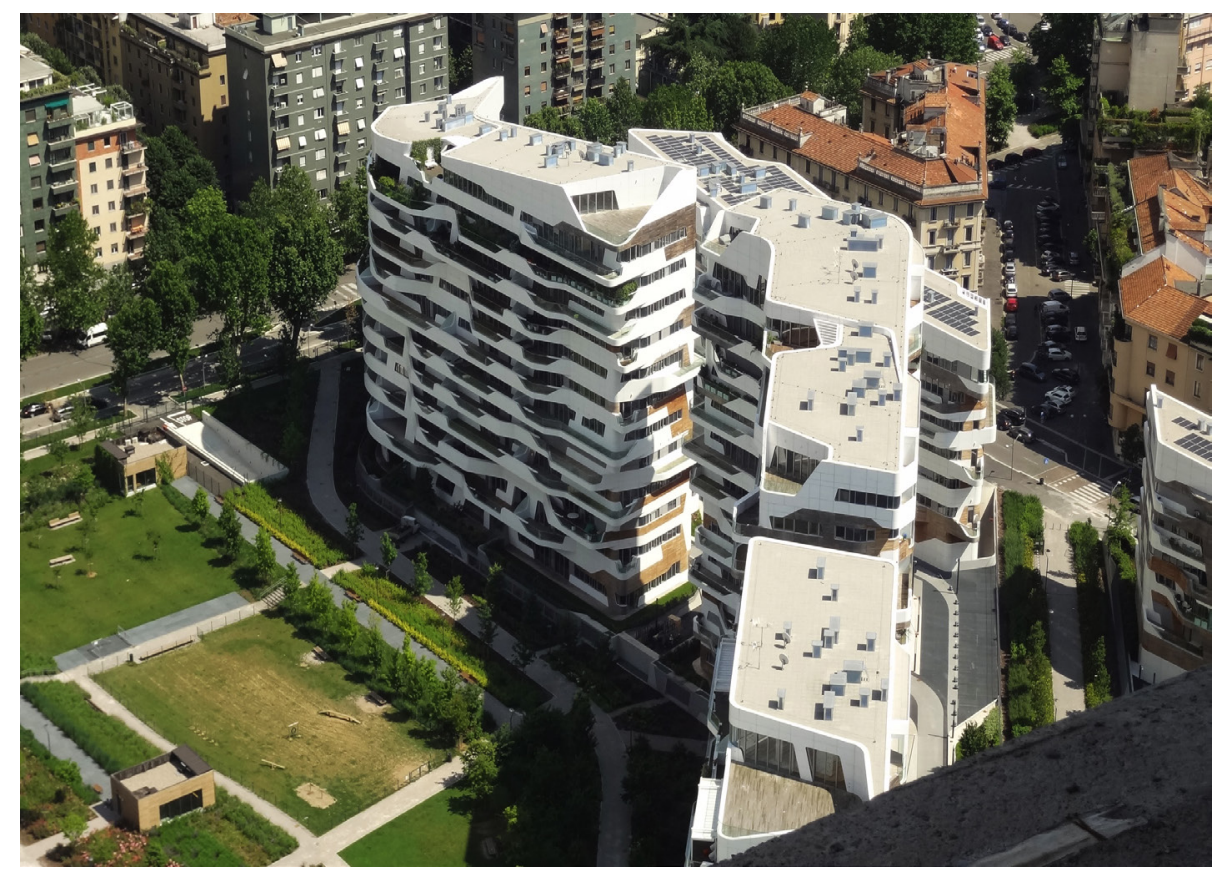




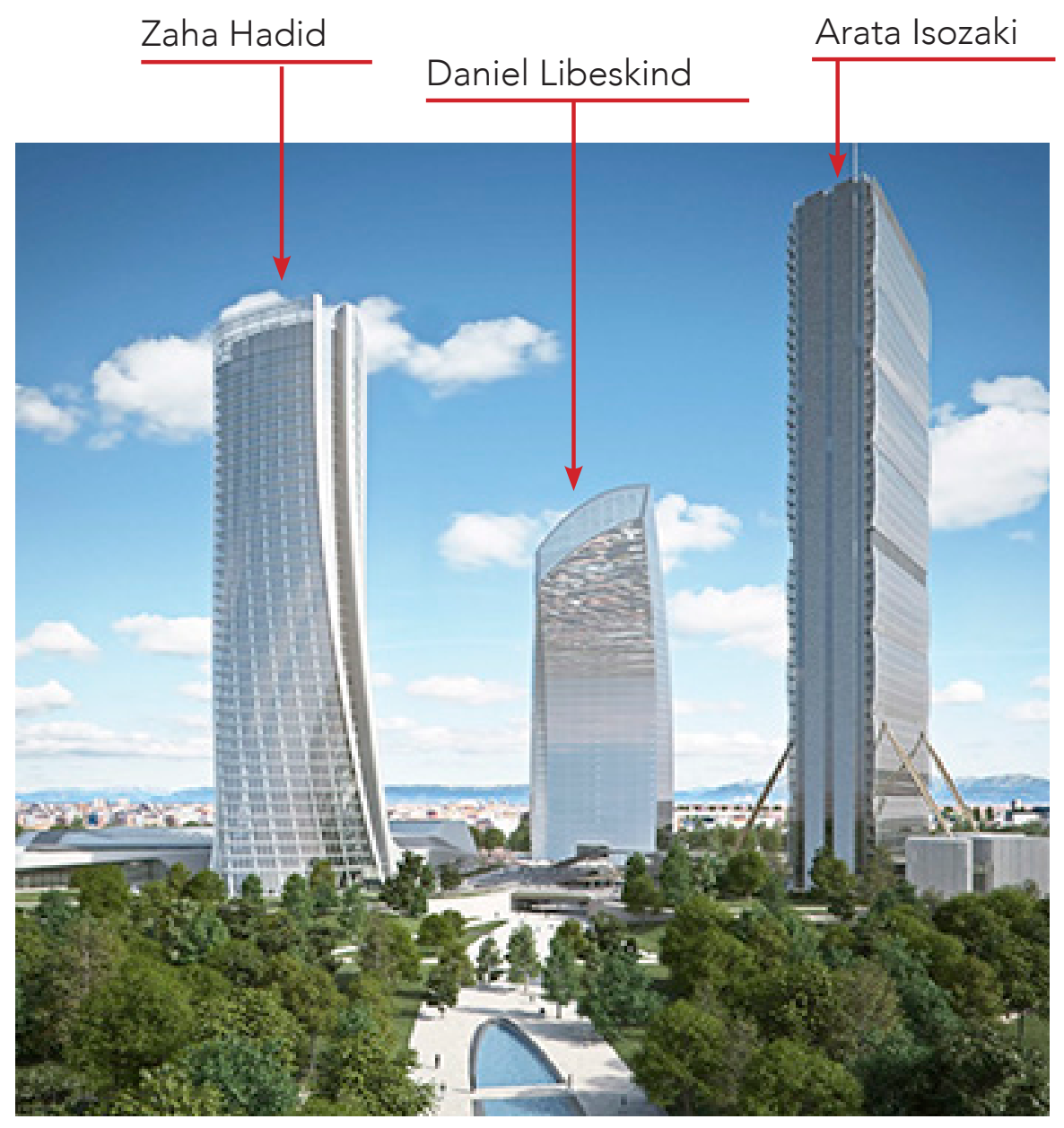


torres. A primeira torre a ser construída foi a lâmina de Isozaki e a segunda a de Hadid, cuja expectativa de finalização é para 2017. Após sua finalização, será iniciada a de Libeskind.

Após a apresentação do empreendimento, o trabalho se deterá em descrever o edifício do escritório Zaha Hadid Archtects e, em especial, a elaboração e produção da pele de vidro.

\section{Conceito}

Figura 81: Três Torres do empreendimento empresarial. Fonte: http://www.city-life.it. Data de acesso: 04 jan 2017.

A torre do escritório foi concebida a partir de planos de lajes cuja torção sob o eixo vertical é controlada algoritmicamente, de modo que cada piso tenha um ângulo relacionado aos pisos superiores e inferiores, levando dinamismo ao edifício'. Com 170 metros de altura, 44 níveis e $67.000 \mathrm{~m}^{2}$ de área construída, possui duas faces com pele dupla de vidro, que envolvem o edifício, e duas fendas, entre as faces, que percorrem a superfície da base ao topo e são cobertas por painéis de alumínio, que saem do nível zero do edifício e seguem a torção.

1 http://www.zaha-hadid.com/architecture/citylife-milano/\# 


\section{Desenvolvimento}

O projeto do empreendimento é resultado de um concurso em que os três escritórios - de Hadid, Isozaki e Libeskind - foram vencedores. $O$ investimento como um todo custou mais de $500 \mathrm{Mi}$ de euros, em $366.000 \mathrm{~m}^{2}$ de área construída. A torre de escritórios de Zaha Hadid Architects tem 67.000 m²; o pódio 15.000 m²; estacionamentos, armazenagens e paisagismo $40.700 \mathrm{~m}^{2}$, somando $122.700 \mathrm{~m}^{2}$ de projeto 2 .

As empresas que fizeram a gestão geral dos projetos foram a J \& A Consultants e a Ramboll, que realizaram a revisão e a aprovação dos desenhos em todos os estágios, da concepção à construção. A empreiteira responsável foi a BMS Projetti SRL, que trabalhou com as estimativas econômicas e consultores dos clientes. Das várias disciplinas envolvidas, tivemos: estruturas, geotécnica, elétrica, serviços, engenharia mecânica, elevadores, acústica, incêndio, transportes e fachadas.

A J\&A Consultants é uma empresa sediada em Milão -

2 Fonte: http://www.designboom.com/architecture/zaha-hadid-office-tower-citylife-milano/. Data de acesso: 17/jan/2017. 
Itália; está no mercado desde 1987, trabalha com gestão, controle e otimização de recursos de projetos, planejamento, gestão de certificações, gestão de custos, aprovações legais, desenvolvimento de testes, revisão de projetos, monitoramento de projetos, supervisão de obras, segurança do trabalho, além de gestão de canteiro de obras. Já atuou nas obras de: Porta Nuova Isola, em Milão - Itália, que é um empreendimento residencial com uma vasta área de jardins em cada apartamento; de Boeri Studio - nesse empreendimento, foi responsável pela gestão e controle de custos, gestão e planejamento de cronograma, planejamento de recursos e gestão geral. Outro projeto é a Fondazione Alda Fendi, em Roma - Itália, do arquiteto Jean Nouvel; é uma requalificação de um edifício em ambiente de exposições e arte. Nesse projeto, a empresa executou a gestão geral e gestão dos projetos.

A empresa Ramboll é uma empresa de origem dinamarquesa, fundada em 1945, e trabalha na área de edificações, transportes, planejamento e projetos urbanos, recursos hídricos, meio ambiente, energia, óleo e gás, telecomunicações e como consultora de gestão. Esteve envolvida nos projetos de expansão do Aeroporto Internacional de 
Abu Dhabi, do escritório Kohn Pedersen Fox Associates (KPF) - nesse projeto, a Ramboll foi responsável pela gestão geral, pelos projetos de engenharia e infraestrutura. No Copenhagen Opera House, do arquiteto Henning Larsen, o escritório atuou como consultor de engenharia e no Vanke Pavilion - uma edificação desenvolvida para a Expo 2015 -, do Studio Daniel Libeskind, o escritório trabalhou no projeto de estruturas e vedação do pavilhão; um complexo trabalho que utilizou aço e placas de vedação que lembram escamas de serpente.

Em relação ao detalhamento da fachada da Torre CityLife, esta foi realizada inicialmente pelo escritório ARUP Milão e, posteriormente, executada por uma empresa de origem chinesa chamada Yuanda ${ }^{3}$, que está se instalando também na Europa:

- A ARUP - Milão é um escritório como tantos outros que estão distribuídos por todo o mundo, inclusive no Brasil. Trabalha com projetos e detalhamentos, gestão e planejamento, projetos de infraestruturas, consultoria de gestão e serviços técnicos especializados. $\bigcirc$ escritório de Milão esteve envolvido no

3 Fonte: http://www.yuandacn.com/index.php?lang=en 
projeto do Museu do Amanhã do Rio de Janeiro, de Santiago Calatrava, além de ter realizado o projeto das peles de vidro dos outros edifícios do empreendimento analisado.

- A fábrica Yuanda se localiza na China, e alguns escritórios de desenvolvimento estão sediados em países europeus. É especializada em fabricação de estruturas e sistemas de fechamento, utilizando vidro e materiais flexíveis, especialmente Curtain Walls. Tem em seu portfólio obras como o Cubo D'água construído para as Olimpíadas de Pequim,do arquiteto John Pauline, em 2008, o Ninho do Pássaro, de Herzog \& De Meuron, entre outros.

- A empreiteira responsável pela construção foi a BMS Projetti SRL, de origem italiana, fundada em 1988. É subdividida em arquitetura, estruturas e MEP (Mechanical, Electrical and Plumbing - Mecânica, Eletrica e Hidráulica); oferece serviços nas áreas de desenvolvimento e detalhamento de projetos, gestão de projetos e construção, consultorias técnicas e administrativas, coordenação de segurança e supervisão de trabalhos. Foi responsável pelo projeto estrutural 


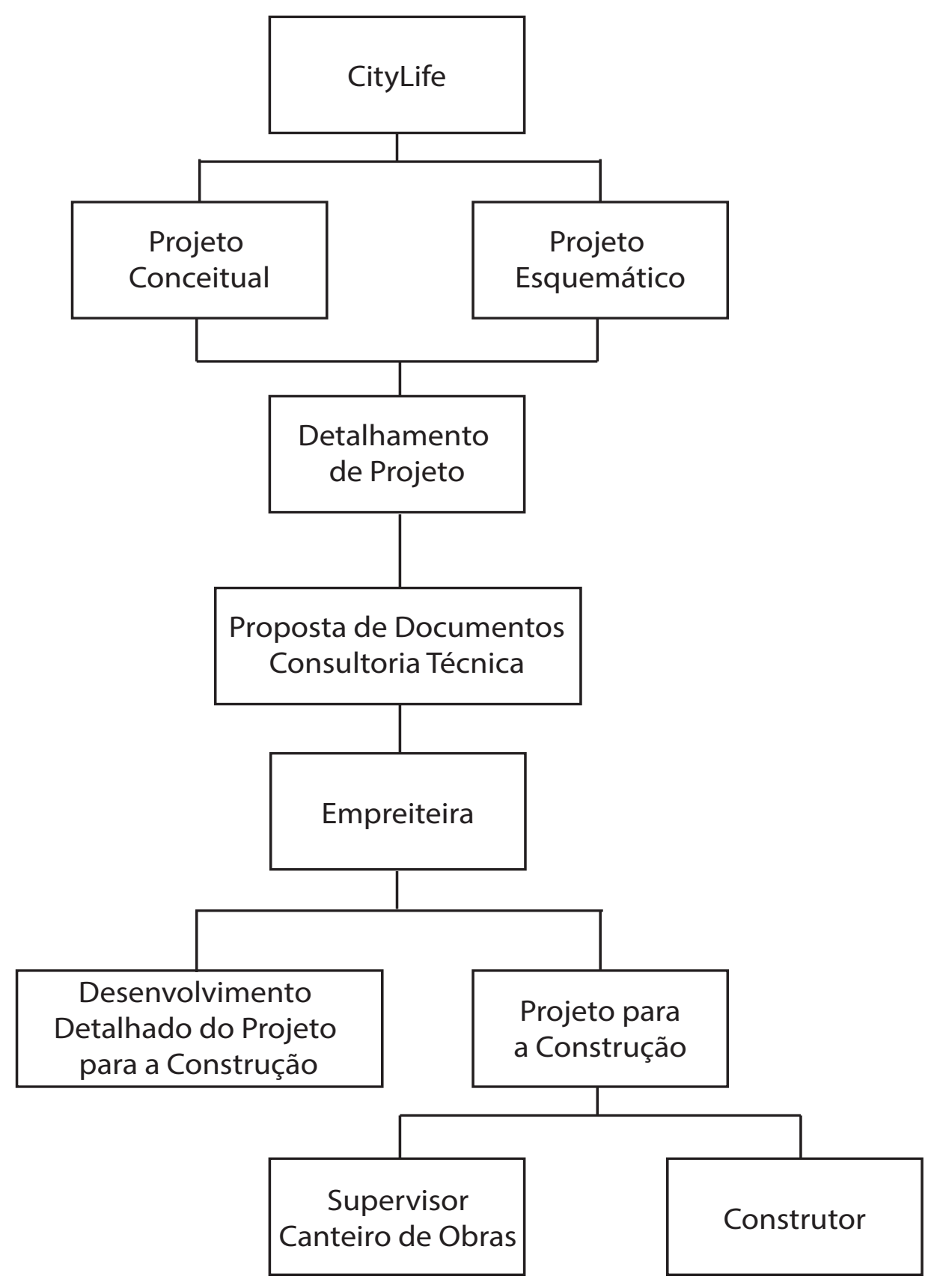

Diagrama 9: Organograma de Desenvolvimento de projeto. Fonte: autor, segundo entrevista de Roberto Ferrari - Ramboll. Data: 2016. 
e MEP do pavilhão da Itália na Expo 2015, do escritório Nemesi \& Partners SrL, pela reforma da Estação Central de Milão, originalmente de Louis-Jules Bouchot, de 1846, e pela cobertura da área de circulação da Feira de Milão do Studio Fuksas, em 2005.

Em relação à organização do trabalho, os clientes denominados CityLife contrataram o escritório de arquitetura para o desenvolvimento do projeto conceitual e os primeiros esboços. A partir disso, esse projeto foi encaminhado para escritórios especializados, que desenvolveram cada disciplina correspondente.

No caso da vedação da torre de Zaha Hadid Architects, o projeto foi desenvolvido pelo escritório de Milão e supervisionado pela Ramboll. No entanto, esse projeto passou para a execução da empresa chinesa, que adequou os desenhos, produziu os componentes e foi responsável pela montagem em canteiro de obras.

Em relação às outras disciplinas, o processo foi semelhante, sendo que a gestão geral e a compatibilização dos vários projetos foram realizadas pela própria empreiteira e também pela coordenadora de projetos, que recebia os 
desenhos já verificados e aplicava no programa para uni-los. Assim, a gestão para a produção do empreendimento foi toda realizada pela própria empreiteira, que estava diretamente ligada ao cliente promotor do empreendimento. Nesse caso, verifica-se que as principais peças são os revisores dos projetos, e a empreiteira, que agrega e compatibiliza praticamente todos os projetos, faz a gestão de recursos e da obra.

As informações disponíveis sobre as compatibilizações através dos sistemas BIM foram utilizadas para a fase de revisão das diversas disciplinas de projeto. A empresa utilizou o programa NavisWorks, da Autodesk, e a empreiteira executou as compatibilizações através do Revit, também da Autodesk. O projeto das estruturas e o de gestão da construção foram feitos com o programa TEKLA, pois, no campo da produção, são mais efetivos em relação aos custos e à qualidade. A utilização dos programas de modelagem é uma realidade e o seu uso no processo certamente contribuiu para a diminuição dos equívocos que poderiam ser provocados no estágio da execução. 


\section{Organização do Espaço - Plantas}

Em sua base, o edifício possui a parte comercial, denominada pódio, que é ocupada por área de alimentação e serviços, e o setor da torre é ocupado por escritórios, como demonstra a figura 82.

A planta do pódio (Figura 83) é composta pela área pública comercial, que possui duas entradas laterais, e os serviços são distribuídos na periferia. A estrutura da cobertura do pódio é metálica, com dupla camada: parte em vidro e parte em alumínio.

A planta da torre (Figura 84) possui, no núcleo central, as áreas de circulação vertical, com as caixas de armazenagem e sanitários, e, na região periférica, as áreas de trabaIho e escritórios, com a circulação horizontal entre a periferia e o centro. A planta é segmentada pelas duas fendas nas extremidades, que, de um lado, estão voltadas para a vista de quem chega ao piso pelos elevadores (Figura 85) e, do outro lado, estão reservadas para as salas de reuniões. 


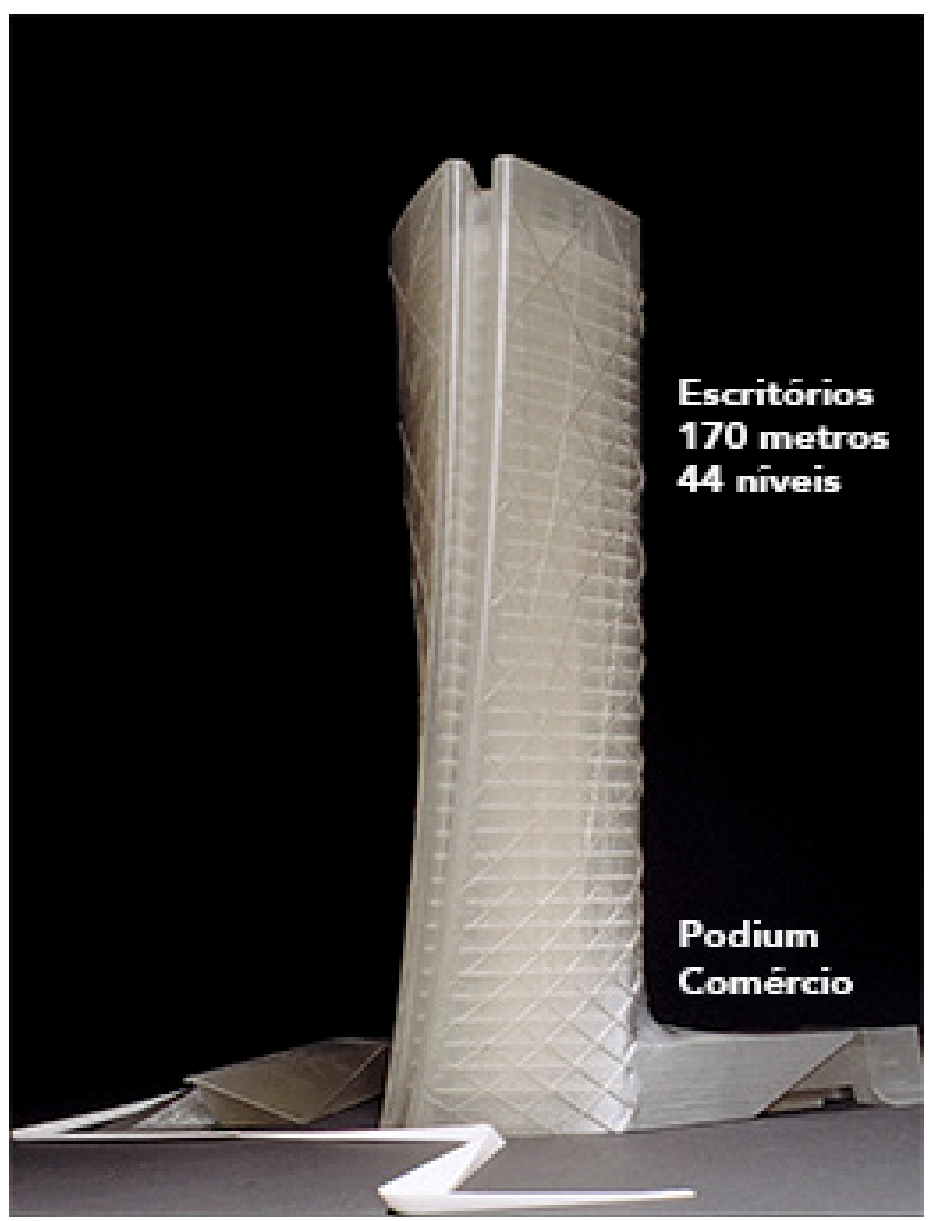

Figura 82: Maquete ilustrativa do edifício misto. Fonte: http:// www.zaha-hadid.com/architecture/citylife-milano/\#. Data acesso: 21 jul 2017 


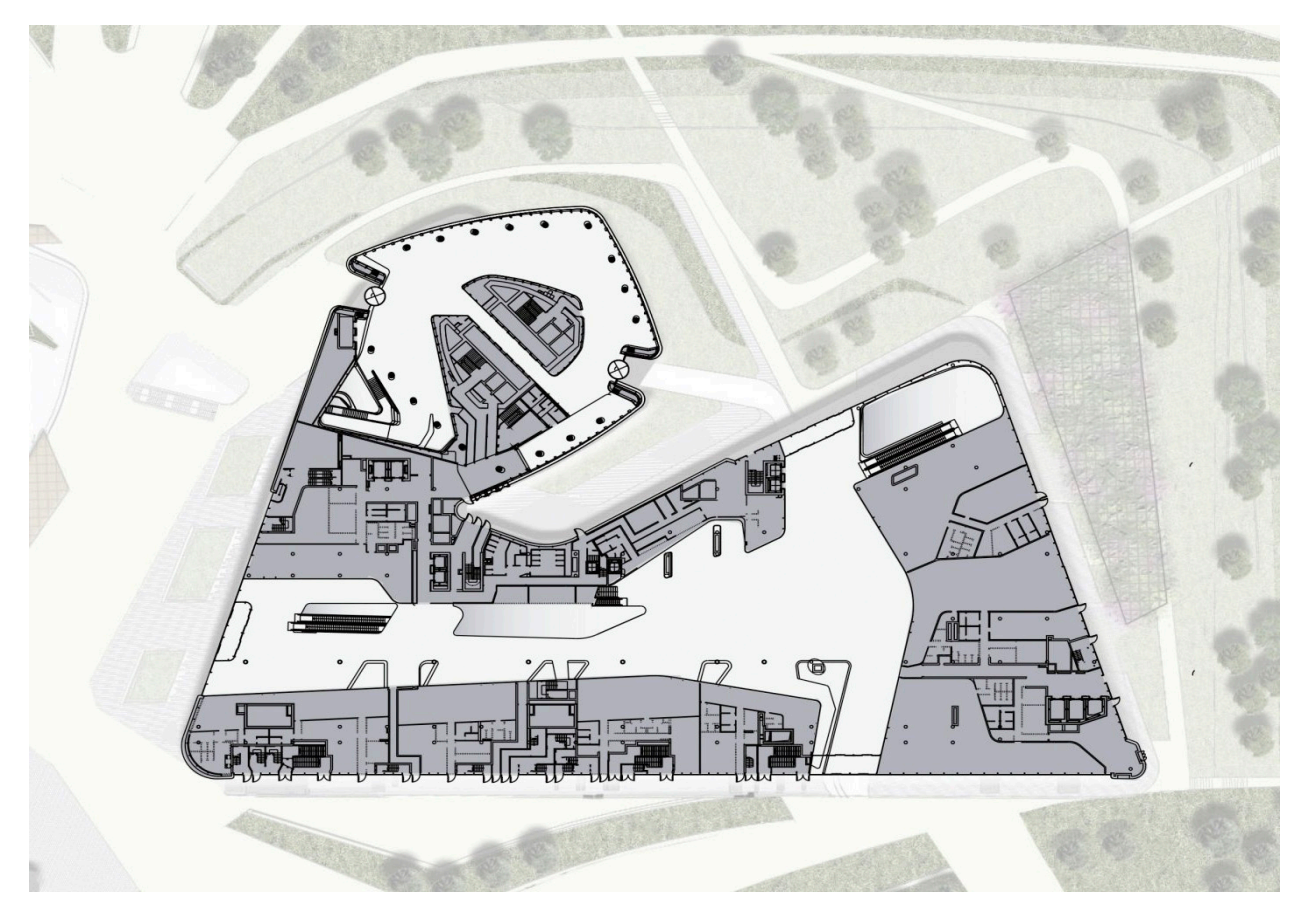

Figura 83: Planta Pódio. Fonte:

http://www.zaha-hadid.com/

architecture/citylife-milano. Data

de acesso: 27 jun 2017. 


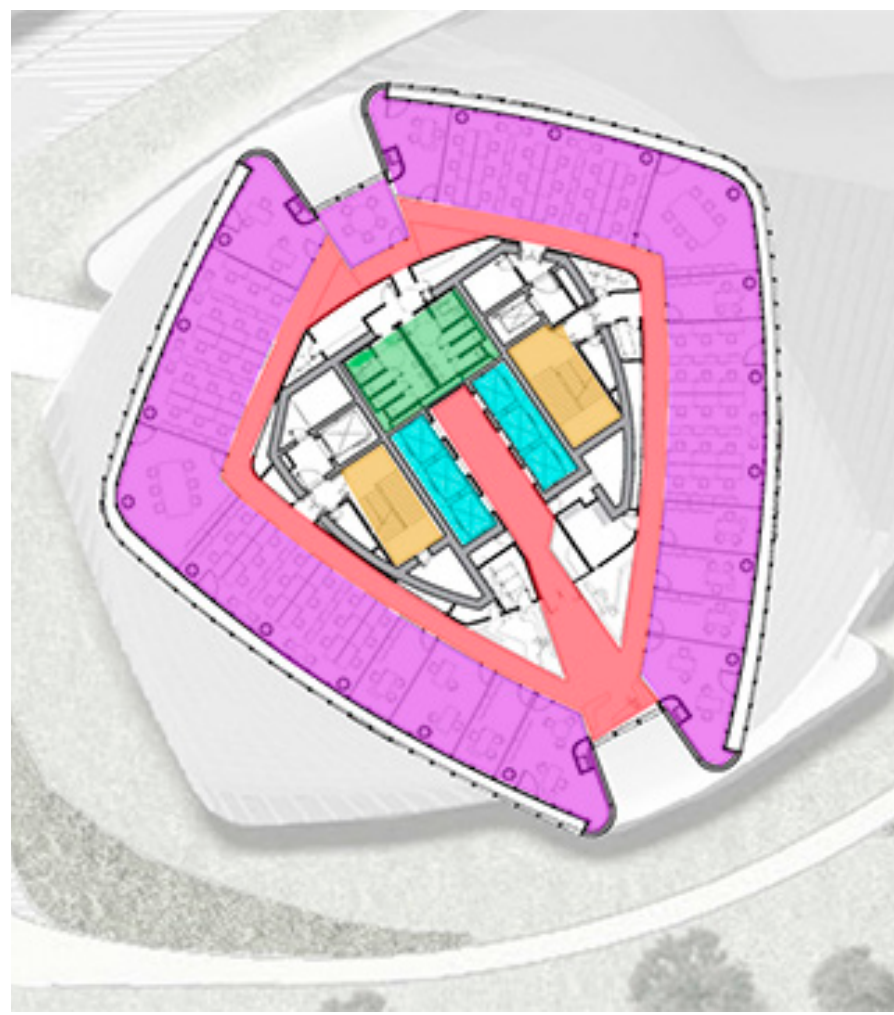

Escritórios

Circulação Vertical Elevadores

Circulação Vertical Escadas

Sanitários

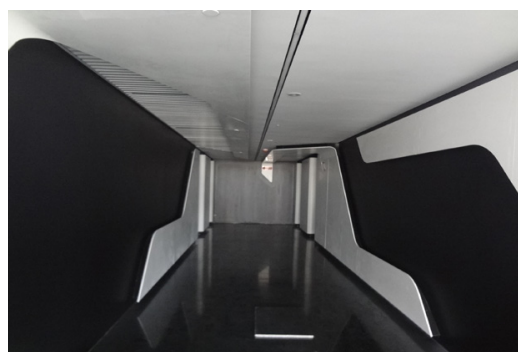


Nos cortes, é possível observar a conexão entre as áreas reservadas para o estacionamento, pódio e torre, além do piso superior com pé direito triplo, que é utilizado para reuniões maiores e atividades de confraternização, além de ser um mirante para a cidade de Milão, que tem aos seus pés o estádio de futebol do Inter de Milão e toda a extensão da cidade: deste local, é possível ver a catedral de Duomo e os prédios altos do setor empresarial de Porta Garibaldi, próximo ao centro (Figuras 86/87).

A vista é garantida pelo gabarito da cidade, que, em grande parte, possui no máximo 6 pavimentos, e as áreas com edifícios altos são: a região já mencionada acima, a região das 3 torres e a região de exposições e feiras. Resultado desse gabarito são os aspectos visuais, de insolação, ventilação e qualidade do ar, que são características de uma qualidade de vida notável dos cidadãos em uma cidade deste porte, com aproximadamente 1.300 .000 habitantes.

Figura 84: Planta Torre. Fonte: www.zaha-hadid.com/architecture/citylife-milano. Data de acesso: 27 jun 2017. 


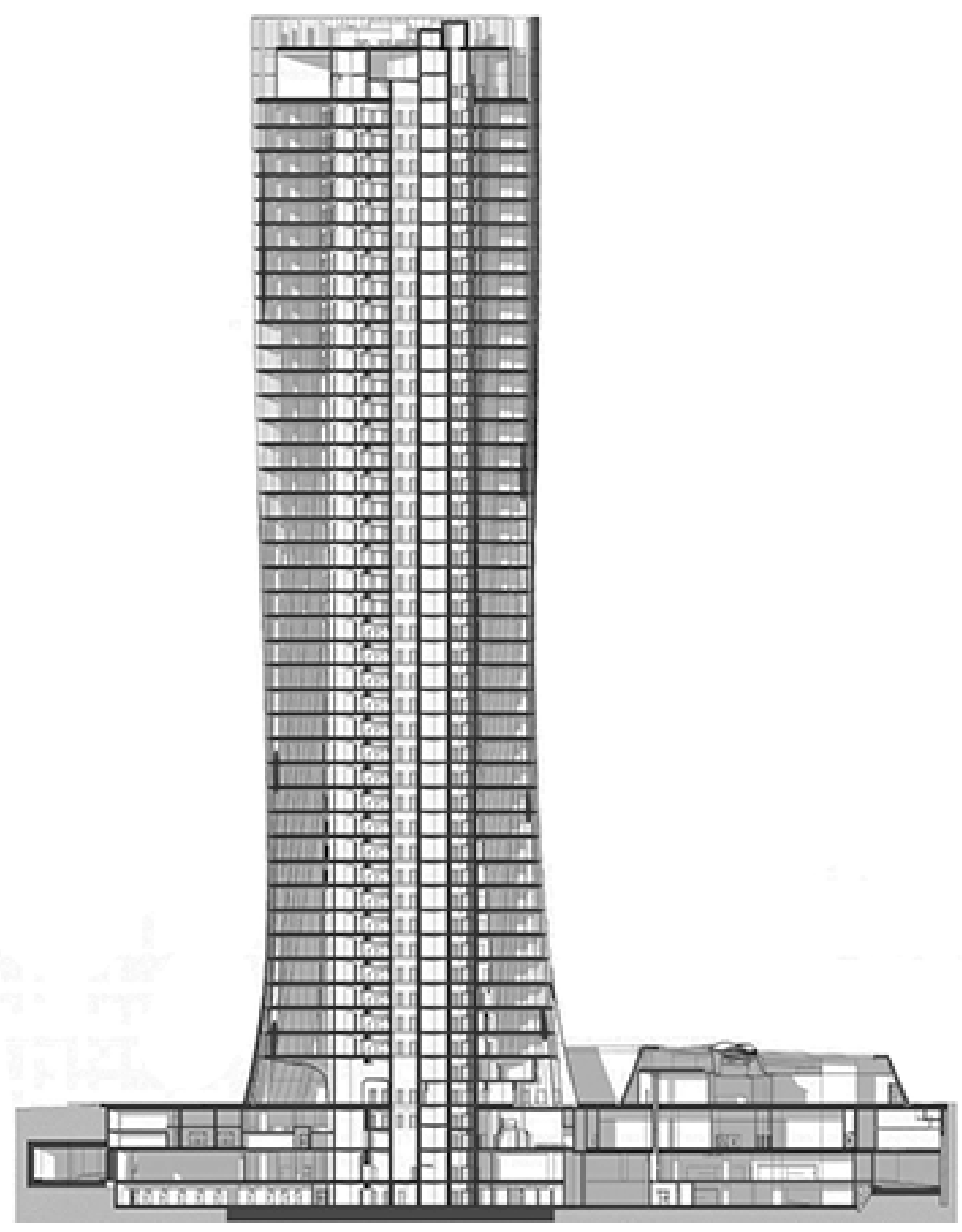

Figura 86: Corte da torre com pódio. Fonte:

http://www.zahahadid.com/architecture/citylife-

-milano. Data de acesso: 27 jun 2017. 


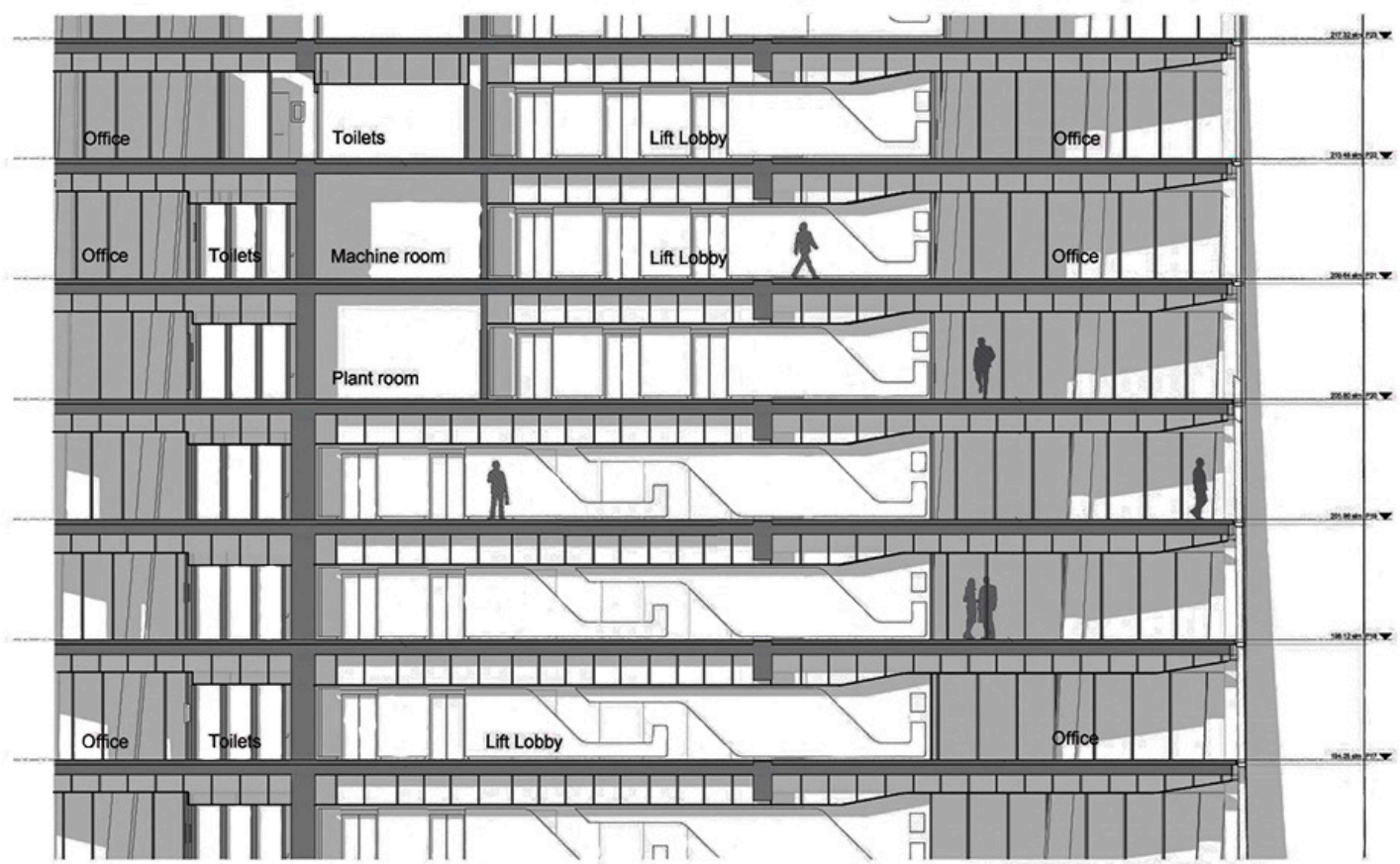

Figura 87: Corte da torre. Fonte:

http://www.zaha-hadid.com/

architecture/citylife-milano. Data

de acesso: 27 jun 2017. 


\section{Estrutura}

A estrutura da torre é formada pelo núcleo central vertical de concreto armado (Figura 88/89), que envolve a circulação vertical e os banheiros, e pelos pilares na periferia do edifício. $\bigcirc$ núcleo do edifício é fixo e a torção é dada na construção das lajes. Os pilares nos níveis inferiores são mais espessos (aproximadamente $80 \mathrm{~cm}$ de diâmetro) e seguem a mesma inclinação da torção da torre, com $180^{4}$. Nos níveis superiores, estes estão praticamente em ângulo reto em relação ao piso e sua espessura se reduz a aproximadamente $20 \mathrm{~cm}$ de diâmetro. Importante lembrar que na Itália podem ocorrer abalos sísmicos, sendo fundamental assegurar uma estrutura robusta, que garanta a segurança dos usuários; sendo assim, o sistema construtivo utilizado para se obter maior rigidez é o concreto armado com formas.

Para a execução da fundação, foi construída uma grande gaiola armada, que pega toda a extensão do edifício, formando uma plataforma. Foram necessárias 50 horas contínuas de concretagem, provenientes de 4 usinas, com uma

$4 \bigcirc$ ângulo dos pilares era $25^{\circ}$, que foram modificados para $18^{\circ}$, atendendo à solicitação da equipe de projeto para a produção.
Figura 88: Estrutura da Torre.

Fonte: http://www.zaha-hadid. com/architecture/citylife-milano. Data de acesso: 27 jun 2017.

Figura 89: Núcleo central de concreto. Foto: autor. Data: 2016.

Figura 90: Largura da área de escritórios e circulação, coluna inclinada em $6^{\circ}$ piso. Foto: Autor, Data: 2016. 

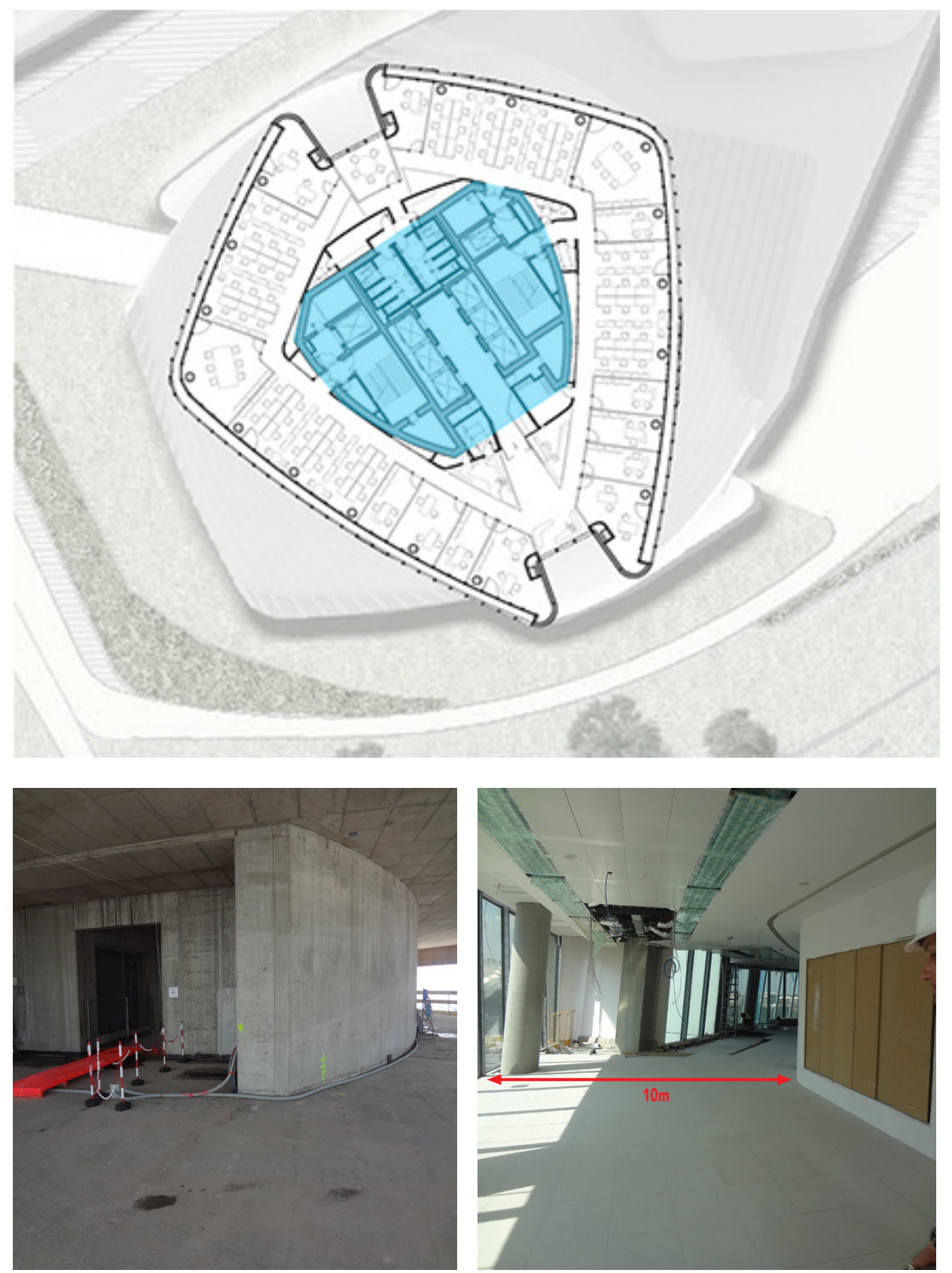
descarga de 750 betoneiras.

A área para os escritórios está distribuída em uma laje com 10 m de largura (Figura 90), no entorno do núcleo de circulação, que é apoiado pelos pilares externos. Essa laje teve sua extensão aumentada para a colocação das esquadrias dos vidros duplos (Figura 91), sob solicitação do escritório que desenvolveu o projeto da vedação do edifício. Nesse esquema abaixo, do sexto pavimento, também é possível verificar os pilares inclinados de espessura média, o sistema de ar-condicionado e calefação sob o teto e o piso elevado aplicado sobre a laje.

A partir disso, a próxima etapa é descrever o projeto para a produção da superfície da torre do escritório Zaha Hadid Architects. 


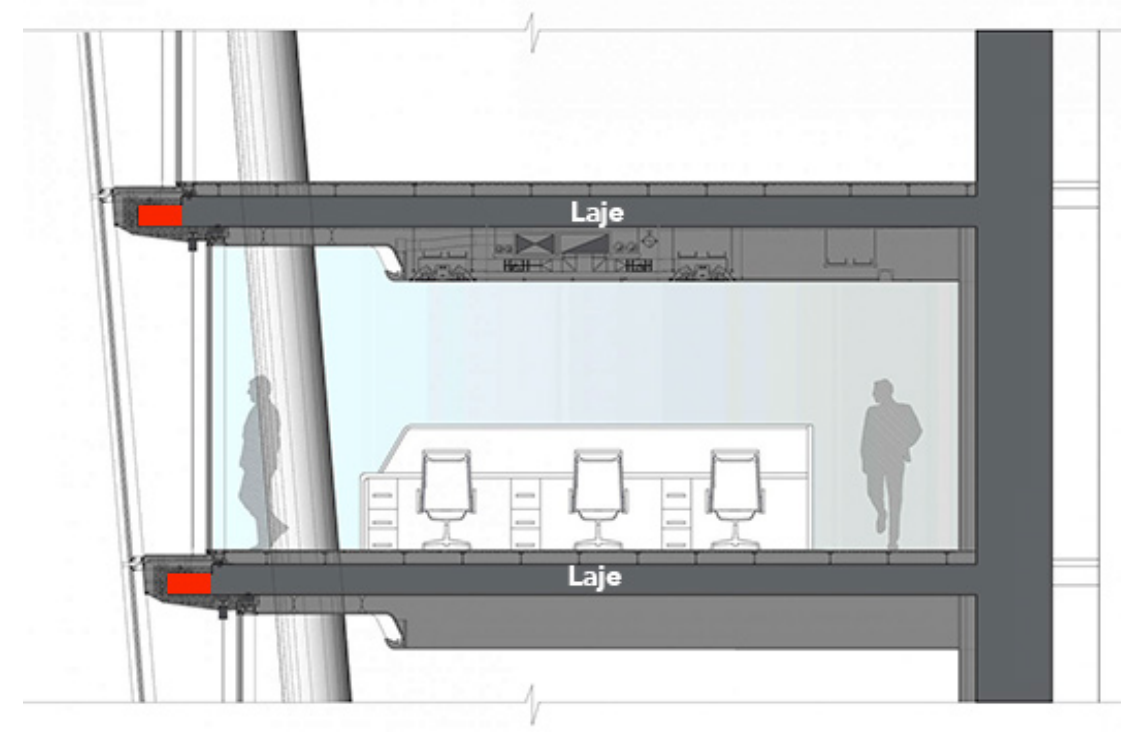




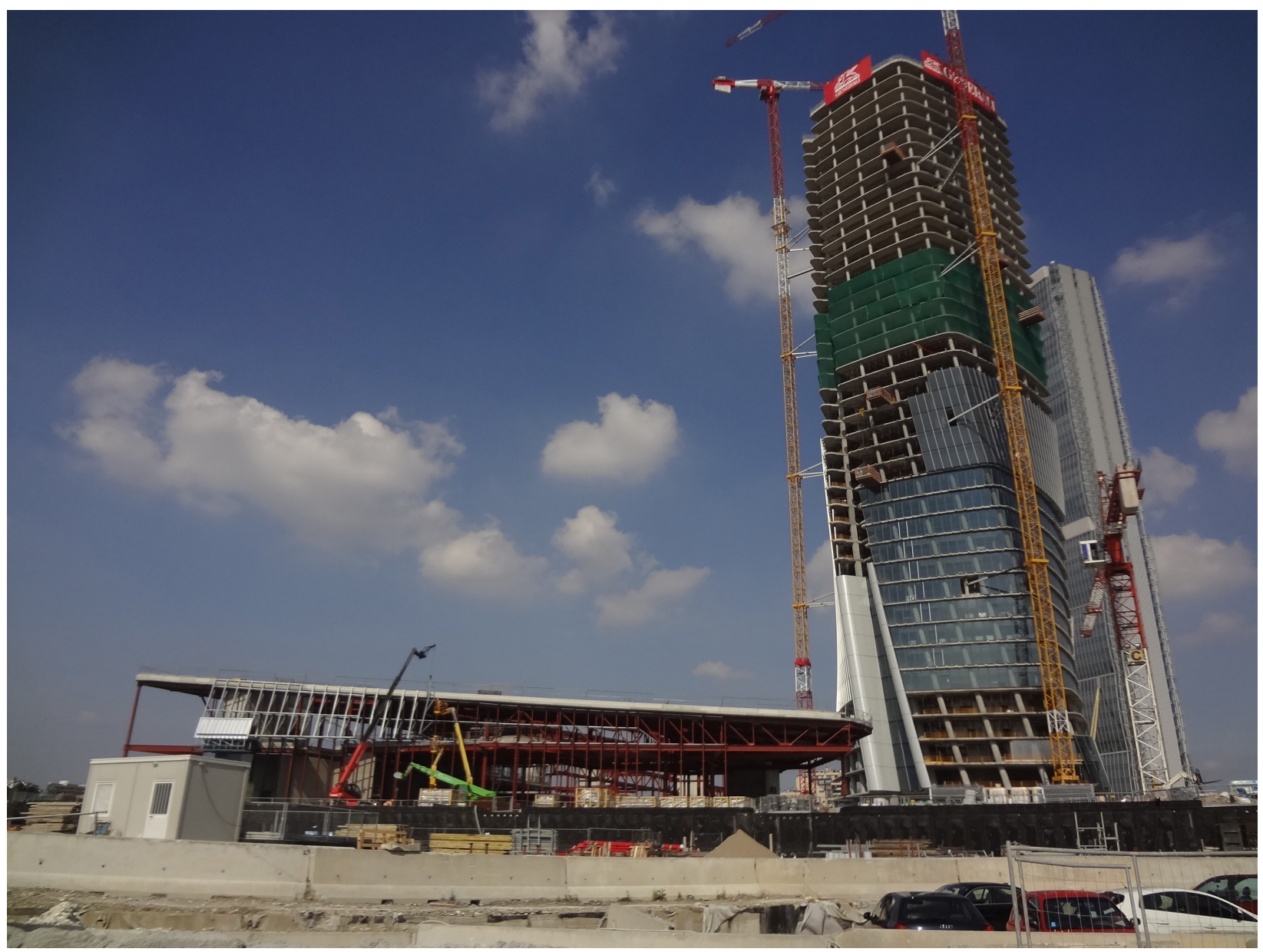




\section{Projeto para a Produção dos Painéis}

A elaboração da superfície de $15.000 \mathrm{~m}^{2}$ tem conformação com vidros duplos e foi projetada em planos independentes, como duas peles separadas. A superfície de vedação da torre é composta basicamente de vidro e aço; as células foram desenhadas individualmente com uma placa de vidro e sua esquadria.

A pele externa define a forma distorcida do edifício; é gerada por um algoritmo em que, geometricamente, o modelo está sempre sob controle das dimensões dos painéis, da orientação, torção, do grau de insolação etc. O escritório que desenvolveu o projeto faz uso dos programas Rhinoceros com plugin Grasshopper, Catia (Computer Aided Three-Dimensional Interactive Application), desenvolvido para o setor de manufatura, engenharia, criado pela Dassault Systèmes, e o programa SolidWorks, também da Dassault Systèmes, um dos mais antigos e é utilizado para modelagem 3D do setor da engenharia mecânica, nas demais engenharias e na manufatura.

Figura 92: Torre + pódio em construção. Foto: autor. Data: 2016
A geometria da superfície é criada a partir de um projeto conceitual do escritório de arquitetura. A partir disso, o 
escritório responsável pelo projeto analisa a melhor geometria e qual a melhor forma de parametrizar essa superfície de acordo com as indicações dos autores, incorporando as necessidades de conforto ambiental, requisitos de aberturas, ventilação etc. Para a sua elaboração, é necessário satisfazer os requisitos de arquitetura, de estruturas e subestruturas e os requisitos da fachada, que são determinados pelos parâmetros dados da geometria. Ao atender esses requisitos, estão definidos os indicadores preliminares para o desenvolvimento dos desenhos de conexões e encaixes.

Com vidros laminados simples, irregulares, variáveis em sua dimensão e inclinação, esses são deformados de acordo com a torção do prédio. $O$ ângulo de inclinação do vidro pode variar, em um mesmo nível, em grau negativo, zero ou positivo, como mostram as figuras 93/94. Foi necessário realizar estudos das dinâmicas nos 44 níveis e criar soluções tecnológicas específicas.

A pele interna é uma fachada padrão com uma estrutura convencional, plana, com esquadrias verticais de mesma dimensão, apoiadas sobre a laje, que podem ser montadas rapidamente, sem maiores complexidades. A distân314
Figura 93: Seção da pele de vidro externa e interna. Fonte: Arup Milão, Arq. Francesco Catalano Data: 2016.

Figura 94: Croqui explicativo dos ângulos da pele externa. Fonte: Arup Milão, Arq. Francesco Catalano Data: 2016. 

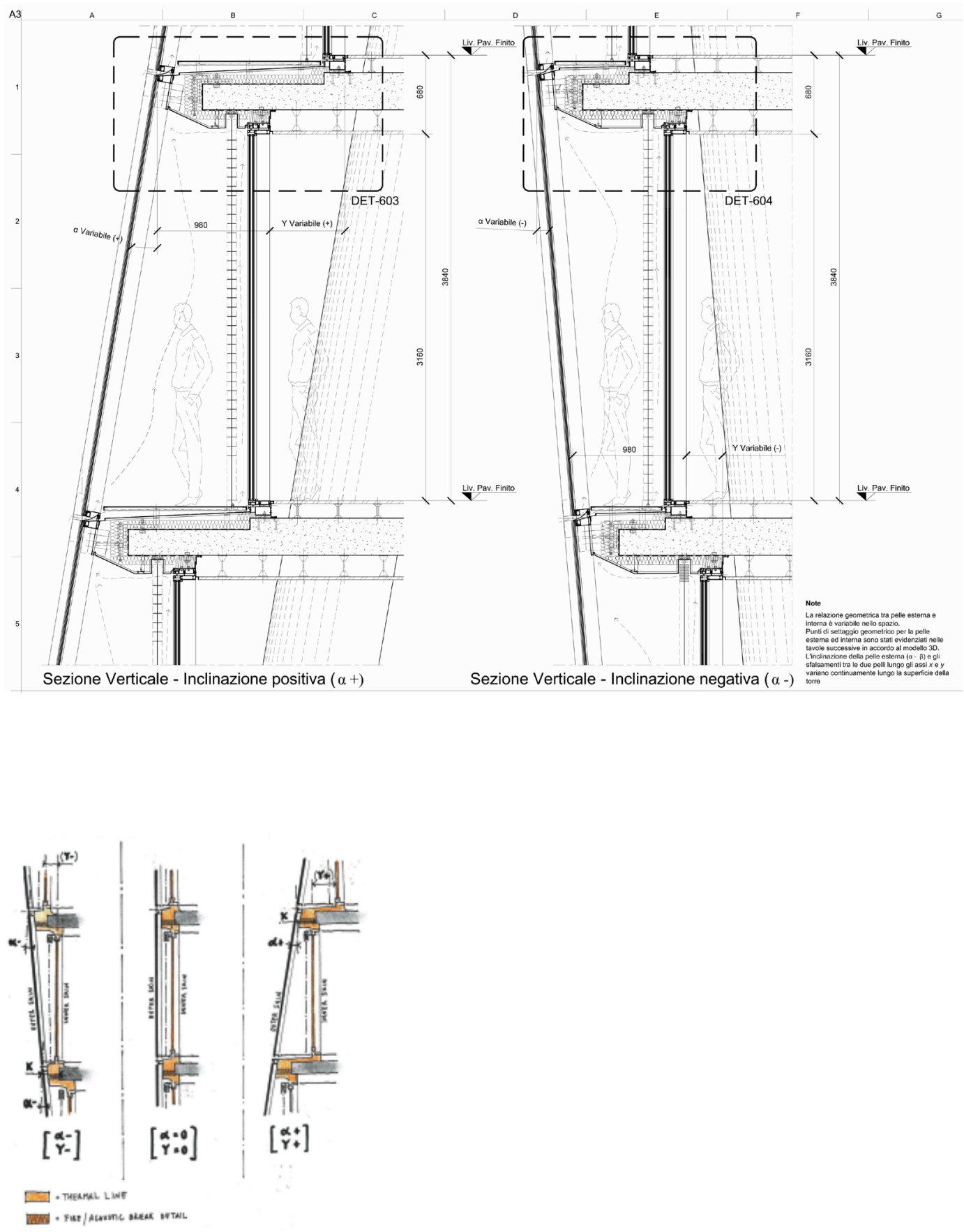
cia entre a pele interna e a externa varia em planta e em corte por toda a periferia do edifício (Figura 95).

Com esse artifício, os técnicos conseguiram a dupla camada de vidro, que guarda as suas vantagens de conforto, e solucionaram grande parte dos problemas com a configuração do giro da superfície externa. A pesquisa não tem dados sobre o quanto essa estratégia otimizou os custos de projeto, montagem e utilização dos materiais, mas é clara ao mostrar como as soluções de projeto podem beneficiar os diferentes aspectos do desenvolvimento do edifício.

A superfície externa não tem função de vedação à água e proteção térmica e é responsável pela entrada de ar entre as duas superfícies; a pele é uma barreira para a superfície interna que cumpre todos esses requisitos. A extensão da laje que recebe a pele externa também foi importante para atender às normas de incêndio e às análises teóricas com sistemas de estudo de referência laboratorial sobre a temperatura e pressão da ventilação entre os dois vidros, como mostra a figura 95.

O edifício é formado por 3 tipos de arcos, com diferentes
Figura 95: Detalhe da conexão entre a laje e fixação da esquadria interna e externa. Fonte: Arup Milão, Arq. Francesco Catalano. Data: 2016. 


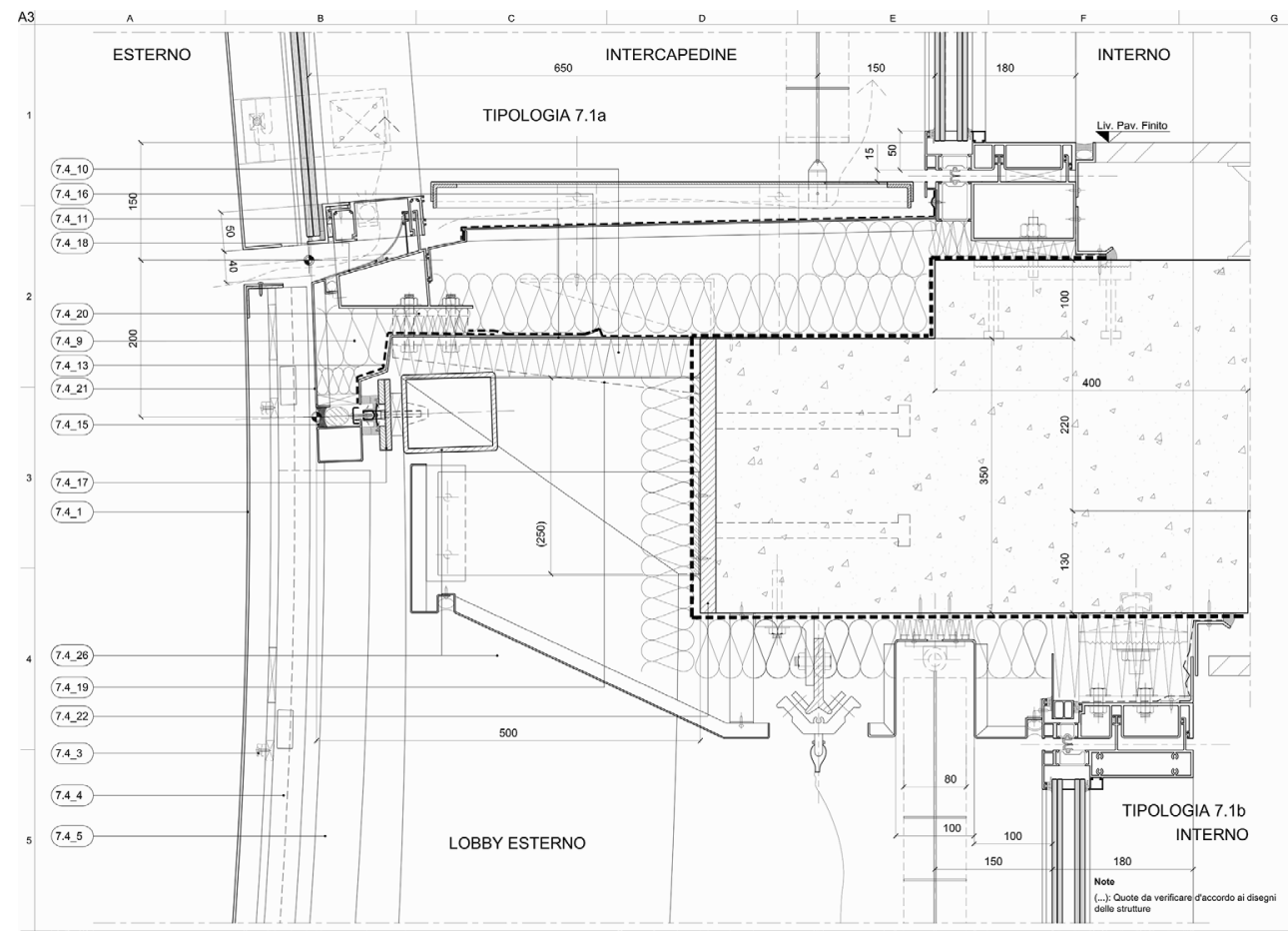




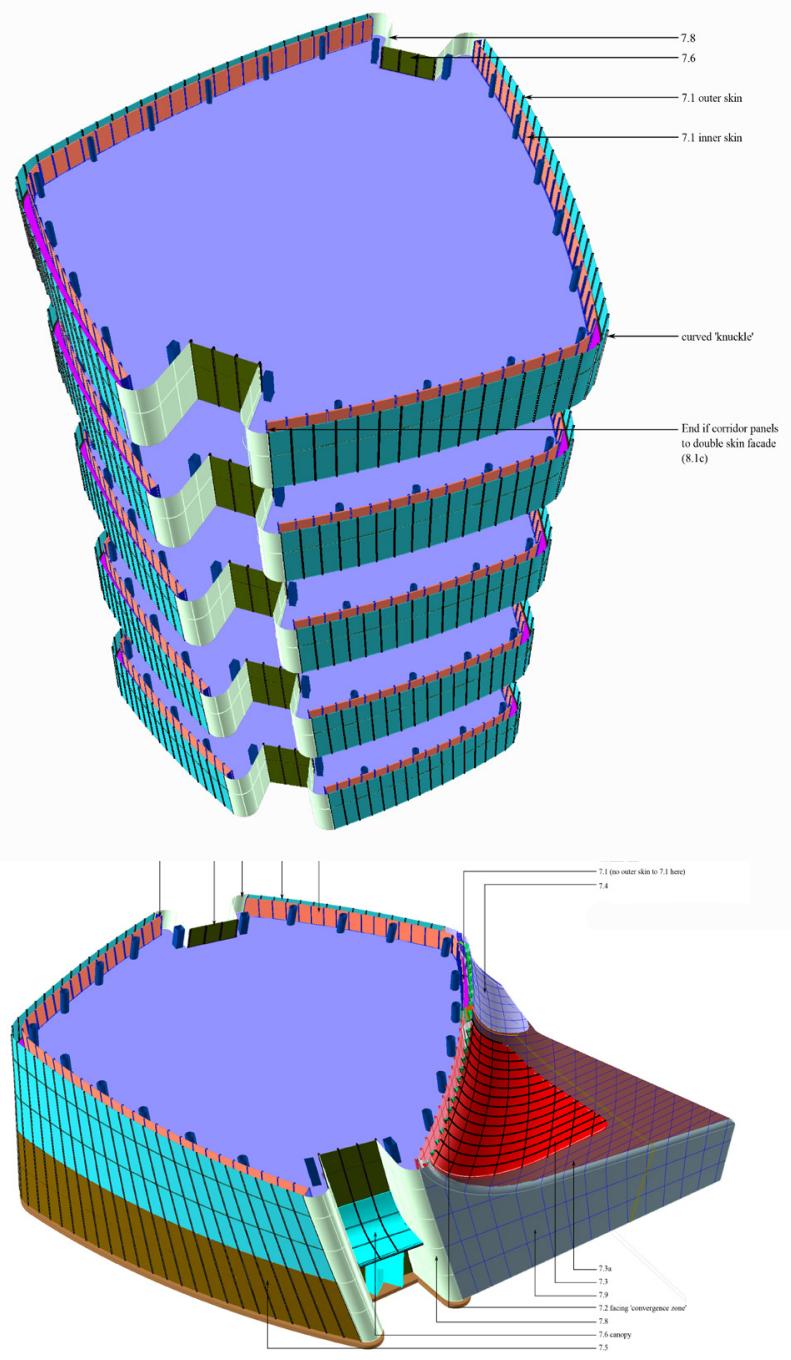

Figura 96: Planta esquemática da rotação do edifício. Fonte: Arup, Arq. Francesco Catalano, Data: 2015. 


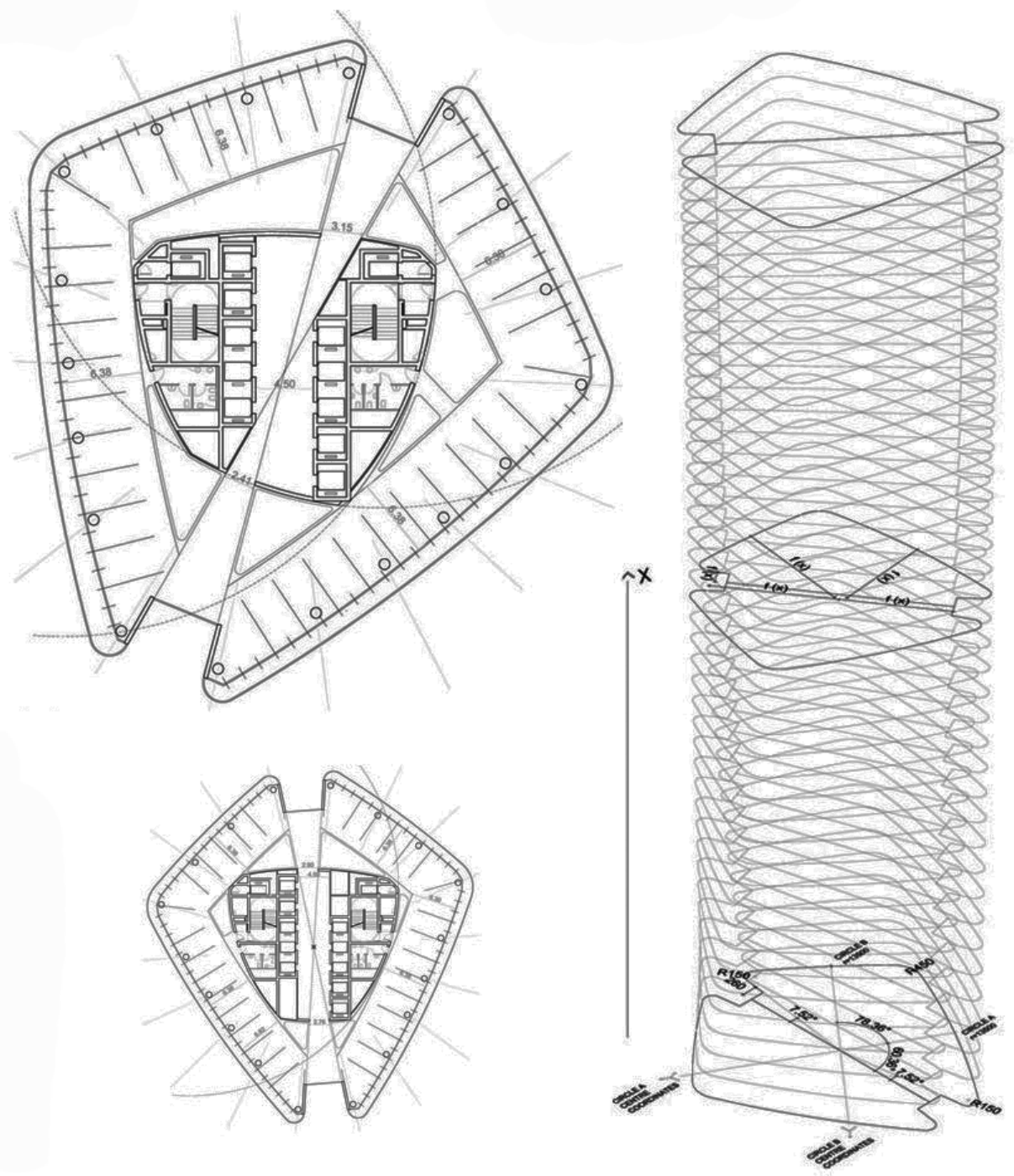

Figura 97: Geometria da torre. Fonte: www.designboom.com/ architecture/zaha-hadid-office-tower-citylife-milano/. Data de acesso: 17 jan 2017. 
raios nos pisos em sua geometria em planta. A planta começa em uma posição, sofre uma rotação com um movimento de $3 \mathrm{~cm}$ em cada nível e muda a escala; o raio dos arcos muda em cada pavimento e este tem uma dimensão e geometria diferentes figura 97.

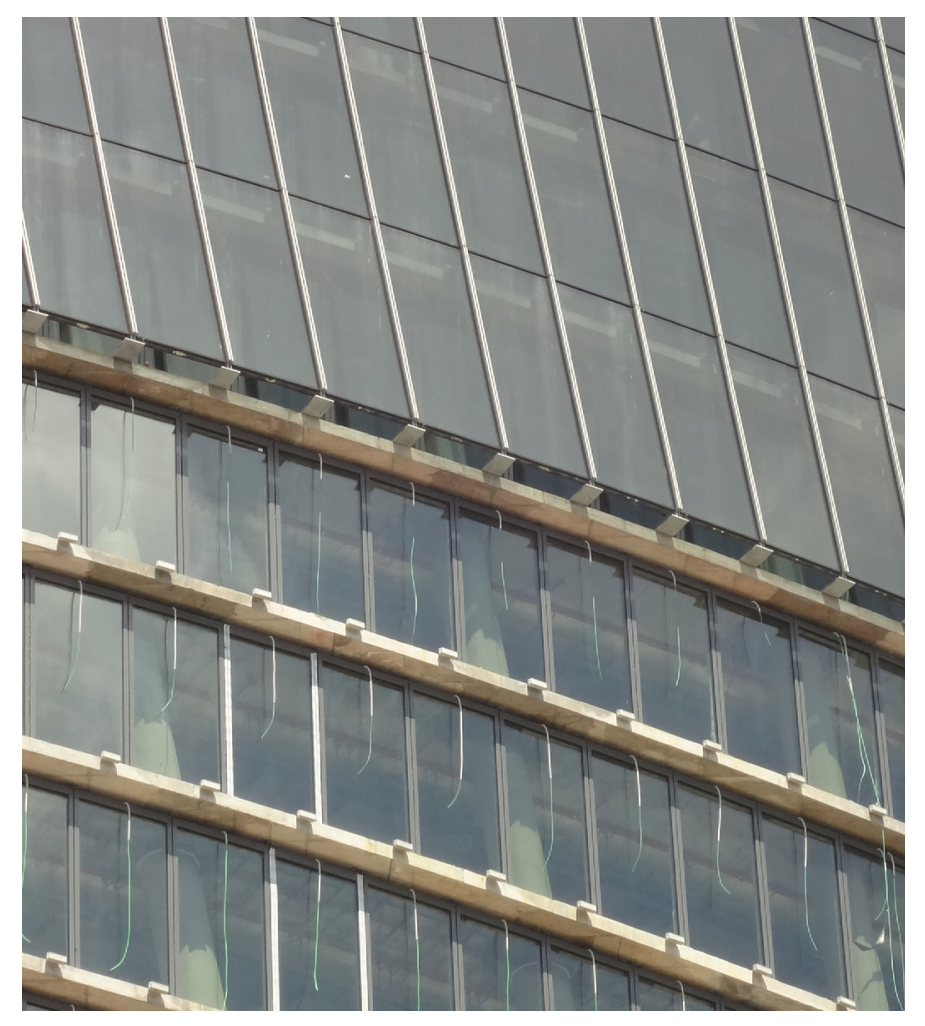

Figura 98: Superfície interna padrão e superfície externa rotacionada. Foto: autor. Data: 2016.

Figura 99: Vista frontal e corte da célula. Fonte: Arup Milão, Arq. Francesco Catalano, Data: 2016. 

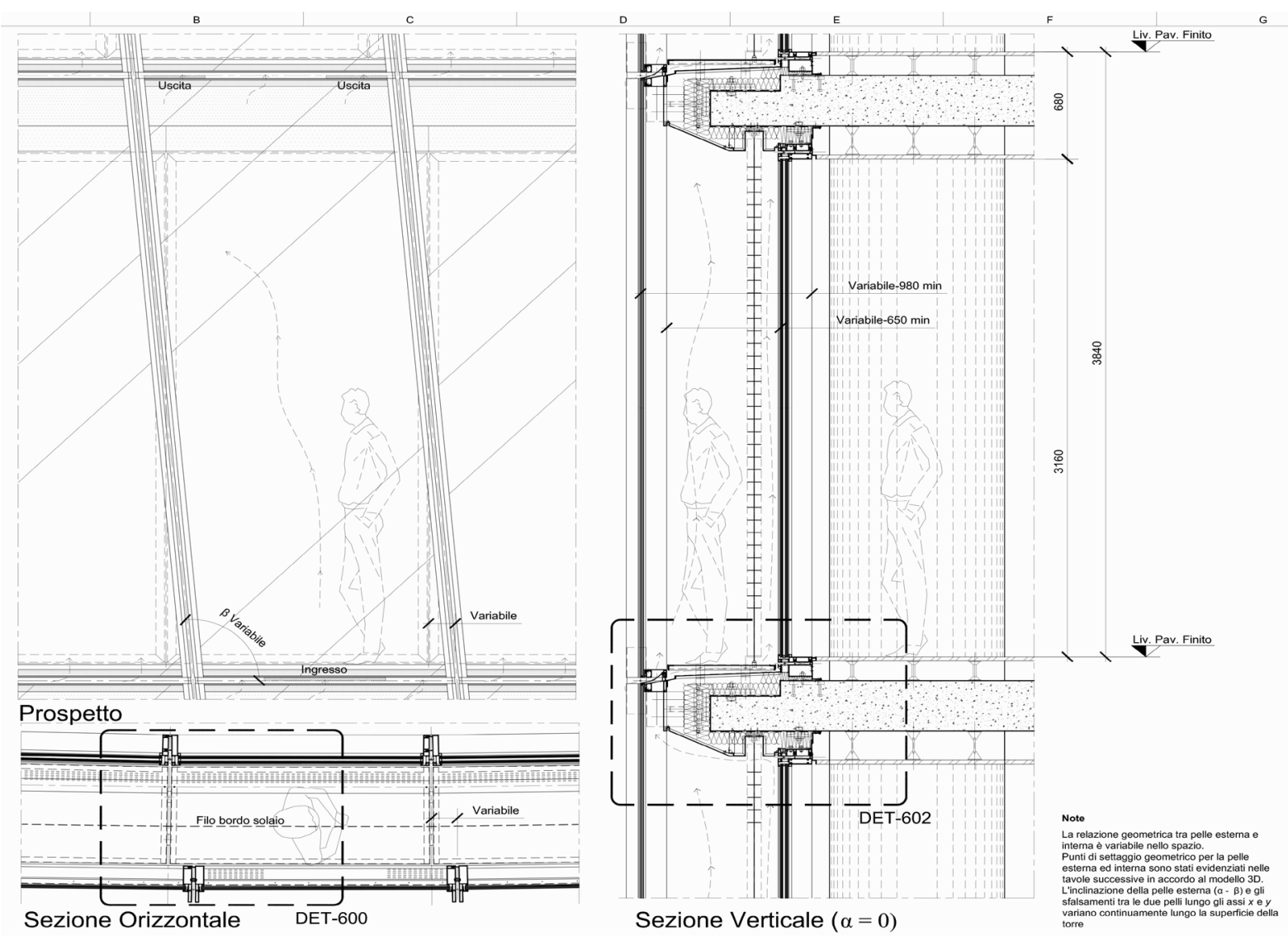


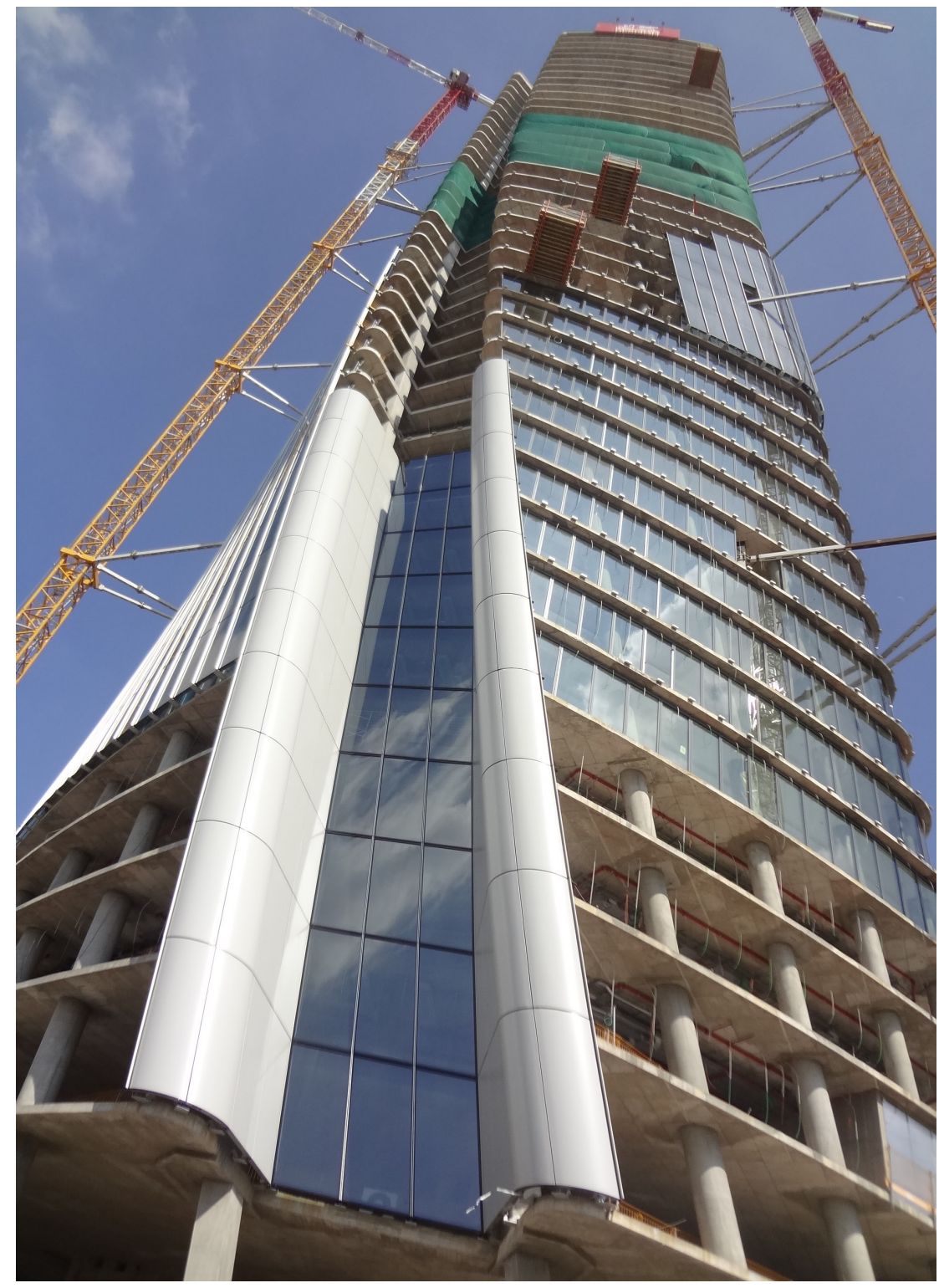


Entre as duas camadas de vidro, existe um pequeno terraço, acessível para manutenção e limpeza. $\bigcirc$ acesso ao interior dos dois planos de vidro é realizado por uma porta no nível do piso.

Geralmente, em projetos muito complexos, como é o caso da torre de Hadid, são contratados vários escritórios para o desenvolvimento de cada projeto, como fachada, estrutura, engenharia mecânica, entre outros, que são responsáveis por viabilizar em relação ao orçamento, ao desenvolvimento dos desenhos, da produção e da montagem.

Os desenhos para a produção são compostos por elevações, plantas, cortes, níveis, dimensões, materiais, pontos de fixação e detalhes de interface. Os projetos de cálculos estruturais, conforto térmico e outros são submetidos como parte do processo do projeto da construção.

O trabalho do escritório que propôs as soluções para a pele dupla de vidro da torre encontrou soluções brilhantes para a viabilização do objeto, graças a pequenas modificações no projeto original que alteraram completamente

Figura 100: Perspectiva do empreendimento vista pelo lado da fenda. Foto: autor. Data: 2016. o resultado final, interferindo diretamente nos investimentos, na fabricação dos componentes e na montagem. Tais 
soluções são:

1. extensão da laje, que possibilitou a separação entre os dois planos;

2. colocação da torção da torre somente no plano de vidro externo;

3. vedação no plano de interno com esquadrias convencionais, retangulares e idênticas;

4. planos de vidro laminado com curva forçada a frio, que será discutido a seguir,

5. sistema de ventilação natural entre os dois planos, atendendo às normas de incêndio. 


\section{Fabricação}

Os desenhos para a fabricação, habitualmente, são planilhas internas, subdivididas em peças para corte, peças para solda e acabamento. Indicam os requisitos dos perfis, medidas de cortes, detalhes para preparação do trabalho, montagem dos componentes, fabricação de elementos e detalhes de requisição de materiais. Todos os desenhos para a fabricação dos componentes são preparados, submetidos, aprovados prioritariamente de acordo com a relevância das atividades.

Os painéis são fabricados em células trapezoidais individuais, com diferentes esforços na subestrutura. Talvez somente no topo do edifício os esforços aplicados na esquadria e nos vidros sejam praticamente zero, devido ao seu desenho ser próximo ao ortogonal. O comportamento de uma peça em formato trapezoidal é completamente diferente do de uma peça retangular, pois cria forças diagonais sobre a subestrutura (Figura 100).

Os painéis externos nos primeiros 10 níveis são inclinados entre $15 \mathrm{~cm}$ ou $20 \mathrm{~cm}$ e foram desenhados especificamente para o seu local, com um sistema em quadro de aço 


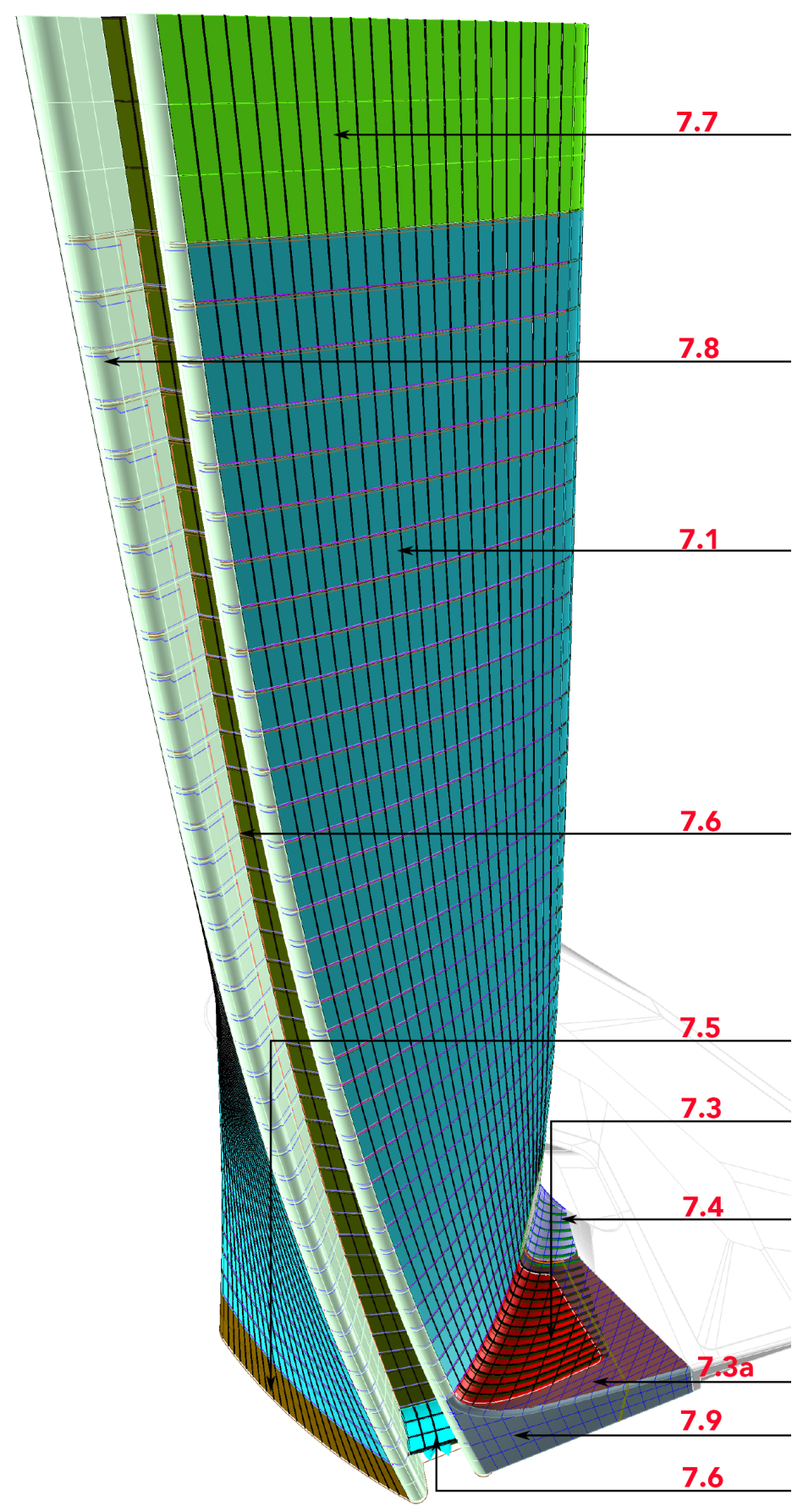

IMAGE LOOKING FROM NORTH 
e impermeabilização. O grau de obliquidade varia com a altura do edifício. No plano superior, os painéis são próximos ao retângulo, mas, na base da torre, a obliquidade aumenta progressivamente.

De acordo com o esquema ao lado (Figura 101), é possível verificar os diferentes tipos de painéis utilizados para formar a pele de vidro.

Na produção das células, foram criadas 12 macrofamílias de componentes para a fabricação.

- A tipologia 7.1 é a que tem a maior superfície, com aproximadamente $20.000 \mathrm{~m}^{2}$ na face externa.

- A tipologia 7.7, que se localiza no topo do edifício, é de alumínio, mantém a continuidade visual e é suspensa sobre uma estrutura de aço fixada no nível do piso 41. Possui pele simples, com painéis geralmente planos, com leve torção, semelhantes aos painéis 7.1.

- A tipologia 7.5, da base da torre, também é de alumínio e recebe a carga dos painéis superiores.

- A tipologia 7.8 é a que está na junção entre a face 
da pele e as fendas. É responsável por enfatizar a torção da torre e utiliza material opaco. É subdividida em 3 subtipologias: (7.8a) painéis curvos em alumínio, (7.8b) painéis laterais não curvos em alumínio e (7.8c) painéis planos de interface com a fachada 7.1, fixados na laje. A tipologia 7.8 é montada em fábrica como um sistema único e chega ao canteiro para a instalação. Cada célula tem sua característica própria, de acordo com a geometria, torção e deformação. Possui um painel de revestimento externo enganchado e fixo para escoamento de água. Esse sistema foi encaminhado para confecção de um mockup, artifício que ajuda na verificação dos comportamentos no local em que será utilizado (Figura 102).

- A tipologia 7.6 é uma fachada em vidro curva que vai da base para o topo em torção contínua. Tem estrutura em aço e é composta por vidro duplo para maior visibilidade. Em sua base, a superfície se estende em um abrigo sobre a porta giratória. 


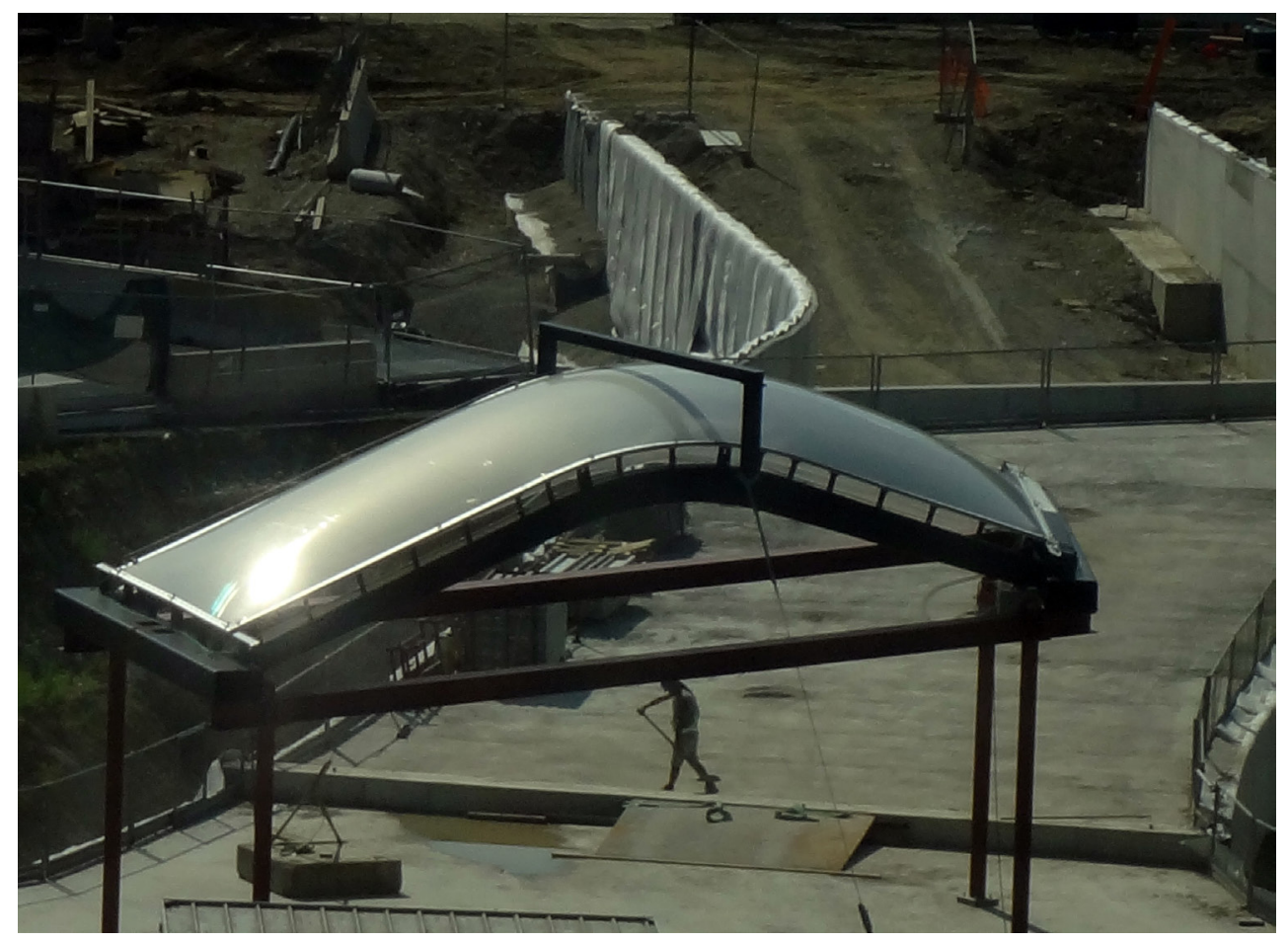


Os vidros foram cortados sempre em posição vertical em relação à placa matriz (Figura 104), para que todos tenham a mesma formação em relação às suas resistências e sua aparência final, e, posteriormente, montados na esquadria sobre uma camada de silicone e forçados para a dobra do mesmo em sistema frio (Figura 105). Esse sistema diminui os custos da produção e respeita as propriedades físicas do material, além de ser verificado com testes a cada 10 anos.

O ângulo máximo de deflexão do vidro a frio, conforme os desenhos ao lado, é de $3 \mathrm{~cm}$ em cada extremidade para essas dimensões da placa, que se referem ao comportamento máximo do vidro de acordo com o seu nível de estresse (Figura 103).

Com exceção dos locais onde a curvatura é maior, todos os outros vidros são planos, com curvatura produzida em fábrica. Para encontrar essas soluções, foram realizadas várias propostas de geometria, com o intuito de buscar respostas a todas às questões. Como cita o arquiteto coordenador do projeto, "A solução talvez não seja a meIhor, mas é a mais adequada diante do contexto" (CATALANO, 2016).
Figura 103: Diagrama de torção do vidro a frio e grau de esforço maior na base da torre. Fonte: Arup Milão, Arq. Francesco Catalano, Data; 2015.

Figura 104: Indicação de corte do vidro em relação a placa mestra. Fonte: Arup Milão, Arq. Francesco Catalano. Data: 2015. 

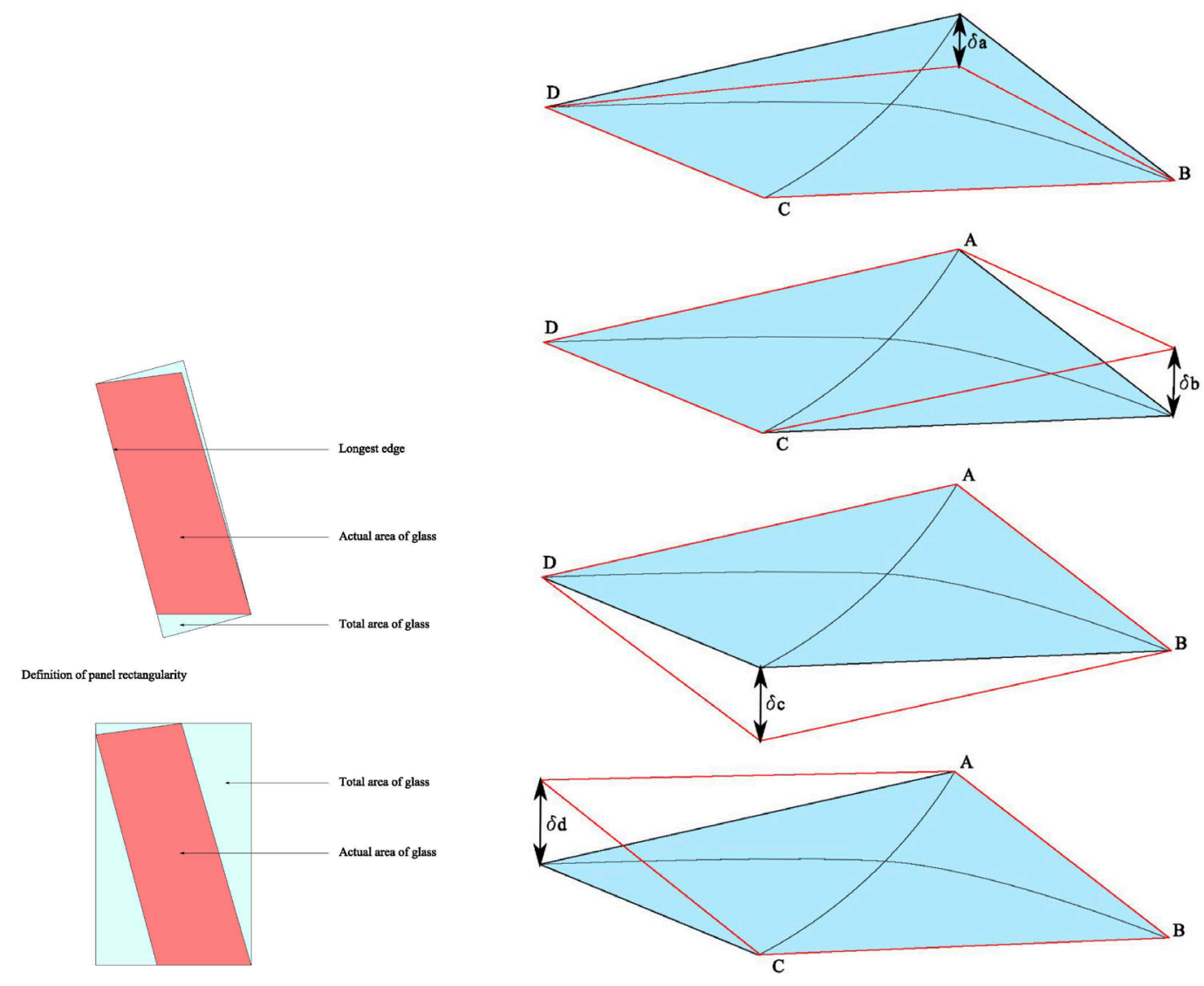
Para a produção da curvatura a quente, o vidro passa por um aquecimento e, posteriormente, é colocado sobre um molde. Essa tecnologia, além de ser muito mais dispendiosa, altera a cor do material. Os painéis da pele externa na zona de conexão são painéis de vidro curvos a quente, com a geometria de um cilindro e placas cortadas inclinadas. $O$ ângulo do montante da pele interna geralmente é uniforme, mas existem alguns pontos de descontinuidade em correspondência com a zona de transição.
Figura 105: Vista interna das peles de vedação. Inclinação positiva - $6^{\circ}$ andar. Foto: autor Data: 2016.

Figura 106: Vista interna das peles de vedação. Inclinação negativa - $6^{\circ}$ andar. Foto: autor. Data: 2016. 

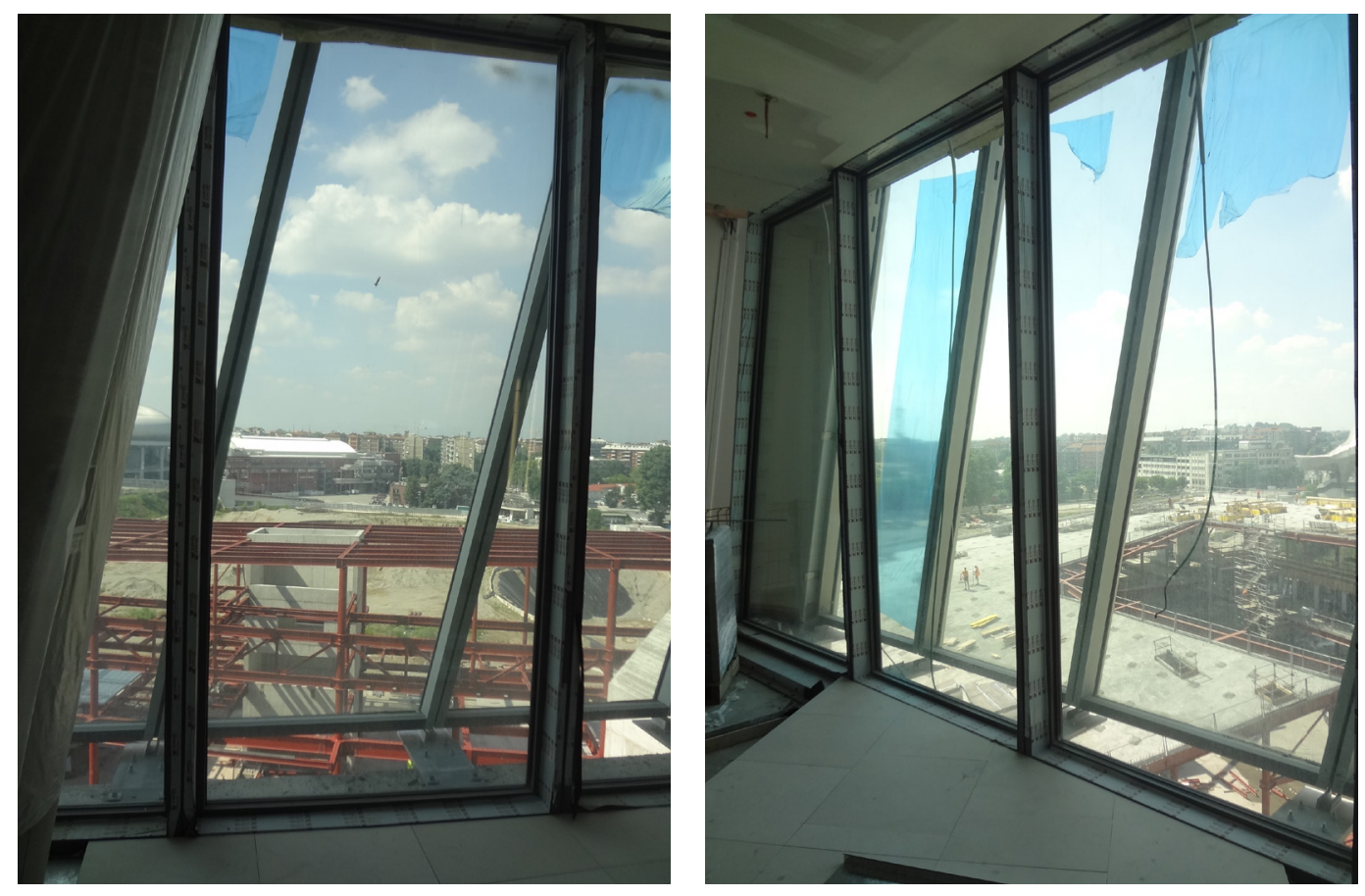
O projeto do pódio é um projeto à parte, apesar de não constituir objeto do estudo; é um ambiente com uma geometria complexa, no qual existem áreas em alumínio, vidro, ETFE, painéis perfurados e sua superfície é contínua à torre. Os painéis também utilizam a tecnologia de curva a quente e a frio, sendo que, em alguns casos, são manufaturados em dupla curvatura. Há a utilização de placas fotovoltaicas e áreas com cobertura translúcida, transparente e opaca.

Diante do desenvolvimento do projeto, verifica-se que o trabalho foi meticuloso e, com a ajuda da programação e associação com a aplicação de algoritmos, foi possível projetar e descrever cada célula, com suas devidas dimensões e especificidades, e também o processo a ser realizado no canteiro de obras para a correta instalação e obtenção dos resultados esperados.
Figura 107: Imagem ilustrativa dos diferentes tipos de painéis que compõem o podium. Fonte: Arup. Data: 2016. 

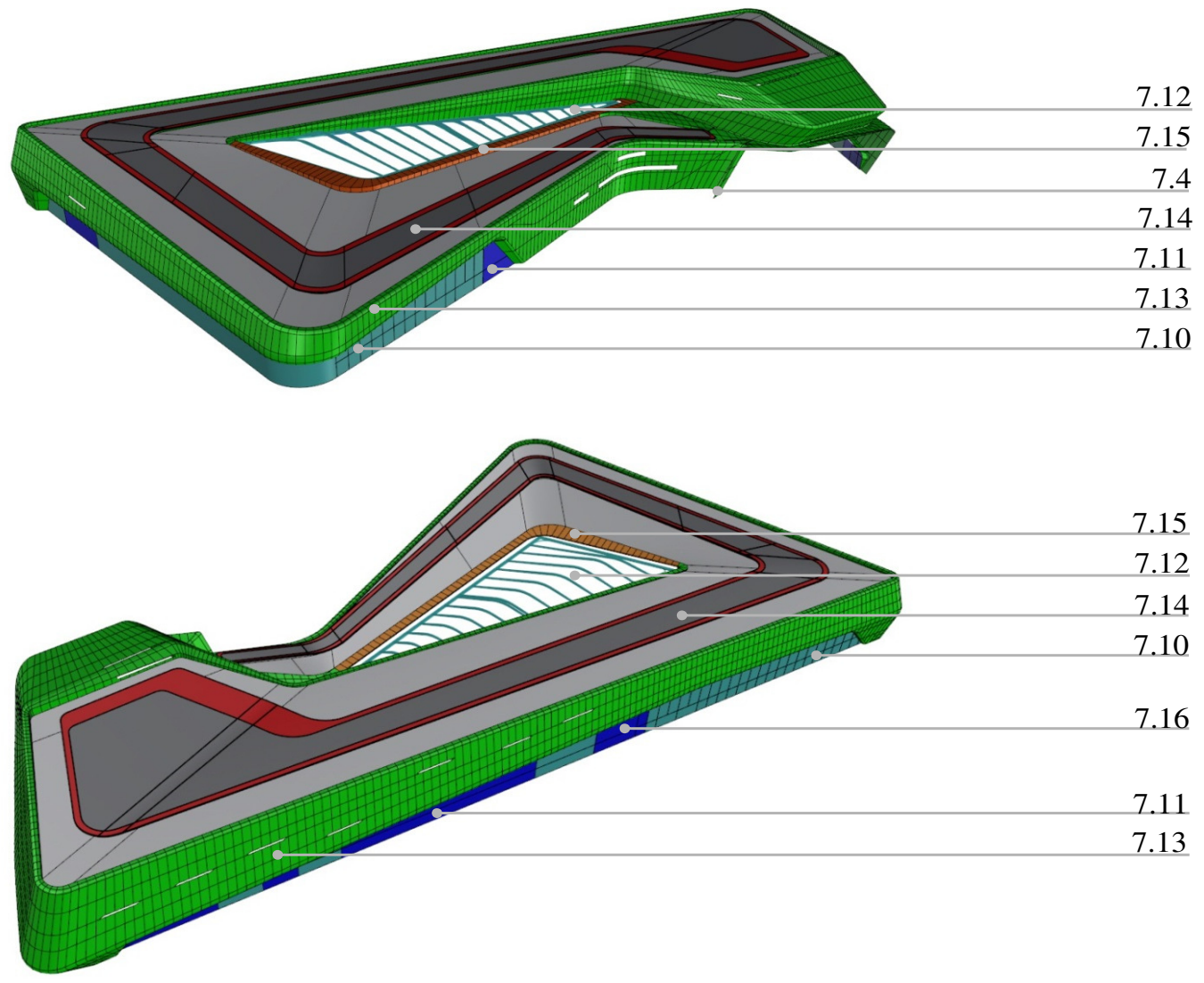


\section{Montagem}

Os desenhos preparados para o canteiro de obras identificam partes e elementos e demonstram a sequência da instalação. Os desenhos da instalação definem a localização correta de todos os componentes, seus detalhes e conexões com as peças imediatas.

A instalação das esquadrias internas é simples, pelo seu formato convencional e sem maiores esforços. Já a instalação da pele externa é complexa, visto que cada célula é praticamente única, em formato trapezoidal, com vidros sob estresse pela curva aplicada a elas. A sequência deve ser a partir de cada nível e unidirecional, pois as 200 células são apoiadas sobre a extensão da laje e se encaixam na esquadria lateral anterior e subsequente.

Assim como as construções industrializadas, a montagem destes elementos é acompanhada por um mapa de localização das 2.200 células e cada uma é identificada com seu nome específico, além de instruções para a colocação das esperas sobre a laje e os encaixes das células sobre estas conexões. A produção em fábrica deve estar sincronizada com a instalação, visto que a logística deve ser específica 
e detalhada desde o pedido de peças para a produção, montagem das células, o transporte e o armazenamento.

Os locais especiais, como a junção e as curvas que formam as fendas, foram pré-montados em fábrica como um sistema ${ }^{5}$, no intuito de haver maior controle, já que são elementos especiais, com vidros curvos, e requerem maior elaboração. A foto a seguir (Figura 108) ilustra um sistema de experimentação do protótipo no local.

O trabalho para o desenvolvimento e a interação entre os vários sistemas e suas conexões tem como intuito viabilizar, da melhor forma, a superfície elaborada pelo escritório de arquitetura autor do projeto. Importante ressaltar também que o projeto de manutenção e limpeza também faz parte do projeto; existem duas gaiolas com roldanas sobre a cobertura preparadas para a realização das tarefas.

O desenvolvimento da pele de vidro da torre de Zaha Hadid Architects é um trabalho complexo que teve vários pontos importantes e fundamentais de solução em pro-

5 Em meados do século 20, a abordagem de sistemas para superfícies complexas foi empregada como um novo conceito, sendo que esses artefatos eram pensados enquanto seu desempenho e como parte de um sistema maior (ADDIS, 2009). 


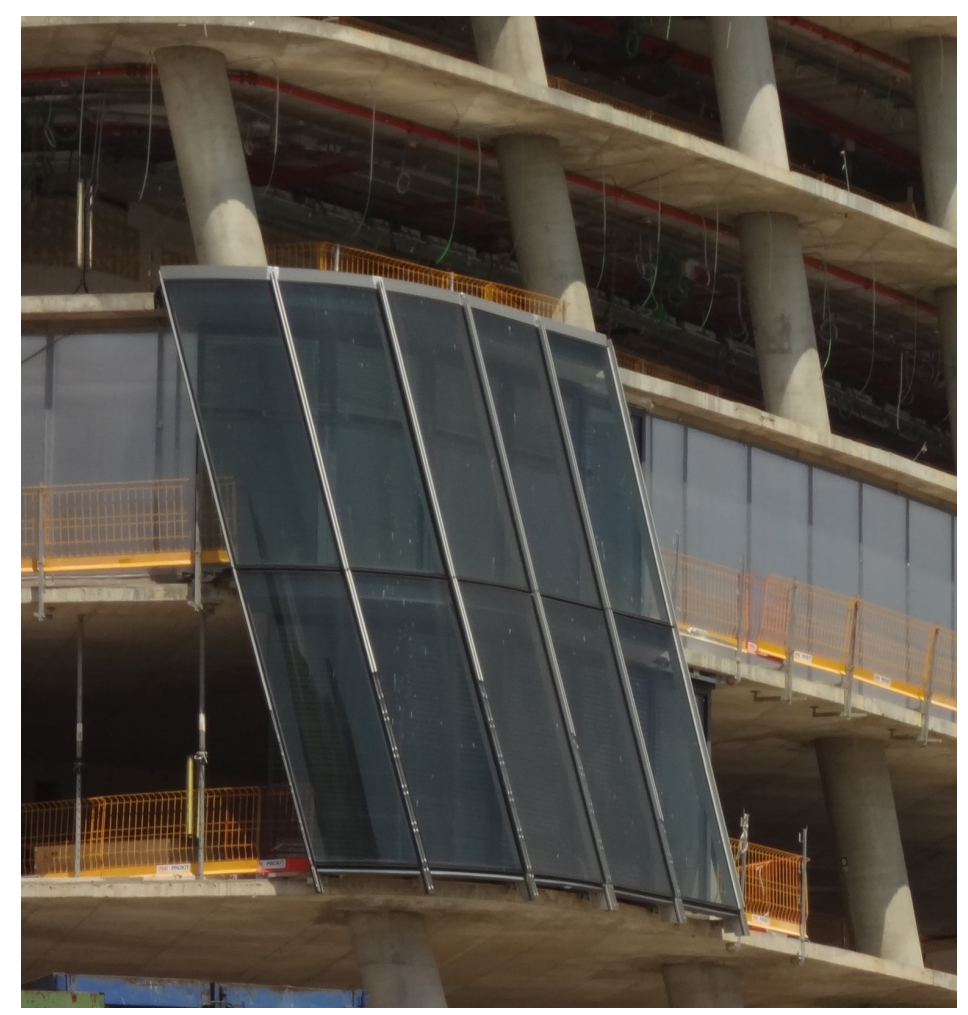


jeto que tornou o objeto mais acessível e com recursos interessantes para a fabricação e a montagem, com conforto e economia energética. Acredita-se que, apesar de o coordenador de projetos da superfície ter comentado sobre as soluções adequadas para o contexto, estes são aspectos do desenvolvimento que deixam o projeto ainda mais instigante. 
Figura 109: Gindaste instalado para realização dos trabalhos da Torre CityLife - Milão. Foto: autor. Data: 2016. 
H.

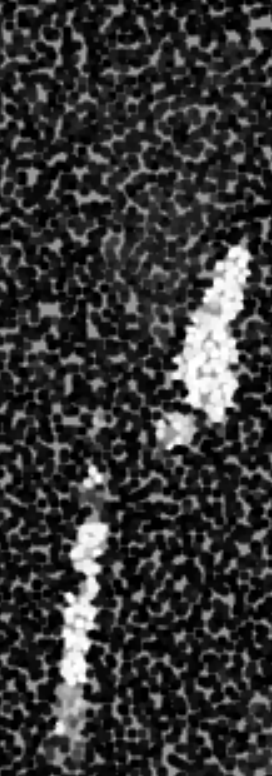

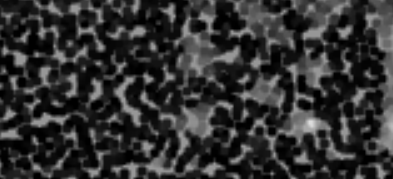

s.
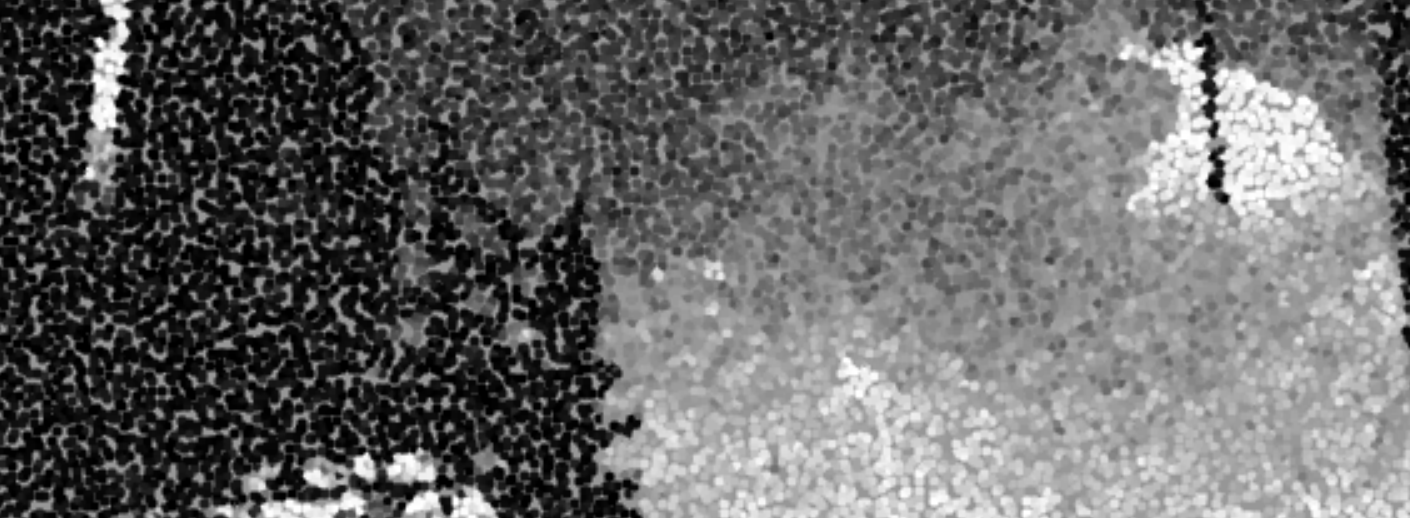

$32 x^{2}$

21

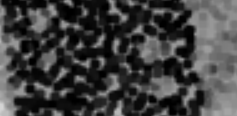

is:

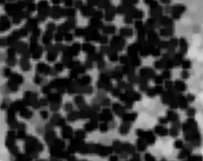

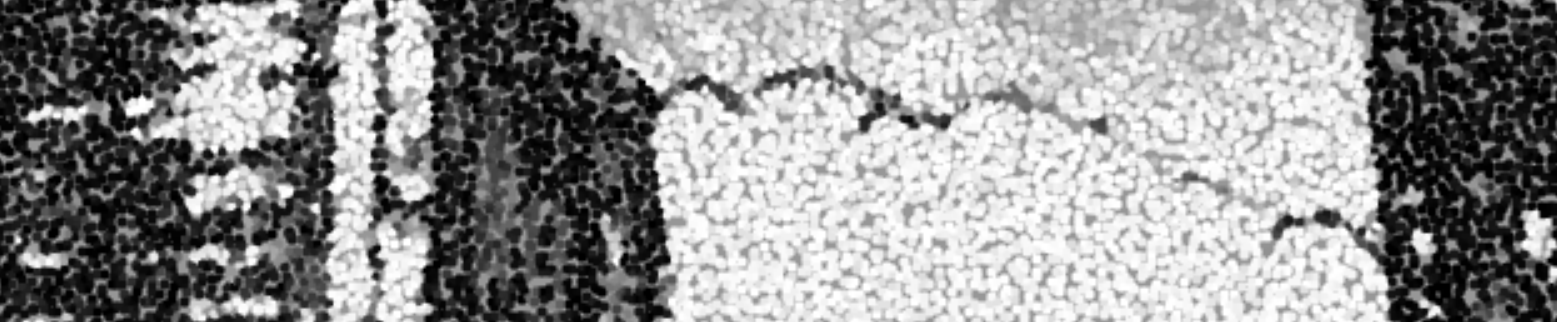

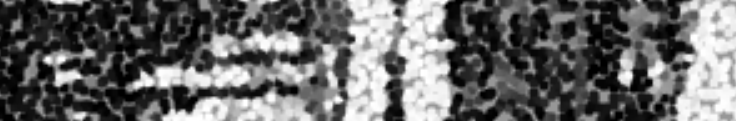

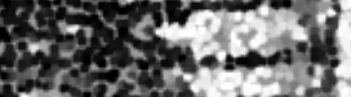

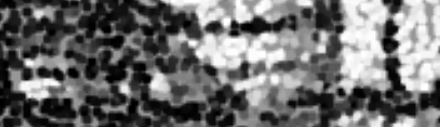
$\operatorname{lin}^{2}+3$

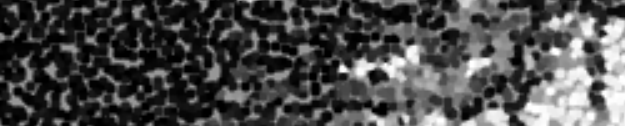

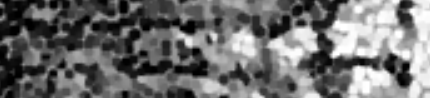

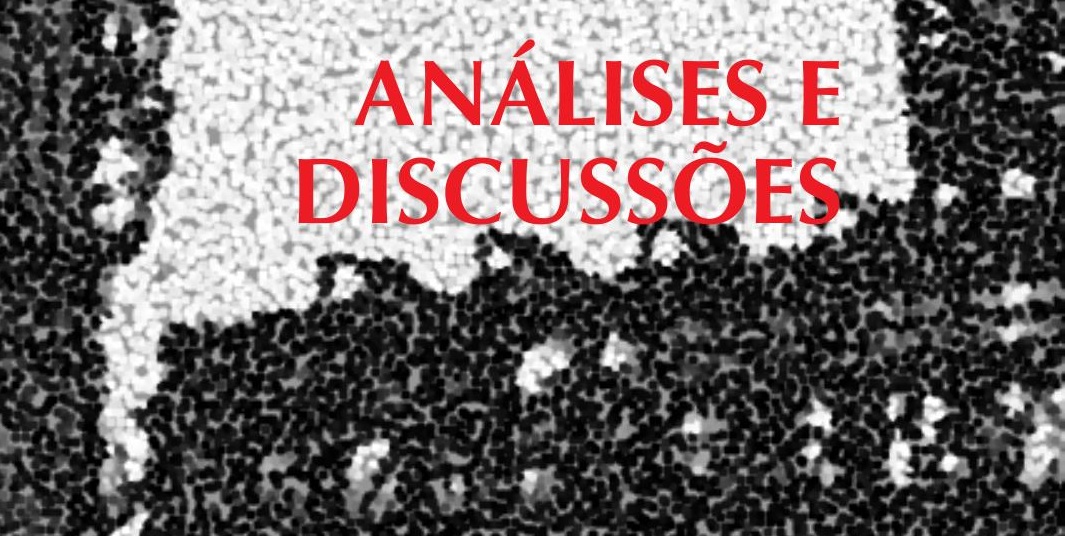

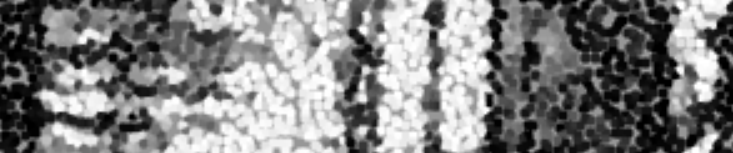
7.5. 1

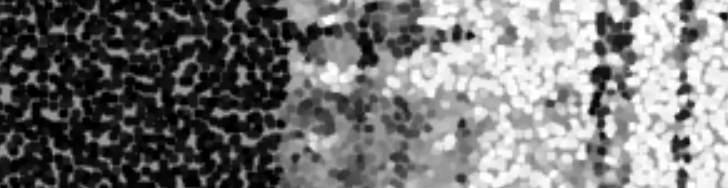

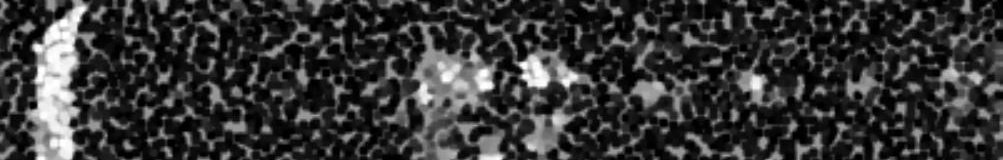
C. "s. 



\section{Considerações sobre o Contexto}

Para tratar da dinâmica da construção civil diante do contexto do mundo digitalizado como desenvolvido nos conceitos que se referem ao cotidiano, há que se lembrar que os objetos ou edifícios são singulares, isto é, possuem escalas diferenciadas e durabilidade que passa por várias gerações. Para a sua elaboração e execução, são necessários profissionais de muitas disciplinas e especialidades, evidenciando um setor com grande segmentação no trabalho e alto grau de hierarquia. Todas essas variáveis contribuem para que o setor tenha maiores dificuldades para a sua automação e participação no mercado da Indústria 4.0, como evidencia a literatura a respeito.

Outros pontos a ponderar são os instrumentos utilizados na política de incentivo à digitalização do mercado. Não parece adequado utilizar o mercado de internet (e-commerce) como um meio de aquisição ou compra de um edifício, já que este provavelmente será de um valor bem acima do que se comercializa por cartões de crédito, já que os valores habitualmente são financiados e necessitam da participação de entidades bancárias. Em outras palavras, 
quando se trata do mercado da construção civil, há que se verificar como este se adequa às ferramentas utilizáveis ao setor, no uso de dispositivos, máquinas inteligentes, robôs, rede de fábricas, nuvem de dados, dentre outros, embora seja uma realidade a utilização, pelo mercado, de ambientes de comunicação em rede para a busca de imóveis, que atraem os clientes através de fotografias com áreas verdes, mapas e propagandas de benfeitorias locais, sempre mostrando imagens de famílias tradicionais e felizes, mesmo que o panorama não seja exatamente esse na realidade.

A digitalização do processo na construção civil faz parte da digitalização social; seus instrumentos e ferramentas estão disponíveis no mercado, não são específicos para a área; mesmo os dispositivos são instrumentos adaptados para o setor. De modo geral, a construção civil anda em passos lentos para a utilização dos equipamentos digitais, haja vista os diversos processos de automação que poderiam ser utilizados nas indústrias, mas ainda são considerados de alto custo e inviáveis.

A associação de várias empresas com uma rede de diferentes habilidades, com oferecimento de serviços que 
complementam e agregam valor ao produto, é uma realidade; no entanto, essa rede é segmentada pelas diversas disciplinas que envolvem o trabalho, tais como indústria para a produção da estrutura, que oferece todos os desenhos necessários para o desenvolvimento do mesmo até a montagem em canteiro; indústria de vedação, que muitas vezes está associada a escritórios de elaboração e detalhamento de elementos para a confecção dos sistemas complexos, e também a participação das universidades, que estão prontas para colaborar no ramo da pesquisa e discussão sobre os materiais, as tecnologias e utilização e análise em seus laboratórios. $\bigcirc$ ambiente colaborativo se faz pela separação das disciplinas e é, portanto, fundamental a figura de um gestor para a coordenação dos vários parceiros.

No ramo da automação predial, esse sim parece responder às relações entre a Internet das coisas, a Indústria 4.0, em que as máquinas e objetos inteligentes se comunicam com os clientes e são capazes de responder a estímulos humanos e, automaticamente, reconfigurar de acordo com a melhor situação. Atuam com uma rede de máquinas inteligentes que se retroalimentam e impulsionam ou- 
tras condutas com atitudes reelaboradas.

As inovações em relação a impressão aditiva, uso de robôs e nanotecnologia estão em plena investigação, principalmente nos grandes centros de pesquisa; no entanto, são escassos os casos em que essa tecnologia é utilizada, mostrando que os esforços para que essas tecnologias se tornem viáveis ainda estão distantes da realidade das indústrias da construção civil, apesar da experiência realizada pela Arup nas conexões impressas em metal.

Em relação à utilização de nuvens, a manipulação de grande quantidade de informações e o uso dos meios de comunicação para transferência e captação de dados são uma realidade, mesmo nos ambientes mais simples de escritórios pequenos. Somado a isso, verifica-se que a manipulação de grande quantidade de dados tem contribuído, inclusive, para a criação e elaboração de conteúdos mais complexos, tanto em criação como no setor de gestão e execução dos edifícios, como são verificados nos casos de projetos de arquitetura com formas orgânicas analisados nesta pesquisa.

No contexto e nas circunstâncias atuais, os esforços estão 
voltados nas tendências, em que o comportamento da sociedade está mudando a todo o momento e é essencial a associação com parceiros que têm habilidades diferentes para expandir a competitividade e a participação do mercado. Como analisado por Comu; Taylor; Messner (2012), as razões por trás dessas associações são reduzir custos para clientes em projetos e melhores serviços, para aumentar a qualidade e os tempos mais curtos de ciclo de projeto. Também estão incluídos acordos de negócios híbridos, com combinações colaborativas em tecnologia de ponta e competitividade. A complexidade dos projetos reforça a necessidade de fornecedores diferentes e especializados de vários países.

O processo de colaboração considera a participação de empresas trabalhando em conjunto, compartilhando conhecimentos, aprendendo e construindo consensos para alcançar o mesmo objetivo. Dentro dos benefícios, é possível ver a

[...] melhoria do acesso à informação e às pessoas em toda a empresa, a disponibilidade de dados para a rápida tomada de decisões, o compartilhamento de conhecimento e recursos em todos os níveis com taxas de erro reduzidas ${ }^{1}$ (CHIPRIANOV

$1[\ldots]$ improved access to information and people across the enter- 
et al., 2014, p. 965).

Por outro lado, essas redes também contribuem na indústria, aumentando os lucros e melhora na parceria entre os contratados e subcontratados (WOOD; ELLIS, 2005).

Essa realidade de associações não seria possível sem o avanço das ferramentas tecnológicas disponíveis atualmente. A informação é o principal objeto de gestão e diz respeito a todos os participantes da cadeia da construção civil. Os tipos de comunicação destes trabalhos mostram projetos colaborativos, compartilhados e que geram componentes associados. Coordenar o fluxo de informações torna-se mais fácil com a utilização de tecnologias e software do tipo BIM, que realizam gerenciamento dos diversos projetos, tanto no nível da construção quanto em relação aos cronogramas físicos e financeiros.

A personalização dos produtos, como preconiza a Indústria 4.0, é vista como uma tendência de criação dos escritórios de ponta. Cada vez mais a criação da arquitetura contemporânea está voltada para a elaboração de edifícios em que os componentes são elementos com alta

prise, on-demand availability of data for accelerated deci- sion making, enterprise-wide sharing of knowledge and resources, reduced error rates. 
customização e, em vários casos, para o desenvolvimento de sistemas individualizados para a finalização do edifício. Como descrevem Naboni; Paoletti (2015), as tecnologias utilizadas na customização avançada são atividades contemporâneas que tendem cada vez mais a fazer parte das construções.

A necessidade de flexibilização da indústria para a produção personalizada de produtos parece um assunto que não é problema para o setor, já que estas estão habituadas a trabalhar em projetos para a produção de objetos de elementos em edifícios distintos. A fábrica se adapta para a execução dos componentes customizados. Outro ramo que já foi adaptado ao mercado da construção civil é a produção descentralizada do produto, preferencialmente próxima do local onde ele será utilizado. Para essa questão, as indústrias possuem ambientes para montagem em diversos países, facilitando o processo de transporte e montagem no edifício. Essa forma de gestão provavelmente é resultado da escala do objeto, como comentado anteriormente, como uma das variáveis do setor da construção civil.

No tópico em que a Indústria 4.0 defende a participação 
dos clientes de forma ativa, no mercado da construção civil, observam-se mudanças nos comportamentos dos clientes contemporâneos e os desafios a serem enfrentados são (HAN et al., 2010):

1. os clientes estão analisando os serviços adicionais oferecidos, tais como transferência de tecnologia e riscos;

2. são necessários mais recursos com investimentos privados, expandindo grandes projetos como esquemas integrados;

3. os programas de financiamento são fundamentais para aumentar as oportunidades no mercado da construção,

4. existem vários riscos envolvendo custos, equipamento e diferenças culturais.

Desse modo, verifica-se um cliente mais pró-ativo e menos envolvido com os dispositivos publicitários para venda.

A utilização dos sensores, atuadores e da retroalimentação do setor industrial da construção civil é vista, principalmente, nas máquinas com tecnologia de ponta, presentes nas indústrias ligadas à siderurgia e que são adaptadas para a indústria da construção civil. Esses equipamentos 
são providos de controle e verificação, com dispositivos que informam a necessidade de troca de peças ou manutenção periódica. É evidente que o processo de digitalização dos equipamentos é uma onda sem precedentes e envolve todos os ramos da sociedade e da produção; ainda que não seja o mais avançado, como nos setores da automação predial, está no caminho para atingir esses parâmetros.

Diante dessas análises sobre a construção civil e o seu contexto dentro do mundo digitalizado e proposto pela indústria 4.0, considera-se que o setor tem feito uso das ferramentas digitais, principalmente em relação ao desenvolvimento de projetos que demandam uma grande quantidade de dados, no desenvolvimento de dispositivos de automação predial e na associação de diversas empresas com habilidades distintas para a sua manutenção no mercado competitivo e diversificado. Contudo, vê-se que a rede formada entre consumidor com dispositivos diretos ligados à indústria, como preconizam as políticas de incentivo à digitalização, talvez ainda não se aplique ao setor, dadas as variáveis específicas como custo, durabilidade, escala, dentre outros. 
A automação associada às máquinas com tecnologia avançada tende a deslocar os trabalhadores para outras atividades com habilidades diferenciadas em outros setores. Esse movimento ocorre com a transformação do trabalho humano no investimento em equipamentos de alto custo e acaba forçando a criação de novos bens, serviços e negócios e novas empresas (SCHWAB, 2016), sendo indicado pela criação de novos protocolos, evidenciados nos casos em que os programadores passam a ser técnicos fundamentais para o processo.

Nas novas relações de produção, direcionadas pelas tecnologias de informação e comunicação, abrem-se campos para redes e associação de serviços de produtos inteligentes; cadeias de valor descentralizadas, com trabalhos realizados em rede; avanços constantes entre equipamentos virtuais e físicos, conectividade com captação, análise e retroalimentação de dados em tempo real e sinergia entre homem-máquina de forma inteligente (POSADA; TORO; BARANDIARAN; OYARZUN, 2015). A associação de diversas empresas, distribuídas em diferentes continentes, demostrada nos dois casos confirma essa afirmação, como as 
fábricas de componentes da China, a gestão na Inglaterra e Coreia.

\section{Sobre os Casos}

A partir da análise dos casos associados à literatura e à verificação de outros exemplos, pode-se conduzir uma proposta de um modelo de Projeto para a Produção com o intuito de contribuir para a compreensão do processo e de possíveis encaminhamentos para a sua reprodução.

O projeto inicial, de autoria do escritório de arquitetura, define os princípios gerais da forma, sua materialidade e funcionalidade. Esse projeto de arquitetura é o ponto de partida para o desenvolvimento do Processo de Projeto para a Produção, que atua na materialização, no detalhamento e na viabilização do objeto até chegar à sua concretização.

De acordo com os coordenadores dos casos, a fase em que se tem o conceito do projeto é o momento em que os autores colocam suas intenções de acordo com a proposta. A partir disso, a equipe de desenvolvimento faz as opções para o desenho, a definição da geometria e encami- 
nha as melhores propostas para a superfície. Nessa etapa, são discutidos os materiais e os devidos desempenhos.

A próxima etapa se destina ao desenvolvimento do Projeto para a Produção propriamente dito. Nessa fase, são concebidos os desenhos do projeto, que têm como objetivo indicar como fazer os componentes que são parte da superfície, tais como plantas, vistas, cortes e, consequentemente, a definição do sistema como um todo; os encaixes; conexões; sistemas de instalação, testes e pesquisas com os diferentes materiais e definição dos detalhes.

Essa etapa desenvolve o corpo do projeto com as soluções técnicas e abrange toda a gestão dos diferentes profissionais envolvidos e as diversas ferramentas informacionais. Aqui, também, há a indicação dos fornecedores e a especificação dos tipos de materiais. Para o planejamento da produção dos componentes, a fase de projeto é essencial para sua otimização, com respeito aos custos, à materialidade, ao tempo, à logística e à instalação.

A partir do projeto original, a superfície passa por uma etapa que é chamada de Geometria da Arquitetura e corresponde a uma das principais etapas de viabilização 
do projeto. A Geometria da Arquitetura ou Tessellation foi iniciada com as obras de Frank Gehry, a partir do início dos anos 1990. Segundo Pottmann (2013), cada placa utilizada nas obras de Gehry tinha apenas uma curvatura com a mesma tangente, o que facilitava sua fabricação e montagem. $O$ trabalho de Gehry é inovador e impulsionou vários trabalhos, apesar de seu processo de projeto a partir de maquetes físicas e sua posterior digitalização não serem o processo buscado nos dias de hoje.

Pottmann (2013), esclarece que as malhas triangulares são provavelmente as mais fáceis de serem projetadas, mas os seus nós apresentam alta complexidade, pois criam um maior número de elementos que se encontram em um mesmo ponto e possuem eixos quase ortogonais à superfície. Vale notar, também, que a produção de planos triangulares gera um maior número de resíduos do que superfícies retangulares. Por conta disso, estudos com outros tipos de polígonos têm sido desenvolvidos.

O mesmo autor ainda coloca que, a partir da definição do projeto de arquitetura, é necessário um "re-design" da superfície, uma vez que essa superfície deve ser racionalizada para a construção de acordo com o material, com o 
tipo do painel, tipo de estruturas etc. Essa nova racionalização recalcula a geometria considerando os aspectos do projeto e dos painéis, a suavidade da superfície e a viabilização construtiva.

A etapa de Geometria da Arquitetura define todas as etapas subsequentes e, consequentemente, seu sistema construtivo e os custos da superfície a ser construída. É nesse momento que o profissional tentará formar o maior número de famílias com peças iguais ou semelhantes para racionalizar e otimizar ao máximo o processo de manufatura, construção dos componentes e montagem em canteiro de obras.

O uso dos programas contribui fortemente para a criação da geometria da superfície, em que a lógica de produção tem como pano de fundo a produção com um parâmetro, criando componentes que, mesmo variando em suas unidades, tem o mesmo conceito, como foi a criação de macrofamílias, no caso de Hadid, que guardam em si a mesma lógica.

Os programas de modelagem e gestão são instrumentos indispensáveis para a criação de projetos dos diversos sis- 
temas do edifício. Nos casos da superfície de forma complexa, foram utilizados os softwares Rhinoceros com plugin Grasshoper, Catia e SolidWorks, que contribuíram para a parametrização da superfície, para os tipos de ondulação, textura, espessuras das curvaturas e, posteriormente, para o desenho das peças e componentes. Todos eles são programas de visualização 3D, que facilitam o entendimento e a apropriação de como são as conexões e as relações entre a estrutura do edifício e do sistema de vedação.

Os processos digitais contribuem em todos os estágios, tanto na definição dessas pequenas alterações entre os componentes como na confecção dos mesmos em fábrica, que tem a capacidade de produção minuciosa dada pelos equipamentos. Esses encaminhamentos seriam praticamente impossíveis em um trabalho manual, tanto pelo tempo, mas, também, pelo custo e pela exatidão dada pelos algoritmos.

A estratégia de usar a produção com customização avançada de componentes propicia agilidade na manufatura, na fabricação dos moldes, economia de espaço e tempo para produção, faz parte da atualização da empresa para fazer parte do mercado competitivo, sem o qual muitos 
trabalhos demandariam maior tempo ou até mesmo seriam impossibilitados de execução.

Ao mesmo tempo ocorre o desenvolvimento da estrutura principal do edifício, que deverá acolher a superfície. Essa estrutura será desenvolvida juntamente com a superfície de vedação, de forma que tenha engates ou conexões para receber a superfície vedante. Deve, portanto, ser dimensionado de acordo com a subestrutura do componente, peso, movimentações etc.

A partir disso, o componente de vedação é pensado como um sistema, considerado como um elemento ou uma célula que é pré-montada em fábrica para ser instalada no local. Ela contém uma subestrutura que faz a ligação entre o material de vedação e a estrutura do edifício. Pode ser um elemento composto, com várias aberturas e que possui maiores dimensões, com o intuito de ter melhor controle do componente, já que este é montado em chão de fábrica e tem como meta diminuir o trabalho em canteiro de obras e obter um componente que responda a todos os requisitos mecânicos, legais e de conforto.

Nos casos de superfícies complexas, geralmente as dife- 
renças de curvatura da superfície são colocadas nas juntas, deixando as estruturas em eixos e o material em forma mais plana possível. É evidente que, com a utilização dos meios digitais, o campo de soluções se abre totalmente, podendo utilizar inúmeras possibilidades, embora a busca pela racionalidade seja a base para o desenvolvimento do objeto, já que um dos principais determinantes são os custos. A responsabilidade de elaboração recai inteiramente sobre o Projeto para a Produção, que estará centrado em solucionar a forma mais viável para a manufatura e montagem, buscando sempre a maneira mais simples de resolver o problema.

Faz parte da elaboração dos componentes o conhecimento aprofundado sobre o material, que, no caso do edifício de Hadid, aproveita a capacidade do vidro de curvar até 3 cm para as dimensões da placa, não necessitando realizar o procedimento a quente, diminuindo, assim, os custo de fabricação e, no caso de Foster, a aparência dos painéis confeccionados em argamassa armada, que têm um aspecto final de areia após o processo de fabricação.

Nos dois casos, o conceito do projeto já encaminhava o tipo de produção dos sistemas de vedação: um em planos 
de vidro, com a sua devida torção, e o outro com a fábrica que possuía know-how com o tipo de painel produzido. Sendo assim, os equipamentos utilizados para a obtenção da perfeita confecção já faziam parte do processo produtivo das devidas manufaturas, da confecção de formas complexas com o uso de CNC e topógrafo e da manufatura especializada em sistemas de extensas superfícies envidraçadas.

As programações foram utilizadas para a conformação das superfícies. No caso do pavilhão, o uso foi principalmente para a obtenção dos painéis com curvas projetadas da rampa e na torre. Os algoritmos determinaram o giro da torre e deram os parâmetros para a definição modular das células que compõem a superfície complexa.

No desenvolvimento do sistema da superfície, os painéis de argamassa armada foram elaborados com estrutura metálica; a subestrutura continha o suporte para apoio na estrutura principal e a sua conexão com o painel. No plano de vidro, a solução foi aumentar a extensão da laje, separar os dois planos de vidro, colocar a torção sobre o plano externo e o plano interno com a função de vedação; aspectos que interferiram enormemente na viabilidade do 
empreendimento e nos processos construtivos para a sua finalização, atendendo aos requisitos legais e de eficiência energética.

A etapa para finalizar o Projeto para a Produção é a fase de Documentação dos Processos, em que os elementos são verificados e analisados e, a partir disso, são produzidos os instrumentos necessários, através de cadernos explicativos, diagramas de localização, plantas, cortes e detalhes, além de todo o material necessário para o encaminhamento da manufatura e das instalações em canteiro de obras. Nessa fase, tem-se o entendimento do todo e a clareza das ferramentas para sua divulgação é fundamental para a boa compreensão e comunicação da equipe de trabalho.

A partir do momento que o projeto do sistema foi desenvolvido, a próxima etapa é viabilizar a fabricação dos componentes. Na etapa de fabricação, a estrutura será modelada em sistema BIM. Para esse fim, os programas mais utilizados no setor de fabricação com metais ou concreto são o Tekla, já comentado anteriormente, o Inventor, da Autodesk, utilizado para a engenharia mecânica, documentação e simulação de produtos, e o Prosteel, da 
Bentley, comum na manufatura de estruturas metálicas. Esses programas, assim como os exemplares utilizados na área de arquitetura e engenharia, são capazes de modelar e compatibilizar as diferentes disciplinas do setor, além de contribuírem na gestão do processo de manufatura, produzindo desenhos para a fabricação em plantas, cortes e vistas, desenhos para montagem, levantamentos de quantidades para compra de material, custos e gestão de consumos.

As etapas para a fabricação envolvem desenvolvimento dos desenhos de todas as peças que fazem parte do componente, que podem conter curvaturas, soldagens, desenvolvimento da estrutura com aprovação dos engenheiros de estática, verificação das cargas e otimização dos elementos. Após a produção das peças, esse material entra para a linha de montagem das células ou sistemas, com as devidas identificações e os mapas de localização para a obra. Faz parte desse processo pensar na gestão de custos, nos insumos, no controle de chão de fábrica, na gestão de projetos e também na logística associada à produção, que prevê o carregamento, transporte, tempo e a armazenagem. Em ambos os casos, a produção dos 
painéis foi realizada na China, o que certamente demandou uma logística minuciosa em relação a todos os itens citados acima, além da coordenação com os demais grupos de trabalho, que estavam em fusos horários diferentes e tinham culturas e línguas distintas.

As células finais, os componentes ou sistemas de vedação estão prontos para o encaminhamento da instalação em canteiro de obras, acompanhados de seus devidos mapas e desenhos 3D, produzidos pelo programa de modelagem. Finalizando o processo, há a verificação dos comportamentos com protótipos, que indicam a adequação de todas as etapas do processo para a produção da célula e para a superfície de vedação. No âmbito da produção, estão presentes as máquinas com controle digital para corte de metais e as máquinas fresadoras para a produção de formas ou moldes; contudo, os níveis de automação ainda são escassos, apesar de existirem equipamentos capazes de agilizar o processo.

Finalmente, no canteiro de obras, o componente será encaminhado de acordo com a logística de armazenamento e instalação, juntamente com os instrumentos de localização e técnica de montagem e com equipe especializada 
para tal procedimento. Vale lembrar que aqui são verificados a continuidade do desenho entre os painéis, problemas relacionados ao acabamento, suas devidas restaurações e a necessidade de possíveis cortes na placa para encaixe final.

O plano de vidro foi projetado para ser montado em sequência direcional em cada nível; os apoios na laje mais as conexões laterais estavam ligados e dão suporte aos componentes laterais. Os sistemas curvos das áreas das fendas são colocados sobre apoios do local e chegam pré-montados em fábrica. Já no pavilhão da Expo, a sequência de montagem se deu de trás para frente, sendo que os painéis com projeções foram os últimos, pela sua fragilidade e complexidade.

O desmonte, programado desde o início do conceito, envolveu outro projeto, com logística particular para isso, com os devidos meios de transporte, acondicionamento, identificação, pessoal e equipamentos necessários para o trabalho. Da mesma forma que a sua montagem inicial, esse processo também possui cronograma minucioso, atendimento à segurança, regras para descarte de material e entrega do terreno. Não consiste, portanto, ativida- 
de menos importante em todo o processo de Projeto para a Produção da superfície.

O trabalho do arquiteto propositor do projeto conceitual inicial tende a envolver, de forma mais intensa, que os profissionais se aproximem dos processos de fabricação e, consequentemente, do fazer dos componentes construtivos, devido ao nível de personalização determinada pelas propostas de fabricação digital, que têm maior detalhamento para a definição do objeto, agregando profissionais com equipamentos com alta performance, capazes de flexibilizar a produção para diferentes tipos de componentes para a obtenção da superfície complexa.

Apesar dessa aproximação do projeto idealizado com os modos de produção do edifício, o processo de Projeto para a Produção da superfície complexa é bem mais amplo e profundo, no sentido que busca solucionar questões desde a construtibilidade da superfície até questões da obra propriamente dita, que prevê a incorporação de diversas empresas e de profissionais distintos para a obtenção do produto, com gestão direcionada para as diferentes etapas do processo. 
Na gestão dos empreendimentos, verifica-se que a organização em rede de vários parceiros é necessária, diante das habilidades requeridas para a construção do edifício, e a participação das empresas está diretamente ligada à sua competência técnica, às relações já firmadas anteriormente e à capacidade de solução de problemas.

No sistema BIM, para a detecção de incompatibilidades das diversas engenharias e sistemas, as empresas utilizaram os programas Revit e Navisworks. A administração se beneficia enormemente com o uso do programa, haja vista a quantidade de elementos que devem ser compatibilizados no projeto, o que, sem essa ferramenta, seria enormemente dificultado e os problemas, muitas vezes, seriam detectados somente no momento da execução em canteiro de obras.

A previsão do problema através dos programas de modelagem, gestão e compatibilização faz com que o processo corra em um fluxo mais linear, sem trabalhos adicionais e inesperados, o que, em última instância, significa ter um controle praticamente total sobre o planejamento do projeto e da execução do edifício, resultando em um domínio dos custos, investimentos e prioridades e, ainda assim, 
atuando na diminuição dos descartes e resíduos, devido à utilização mais racional de materiais e métodos.

O uso das tecnologias que envolvem a internet, a nuvem de dados e os dispositivos para acessar esses dados é fundamental para o trabalho, uma vez que os participantes estão em locais distribuídos no globo, embora os encontros presenciais sejam fundamentais para decisões de maior porte ou para o nivelamento do trabalho em grupo.

A característica formal dos organogramas é piramidal, o que evidencia uma forte gestão de coordenação, em que a tomada de decisão está centralizada, principalmente, no topo da hierarquia. Portanto, as decisões são em nível técnico de projeto de arquitetura e pouco distribuídas em relação aos executores da base do organograma, o que parece adequado, pois as questões são previsíveis e sem necessidade de soluções nos momentos de execução. Melhor dizendo, solucionar o problema na base da hierarquia significaria buscar adequações em canteiro de obras ou chão de fábrica.

A gestão apresenta alguns pontos-chave para o desenvolvimento do empreendimento. No primeiro caso, o Ges- 
tor Principal, que coordena todo o processo e evolução, mas também o Coordenador de Projetos, que consegue visualizar o processo geral e direcionar esforços de acordo com as prioridades de desenvolvimento. Nesse caso, esse personagem também coordena o canteiro de obras, que possibilita a articulação e o andamento dos vários sistemas envolvidos.

Na gestão geral do empreendimento de Hadid, os pontos-chave são a empresa que faz a revisão dos projetos e a própria empreiteira, responsável por juntar as disciplinas, pelos fabricantes e pela construção propriamente dita. Observa-se que, assim como no caso anterior, as tecnologias de comunicação e informação são fundamentais para que o empreendimento se concretize.

Ter como pontos-chave do processo as equipes de projeto significa organizar um planejamento e controle minucioso do processo, desde a elaboração de pequenos detalhes de desenho do objeto até o desenvolvimento controlado dos recursos e da construção do edifício. O Projeto para a Produção do edifício é, portanto, a etapa do processo em que a materialização do empreendimento é cuidadosamente elaborada no sentido de produzir os instrumentos 
para a viabilização e o planejamento administrativo para prevenir e solucionar todos os problemas que possam ocorrer.

A partir das elaborações dos dois casos, esse trabalho propõe a indicação do Modelo do Processo de Projeto para a Produção de superfícies complexas para a construção civil e suas discussões. 
Projeto para a Produção de Superfícies Complexas

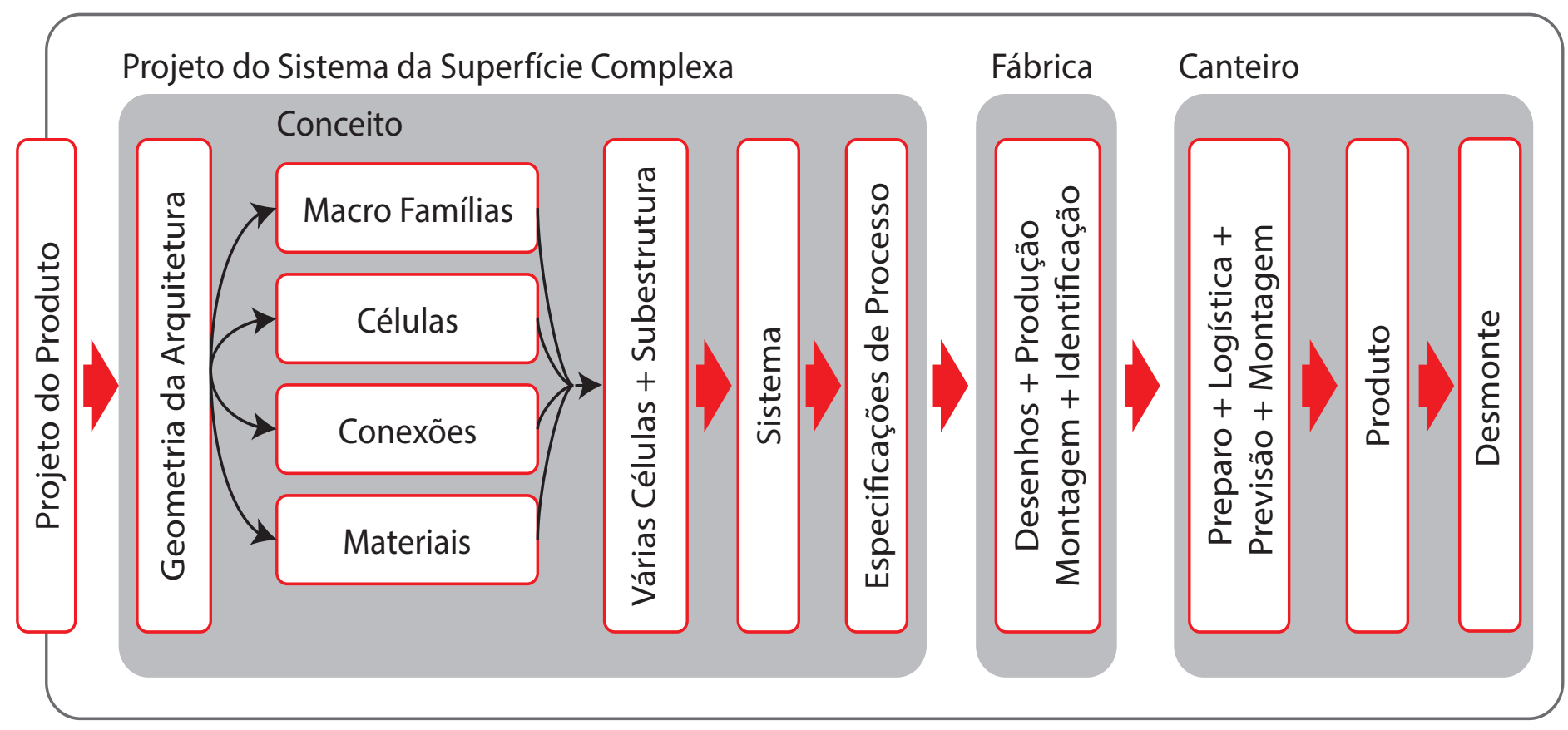

Diagrama 10: Projeto para a Produção de Superfícies Complexas. Fonte: Autor. 
O projeto do produto do escritório de arquitetura traz as indicações iniciais dos autores do projeto e a sugestão dos polígonos que comporão a superfície complexa. O Projeto para a Produção da superfície se inicia desde a proposta conceitual, elaborada a partir de algoritmos geralmente trabalhados nos programas de modelagem (SHINDLER; BRAACH; SHEURER, 2006).

A etapa subsequente, realizada por profissionais capacitados em programação, é verificar, diante da superfície complexa, qual é a melhor forma de realizar a geometria da arquitetura, traduzindo em um polígono que absorva as curvaturas, suavidade e cargas, que produza o menor número de resíduos, que seja adequado ao material, à tipologia e à estrutura e passível de construção (POTTMANN, 2013). Trata-se de uma das etapas mais importantes do processo, pois interfere em todas as fases subsequentes, pensa na execução em fábrica, na forma de utilização do material e nos custos, além de tantas outras variáveis como os planos de vedação, os detalhamentos entre as diversas conexões, elementos de vedação, tipos diversos de materiais, normas, conforto ambiental, etc. (ANDERSON; TANG, 2011). 
A formação do conceito propriamente dito do projeto passa pela elaboração das macrofamílias e famílias, que constituirão as células com as conexões entre as mesmas, a subestrutura e estrutura principal do edifício. Essa etapa associa os profissionais que realizaram a geometria e o pessoal pela produção, que vai discutir o material, os equipamentos disponíveis e a transformação da matéria-prima em objeto, analisando desde a construtibilidade até a sua montagem, as propriedades mecânicas, as conexões e aspectos como implantação do objeto no local. Faz análises e pesquisa a respeito do comportamento dos materiais a serem utilizados e, finalmente, propõe as células que formam a superfície. A organização das superfícies tem a intenção de criar o processo racionalizado para cada parte do edifício, tendo nelas em comum o tipo de curvatura, o parâmetro, o desenho e o material, como no caso da torre desenvolvida pelo escritório Arup - Milão.

As conexões são as relações entre as células, entre a célula e a subestrutura e entre a subestrutura e a estrutura do edifício. No caso de Foster \& Partners, os painéis eram afixados na subestrutura, que possui suportes de encaixe na estrutura, um artifício simples de apoio e fixação. No 
segundo caso, a superfície é apoiada sobre a extensão da laje e engastada na célula ao lado e, consequentemente, necessita de uma ordem na instalação dos painéis, o que deixa a montagem mais complexa e cuidadosa.

Projetar a superfície complexa significa acolher as necessidades de conforto, atender aos requisitos legais de ventilação, aberturas, segurança etc., além de resolver as questões técnicas como vedação, barreira de ventos, insolação e outros. No primeiro caso, a ideia de fazer os lados dos painéis idênticos possibilitou uma enorme economia na produção e na montagem dos painéis. No segundo caso, a separação entre os dois planos de vidro, além de contribuir para a racionalização do produto, conservou a pele dupla de vidro, que contribui para os requisitos de conforto interno dos ambientes e para a economia de energia.

Respeitar o comportamento do material significa utilizar de suas potencialidades e, ao mesmo tempo, garantir a segurança aos usuários. A estratégia de utilizar a curva a frio no edifício de Zaha Hadid Architects é de alta expertise, pois garante uma economia em escala da produção dos painéis, tornando o empreendimento mais viável. 
A constituição de sistemas é um artifício empregado há décadas nos países em que a construção civil industrializada é mais avançada (SZALAPAJ, 2005). Ela prevê a união de vários componentes ou células montadas previamente, no sentido de diminuir os riscos em canteiro de obras e também solucionar problemas com peças de maior complexidade (KNAACK et al. 2007). Como o caso do local em conexão entre a fenda e a superfície de vedação do edifício de Hadid, que utiliza vidros curvos em sistema quente e tem a estrutura seguindo o limite da curvatura.

O Projeto para a Produção considera o projeto para a fabricação, a partir dos desenhos das peças e do encaminhamento à produção dos componentes. Esta etapa é um projeto para a fabricação, geralmente coordenada por engenheiros: civis, mecânicos e de produção, pois a confecção das células tem que ser dissecada para a produção individual de cada peça e, posteriormente, do sistema. Mesmo nessa etapa, são importantes as modelagens de cada chapa e as suas conexões. As indústrias para a construção civil requerem alto controle na compra de materiais, montagem e instalações, dando poucas margens para perdas ou desperdícios. O processo prevê logísticas 
associadas para o envio e a montagem no canteiro de obras, identificando os componentes, sua localização, previsão de operários orientados para a montagem e equipamentos necessários para o trabalho (RASPALL, 2015). Nos casos analisados, ambas as fábricas solucionaram problemas de transporte por água e terra, trabalharam com cronogramas rígidos e produtos altamente frágeis, como as placas de argamassa armada e os planos de vidro com aplicação de tensão para obtenção da curvatura e formas trapezoidais.

As instalações em canteiro de obras são a concretização do produto, atividade que juntará todos os sistemas das várias disciplinas e mostrará o quanto as etapas de projeto e gestão foram eficazes para o desenvolvimento das ligações entre os sistemas e as compatibilizações entre as engenharias e arquiteturas. $O$ controle do canteiro de obras é tão importante quanto todas as etapas anteriores, como demonstrado no esquema de organização do terreno do pavilhão, com localização da grua, entrada de betoneiras, contâineres administrativos e outros. Habitualmente, existem empresas específicas para a realização de auditorias, verificando os tipos de materiais, a qualidade da constru- 
ção etc.

$\bigcirc$ processo está concluído, do desenvolvimento de soluções da superfície ao seu desmonte, que foi idealizado, desde o início do processo, com componentes reaproveitáveis e logística apropriada para esse objetivo, com organização da nova etapa, que é a remontagem e adequação do edifício. 


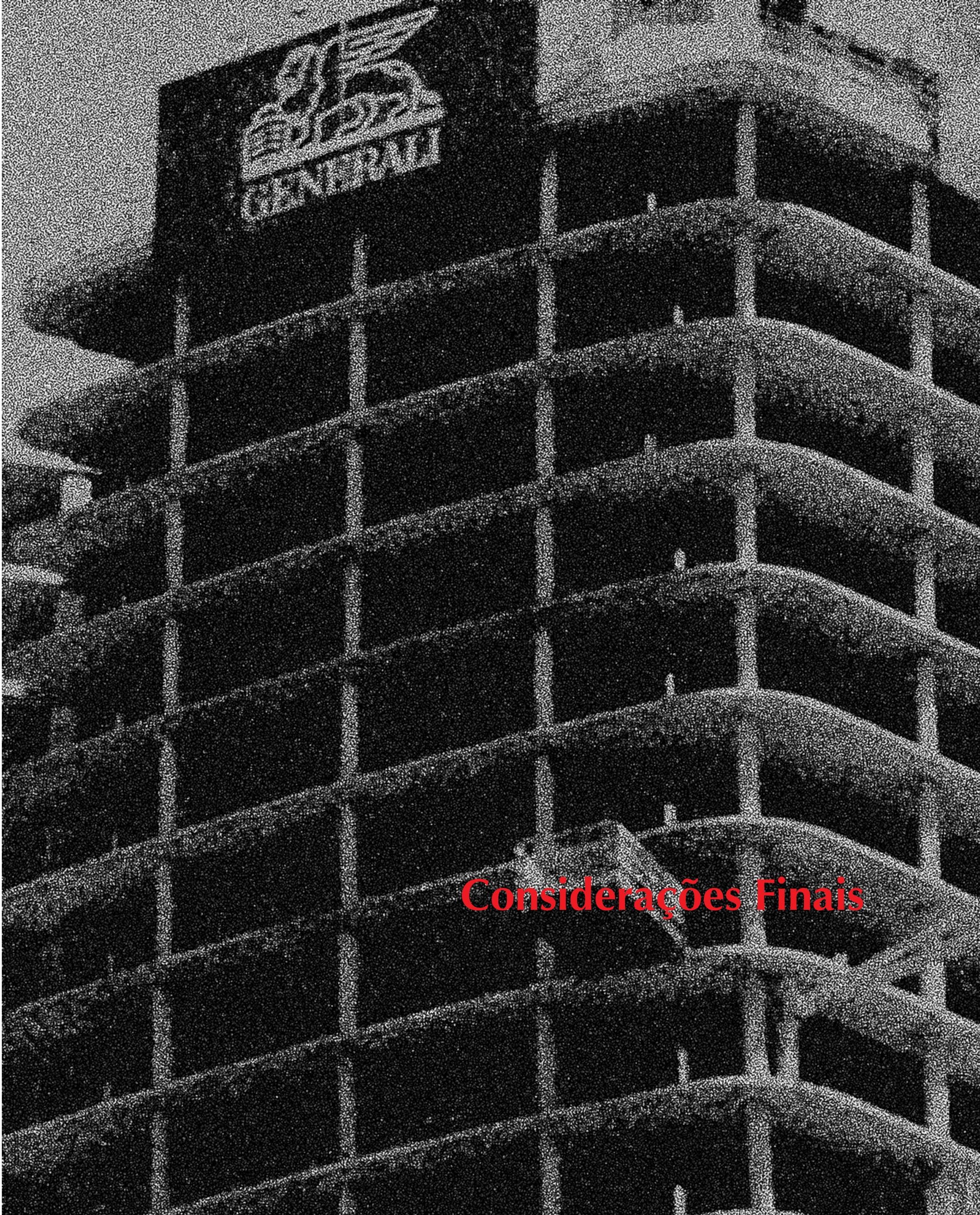



Diante da exposição dos casos, dos esclarecimentos e das soluções encontradas para a elaboração e o desenvolvimento das superfícies complexas, é possível responder à questão inicial da pesquisa:

- Como são desenvolvidas as superfícies complexas de edifícios contemporâneos?

A análise e o aprofundamento dos casos permitiram verificar as atividades envolvidas para a produção da superfície, bem como soluções escolhidas para a confecção dos componentes. Através da estruturação do Projeto para a Produção de superfícies complexas, verificam-se as etapas necessárias para a elaboração do objeto e também as habilidades dos profissionais envolvidos no processo.

O objetivo inicial da pesquisa propôs:

Descrever e discutir como se dão os Projetos para a Produção de superfícies complexas de edifícios contemporâneos reais, pouco descritos na literatura brasileira, e propor um modelo do processo de Projeto para a Produção de superfícies complexas.

A pesquisa atingiu o objetivo, propondo um modelo de 
processo com a sua devida discussão; utilizou, para o seu aprofundamento, a discussão e descrição de dois casos contemporâneos com superfícies complexas idealizados por expoentes da arquitetura mundial, os escritórios internacionais de Foster \& Partners e Zaha Hadid Architects.

Para atingir esses objetivos, a pesquisa buscou literatura a respeito do contexto da digitalização, de como foi o processo histórico da transformação da produção industrial e, consequentemente, da construção civil e do entendimento das discussões a respeito do Projeto para a Produção, para compreender quais eram as temáticas contemporâneas a respeito de sua viabilização nos casos de superfícies complexas.

Diante dos avanços das tecnologias de informação e comunicação, acredita-se que as variáveis que são intrínsecas à construção civil podem necessitar de um tempo para a sua adaptação, no sentido de participarem do contexto da Indústria 4.0. Apesar disso, o movimento de digitalização e a sua consequente automatização são um processo natural que ocorrerá na sociedade e, consequentemente, no mercado e indústria. Considera-se que a construção civil seja parte desse contexto; sendo assim, participa igual- 
mente das mudanças e transformações.

No caminho desta pesquisa, um salto foi perceber que o estudo não deveria ser voltado apenas para a fabricação digital, que olhava para os equipamentos e máquinas, mas para o contexto social, que passa pela digitalização e alteração do mercado para uma situação da indústria na 4. Revolução Industrial. Compreender esse contexto atual do processo de digitalização da sociedade faz pensar nos diversos processos e protocolos existentes e também retomar a situação inicial do problema, que vislumbrava obter a compreensão do processo para a sua utilização no mercado brasileiro. No entanto, verifica-se que essa expectativa envolve diversas variáveis locais, políticas, históricas que, provavelmente, constituem situações que configuram a condição do mercado e das metrópoles atuais. Compreender a tecnologia e seu processo é uma parte da constelação do problema, não menos importante, mas que, em si mesma, não interfere nas situações.

O processo de Projeto para a Produção, como foi desenvolvido em todo o trabalho, é considerado parte do processo de projeto e é fundamental para a sua viabilização. Os vários exemplos da literatura que consideram que a 
atuação do arquiteto está ligada à fabricação como Processo Arquivo-Fábrica (File to Factory) parecem ser uma situação voltada para a pesquisa dos núcleos de pesquisa, que trabalham o uso de equipamentos para a fabricação digital. Citamos como exemplo objetos, geralmente como pavilhões, que permitem o estudo e a análise de processos de projeto em fabricação digital, o que indica que os arquitetos estão mais próximos da confecção dos componentes e das máquinas de produção digital.

O processo de Projeto para a Produção se apresenta de forma complexa para a confecção de edifícios em escala real, necessita de investimentos, tanto em nível de projeto, para encontrar as devidas soluções, para a fabricação e montagem das superfícies, quanto em sua execução propriamente dita, respondendo ao planejamento, à racionalidade e a logísticas minuciosas, evidenciando, assim, a necessidade de conhecimento em parametrização, gestão de projetos em BIM, entendimento sobre os potenciais dos materiais utilizados, necessidades de desenvolvimento de conexões, atendimento às necessidades de eficiência energética e cumprimento às normas legais locais.

Dos cinco casos selecionados, os discutidos neste traba- 
Iho foram fundamentais para a compreensão de "como fazer" superfícies complexas na arquitetura contemporânea. Foram exemplos vivos adicionados a outros casos da literatura e do estudo de edifícios, discutidos nas reuniões de trabalho, nas visitas em canteiro de obras, visitas em fábricas e laboratórios, nas palestras, entrevistas e em disciplinas de projeto. A construção do entendimento e a formação do conceito são um agregado de informações que evoluem com a pesquisa e com o crescimento da pesquisadora, cujo amadurecimento é o alicerce e o estabelecimento da teoria.

O pavilhão da União dos Emirados Árabes apresenta informações relevantes sobre a confecção da argamassa armada, as conexões entre estrutura, subestrutura e painel, a organização para a produção do edifício, desde o desenvolvimento dos detalhes para a sua produção até aspectos de gestão do empreendimento, para coordenar as diversas empresas participantes e as suas devidas responsabilidades. Um projeto pensado para ser remontado em outro local dá a oportunidade de verificar outros pontos, como o desenho idealizado para isso, os aspectos logísticos que envolvem a decisão e até mesmo a viabilidade de 
se construir para esse sistema.

Na torre, a torção realizada sobre o eixo possibilitou verificar os diversos aspectos envolvidos, que partiram de uma parametrização do conceito, determinaram toda a confecção do edifício e da superfície, com vidros trapezoidais, com tipologias diferentes, dimensões únicas dos componentes, e as soluções encontradas para facilitar a produção e o atendimento das normas locais. A gestão e a coordenação do projeto foram realizadas por escritório específico para isso, que verificava todos os desenhos e os aprovava de acordo com as soluções e os processos construtivos.

A partir dessas informações, é possível verificar que:

1. O projeto para a busca de soluções para a viabilização da superfície é fundamental, a partir do aprofundamento dos requisitos necessários e o desenvolvimento das disciplinas específicas;

2. Algumas habilidades específicas são necessárias para a confecção e produção da superfície, desde pessoal capacitado em programação que atue na definição dos polígonos até agentes que compreendam os processos construtivos envolvidos desde 
as definições iniciais de projeto;

3. A gestão com utilização de plataformas BIM é fundamental para realizar todas as etapas administrativas, bem como as demais atividades, como simulações, cronogramas, projeto simultâneo e outros,

4. O Projeto para a Produção é um processo que pensa junto com o produto e realiza a gestão e o planejamento até a finalização. Verifica e desenvolve da melhor forma o projeto, a fabricação, montagem e desmontagem do objeto.

O percurso da pesquisa atende a uma lacuna que é pouco trabalhada na literatura e que tem conexão com a questão inicial da pesquisa, que tenta compreender como viabilizar superfícies complexas. A literatura é vasta nos ramos da projetação e nas modificações dos protocolos, quando utilizada a fabricação digital no processo, mas são poucos os casos que descrevem como os edifícios em escala real foram construídos, quais foram as soluções encontradas para a sua produção, como são desenvolvidas células diferentes na produção industrial, que tem como base a produção parametrizada.

O percurso da pesquisa demonstrou que os equipamentos digitais, juntamente com o desenvolvimento do projeto 
do produto, que utiliza das potencialidades dos equipamentos e materiais, são capazes de materializar os componentes e sistemas. A coordenação através da gestão do processo é fundamental para a previsão e a solução antecipada dos problemas, o que envolve diversos atores com diferentes responsabilidades e habilidades.

O desenvolvimento de um Projeto para a Produção minucioso e contínuo é a chave para o sucesso do empreendimento. É pautado na gestão competente, no conhecimento técnico e associado às tecnologias disponíveis. 


\section{Novas etapas de pesquisa}

Este trabalho é parte de uma constelação de pesquisa e - Brasil possui inúmeras variáveis que interferem para que sejam viabilizadas superfícies complexas. Assim, um dos campos que vale o aprofundamento é investigar a construção civil industrializada em nosso país e verificar como são os processos de projeto para a produção dos edifícios contemporâneos, adicionado a uma pesquisa nos escritórios de arquitetura que desenvolveram os projetos e também nas construtoras que executaram tais construções.

Outro aspecto instigante que este trabalho induziu é a aplicação das tecnologias digitais em análises de projetos existentes, tais como uso de realidade aumentada para a educação patrimonial, uso de tecnologias no ensino de projeto e de tecnologia em geral, uso de tecnologias em avaliação de edifícios ou para a documentação de patrimônio histórico. A gama de caminhos com a aplicação de dispositivos digitais é praticamente infinita e abre possibilidades criativas, principalmente em se tratando de um país emergente como o Brasil.

Aspectos como a arquitetura como espetáculo também 
são tema de interesse da pesquisadora, pois trataria o tema com uma profundidade vista por outro lado do problema, juntamente com questões relativas ao mercado imobiliário que interferem no processo de ocupação e valorização das cidades.

Como mencionado no início, trabalhar em pesquisa é o início de muitas buscas e sempre tenta responder às indagações e inquietações do pesquisador. $O$ processo, apesar de individual, não é possível sem o grupo de pesquisa e a interlocução de nossos colegas, amigos e pessoas que estão à nossa volta.

E o processo só se conclui aqui, após a concretização através da sistematização e da escrita do processo. 

ABIKO, Alex Kenya; MARQUES, Felipe Silveira; CARDOSO, Francisco Ferreira; TIGRE, Paulo Bastos. (2005). Setor de construção civil: Segmento de Edificações, v.1. Brasília: SENAI.

ABRAMOVICl, M.; GÖBEL, J. C.; NEGES, M. (2015). Smart Engineering as Enabler for the 4th Industrial Revolution, In: FATHI, M. (Ed.) Integrated Systems: Innovations and Applications, Siegen: Springer. p. 173-194.

ACHTEN, Henri H. (2007) Experimental Design Methods - A Review. International Journal of Architectural Computing, v.7, n.4, p.505-534.

ADDIS, Bill. (2009). Edificação: 3000 Anos de Projeto, Engenharia e Construção. Tradução de Alexandre Salvaterra, Porto Alegre: Bookman.

AFIFY, H. M.; ELGHAFFAR, Z. A. (2007). Advanced Digital Manufacturing Techniques (CAM) in architecture Authors. Proceedings... The Third International Conference of the Arab Society for Computer Aided Architectural Design (ASCAAD), Alexandria: ASCAAD. p. 67-68.

AGKATHIDIS, A.; BROWN, A. (2011). Tree-Structure Canopy: A Case Study in Design and Fabrication of Complex Steel Structures using DIGITAL TOOLS. International Journal of Architectural Computing, v.11, n.1, p. 87-104.

AGREN, R.; WING, R. D. (2014). Five moments in the history of industrialized building. Construction Management and Economics, v.32, n.1-2, p.7-15.

ALBINO, V.; BERARDI U.; DANGELICO, R. M. Smart Cities: Definitions, Dimensiton, Performance, and Initiatives, Journal fo UrbanTechnology, February, V.22, no. 1,3-21, 2015. DOI: 10.1080/10630732.2014.942092

ANDERSON, J.; TANG, M. (2011). Form Follows Parameters: Parametric Modelling for fabrication and Manufacturin Processes. Proceedings... CAADRIA. v.1, p. 1-10. 
ANDERSON, J.; TANG, M. (2011a). Interactive Information Model for Digital Fabricator. Proceedings... CAADRIA.

ANTONIO, D. (2016). Personalizzazione di Massa - La Diffusione dell'Internet delle cose Permetterà alla Manifattura di Accendere un Dialogo Continuo tra Prodotto, Machina che lo Fabbrica e Consumatore Finale. Milano: Nòva Edu - Lezione di Futuro - 07, II suo 24 ore.

ARANTES, P. F. (2008). O GrauZero da Arquitetura na Era Financeira. Novos Estudos CEBRAP n.80, p.175195.

ASHTON, K. (2015). Kevin Ashton - entrevista exclusiva com o criador do termo "Internet das Coisas". São Paulo: Disponível em: http://finep.gov.br/noticias/ todas-noticias/4446-kevin-ashton-entrevista-exclusiva-com-o-criador-do-termo-internet-das-coisas. Acesso em: 24 jul 2017.

ATZORI, L.; IERA, A.; MORABITO, G. (2010). The internet of things: a survey, v. 54, Cagliari, Calabria: Elsevier B.V.

BALAGUER, C.; ABDERRAHIM, M.(2008). Trends in Robotics and Automation in Construction, p.1-22. In: BALAGUER, C.; ABDERRAHIM, M.(2008) Robotics and Automation in Construction, Europe Union: InTech.

BARBOSA, W.; CARVALHO, G.; CELANI, G. (2006). Samba Reception Desk Compromising aesthetics, fabrication and structural performance in the design process. Proceedings... ECAADE. v.2, p. 245-254. cumincad.

BARROS, M. M. (1996). Metodologia para Implantação de Tecnologias Construtivas Racionalizadas na Produção de Edifícios. São Paulo: Tese (Doutorado em Engenharia Civil), Escola Politécnica, Universidade de São Paulo.

BENEVOLO, L. (1993). História da Cidade, 2a. ed. São Pau- 
lo: Editora Perspectiva.

BOCK, T. (2015). The Future of Construction Automation: Technological Disruption and the Upcoming Ubiquity of robotics. Automation in Construction, v.59, p.113-121.

BOCK, T.; LINNER, T. (2015). Robotic Industrialization: Automation and Robotic Technologies for Customized Component, Module, and Building Prefabrication, New York: Cambridge University Press.

BOOTHROYD, G.; DEWHURST, P.; KNIGHT, W. A. (2011). Summary for Policymakers. Climate Change 2013 The Physical Science Basis, v.1, p. 1-30.

BRELL-COKCAN， S.; REIS， M.; SCHMIEDHOFER, H.; BRAUMANN, J. (2009). Digital Design to Digital Production Flank Milling with a 7-Axis CNC-Milling Robot and Parametric Design. Proceedings... ECAADE 27, p. 323-329.

BRETON, P.; PROUX, S. (2006). Sociologia da Comunicação Tradução: Ana Paula Castellani, 2a. ed., São Paulo: Loyola.

BRUNA, P. J. (1976). Arquitetura Industrialização e Desenvolvimento. São Paulo: Perspectiva.

BRYNJOLFSSON, E.; McAFEE, A. (2011). Race Against The Machine: How the Digital Revolution is Accelerating Innovation, Driving Productivity, and Irreversibly Transforming Employment and the Economy. Massachusets: Digital Frontiers Press.

BRYNJOLFSSON, E.; McAFEE, A. (2014). The Second Machine Age: Work, Progress, and prosperity in a Time of Brilliant Technologies. New York: Erik Brynjolfsson \& Andrew McAfee.

CANEPARO, L. (2014). Digital Fabrication in Architecture, Engineering and Construction. Tradução: Carolyn Winkless, Torino: Springer.

CANO, Wilson (2012). A desindustrialização no Brasil. In- 
stituto de Economia - UNICAMP. Textos para discussão, v.1, 1 ed.

CARDOSO, R. (2008). Uma Introdução à História do Design 3a. ed. São Paulo: Blucher.

CATALANO, F. (2016). Complex Surface: City Life Tower. (E. L. Miyasaka, Entrevistador, Autor, Tradutor) Milão, Lombardia, Itália.

CELANI, G., PICCOLI, V. (2010). The roles of a model. Arquitetura Revista, v.6, n.1, p. 50-62.

CHALITA, A. C. (2010). Estrutura de um projeto para produção de alvenarias de vedação com enfoque na construtibilidade e aumento de eficiência na produção, Dissertação (Mestrado em Engenharia Civil) Escola Politécnica da Universidade de São Paulo. São Paulo.

CHANG, T.C.; WYSK, R. A.; WANG, H.P. (1998). Computer-Aided Manufacturing, 2nd. ed., New York: Prentice Hall.

CHIARANDÁ, G. (2016). Processo de Gestão do Pavilhão da União dos Emirados Árabes. (E. L. Miyasaka, Entrevistador, autor, Tradutor) Milão, Lombardia, Itália.

CHINCHOLKAR, M. M.; HERMANN, J. W.; WEI, Y.-F. (2003). Applying Design for Production Methods for Improved Product Development. Proceedings... ASME 2003 Design Engineering Technical Conferences and Computers and Information in Engineering Conference. p. 1-10.

CHIPRIANOV, V.; KERMSRREC, Y.; ROUVRAIS, S.; SIMONIN, J. (2014). Extending Enterprise Architecture Modeling Languages for Domain Specificity and Collaboration: Application to Telecommunication Service Design. Software and Systems Modeling, v.13, n.3, p. 963-974.

COMU, S.; TAYLOR, J. E.; MESSNER, J. I. (2012). Two-Dimensional Globalizing Index and Globalizing Self-Assessment Tool for Engineering and Con- 
struction Companies. Proceedings... Construction Research Congress 2012, v.31, p.2520-2529.

COSTA, D. B.; FORMOSO, C. T. (2006). O projeto do sistema de produção na gestão de empreendimentos habitacionais de interesse social. Ambiente Construído, v.6, n.2. p. 59-74.

DEUSS, Mario Moacir (2015) Computational Methods for Fabrication-aware Modeling, Rationalization and Assembly of Architectural Structures. 2015. 106p. Tese (Doutorado em Informação e Comunicação) La Faculté Informatique et Communications, École Polytechnique Fédérale de Lausanne, Lausanne.

DRATH, R.; HORCH, A. (2014). Industrie 4.0: Hit or Hype? IEEE Industrial Electronics Magazine, v.8, n.2, p.5658.

DRITSAS, S. (2012). Design-Built Rationalization Strategies and Applications. International Journal of architectural Computing, v.4, n.10, p. 575-594.

DUNN, N. (2012). Digital Fabrication in Architecture. London: Laurence king Publishing.

EGAN, M. (s.d.). Design for X: Eye Opening Desing. London: Modularize. Disponível em: http://www.modularize.co.uk/wp-content/uploads/2015/08/Design-for-X.pdf. Data de Acesso: 24 jul 2017.

FABRÍCIO, M. M.; BAÍA, J. L.; MELHADO, S. B. (1998). Estudo da sequência de etapas do projeto na construção de edifícios: cenário e perspectivas. In: Encontro Nacional de Engenharia de Produção, n.18, Niterói. Anais..., Niterói: UFF.TEP.

FAGHIHI, V.; NEJAT, A.; REINSCHMIDT, K. F.; KANG, J. H. (2015). Automation in construction scheduling: a review of the literature. International Journal of Advanced Manufacturing Technology, 1845-1856.

FALLER, C.; FELDMÜLLER, D. (2015). Industry 4.0 Learning Factory for regional SMEs. Procedia CIRP, v.32, p. 88-91. 
FEDERAL MINISTRY OF EDUCATION AND RESEARCH (BMBF) . (2014). The new High-Tech Strategy Innovations for Germany. Berlin: (BMBF), Federal Ministry of Education and Research. Berlin: Federal Ministry of Education and Research.

FERREIRA, E. d. (1998). Metodologia para elaboração do projeto do canteiro de obras de edifícios. São Paulo: EPUSP.

FONSECA FILHO, C. (2007). História da computação: O caminho do Pensamento e Tecnologia. Porto Alegre: EDIPUCRS.

FROESE, T. M. (2010). The impact of emerging information technology on project management for construction. Automation in Construction, v.19, n.5, p.531538.

GIEDION, S. (2004). Espaço, Tempo e Arquitetura: o desenvolvimento de uma nova tradição. Tradução: Alvamar Lamparelli, São Paulo: Martins Fontes.

GILL, H. (2008). A Continuing Vision: Cyber-phsiycal Systems. Fourth Annual Carnegie Mellon Conference on the Electricity Industry FUTURE. Carnegie Mellon: National Science Foundation. p. 1-28

GRAMAZIO, F.; KOHLER, M.; OESTERLE, S. (2010). Encoding Material. Architectural Design, v.80, n.2, p. 118125.

GRANGEL-GONZÁLEZ, I.; HALILAJ, L.; COSKUN, G.; AUER, S.; COLLARANA, D.; HOFFMEISTER, M. (2016). Towards a Semantic Administrative Shell for Industry 4.0 Components. 2016 IEEE Tenth International Conference on Semantic Computing (ICSC), p. 230-237.

HAN, S. H.; KIM, D. Y.; JANG, H. S.; CHOI, S. (2010). Strategies for contractors to sustain growth in the global construction market. Habitat International, v.34, n.1, p.1-10.

HARVEY, D. (1989). A Condição Pós-Moderna. São Paulo: 
Edições Loyola.

HERMANN, J. W. (2003). Design for Production: Concepts and Applications. Proceedings... Bethlehem: Society of Manufacturing Engineers Annual Members Conference.

HERMANN, J. W.; CHINCHOLKAR, M. M. (2000). Design for Production: A Tool for Reducing Manufacturing Cycle Time. Proceedings of DETC 2000 ASME Anais... _. Design Engineering Technical Conference. p. $\overline{10}-20$.

HUDSON, R.; SHEPHERD, P.; HINES, D. (2009). Aviva Stadium : A case study in integrated parametric design Aviva Stadium : A case study in integrated parametric design. International Journal of Architectural Computing, v.09, n.2, p. 187-204.

JENKS, C. (1997). The Archtecture of the Jumping Universe. New York: Academy Editions.

JESCHKE, S. (2013). Cyber-Physical Systems - History, Presence and Future. Acesso em 14 out 2016, disponível em http://www.ima-zlw-ifu.rwth-aachen.de/: http:// www.ima-zlw-ifu.rwth-aachen.de/fileadmin/user upload/INSTITUTSCLUSTER/Publikation_Medien/ Vortraege/download//CPS_27Feb2013.pdf

JOHANSSON, R. (2003). Case Study Methodology. International Conference Methodologies in Housing Research Stockholm: International Conference Methodologies in Housing Research. p. 22-24.

JONES, J. (2014). 3D Printing Metal for Structural Strength, Space, and Beyond Researchers are 3D printing structural steel and micro-scale components that could revolutionize design and construction. The Journal of the American Institute of Architects. Disponivel em: http://www.architectmagazine. $\mathrm{com} /$ technology/3d-printing-metal-for-structural-strength-space-and-beyond_o. Acesso em 24 jul 2017

KATSUNDO, H. (1994). Automation - its concept and a 
short history. Technovation, v.14, n. 2, p.121-128.

KLINGER, K. R. (2010). Relationas: Information Exchange in Designing and Making Architecture. in KOLAREVIC, B.; KLINGER, K. R. Manufacturing Material Effects: Rethinking Design and Making in Architecture. New York: Routledge.

KNAACK, U.; KLEIN, T.; BILOW, M.; AUER, T. (2007). Façades: Principles of Construction. Intergovernamental Panel on Climate Change, Ed. Cambridge: Cambridge University Press.

KOLAREVIC, B. (2001). Designing and Manufacturing Architecture in the Digital Age. Proceedings ...19th eCAADe Helsinki: eCAADe. p. 117-123.

KOLAREVIC, B. (2003). Architecture in the Digital Age: Design and Manufacturing. London: Taylor \& Francis Group.

KOLAREVIC, B.; KLINGER, K. R. (2010). Manufacturing Material Effects: Rethinking Design and Making in Architecture. London: Routledge.

KUO, T.-C., HUANG, S. H.; ZHANG, H.C. (2001). Design for Manufacture and Design for ' $X$ ': Concepts, applications, and perspectives. Computers \& Industrial Engineering, v. 41, n.1, p. 241-260.

LAMB, Frank (2015) Automação Industrial na Prática: Eixo, Controle e Processos Industriais. Traducão: Márcio José da Cunha, São Paulo: Mc Graw Hill Education e Bookman, AMGH Editora Ltda.

LARIZZA, A. (2016). La Rinascita della Fabrica: Nell'era della Manifattura Digitalizzata, Le Aziende Possono Tornare a Creare Valore a una Condizione: L'uomo dourà Competere al Fianco delle Machine In: La Fabrica Digitale: Come Funziona L'Industria 4.0 e che cosa Possiamo Fare. Milano: Nòva Edu - lezione di Futuro - 07, II suo 24 ore.

LARSEN, K. E., SCHINDLER, C. (2008). From Concept to Reality: Digital Systems in Architectural Design and 
Fabrication. International Journal of Architectural Computing, v.4, n.6, p. 397-414.

LASI, H. L.; KEMPER, H.-G.; FETTKE, P.; FELD, T.; HOFFMAN, M. (2014). Industry 4.0. Business \& Information Systems Engineering, v.6, n.4, p.239-242.

LEE, J.; BAGHERI, B.; KAO, H.-A. (2015). A Cyber-Physical Systems architecture for Industry 4.0 - based manufacturing systems. Manufacturing Letters, v.3, p.1823.

LEE, J.; KAO, H.-A.; YANG, S. (2014). Service innovation and smart analytics for Industry 4.0 and big data environment. Procedia CIRP, v.16, p. 3-8.

LEHTO, J.; HARKONEN, J.; HAAPASALO, H.; BELT, P.; MOTTONEN, M.; KUVAJA, P. (2011). Benefits of DfX in Requirements Engineering. Technology and Investment, v.2, n. February, p. 27-37.

LEONARD, J. (2015). Building Tomorrow's Delivering the benefits of Industry 4.0 requires robust communication. Professional Engineering, v.28, n.2, p.16.

LU, Y.; LI, Y.; SKIBNIEWSKI, M.; WU, Z.; WANG, R.; LE, Y. (2014). Information and Communication Technology Applications in Architecture, Engineering, and Construction Organizations : A 15-Year Review. Journal of Management in Engineering, v.31, n.1, p.1-19.

MA, H.-D. (2011). Internet of Things: Objectives and Scientific Challenges. Journal of Computer Science and Technology, v.26, n.6, p. 919-924.

MARTUCCI, R. (1990). Projeto Tecnológico para Edificações Habitacionais Utopia ou Desafio? São Paulo: Tese (Doutorado em Arquitetura e Urbanismo) Faculdade de Arquitetura e Urbanismo, Universidade de São Paulo.

MARWAH, A. K.; THAKAR, G. (2013). Design for Production: Concepts and Applications. PARIPEX - Indian Journal of Research, v.2, n.3. p.1-9. 
MATTELART, A. (2002). História da Sociedade da Informação. Tradução: Nicolás. Nuimi Campanário, São Paulo: Editora Loyola.

MC-BAUCHEME. (2017). MAR - Museu de Arte do Rio de janeiro. Disponível em http://www.mc-bauchemie. com.br: http://www.mc-bauchemie.com.br/projetos/mar-museu-de-artes-rio-de-janeiro/\#ad-image-0. Acesso em 29 de 06 de 2017

MELHADO, S. B. (1994). Qualidade do projeto na construção de edifícios: aplicação ao caso das empresas de incorporação e construção. (Tese de Doutorado em Engenharia), Escola Politécnica da Universidade de São Paulo, São Paulo.

MELHADO, S. B.; FABRICIO, M. M. (1998). Construção de Edifícios: Discussão e Síntese de Conceitos. Ânais... VII Encontro Nacional de Tecnologia do Ambiente Construído Qualidade no Processo Construtivo Anais_antac.

MENGES, A. (2007). Computational morphogenesis Integral Form Generation and Materialization Processes. Proceedings... of 3rd International ASCAAD Conference on Em'body'ing Virtual Architecture. v.1.

MENGES, A. (2013). Performative Morphology in Architecture. SAJ (icd), v. 5, p. 92-105.

MENGES, A. (2015). The new cyber-physical making in architecture: Computational construction. Architectural Design, v. 85, n.5, p. 28-33.

MENGES, A.; SHWINN, T. (2012). Manifacturing Reciprocities. Architectural Design, v.82, n.2, p. 118-125.

MITCHELL, W. J.; McCULLOUGH, M. (1996). Digital Design Media, 2a. ed. New York: Van Nostrand Reinhold.

MIYASAKA, E.L.; FABRICIO, M.M. (2015) Digital Fabrication in Brazil, Academic Production in the last decade. Proceedings... The next City - New Tecnologies and the future of the built environment (16th 
International Conference CAAD Futures 2015, CAAD Futures, São Paulo.

MIYASAKA E.L.; SCHEEREM, R.; VASCONSELOS, T.; SPERLING, D. M.; FABRICIO, M. M. (2017) Hybrid Cultures: design and construction strategies of complex forms in Brazil in the first digital age. IN: CELANI, G.; KANOUN O. (ED.) (2017) Frontiers of Science and Technology: Automation, Sustainability, Digital Fabrication - Selected extended Papers of the 7th Brazilian-German Conference, Campinas 2016 Brazil, Campinas: De Gruyter.

MONZON, A. (20015) Smart Cities Concept and Challenges: Bases for the Assessment of Smart City Projects, in: M. Helfert et al. (Eds.): Smartgreens 2015 and Vehits 2015, CCIS 579, pp. 17-31. DOI: 10.1007/978-3319-27753-0_2

MORAES, C.; ABREU, C. M. (2006). A história das máquinas - ABIMAQ 70 anos. São Paulo: Magma Cultural e Editora.

NABONI, R.; PAOLETTI, I. (2015). Advanced Customization in Architectural Design and Construction. Milano: Politecnico di Milano - Springer.

NAVY, U. D. (1999). The National Shipbuilding Research Program, Design, Design for Production Manual. Washinton: Standard Form 298.

NEUMAN, E. (2014). Data Reshaped: Literalism in the Age of Digital Design and Architectural Fabrication. Dynamics of Data-Driven Design, n. autumn, p. 43-58.

NOBLE, D. F. (2011). Forces of Production: A Social History of Industrial Automation. London: Transaction Publishers.

NORMAN, F. (2004). Digital to Analog Exploring Digital Processes of Making. Proceedings ... 22nd eCAADe Copenhagen: eCAADe. p. 112-118.

NOVAES, C. C. (1997). Um enfoque diferenciado para o projeto de edificações: projetos para produção. 
Anais... Encontro Nacional de Engenharia de Produção, Gramado. n.16, p. 1-8.

OESTERREICH, T. D.; TEUTEBERG, F. (2016). Understanding the implications of digitisation and automation in the context of Industry 4.0: A triangulation approach and elements of a research agenda for the construction industry. Computers in Industry, v.83, p.121-139.

OOSTERHUIS, K. (2012). Simply complex, toward a new kind of building. Frontiers of Architectural Research, v.1, n.4, p. 411-420.

OOSTERHUIS, K.; BIER, H.; AALBERS, C.; BOER, S. (2004). File to Factory and Real-Time Behavior in Proceedings of ONL-Architecture. 23rd Annual Conference of the Assiociation for Computer Aided Design in Architecture and the 2004 Conference of the AIA Technology in Architectural Practice Knowledge Community, p.294-305.

OXMAN, R. (2006). Theory and design in the first digital age. Design Studies, v.27, n.3, p.229-265.

PAOLETTI, I. (2006). Building Complex Shapes: Innovation, mass-customization and Technology transfer in architecture. Milano: Libreria CLUP.

PERROT, Michelle. (2009). História da Vida Privada: Da Revolução Francesa à Primeira Guerra, Tradução de Denise Bottman e Bernardo Joffily, Vol. 4. São Paulo: Companhia de Bolso.

POSADA, J.; TORO, C.; BARANDIARAN, I.; OYARZUN, D. (2015). Visual Computing as Key Enabling Technology for Industrie 4.0 and Industrial Internet. IEEE Computer Society, v.26, p. 1-11.

POTTMANN, H. (2013). Architectural Geometry and Fabrication-Aware Design. Nexus Network Journal, v.15, n.2, p. 195-208.

RASPALL, F. (2015). A Procedural Framework for Design to Fabrication. Automation in Construction, v.51, p. 
132-139.

REN, S.; GALJAARD, S. (2015). Topology Optimisation for Steel Structural Design with Additive Manufacturing. In: M. R. Thomsen (Ed.), Modelling Behavior: Design Modelling Simposium. London: On Enterprise Architecture.

RICHARD, R.B. (2005). Industrialised Building Systems: Reproduction Before Automation and Robotics. Automation in Construction, v.14, n.4, p.442-451.

ROCHA, D. H.; CELANI, G.; PUPO, R. (2010). Fabricação Digital e sua aplicação no corte de fôrmas de concreto: um exercício de produção. Anais... $8^{\circ}$ Seminário Internacional. Design e Inovação: Mensagens e Produtos para Ambientes Sustentáveis NUTAU. p. 1-10.

ROSER, Christoph (2015). A Critical Look at Industry 4.0. Fonte: Daily Management Review: http:// www. dailymanagementreview.com/Industry-4-0-the-fourth-industrial-revolution_a2006.html. Acesso em 24 jul 2017.

ROSSO, T. (1990). Racionalização da Construção. São Paulo: Universidade de São Paulo.

SABBATINI, F. H. (1998). A industrialização e o processo de produção de vedações: utopia ou elemento de competitividade empresarial. In Anais... São Paulo: Epusp/PCC.

SANISLAV, T.; MICLEA, L. (2012). Cyber-Physical Systems Concept, Challenges and Research Areas. Journal of Control Engineering and Applied Informatics, v.14, n.2, p.28-33.

SANTOS, M.; MOCCELLIN, J. (1999). O Projeto da Produção e a Programação Integrados a um Sistema de Administração da Produção Voltado para a Construção Civil. Disponível em www.abepro.org. br: www.abepro.org.br/biblioteca/ENEGEP1999_ A0229.PDF. Acesso em 19 de março de 2015, 
SASS, L. (2007b). Parametric Constructionist Kits: Physical Design and Delivery System for Rapid Prototyping Devices. International Journal of Architectural Computing, v.7, n.4, p. 623-642.

SASS, L. (2007a). Synthesis of design production with integrated digital fabrication. Automation in Construction, v.16, n.3, p. 298-310.

SASS, L.; BOTHA, M. (2006). The Instant House : A Model of Design Production with Digital Fabrication. International Journal of Architectural Computing, v.4, n.4, p. 109-124.

SASS, L.; MICHAUD, D.; CARDOSO, D. (2006). Materializing a Design with Plywood. Proceedings...eCAADE v.25. Cumincad.

SCHEURER, F. (2008). Size Matters : Digital Manufacturing in Architeture. In: ABRUZZO, E.; SALOMON, J.D (2008). Dimentions, V. 12, p. 59-65. New York: Princeton Architectural Press.

SCHEURER, F. (2009). MATERIALISING Complexity. Architectural Design, v.79, n.4, p. 86-93.

SCHEURER, F.; SCHINDLER, C.; BRAACH, M. (2005). From Design to Production: Three complex structures materialised in Wood. Proceedings... of 6th International Conference Generative Art. Milan: Celestino Soddu.

SCHIMEK, H.; WILTSCHE, A.; MANAHL, M.; PFALLER, C. (2013). Full Scale Prototiping. In: CAADRIA (Ed.), Open Systems: Proceedings... of the 18th International Conference on Computer-Aided Architectural Design Research in Asia. v.1, p. 653-662.

SCHWAB, Klaus (2016). The Fourth Industrial Revolution. New York: World Economic Forum.

SHAFIQA, S. I.; SANINA, C.; SZCZERBICKIB, E.; TOROC, C. (2015). Virtual Engineering Object/virtual Engineering Process: A specialized form of Cyber Physical System for Industrie 4.0. Procedia Computer 
Science, v. 60, n.1, p. 1146-1155.

SHEIL, B. (2012). Manufacturing Bespoke Architecture. Nexus Network Journal, v.14, n.3, p.441-458.

SHEIL, B. (2013). De-Fabricating Protoarchitecture In: STACEY, Michael (2013) Prototyping Architecture: The Conference Papers, London: Building Centre Trust. p. 372-390.

SHINDLER, C.; BRAACH, M.; SHEURER. F. (2006). Inventioneeing Architecture - building a doubly curved section through Switzerland. Proceedings... ACADIA. p. 1-13.

SILVA, E. L.; MENEZES, E. M. (2005). Metodologia da Pesquisa e Elaboração de Dissertação (4a. ed.). Florianópolis: UFSC.

SILVEIRA, L.; LIMA, W. Q. (2003). Um breve histórico conceitual da Automação Industrial e Redes para Automação Industrial. Lagoa Nova: UFRN-PPgEE.

SOMMER, L. (2015). Industrial revolution - industry 4.0: Are German manufacturing SMEs the First Victims of this revolution? Journal of Industrial Engineering and Management, v. 8, n.5, p.1512-1532.

SOUZA F. A.; ULBRICH, C. B. (2009). Engenharia Integrada por Computador e Sistemas CAD/CAM/CNC: Princípios e Aplicações. São Paulo: Arliber Editora.

SYKES, A. K. (org.) (2013). O Campo Ampliado da Arquitetura: Antologia Teórica 1993-2009. Tradução de Denise Bottmann. São Paulo: CosacNaify.

SZALAPAJ, P. (2005). The Digital Design Process in Contemporary Architectural Practice. Proceedings... EcaaD 23. p.751-759.

TEG TEMA WORKING GROUP (2015) EXPO Milano Theme Guide, Milano: Thematic Spaces Department.

TEIXEIRA, L. P.; CARVALHO, F. M. (2005). A Construção Ci- 
vil como Instrumento de Desenvolvimento. Revista Paraense de Desenvolvimento, v.1, n.109, p.9-25.

TIEN, J. M. (2012). The Next Industrial Revolution: Integrated Services and Goods. Journal of Systems Science and Systems Engineering, v.21, n.3, p. 257-296.

TRENTESAUX, D.; BORANGIU, T.; THOMAS, A. (2016). Emerging ICT concepts for smart, safe and sustainable industrial systems. Computers in Industry, v.6, n.4, p. 1-10.

VISWANADHAM, N. (2002). The past, present, and future of supply-chain automation. IEEE Robotics and Automation Magazine, v.9, n.2, p.48-56.

WANG, D.; GROAT, L. (2002). Architectural Research Methods. New York: John Wiley \& Sons.

WANG, S.; WAN, J.; ZHANG, D.; LI, D.; ZHANG, C. (2015). Towards smart factory for Industry 4.0: A self-organized multi-agent system with big data based feedback and coordination. Computer Networks, v.101, p. 158-168.

WARWICK MANUFACTURING GROUP (2007). Design for $X$. Warwick: University of Warwock. Disponível em: http://www2.warwick.ac.uk/fac/sci/wmg/ftm$\mathrm{sc} / \mathrm{modules} / \mathrm{modulelist/peuss/designforx/design}$ for_x_notes_section_5.pdf. Data de Acesso: 24 jū 2017.

WILLIAMS, N.; STEHLING, H.; SCHEURER, F.; OESTERLE, S.; KOHLER, M.; GRAMAZIO, F. (2011). A Case Study of a Collaborative Digital Workflow in the Design and Production of Formwork for 'Non-Standard' Concrete Structures. International Journal of Architectural Computing, v.9, n.3, p. 223-240.

WOMACK, J. P.; JONES, D. T., ROSS, D. (1992). A Máquina que Mudou o Mundo. Tradução: Ivo Korytowski, Rio de Janeiro: Editora Campus.

WOOD, G.; ELLIS, R. (2005). Main Contractor Experiences of Partnering Relationships on UK Construction 
Projects. Construction Management and Economics, v.23, n.3, p. 317-325.

YIN, R. K. (2001). Estudo de Caso: Planejamento e Métodos. Tradução: Daniel Grassi, Porto Alegre: Bookman. 
Figura 112: Peça em madeira com sulcos para curva em duas direções. Foto: autor. Data: 2016. 


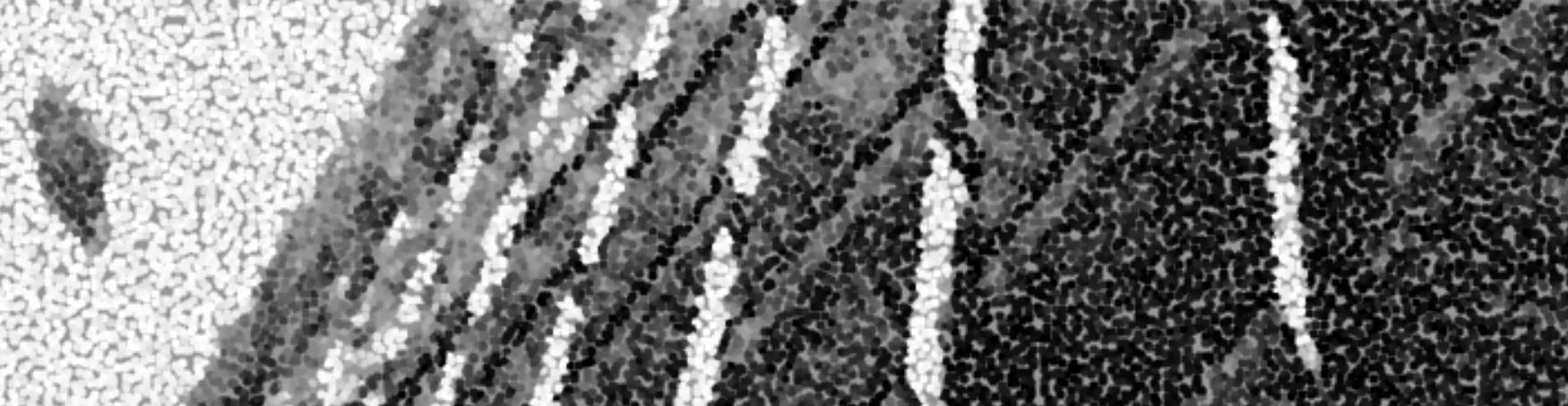

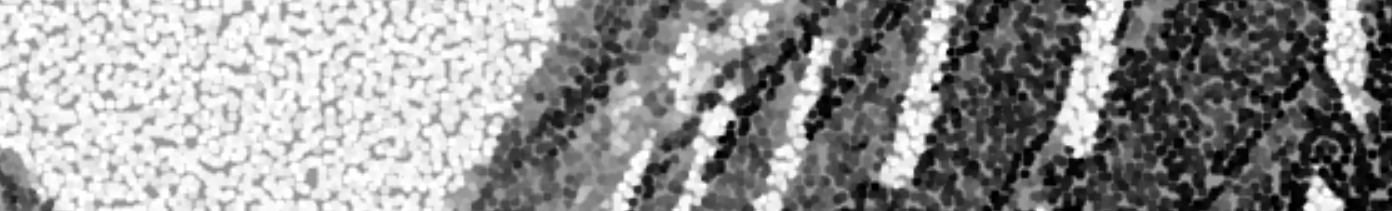

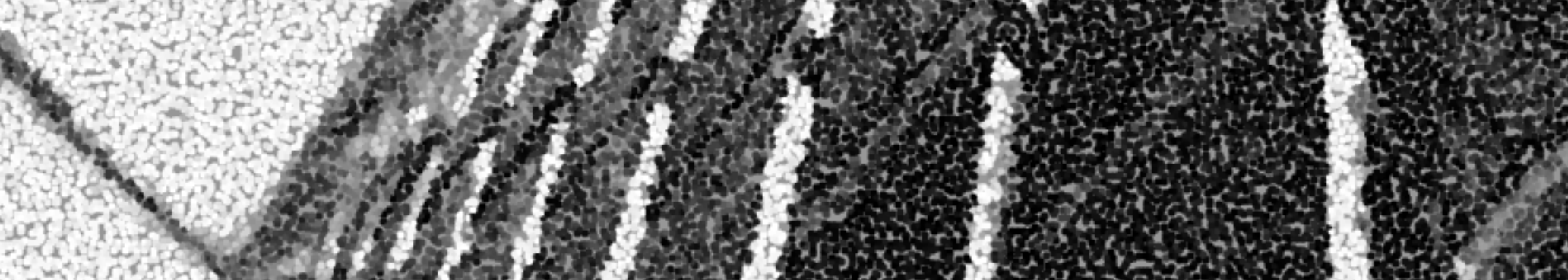

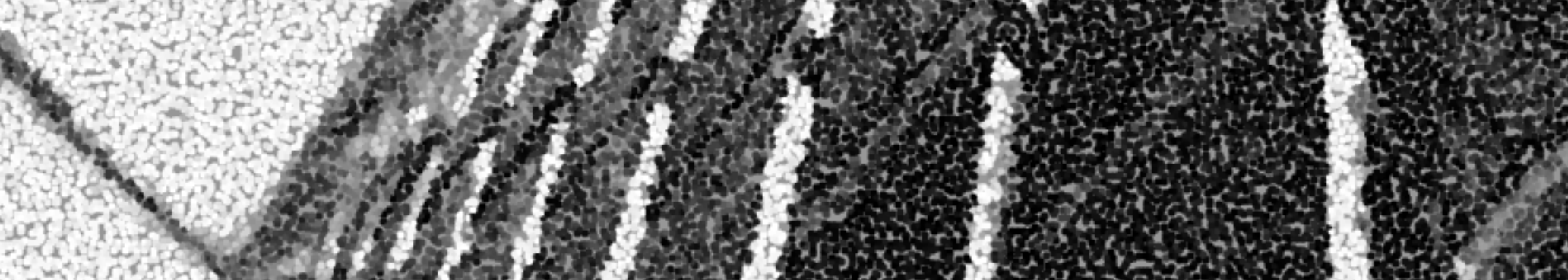

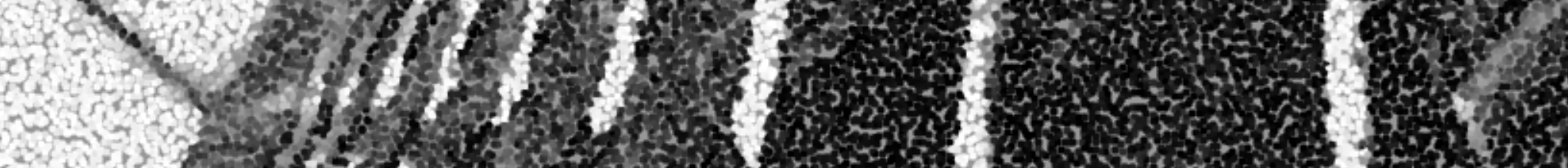
$7,6, z^{2}+2, \ldots$

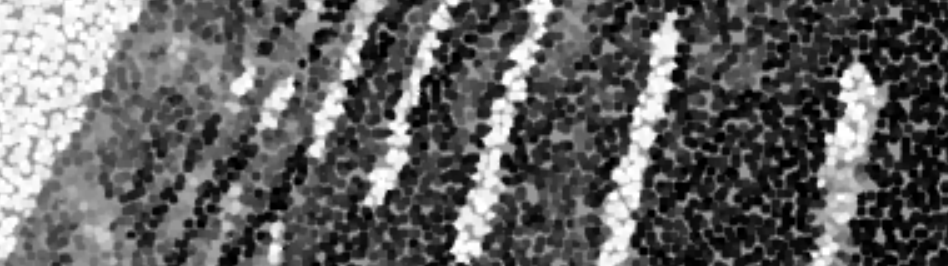

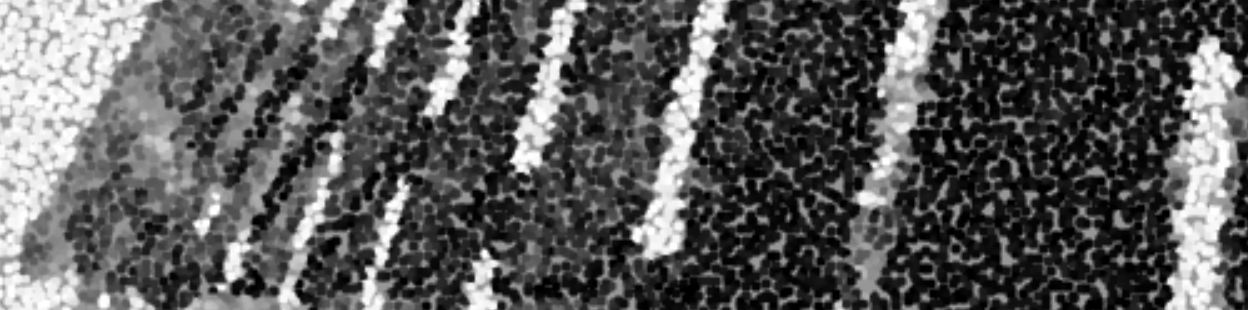

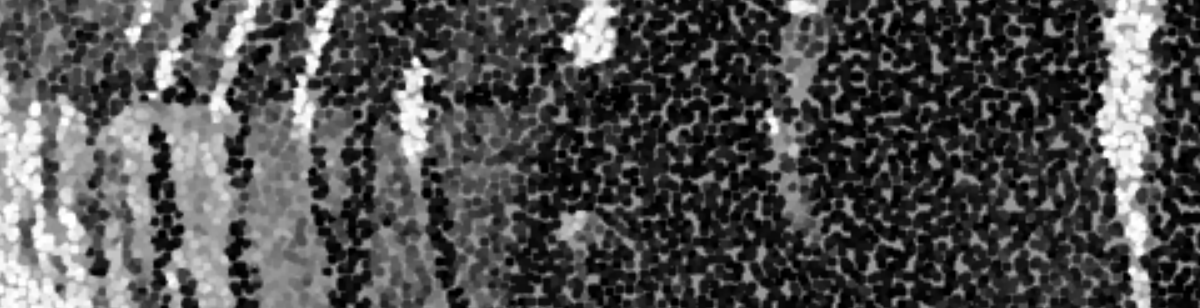
11, 3 , 3n 3 H t (1)

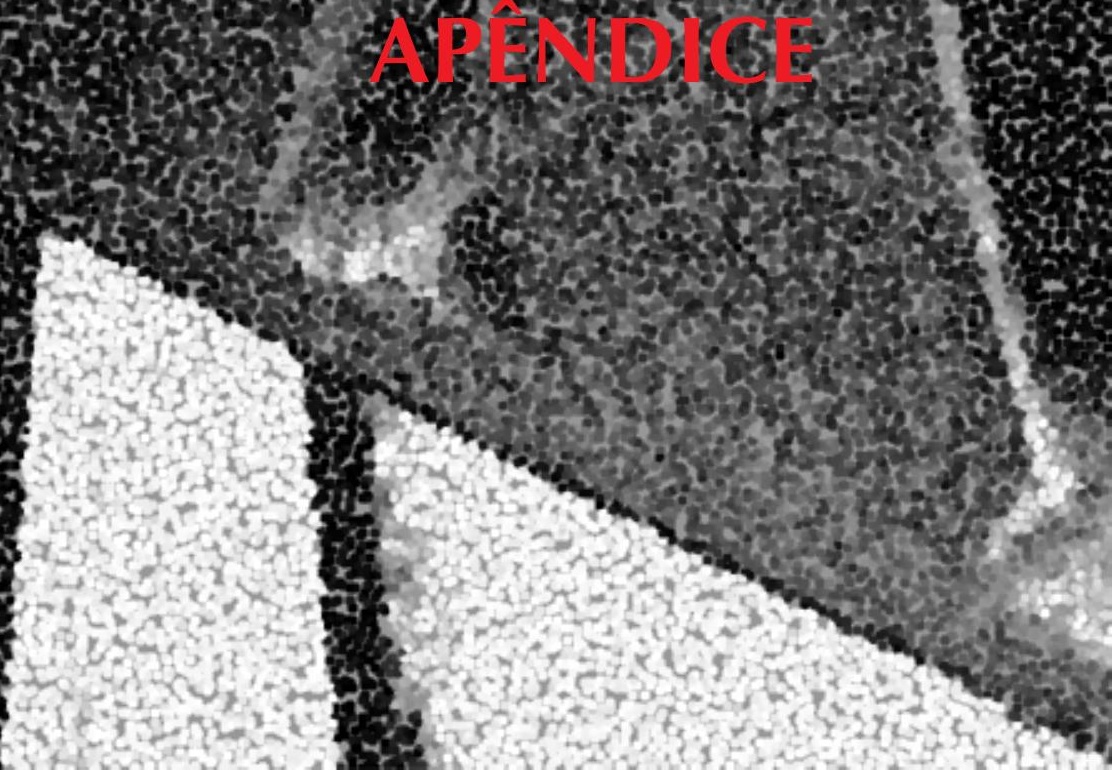





\section{Apêndice 1}

Tabela 6: Relação de autores que trabalharam o conceito de Projeto para a Produção.

\begin{tabular}{|c|c|c|}
\hline Autor & Temática & Abordagem \\
\hline $\begin{array}{l}\text { Bruna } \\
(1976)\end{array}$ & $\begin{array}{l}\text { Arquitetura, Indus- } \\
\text { trialização e Desen- } \\
\text { volvimento }\end{array}$ & $\begin{array}{l}\text { Planejamento para a produção como um instrumento de oti- } \\
\text { mização no plano qualitativo e econômico do produto. }\end{array}$ \\
\hline $\begin{array}{l}\text { Rosso } \\
(1990)\end{array}$ & $\begin{array}{l}\text { Racionalização de } \\
\text { um Processo de } \\
\text { Produção }\end{array}$ & $\begin{array}{l}\text { Conjunto de ações reformadoras que se propõe substituir as } \\
\text { práticas rotineiras convencionais por recursos e métodos ba- } \\
\text { seados em raciocínio sistemático, visando eliminar a causali- } \\
\text { dade nas decisões (Rosso, 1990, p. 33). }\end{array}$ \\
\hline $\begin{array}{l}\text { Martucci } \\
(1990)\end{array}$ & $\begin{array}{l}\text { Projeto da } \\
\text { Produção }\end{array}$ & $\begin{array}{l}\text { [...] estabelece critérios para se definir subdivisões no proces- } \\
\text { so de execução, propiciando maior facilidade de controle e } \\
\text { uma programação da obra mais descentralizada. } \\
\text { Trabalha sobre a ótica da previsão da execução do edifício, } \\
\text { como instrumento de discussão e decisão na etapa de execu- } \\
\text { ção da obra. }\end{array}$ \\
\hline $\begin{array}{l}\text { Barros } \\
(1996)\end{array}$ & $\begin{array}{l}\text { Processo de } \\
\text { rodução de } \\
\text { Edifícios }\end{array}$ & $\begin{array}{l}\text { O conjunto das etapas físicas, organizadas de forma coerente } \\
\text { no tempo, que dizem respeito à construção de uma obra; es- } \\
\text { sas etapas concentram-se sobre a execução, mas vão desde } \\
\text { os 'estudos comerciais', até a utilização da obra, e são assegu- } \\
\text { radas por diferentes agentes (Barros, 1996, p. 18). }\end{array}$ \\
\hline $\begin{array}{l}\text { Novaes } \\
(1997)\end{array}$ & $\begin{array}{l}\text { Projeto para a } \\
\text { Produção }\end{array}$ & $\begin{array}{l}\text { "[...] confere ao projeto um sentido de processo, através do } \\
\text { qual as soluções são elaboradas e compatibilizadas" (Novaes, } \\
\text { 1997, p.1) e apresenta soluções de detalhamento e apoia as } \\
\text { decisões da produção. É, portanto, a orientação das informa- } \\
\text { ções necessárias para as atividades a serem realizadas durante } \\
\text { a produção. }\end{array}$ \\
\hline $\begin{array}{l}\text { Ferreira } \\
(1998)\end{array}$ & $\begin{array}{l}\text { Implantação da } \\
\text { Norma Regulamen- } \\
\quad \text { tar no. } 18\end{array}$ & $\begin{array}{l}\text { Condições e meio ambiente do trabalho na indústria da cons- } \\
\text { trução, que tornava necessário o arranjo físico inicial do can- } \\
\text { teiro de obras. }\end{array}$ \\
\hline
\end{tabular}


continuação

\begin{tabular}{|c|c|c|}
\hline Autor & Temática & Abordagem \\
\hline $\begin{array}{l}\text { Sabbatini } \\
\text { (1998) }\end{array}$ & $\begin{array}{c}\text { Projeto para a } \\
\text { Produção }\end{array}$ & $\begin{array}{l}\text { Descreve que é COMO FAZER, planejar, pensar colocando } \\
\text { em etapas para a execução. Com tomada de decisões do que } \\
\text { deve ser feito antes de sua execução. - conjunto de informa- } \\
\text { ções que define completamente todas as atividades necessá- } \\
\text { rias para produzir um produto e deve contemplar: } 1 \text {. definição } \\
\text { dos materiais e componentes a serem empregados; } 2 \text {. defi- } \\
\text { nições relacionadas com o planejamento da execução e; } 3 . \\
\text { definição de parâmetros para gestão e controle do processo } \\
\text { de produção (inclui orçamento). }\end{array}$ \\
\hline $\begin{array}{l}\text { Melhado } \\
\text { (1994) }\end{array}$ & $\begin{array}{c}\text { Projeto } \\
\text { Simultâneo }\end{array}$ & $\begin{array}{l}\text { Conjunto de elementos de projeto elaborados de forma simul- } \\
\text { tânea ao detalhamento do projeto executivo, para utilização } \\
\text { no âmbito das atividades de produção em obra, contendo as } \\
\text { definições de: disposição e sequência de atividades de obra } \\
\text { e frentes de serviço; uso de equipamentos; arranjo e evolução } \\
\text { do canteiro; dentre outros itens vinculados às características e } \\
\text { recursos próprios da empresa construtora MELHADO (1994) } \\
\text { apud Melhado \& Fabricio (1998). }\end{array}$ \\
\hline $\begin{array}{c}\text { Melhado \& } \\
\text { Fabricio } \\
\text { (1998) }\end{array}$ & $\begin{array}{l}\text { Projeto para a } \\
\text { Produção }\end{array}$ & $\begin{array}{l}\text { Sequência e métodos de execução (em projeto) de determi- } \\
\text { nadas etapas críticas da obra, como forma de ampliar o de- } \\
\text { sempenho na produção dessas etapas. Acentuam que o es- } \\
\text { tabelecimento de procedimentos e acompanhamento com } \\
\text { retroalimentação possibilita a especialização e consequente } \\
\text { melhoria do produto. }\end{array}$ \\
\hline $\begin{array}{c}\text { Fabrício, } \\
\text { Baía e } \\
\text { Melhado } \\
\text { (1998) }\end{array}$ & $\begin{array}{c}\text { Projeto para a } \\
\text { Produção }\end{array}$ & $\begin{array}{l}\text { Faz parte da etapa de desenvolvimento do produto dentro } \\
\text { das etapas de projeto na construção de edifícios, envolve a } \\
\text { seleção da tecnologia construtiva, a análise das interfaces } \\
\text { com a produção, seu desenvolvimento e é detalhado junta- } \\
\text { mente com o projeto executivo de arquitetura e produção do } \\
\text { edifício. }\end{array}$ \\
\hline
\end{tabular}


continuação

\begin{tabular}{|c|c|c|}
\hline Autor & Temática & Abordagem \\
\hline $\begin{array}{c}\text { Ferreira } \\
(1998)\end{array}$ & $\begin{array}{l}\text { Projeto de } \\
\text { Produção }\end{array}$ & $\begin{array}{l}\text { Devem ser analisados o processo global e os subprocessos } \\
\text { específicos, dentro de uma visão holística do empreendimen- } \\
\text { to, analisando os fluxos e os ciclos de produção, evitando a } \\
\text { ocorrência de perdas, identificando as atividades que agre- } \\
\text { gam e as que não agregam valor; em relação aos desejos e } \\
\text { expectativas dos clientes internos e externos, atendendo às } \\
\text { especificações que traduzem as necessidades dos clientes } \\
\text { e incorporando a facilidade de serem executadas (Ferreira, } \\
\text { 1998. p. 2). }\end{array}$ \\
\hline $\begin{array}{c}\text { Santos \& } \\
\text { Moccellin } \\
\text { (1999) }\end{array}$ & $\begin{array}{l}\text { Projeto da } \\
\text { Produção }\end{array}$ & $\begin{array}{l}\text { É a etapa onde, através de políticas e estratégias produtivas } \\
\text { de desenvolvimento do processo de trabalho e da organiza- } \\
\text { ção e planejamento da produção, são definidas as atividades } \\
\text { produtivas e sua sequência tecnológica de produção bem } \\
\text { como sua base técnica (SANTOS \& MOCCELLIN, 1999, p.6). }\end{array}$ \\
\hline $\begin{array}{c}\text { Costa \& } \\
\text { Formoso } \\
(2006)\end{array}$ & $\begin{array}{l}\text { Projeto do sistema } \\
\text { de Produção }\end{array}$ & $\begin{array}{l}\text { Consiste no processo de análise e discussão de alternativas } \\
\text { de organização do sistema de produção do empreendimento, } \\
\text { e na seleção da alternativa mais adequada à consecução de } \\
\text { um desempenho adequado deste sistema durante a etapa de } \\
\text { execução considerando suas especificidades (Costa \& Formo- } \\
\text { so, 2006. p.62) }\end{array}$ \\
\hline $\begin{array}{l}\text { Chalita } \\
\text { (2010) }\end{array}$ & $\begin{array}{l}\text { Projeto para a } \\
\text { Produção }\end{array}$ & $\begin{array}{l}\text { O projeto deve conter informações sobre o sistema construti- } \\
\text { vo, processo, com características dos materiais, componentes, } \\
\text { planejamento da produção com estratégias, normas, procedi- } \\
\text { mentos, sequência de produção, equipamentos, logística, re- } \\
\text { lação entre os subsistemas, metas de produtividade, métodos } \\
\text { de controle e parâmetros de gestão e controle do processo } \\
\text { de produção (CHALITA, 2010, P. 48). }\end{array}$ \\
\hline
\end{tabular}


continuação

\begin{tabular}{|c|c|c|}
\hline Autor & Temática & Abordagem \\
\hline $\begin{array}{l}\text { Herrmann \& } \\
\text { Chincholkar } \\
\quad(2000)\end{array}$ & $\begin{array}{c}\text { Projeto para a } \\
\text { Produção }\end{array}$ & $\begin{array}{l}\text { Métodos que determinam se o sistema de produção tem ca- } \\
\text { pacidade suficiente para alcançar a taxa de transferência e os } \\
\text { métodos que estimam o tempo de ciclo de fabricação deseja- } \\
\text { do. Esse processo requer informações sobre o produto, (pro- } \\
\text { jeto), } \\
\text { Planejamento do processo, quantidade de produção, infor- } \\
\text { mações sobre o sistema de produção que vai fabricar o pro- } \\
\text { duto e avaliar a capacidade de saída e qual o tempo para isso. }\end{array}$ \\
\hline $\begin{array}{c}\text { Kuo, } \\
\text { Huang, \& } \\
\text { Zhang } \\
\text { (2001) }\end{array}$ & Design for $X$ & $\begin{array}{l}\text { O DfX enfatiza os objetivos de projeto relativos às restrições } \\
\text { nos estágios iniciais. Resultando em melhores produtos, com } \\
\text { comercialização mais rápida, com produtos sem problemas, } \\
\text { atrasos ou modificações, com custo mínimo, e produzido com } \\
\text { facilidade. E posteriormente, com descarte ou reciclagem já } \\
\text { programados, respeitando aspectos sustentáveis. }\end{array}$ \\
\hline \multirow[t]{2}{*}{$\begin{array}{l}\text { Hermann } \\
\text { (2003) }\end{array}$} & $\begin{array}{c}\text { Projeto para a } \\
\text { Produção }\end{array}$ & $\begin{array}{l}\text { Refere-se às tecnologias de produção, à visão do sistema de } \\
\text { produção e distribuição do produto, à logística e aos fornece- } \\
\text { dores. Tem como princípios o uso de bom senso, o planeja- } \\
\text { mento e definições, deve considerar instalações disponíveis, } \\
\text { ferramentas, qualificação de mão de obra, empregar a simpli- } \\
\text { cidade e buscar a estandardização. E tem como orientações: } \\
\text { minimizar o número total de partes, desenvolver um projeto } \\
\text { modular, minimizar as variações de peças, desenvolver pro- } \\
\text { jeto de peças serem para multifuncionais, projeto para peças } \\
\text { multiuso, projeto de peças para facilidade de fabricação, evi- } \\
\text { tar fixadores separados, minimizar direções de montagem, } \\
\text { manipulação, complexidade do design, maximizar peças e } \\
\text { acessórios comuns, otimizar posições de trabalho, e facilitar } \\
\text { o acesso à circulação. }\end{array}$ \\
\hline & $\begin{array}{l}\text { Design for } X \\
\text { (Excellence) }\end{array}$ & $\begin{array}{l}\text { É uma variação do Projeto da manufatura e Projeto para a } \\
\text { Montagem, derivando outras categorias de projeto, com me- } \\
\text { todologia e etapas subdimensionadas. }\end{array}$ \\
\hline
\end{tabular}


continuação

\begin{tabular}{|c|c|l|}
\hline Autor & Temática & \multicolumn{1}{c|}{ Abordagem } \\
\hline $\begin{array}{c}\text { Egan (s.d.), } \\
\text { Warwick Manu- } \\
\text { facturing Group } \\
(2007)\end{array}$ & Design for X & $\begin{array}{l}\text { X de excellence ou como uma variável qualquer, com a aplica- } \\
\text { ção de uma metodologia especifica, tais como de custo, pro- } \\
\text { vimentos, qualidade, produtividade, flexibilidade, eficiência, } \\
\text { ciclo de vida, manufatura e montagem, etc. }\end{array}$ \\
\hline $\begin{array}{c}\text { Lehto, et al } \\
(2011)\end{array}$ & $\begin{array}{c}\text { Design for } X \\
\text { (DfX) }\end{array}$ & $\begin{array}{l}\text { Projeto para alguma coisa. Benefícios: custo competitivo, cus- } \\
\text { tomização de serviços, produtos confiáveis, entregas no tem- } \\
\text { po, flexibilidade de produtos, escolha do melhor processo de } \\
\text { produção, cadeia produtiva sem folgas, montagem econômi- } \\
\text { cas, controle, produtos sustentáveis. }\end{array}$ \\
\hline
\end{tabular}



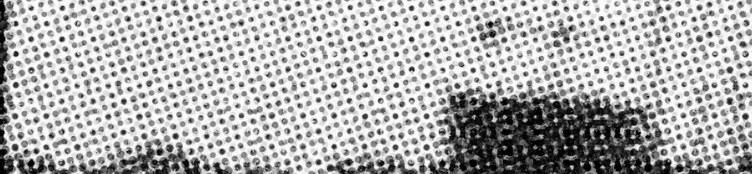

14

4.1.

6.

1. OHentom

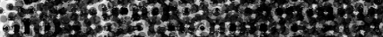

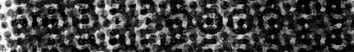

it 2 (1)

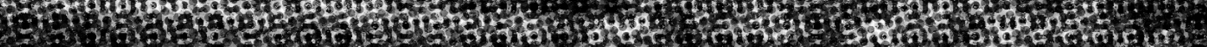

1.

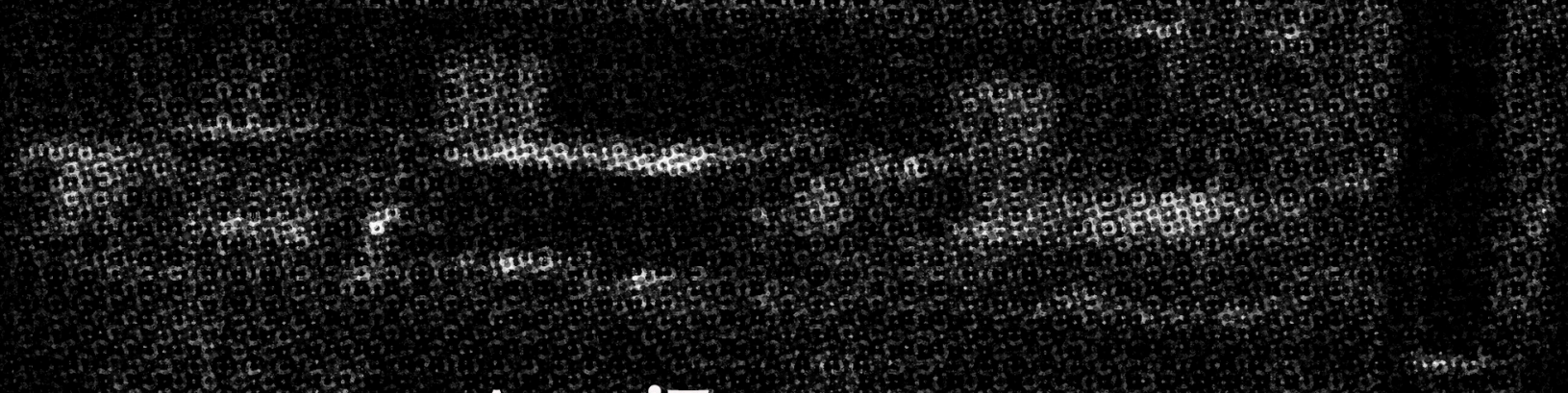

Arquitec

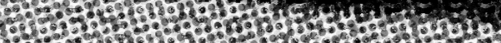

4.

H.7.

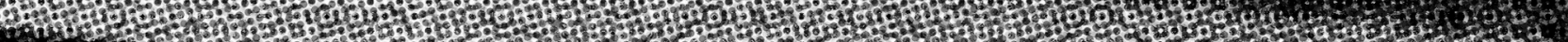

คค:ค

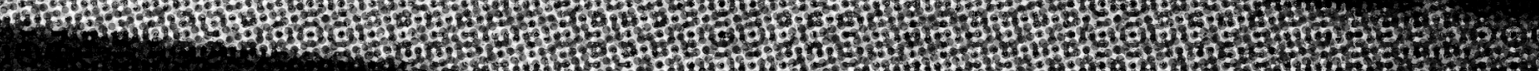

How H.7. 